\title{
Marcos Barbosa-Ferreira
}

\author{
Proposta de modelo para o estudo de \\ toxicologia perinatal em ruminantes: avaliação \\ dos efeitos tóxicos da Senna occidentalis em \\ caprinos
}




\section{Marcos Barbosa-Ferreira}

\section{Proposta de modelo para o estudo de toxicologia perinatal em ruminantes: avaliação dos efeitos tóxicos da Senna occidentalis em caprinos}

Tese apresentada ao Programa de Pós-Graduação em Patologia Experimental e Comparada da Faculdade de Medicina Veterinária e Zootecnia da Universidade de São Paulo, para obtenção do título de Doutor em ciências

Departamento:

Patologia

Área de concentração:

Patologia Experimental e Comparada

Orientador:

Profa. Dra. Silvana Lima Górniak

São Paulo 2008 
Autorizo a reprodução parcial ou total desta obra, para fins acadêmicos, desde que citada a fonte.

DADOS INTERNACIONAIS DE CATALOGAÇÃO-NA-PUBLICAÇÃO

(Biblioteca Virginie Buff D’Ápice da Faculdade de Medicina Veterinária e Zootecnia da Universidade de Săo Paulo)

\section{T.1952 Barbosa-Ferreira, Marcos}

FMVZ Proposta de modelo para o estudo de toxicologia perinatal em ruminantes: avaliaçăo dos efeitos tóxicos da Senna occidentalis em caprinos / Marcos Barbosa-Ferreira. - São Paulo: M. Barbosa-Ferreira, 2008.

185 f. : il.

Tese (doutorado) - Universidade de São Paulo. Faculdade de Medicina Veterinária e Zootecnia. Departamento de Patologia, 2008.

Programa de Pós-Graduação: Patologia Experimental e Comparada.

Área de concentração: Patologia Experimental e Comparada

Orientador: Profa. Dra. Silvana Lima Górniak.

1. Senna occidentalis. 2. Toxicologia perinatal. 3. Toxicologia do desenvolvimento. 4. Avaliaçăo neurocomportamental. 5. Caprinos. I. Título. 


\begin{tabular}{|c|c|c|c|c|}
\hline \multicolumn{5}{|c|}{ ERRATA } \\
\hline Página & Parágrafo & Linha & Onde se lê & Leia-se \\
\hline 10 & 1 & 4 & $188 \mathrm{f}$. & $185 \mathrm{f}$. \\
\hline 12 & 1 & 4 & $188 \mathrm{f}$. & $185 \mathrm{f}$. \\
\hline
\end{tabular}




\title{
PARECER DA COMISSÃO DE BIOÉTICA
}

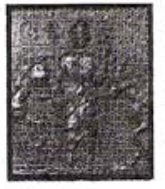

\author{
UNIVERSIDADE DE SÃO PAULO \\ Faculdade de Medicina Veterinária e Zootecnia \\ Cidade Universitária "Armando de Salles Oliveira" \\ Comissão Bioética
}

\section{CERTIFICADO}

Certificamos que o Projeto intitulado "Avaliação dos possíveis efeitos teratogênicos produzidos pela Senna accidentalis em caprinos. Aspectos Bioquímicos, Ultra-sonográficos e Anatomopatológicos", Protocolo $n^{\circ} 390 / 2003$, utilizando 20 caprinos, sob a responsabilidade da Prof Dra $^{\mathrm{a}}$ Silvana Lima Górniak, está de acordo com os princípios éticos de experimentação animal da Comissão de Bioética da Faculdade de Medicina Veterinária e Zootecnia da Universidade de São Paulo e foi aprovado em reunião de 26/11/03.

(We certify that the Research "Evaluation of possible teratogenic effects produced by Senna occidetalis seeds in goats. Biochemistry, ultrasound and pathologic evaluation" protocol number 390/2003, utilizing 20 goats, under the responsibility of Prof. Dr. Silvana Lima Górniak, agree with Ethical Principles in Animal Research adopted by Bioethic Commission of the Faculty of Veterinary Medicine and Zootechny of University of São Paulo and was approved in $11 / 26 / 2003$, meeting.

São Paulo, 27 de novembro de 2003

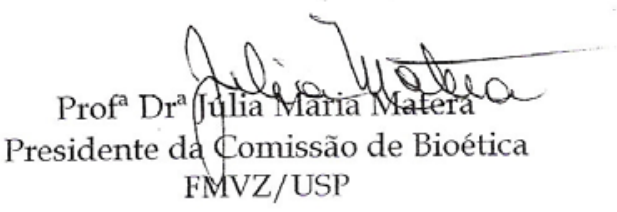

Av. Prof. Dr. Orlando Marques de Paiva, 87 - 05508-000 - Cid. Univ. "Armando de Salles Oliveira" Fones: (011) 3091-7671/3091-7676 Fax: (011) 3032-2224 


\section{FOLHA DE AVALIAÇÃO \\ Nome: BARBOSA-FERREIRA, Marcos \\ Título: Proposta de modelo para o estudo de toxicologia perinatal em ruminantes: avaliação dos efeitos tóxicos da Senna occidentalis em caprinos}

Tese apresentada ao Programa de Pós-Graduação em Patologia Experimental e Comparada da Faculdade de Medicina Veterinária e Zootecnia da Universidade de São Paulo, para obtenção do título de Doutor em ciências

Data:___ I _

\section{Banca examinadora}

Prof. Dr.:

Instituição:

Assinatura:

Julgamento:

Prof. Dr.:

Instituição:

Assinatura:

Julgamento:

Prof. Dr.:

Instituição:

Assinatura:

Julgamento:

Prof. Dr.:

Instituição:

Assinatura:

Julgamento: 
Esta Tese é dedicada a todos que me incentivaram e ajudaram na realização deste trabalho. Àqueles que, em qualquer momento, estiveram ao meu lado, independentemente de tempo e espaço, nas horas boas e más, sempre. Àqueles que posso chamar de amigos de verdade.

Especialmente àqueles que sempre estiveram ao meu lado e sempre estarão.

Portanto, dedico este trabalho a vocês Pai e Mãe 
À minha eterna companheira, Karine, minha parceira em todos os momentos. Te amo. 
À minha Orientadora, Silvana, que sempre esteve presente e solícita, ajudando a seguir os passos da Ciência. Você me ensinou muito. Obrigado. 


\section{AGRADECIMENTOS}

Ao pessoal do CEPTOX, que sempre teve disposição e criatividade (muita) para podermos realizar nossos intentos: Paulo César (PC), Ester, Marquinhos, Estevão e Adilson;

$\star$ À Professora Mitsue Haraguchi que sempre ajudou muito em todos os aspectos;

Aos Professores Maria Lúcia Zaidan Dagli, José Luis Guerra, Paulo Maiorka; pelos ensinamentos e precioso auxílio no desenvolvimento do presente trabalho

Ao Professor Idércio Sinhorini, grande professor e amigo, que ensina sempre a filosofia do aprender.

Aos amigos Cláudio e Luciano, pelo valiosíssimo auxílio e presteza no processamento do material histopatológico e pelos momentos de descontração e troca de conhecimento, as lâminas ficaram boas;

Aos meus irmãos científicos: André, Vânius, Domênica, Júlia, Lu Lipi, Vinícius, Altamir, Andréia, Helena, Benito, Breno e Isis;

Aos meus amigos do departamento, Dario, Ricardo, Soraia, Isabel, Adriana, Portela, Karen, Nato, Dudu, Nonato, Tereza, Luciana, Renato, Heidge, Daniel (ainda Ihe devo um requeijão) e Caio;

Ao pessoal dos laboratórios, os guardiões dos tubos e reagentes: Priscila, Ricardo Jibóia, Marguiti e Magali;

Às garotas da secretaria de pós-graduação: Joana, Cláudia e Deise. Nossa, como vocês me aturaram (de novo)...

Às garotas das secretarias do departamento: Cris, Cláudia e Silvia. Muito obrigado pelo seu apoio;

* A todos os funcionários da Biblioteca pelo auxílio na finalização desta dissertação; 
$\star$ À CAPES, pelo apoio financeiro oferecido;

* Aos meus companheiros de todas as horas e que tive a sorte de conhecer, meu irmão André (muitos planos), meu irmão Felipe (Godfather), meu irmão Samuel (Bah guri), meu irmão Walter (Varte o maníaco), meu irmão Bruno (no contában com my astúcia), minha irmã Carolina Bacha (brima), PC e Ester, José luíz (andeamos ad montem...), Marcelo Contieri (jajá será pai);

Aos Professores de Pirassununga, Julio C. Baliero, Paulo Maza, Marcos Veiga (James), Valdo, Ricardo (e viva o churrasco e música caipira) e Ed Hoffman que orientaram este Doutorando, mesmo, às vezes, sem perceber... 


\section{RESUMO}

BARBOSA-FERREIRA, M. Proposta de modelo para o estudo de toxicologia perinatal em ruminantes: avaliação dos efeitos tóxicos da Senna occidentalis em caprinos. [A model for prenatal toxicological studies in ruminants: evaluation of toxic effects caused by Senna occidentalis in goats]. 2008. $188 \mathrm{f}$. Tese (Doutorado em Ciências) - Faculdade de Medicina Veterinária e Zootecnia, Universidade de São Paulo, São Paulo, 2008.

A Senna occidentalis (So), Fabaceae-Caesalpinoideae (Leguminosae), conhecida como fedegoso, entre outros nomes populares causa, em animais de criação, intoxicação pelo consumo, tanto de suas folhas a campo, como pela ingestão de suas sementes quando presentes em rações. Estas intoxicações podem ser de caráter crônico ou agudo, em ruminantes ou monogástricos, tendo sido já reproduzida em animais de laboratório. Os principais achados histológicos são degenerações em músculos esquelético e cardíaco, fígado, rim e, recentemente publicado, lesões no sistema nervoso central. Porém, pouco se sabe sobre os efeitos do princípio ativo desta planta, a diantrona, na toxicologia perinatal. $O$ objetivo do presente trabalho foi estudar os possíveis efeitos teratogênicos desta planta em caprinos, utilizando um protocolo de avaliação de toxicologia do desenvolvimento. Para tanto, foi somado a um protocolo pré-existente de acompanhamento da gestação de cabras, por meio de ultra-sonografia e dados clínicos, como pesagem semanal e coleta quinzenal de sangue para realização de bioquímica sérica, a avaliação de filhotes por morfometria corporal esde o nascimento ao $4^{\circ}$ mês de idade, além de avaliação neurocomportamental até a $10^{a}$ semana de idade. Assim, trinta e oito fêmeas nulíparas, receberam rações contendo 0\% (controle), 1\% (So1), 2\% (So2), 3\% (So3) e 4\% (So4) de sementes da planta, desde a confirmação da gestação, no $27^{\circ}$ dia pós-coito, até o parto. Outro grupo de cabras (LAC) consumiu ração contendo $4 \%$ de sementes da planta durante a lactação. Amostras de leite das cabras foram colhidas para a tentativa de detecção da diantrona. Foi observado queda no ganho de peso nas fêmeas pertencentes ao grupo So3 durante a gestação. No grupo So4 ocorreu a morte de uma fêmea, duas mortes fetais, e morte pós-natal de um filhote. À análise histológica da cabra que morreu, observou-se severas lesões em fígado, rim, músculo esquelético e cardíaco. Foi observado, pela primeira vez na literatura, lesões em nervo ciático. Nas cabras 
do grupo LAC foram observadas lesões teciduais brandas, exceto em nervo ciático. Não se observaram malformações físicas nos filhotes. Somente pequenas alterações bioquímicas foram observadas nas mães e na prole. A morfometria evidenciou poucas alterações nos filhotes do grupo LAC. Histologicamente, estes filhotes LAC tiveram lesões focais brandas em musculatura esquelética e cardíaca, fígado e rim, revelando que o princípio ativo da planta pode ser transferido para o leite. Os testes neurocomportamentais revelaram déficit de aprendizado dos filhotes do grupo So3. Não foi possível a detecção da diantrona no leite avaliado. Este estudo permitiu verificar que a So, embora não seja um potente teratógeno, quando consumida durante a gestação, pode causar efeitos tóxicos no feto, como evidenciado pela avaliação neurocomportamental. O protocolo sugerido poderá ter grande valia para estudar o potencial teratogênico de diversas substâncias as quais os ruminantes possam estar expostos.

Palavras-chave: Senna occidentalis. Toxicologia perinatal. Toxicologia do desenvolvimento. Avaliação neurocomportamental. Caprinos. 


\section{ABSTRACT}

BARBOSA-FERREIRA, M. A model for prenatal toxicological studies in ruminants: evaluation of toxic effects caused by Senna occidentalis in goats. [Proposta de modelo para o estudo de toxicologia perinatal em ruminantes: avaliação dos efeitos tóxicos da Senna occidentalis em caprinos]. 2008. 188 f. Tese (Doutorado em Ciências) - Faculdade de Medicina Veterinária e Zootecnia, Universidade de São Paulo, São Paulo, 2008.

Senna occidentalis (So - formerly Cassia occidentalis), Fabaceae-Caesalpinoideae (Leguminosae) is a weed growing in pastures and in cultivated fields such as corn and soybeans in many tropical and subtropical areas worldwide. Many reports have shown that So is toxic to different animal species. Histologic lesions plant-related are degeneration skeltal and cardiac muscles, liver and kidney. Recently was related leions in the central nervous system. Even so, very little is known about the possible effects of prolonged exposure at low doses of So on developmental toxicology. Thus, the present study proposes an approach to evaluate the perinatal toxicity from gestational intoxication of So seeds in goats. Third-eight pregnant goats were fed rations containing $0 \%$ (control group), 1\% (So1 group), 2\% (So2 group), 3\% (So3) and $4 \%$ (So4 group) mature So seeds from pregnancy detection on day 27 after mating until parturition. Another group (LAC) was fed with ration containing $4 \%$ of So seeds only in the lactation period; clinic observations such weight gains, general body status and serum biochemistry were evaluated. Fetuses were evaluated during the pregnancy using ultrasonographic measurements; neonates were evaluated after birth using body morphometry, weight gains, corporal status and serum biochemistry. Neurobehavioral tests was performed on kids from So3 group. In the So4 group was observed fetal dead from 2 dams, dead of one newborn and dead of one pregnant dam. None malformations was observed. Only a few minor alterations in serum biochemistry were observed in dams and kids; even so one So4 group dam had several and diffuse tissue lesions as vacuolations in hepatocytes; vacuolations in the endothelium of the convoluted tubules in kidneys, necrosis in skeletal and cardiac muscles, and for the first time vacuolation was observed in sciatic nerve. Alterations in body morphometry were observed only in kids from LAC group during first month of lactation. Also, tissue lesions was observed in these kids, showing the capacity of the diantrona (active principle of the palnt) be carried to milk. Neurobehavioral tests 
revealed deficit on learning hability in the So3 kids. Diantrone didn't was detected in milk samples. This study shows that, despite $S$. occidentalis isn't a powerfull teratogen when ate during gestation, can cause toxic effects on the fetus, as neurobehavioral test revealed. Protocol utilized here is usefull to study the potential teratogenic effects of drugs and other substancies whose an animal could be exposed.

Key words: Senna occidentalis. Developmental toxicology. Goats. Body morphometry. Perinatal toxicity. 


\section{LISTA DE FIGURAS}

Figura 1 - Senna occidentalis.

Figura 2 - Imagens ultrassonográficas de caprinos. A) Diagnóstico de gestação, evidenciando as vesículas embrionárias e o coração (seta); B) CCC, $43^{\circ}$ dia; C) DBP, $69^{\circ}$ dia; D) DA, 69 dia; E) DT,

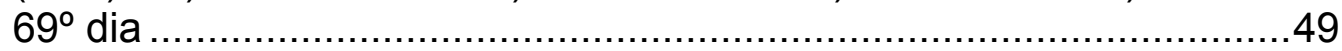

Figura 3 - Locais onde foram realizadas as mensurações corporais.

Figura 4 - Primeira prova de obstáculo. Desenho esquemático da área de teste, mostrando a posição de partida do filhote e a posição de chegada, onde está a mãe.

Figura 5 - Prova de obstáculos com duas mães. Fotografia do teste, em primeiro plano o local onde o filhote é colocado no início do teste e, ao fundo, como ficam dispostas as mães.

Figura 6 - Fotografia do labirinto progressivo durante o segundo dia de idade, apresentando o primeiro obstáculo (A). Esquema do labirinto e disposição da mãe e seu filhote (B)

Figura 7 - Labirinto em $T$, fotografia $(A)$ e desenho esquemático, com as dimensões, da área de teste (B)

Figura 8 - Labirinto médio ("Lashley Maze"). Fotografia apresentando um filhote no segundo braço (A). Desenho esquemático, com as dimensões, da área de teste e os respectivos corredores (B) 58

Figura 9 - Labirinto difícil ("Hebb-Williams Maze"). Desenho esquemático, com as dimensões, da área de teste.

Figura 10 - Peso médio $(\mathrm{kg})$ inicial, final e total (quadro) de cabras que consumiram diferentes concentrações de sementes de Senna occidentalis durante a gestação. São apresentadas as médias e os respectivos erros padrão.

Figura 11 - Níveis séricos de albumina (g/L), colinesterase (U/L), aldolase $(U / L)$ e creatinina (U/L) de cabras que consumiram diferentes concentrações de sementes de Senna occidentalis durante a gestação. São apresentadas as médias e os respectivos erros padrão. ${ }^{*} P<0,05$. Análise da variância ANOVA, seguida de teste T de Student. Os dados são apresentados através do método dos quadrados mínimos.

Figura 12 - Níveis séricos de glicose (mg/dl), GGT (u/l), AST (u/l) e LDH (u/l) de cabras que consumiram diferentes concentrações de sementes de Senna occidentalis durante a gestação. São apresentadas as médias e os respectivos erros padrão. Análise da variância ANOVA, seguida de teste $T$ de Student. Os dados são apresentados através do método dos quadrados mínimos

Figura 13 - Níveis séricos de CK (U/L), proteína $(\mathrm{g} / \mathrm{dl})$ e uréia $(\mathrm{mg} / \mathrm{dl})$ de cabras que consumiram diferentes concentrações de sementes de Senna occidentalis durante a gestação. São apresentadas as 
médias e os respectivos erros padrão. Análise da variância ANOVA, seguida de teste $T$ de Student. Os dados são apresentados através do método dos quadrados mínimos.

Figura 14 - Parâmetros ultrassonográficos de cabras que consumiram diferentes concentrações de sementes de Senna occidentalis durante a gestação. Freqüência cardíaca $(\mathrm{FC})$, movimento fetal (MF) e comprimento crânio caudal (CCC). São apresentados as médias e os respectivos erros padrão. * Difere significantemente do controle. ANOVA, seguida de teste $T$ de Student. Dados apresentados pelo método dos quadrados mínimos.

Figura 15 - Parâmetros ultrassonográficos de cabras que consumiram diferentes concentrações de sementes de Senna occidentalis durante $069^{\circ}$ dia da gestação. Diâmetro abdominal (DA), diâmetro torácico (DT) e diâmetro biparietal (DBP). São apresentadas as médias e os respectivos erros padrão. ANOVA, seguida de teste T de Student. Dados apresentados pelo método dos quadrados mínimos

Figura 16 - Fotomicrografia de luz de fígado de cabra, pertencente ao grupo So4 (A) e grupo controle (B), evidencia-se severa vacuolização de hepatócitos (setas), HE, A: 10x. Rim de cabra, pertencente ao grupo So4 (C) e controle (D). Evidencia-se discreta vacuolização de endotélio de túbulo contornado (setas), $\mathrm{HE}, \mathrm{A}: 20 \mathrm{x}$

Figura 17 - Fotomicrografia de luz de músculo esquelético de cabra do grupo So4 (A) e controle (B). Evidencia-se necrose, e tumefação (seta), e afrouxamento de fibras (estrela), HE, A: 20x. Músculo cardíaco de cabra do grupo So4 (C) e controle (D). Evidencia-se, edema intersticial e vacuolização (seta), necrose, e tumefação (cabeça de seta) HE, A: 20x

Figura 18 - Fotomicrografia de luz de nervo ciático de cabra pertencente ao grupo So4. São evidenciadas tumefação axonal (setas) e câmaras de digestão em bainha de mielina (cabeças de seta). $\mathrm{HE}, \mathrm{A}: 10 \mathrm{x}(\mathrm{A})$ e $20 \mathrm{X}(\mathrm{B})$.

Figura 19 - Média do ganho de peso $(\mathrm{kg})$ inicial, final e total (quadro) de cabras que consumiram ração contendo 0 e $3 \%$ de sementes de Senna occidentalis durante a gestação. São apresentadas as médias e os respectivos erros padrão, pelo método dos quadrados mínimos.

Figura 20 - Níveis séricos de albumina $(\mathrm{g} / \mathrm{l})$, proteína $(\mathrm{g} / \mathrm{dl})$, colesterol ( $\mathrm{mg} / \mathrm{dl})$ e triglicerídeos $(\mathrm{mg} / \mathrm{dl})$, de cabras que consumiram ração contendo 0 e $3 \%$ de sementes de Senna occidentalis durante a gestação. São apresentadas as médias e os respectivos erros padrão, pelo método dos quadrados mínimos. ANOVA, seguida de teste T de Student

Figura 21 - Níveis séricos de glicose (mg/dl), e atividade de GGT (U/l), AST (U/I) e LDH (U/I) de cabras que consumiram ração contendo 0 e $3 \%$ de sementes de Senna occidentalis durante a gestação. São apresentadas as médias e os respectivos erros padrão, pelo 
método dos quadrados mínimos. ANOVA, seguida de teste T de Student.....

Figura 22 - Atividade sérica de CK (U/I), FA (U/I) e níveis séricos de creatinina (U/l) e uréia $(\mathrm{mg} / \mathrm{dl})$ de cabras que consumiram ração contendo 0 e $3 \%$ de sementes de Senna occidentalis durante a gestação. São apresentadas as médias e os respectivos erros padrão, pelo método dos quadrados mínimos. ANOVA, seguida de teste $T$ de Student.

Figura 23 - Parâmetros ultrassonográficos de cabras que consumiram ração contendo 0 e $3 \%$ de sementes de Senna occidentalis durante a gestação. Freqüência cardíaca (FC), movimento fetal (MF) e comprimento crânio caudal (CCC). São apresentadas as médias e os respectivos erros padrão, pelo método dos quadrados mínimos. ANOVA, seguida de teste T de Student

Figura 24 - Parâmetros ultrassonográficos de cabras que consumiram ração contendo 0 e $3 \%$ de sementes de Senna occidentalis durante a gestação. Diâmetro abdominal (DA), diâmetro torácico (DT) e diâmetro biparietal (DBP). São apresentadas as médias e os respectivos erros padrão, pelo método dos quadrados mínimos. ANOVA, seguida de teste $T$ de Student

Figura 25 - Pesos médios $(\mathrm{kg})$ iniciais, finais e totais (quadro) de cabras que receberam ração contendo 0 e $4 \%$ de sementes de Senna occidentalis durante a lactação. São apresentadas as médias e os respectivos erros padrão, pelo método dos quadrados mínimos. ANCOVA, seguida de teste T de Student.

Figura 26 - Níveis séricos de albumina (g/l), colesterol (U/l), aldolase (U/l) e creatinina (U/I) de cabras que consumiram ração contendo 0 e $4 \%$ de sementes de Senna occidentalis durante a lactação. São apresentadas as médias e os respectivos erros padrão. ANOVA, seguida de teste $\mathrm{T}$ de Student. Os dados são apresentados através do método dos quadrados mínimos

Figura 27 - Níveis séricos de glicose (mg/dl), GGT (u/l), AST (u/l) e LDH (u/l) de cabras que consumiram ração contendo 0 e $4 \%$ de sementes de Senna occidentalis durante a lactação. São apresentadas as médias e os respectivos erros padrão. ANOVA, seguida de teste $\mathrm{T}$ de Student. Os dados são apresentados através do método dos quadrados mínimos.

Figura 28- Níveis séricos de CK (U/l), proteína (g/dl) e aldolase (mg/dl) de cabras que consumiram ração contendo 0 e $4 \%$ de sementes de Senna occidentalis durante a lactação. São apresentadas as médias e os respectivos erros padrão. ANOVA, seguida de teste $T$ de Student. Os dados são apresentados através do método dos quadrados mínimos

Figura 29 - Fotomicrografia de luz de rim de cabra, pertencente ao grupo LAC (A) e controle (B). Evidencia-se discreta vacuolização de epitélio de túbulo contornado (setas), HE, A: 20x. Músculo esquelético de cabra, pertencente ao grupo LAC (C) e controle 
(D), evidencia-se necrose com desorganização de sarcolema (setas), HE, A: 10x

Figura 30 - Fotomicrografia de luz de músculo cardíaco de cabra, pertencente ao grupo LAC (A) e controle (B). Evidencia-se necrose focal com edema intersticial e tumefação de fibra muscular (setas), HE, A: $20 \mathrm{x}$

Figura 31 - Pesos médios $(\mathrm{kg})$ de cabritos filhos de cabras que consumiram ração contendo diferentes concentrações $(0,1 \%$ e $2 \%)$ de sementes de Senna occidentalis durante a gestação. São apresentadas as médias e os respectivos erros padrão. Análise da variância ANOVA, seguida de LSM e teste "T" de Student.

Figura 32 - Níveis séricos de glicose ( $\mathrm{mg} / \mathrm{dl})$, aldolase $(\mathrm{u} / \mathrm{l})$, GGT (u/l) e AST $(\mathrm{u} / \mathrm{l})$ de cabritos cujas mães consumiram diferentes concentrações de sementes de Senna occidentalis durante a gestação. São apresentadas as médias e os respectivos erros padrão. Análise da variância ANOVA, seguida de teste $T$ de Student. Os dados são apresentados através do método dos quadrados mínimos

Figura 33 - Níveis séricos de FA (u/l), CK (u/l), LDH (u/l) e triglicerídeos (u/l) de cabritos cujas mães consumiram diferentes concentrações de sementes de Senna occidentalis durante a gestação. São apresentadas as médias e os respectivos erros padrão. Análise da variância ANOVA, seguida de teste "T" de Student. Os dados são apresentados através do método dos quadrados mínimos

Figura 34 - Níveis séricos de proteína total $(\mathrm{mg} / \mathrm{dl})$, albumina $(\mathrm{g} / \mathrm{l})$, uréia $(\mathrm{mg} / \mathrm{dl})$ e creatinina $(\mathrm{u} / \mathrm{l})$ de cabritos cujas mães consumiram diferentes concentrações de sementes de Senna occidentalis durante a gestação. São apresentadas as médias e os respectivos erros padrão. ANOVA, seguida de teste $T$ de Student. Os dados são apresentados através do método dos quadrados mínimos.

Figura 35 - Níveis séricos de colinesterase $(u / l)$ de cabritos cujas mães consumiram diferentes concentrações de sementes de Senna occidentalis durante a gestação. São apresentadas as médias e os respectivos erros padrão. Os dados são apresentados através do método dos quadrados mínimos

Figura 36 - Comprimento do metatarso (CMT), altura corporal (AC), comprimento corporal (CC) e perímetro torácico (PT) de cabritos cujas mães consumiram diferentes concentrações de sementes de Senna occidentalis durante a gestação. São apresentadas as médias e os respectivos erros padrão, através do método dos quadrados mínimos

Figura 37 - Comprimento da cabeça (CCab), diâmetro da cabeça (DCab), comprimento do rádio (CRad) e comprimento da tíbia (CTIB) de cabritos cujas mães consumiram diferentes concentrações de sementes de Senna occidentalis durante a gestação. Médias e 
respectivos erros padrão através do método dos quadrados mínimos. ANOVA seguida de teste T de Student

Figura 38- Comprimento do metacarpo (CMC), circunferência do metacarpo (CIMC) e circunferência do metatarso (CIMT) de cabritos cujas mães consumiram diferentes concentrações de sementes de Senna occidentalis durante a gestação. São apresentadas as médias e os respectivos erros padrão através do método dos quadrados mínimos. ANOVA seguida de teste T de Student.

Figura 39 - Peso médio e total (quadro), de cabritos cujas mães consumiram ração contendo 0 e $3 \%$ de sementes de Senna occidentalis durante a gestação. São apresentadas as médias e os respectivos erros padrão, através do método dos quadrados mínimos. ANOVA, seguida de teste " $T$ " de Student.....

Figura 40 - Níveis séricos de glicose ( $\mathrm{mg} / \mathrm{dl})$, aldolase (u/l), GGT (u/l) e AST (u/l) de cabritos de cabritos cujas mães consumiram ração contendo 0 e $3 \%$ de sementes de Senna occidentalis durante a gestação. São apresentadas as médias e os respectivos erros padrão, através do método dos quadrados mínimos. ANOVA, seguida de teste "T" de Student.

Figura 41- Níveis séricos de FA (u/l), CK (u/l) E LDH (u/l) de cabritos de cabritos cujas mães consumiram ração contendo 0 e $3 \%$ de Senna occidentalis durante a gestação. São apresentadas as médias e os respectivos erros padrão, através do método dos quadrados mínimos. ANOVA, seguida de teste "T" de Student

Figura 42 - Níveis séricos de proteína total $(\mathrm{mg} / \mathrm{dl})$, albumina $(\mathrm{g} / \mathrm{l})$, uréia (mg/dl) e creatinina ( $\mathrm{u} / \mathrm{l})$ de cabritos cujas mães consumiram ração contendo 0 e $3 \%$ de sementes de Senna occidentalis durante a gestação. São apresentadas as médias e os respectivos erros padrão, através do método dos quadrados mínimos. ANOVA, seguida de teste "T" de Student.

Figura 43 - Altura corporal (AC), comprimento corporal (CC), perímetro torácico $(\mathrm{PT})$ e comprimento da tíbia (CTib) de cabritos cujas mães consumiram ração contendo 0 e $3 \%$ de sementes de Senna occidentalis durante a gestação. São apresentadas as médias e os respectivos erros padrão, através do método dos quadrados mínimos. ANOVA, seguida de teste "T" de Student

Figura 44 - Comprimento do rádio (CRad), comprimento do metatarso (CMT), comprimento do metacarpo (CMC) e comprimento da cabeça (CCab) de cabritos cujas mães consumiram ração contendo 0 e $3 \%$ de sementes de sementes de Senna occidentalis durante a gestação. São apresentadas as médias e os respectivos erros padrão. ANOVA, seguida de teste T de Student

Figura 45 - Diâmetro da cabeça (DCab), circunferência do metatarso (CIMT) e circunferência do metacarpo (CIMC) de cabritos cujas mães consumiram ração contendo 0 e $3 \%$ de sementes de Senna occidentalis durante a gestação. São apresentadas as médias e 
os respectivos erros padrão. ANOVA, seguida de teste $\mathrm{T}$ de Student

Figura 46 - Labirinto progressivo realizado por cabritos cujas mães consumiram ração contendo 0 e $3 \%$ de sementes de Senna occidentalis durante a gestação. São apresentadas as médias e os respectivos erros padrão.

Figura 47 - Labirinto em T (tempo total até a mãe) realizado por cabritos cujas mães consumiram ração contendo 0 e $3 \%$ de sementes de Senna occidentalis durante a gestação. São apresentadas as médias e os respectivos erros padrão

Figura 48 - Labirinto médio realizado por cabritos cujas mães consumiram ração contendo 0 e $3 \%$ de sementes de Senna occidentalis durante a gestação. São apresentadas as médias e os respectivos erros padrão. PDIFF, seguida de teste $F$

Figura 49 - Labirinto difícil realizado por cabritos cujas mães consumiram ração contendo 0 e $3 \%$ de sementes de Senna occidentalis durante a gestação. São apresentadas as médias e os respectivos erros padrão.

Figura 50 - Média do ganho de peso $(\mathrm{kg})$ mensal e total de cabritos cujas mães consumiram ração contendo 0 e $4 \%$ (LAC) de sementes de Senna occidentalis durante a lactação. São apresentadas as médias e os respectivos erros padrão através do método dos quadrados mínimos. ANOVA seguida de teste T de student

Figura 51 - Níveis séricos de glicose (mg/dl), aldolase (u/l), GGT (u/l) e AST (u/l) de cabritos cujas mães consumiram ração contendo 0 e $4 \%$ (LAC) de sementes de Senna occidentalis durante a lactação. São apresentadas as médias e os respectivos erros padrão através do método dos quadrados mínimos. ANOVA seguida de teste $\mathrm{T}$ de student.

Figura 52 - Níveis séricos de FA (u/l), CK (u/l), LDH (u/l) e triglicerídeos (u/l) de cabritos cujas mães consumiram ração contendo 0 e $4 \%$ (LAC) de sementes de Senna occidentalis durante a lactação. São apresentadas as médias e os respectivos erros padrão através do método dos quadrados mínimos. ANOVA, seguida de teste "T" de Student.

Figura 53 - Níveis séricos de proteína total (mg/dl), albumina $(\mathrm{g} / \mathrm{L})$, uréia (mg/dl) e creatinina ( $\mathrm{u} / \mathrm{l})$ de cabritos cujas mães consumiram ração contendo 0 e $4 \%$ (LAC) de sementes de Senna occidentalis durante a lactação. São apresentadas as médias e os respectivos erros padrão através do método dos quadrados mínimos. ANOVA, seguida de teste "T" de Student

Figura 54 - Níveis séricos de colesterol $(\mathrm{mg} / \mathrm{dl})$ de cabritos cujas mães consumiram ração contendo 0 e $4 \%$ (LAC) de sementes de Senna occidentalis durante a lactação. São apresentadas as médias e os respectivos erros padrão através do método dos quadrados mínimos. ANOVA, seguida de teste "T" de Student 
Figura 55 - Altura corporal (AC), comprimento corporal (CC), perímetro torácico $(\mathrm{PT})$ e comprimento da tíbia (CTib) de cabritos cujas mães consumiram ração contendo 0 e $4 \%$ (LAC) de sementes de Senna occidentalis durante a lactação. São apresentadas as médias e os respectivos erros padrão através do método dos quadrados mínimos. ANOVA seguida de teste T de Student.

Figura 56 - Comprimento do rádio (CRad), comprimento do metatarso (CMT), comprimento do metacarpo (CMC) e comprimento da cabeça (CCab) de cabritos cujas mães consumiram ração contendo 0 e $4 \%$ (LAC) de sementes de Senna occidentalis durante a lactação. São apresentadas as médias e os respectivos erros padrão através do método dos quadrados mínimos. ANOVA seguida de teste T de Student

Figura 57 - Diâmetro da cabeça (DCab), circunferência do metatarso (CIMT) e circunferência do metacarpo (CIMC) de cabritos cujas mães consumiram ração contendo 0 e $4 \%$ (LAC) de sementes de sementes de Senna occidentalis durante a lactação. São apresentadas as médias e os respectivos erros padrão.....

Figura 58 - Fotomicrografia de luz de cortes histológicos cabritos pertencentes ao grupo LAC. Músculo diafragmático (A), observase lesões caracterizadas por necrose tumefação e afrouxamento de fibras (setas). HE, A: 10X. Coração (B), observa-se necrose, vacuolizações (cabeça de seta), edema intersticial, tumefação (setas) e fragmentação de fibras. HE, A: 20X. Fígado (C), evidencia-se extensa vacuolização de hepatócitos em torno da veia hepática terminal. HE, A: 10X. Rim (D) observam-se discretas vacuolizações de túbulos contornados e em glomérulos (setas) HE, A: 20X.

Figura 59 - Fotografias de cromatogramas revelados em câmara de iodo $10 \%$; solução $\mathrm{CH} 3 \mathrm{OH}+\mathrm{KOH} 10 \%$ e, por último HNO3 100\%, desenvolvidos em acetato de etila:metanol:água (77:13:10). São evidenciadas as manchas obtidas após o desenvolvimento. Manchas róseas, indicativas da presença de antraquinonas (setas) 


\section{LISTA DE TABELAS}

Tabela 1 - Parâmetros reprodutivos de mães tratadas com sementes de $S$. occidentalis do $27^{\circ}$ dia de gestação até o parto

Tabela 2 - Peso médio $(\mathrm{kg})$ inicial, final e total de cabras que consumiram diferentes concentrações de sementes de Senna occidentalis durante a gestação. São apresentados as médias e os respectivos erros padrão, pelo método dos quadrados mínimos. ANOVA, seguida de teste T de Student

Tabela 3 - Níveis séricos de albumina $(\mathrm{g} / \mathrm{l})$, colinesterase $(\mathrm{u} / \mathrm{l})$, Aldolase $(\mathrm{u} / \mathrm{l})$ e creatinina $(\mathrm{u} / \mathrm{l})$ de cabras que consumiram diferentes concentrações de sementes de Senna occidentalis durante a gestação. São apresentadas as médias e os respectivos erros padrão, pelo método dos quadrados mínimos. ANOVA, seguida de teste T de Student

Tabela 4 - Níveis séricos de glicose (mg/dl), GGT (u/l), AST (u/l) e LDH (u/l) de cabras que consumiram diferentes concentrações de sementes de Senna occidentalis durante a gestação. São apresentadas as médias e os respectivos erros padrão, pelo método dos quadrados mínimos. ANOVA, seguida de teste T de Student

Tabela 5 - Níveis séricos de CK (U/L), proteína $(\mathrm{g} / \mathrm{dl})$ e uréia $(\mathrm{mg} / \mathrm{dl}) \mathrm{de}$ cabras que consumiram diferentes concentrações de sementes de Senna occidentalis durante a gestação São apresentadas as médias e os respectivos erros padrão, pelo método dos quadrados mínimos. ANOVA, seguida de teste T de Student.

Tabela 6 - Parâmetros ultrassonográficos de cabras que consumiram diferentes concentrações de sementes de Senna occidentalis durante a gestação. Freqüência cardíaca (FC), movimento fetal (MF) e comprimento crânio caudal (CCC). São apresentadas as médias e os respectivos erros padrão, pelo método dos quadrados mínimos. ANOVA, seguida de teste T de Student.

Tabela 7 - Parâmetros ultrassonográficos de cabras que consumiram diferentes concentrações de sementes de Senna occidentalis durante a gestação. Diâmetro abdominal (DA), diâmetro torácico (DT) e diâmetro biparietal (DBP). São apresentadas as médias e os respectivos erros padrão, pelo método dos quadrados mínimos. ANOVA, seguida de teste $T$ de Student

Tabela 8 - Parâmetros reprodutivos de cabras que consumiram ração contendo 0 e $3 \%$ de sementes de Senna occidentalis durante a gestação. São apresentadas as médias, respectivos erros padrão e porcentagens dos principais eventos

Tabela 9 - Peso médio $(\mathrm{kg})$ inicial, final e total de cabras que consumiram ração contendo 0 e $3 \%$ de sementes de Senna occidentalis durante a gestação. São apresentadas as médias e os respectivos erros padrão, pelo método dos quadrados mínimos. 
Tabela 10 - Níveis séricos de albumina ( $g / l)$, proteína $(\mathrm{g} / \mathrm{dl})$, colesterol $(\mathrm{u} / \mathrm{l})$ e triglicerídeos (mg/dl), de cabras que consumiram ração contendo 0 e 3\% de sementes de Senna occidentalis durante a gestação. São apresentadas as médias e os respectivos erros padrão, pelo método dos quadrados mínimos. ANOVA, seguida de teste T de Student

Tabela 11 - Níveis séricos de glicose (mg/dl), e atividade de GGT (u/l), AST (u/l) e LDH (u/l) de cabras que consumiram ração contendo 0 e $3 \%$ de sementes de Senna occidentalis durante a gestação. São apresentadas as médias e os respectivos erros padrão, pelo método dos quadrados mínimos. ANOVA, seguida de teste $\mathrm{T}$ de Student.

Tabela 12 - Atividade sérica de CK (U/I), FA (U/I) e níveis séricos de creatinina (U/l) e uréia $(\mathrm{mg} / \mathrm{dl})$ de cabras que consumiram ração contendo 0 e $3 \%$ de sementes de Senna occidentalis durante a gestação. São apresentadas as médias e os respectivos erros padrão, pelo método dos quadrados mínimos. ANOVA, seguida de teste T de Student

Tabela 13 - Parâmetros ultra-sonográficos de cabras que consumiram ração contendo 0 e $3 \%$ de sementes de Senna occidentalis durante a gestação. Freqüência cardíaca (FC), movimento fetal (MF) e comprimento crânio caudal (CCC). São apresentadas as médias e os respectivos erros padrão, pelo método dos quadrados mínimos. ANOVA, seguida de teste T de Student

Tabela 14 - Parâmetros ultrassonográficos de cabras que consumiram ração contendo 0 e $3 \%$ de sementes de Senna occidentalis durante a gestação. Diâmetro abdominal (DA), diâmetro torácico (DT) e diâmetro biparietal (DBP). São apresentadas as médias e os respectivos erros padrão, pelo método dos quadrados mínimos. ANOVA seguida de teste $T$ de Student

Tabela 15 - Ganho de peso médio (kg) inicial, final e total de cabras que receberam ração contendo 0 e $4 \%$ de sementes de Senna occidentalis durante a lactação. São apresentadas as médias e os respectivos erros padrão, pelo método dos quadrados mínimos. ANCOVA, seguida de teste T de Student.

Tabela 16 - Níveis séricos de albumina $(\mathrm{g} / \mathrm{l})$, colesterol $(\mathrm{u} / \mathrm{l})$, uréia $(\mathrm{mg} / \mathrm{dl})$ e creatinina (u/l) de cabras que receberam ração contendo 0 e $4 \%$ de sementes de Senna occidentalis durante a lactação. São apresentados as médias e os respectivos erros padrão. ANOVA, seguida de teste $\mathrm{T}$ de Student. Os dados são apresentados através do método dos quadrados mínimos

Tabela 17 - Níveis séricos de glicose (mg/dl), GGT (u/l), AST (u/l) e LDH (u/l) de cabras que consumiram ração contendo 0 e $4 \%$ de sementes de Senna occidentalis durante a lactação. São apresentadas as médias e os respectivos erros padrão. ANOVA, seguida de teste $\mathrm{T}$ de Student. Os dados são apresentados através do método dos quadrados mínimos 
Tabela 18 - Níveis séricos de CK (U/l), proteína $(\mathrm{g} / \mathrm{dl})$ e uréia $(\mathrm{mg} / \mathrm{dl})$ de cabras que consumiram ração contendo 0 e $4 \%$ de sementes de Senna occidentalis durante a lactação. São apresentados as médias e os respectivos erros padrão. ANOVA, seguida de teste $T$ de Student. Os dados são apresentados através do método dos quadrados mínimos

Tabela 19 - Pesos médios $(\mathrm{kg}$ ) de cabritos filhos de cabras que consumiram ração contendo diferentes concentrações $(0,1 \%$ e $2 \%)$ de sementes de Senna occidentalis durante a gestação. São apresentadas as médias e os respectivos erros padrão. Análise da variância ANOVA, seguida de LSM e teste "T" de Student

Tabela 20 - Níveis séricos de glicose (mg/dl), aldolase (u/l), GGT (u/l) e AST (u/l) de cabritos cujas mães consumiram diferentes concentrações de sementes de Senna occidentalis durante a gestação. São apresentadas as médias e os respectivos erros padrão. Análise da variância ANOVA, seguida de teste "T" de Student. Os dados são apresentados através do método dos quadrados mínimos.

Tabela 21 - Níveis séricos de FA (u/l), CK (u/l), LDH (u/l) e triglicerídeos (u/l) de cabritos cujas mães consumiram diferentes concentrações de sementes de Senna occidentalis durante a gestação. São apresentadas as médias e os respectivos erros padrão. Os dados são apresentados através do método dos quadrados mínimos

Tabela 22 - Níveis séricos de proteína total $(\mathrm{mg} / \mathrm{dl})$, albumina $(\mathrm{g} / \mathrm{l})$, uréia (mg/dl) e creatinina $(\mathrm{u} / \mathrm{l})$ de cabritos cujas mães consumiram diferentes concentrações de sementes de Senna occidentalis durante a gestação. São apresentadas as médias e os respectivos erros padrão. Os dados são apresentados através do método dos quadrados mínimos

Tabela 23 - Níveis séricos de colinesterase (u/l) de cabritos cujas mães consumiram diferentes concentrações de sementes de Senna occidentalis durante a gestação. São apresentadas as médias e os respectivos erros padrão. Os dados são apresentados através do método dos quadrados mínimos

Tabela 24 - Comprimento do metatarso (CMT), altura corporal (AC), comprimento corporal (CC) e perímetro torácico (PT) de cabritos cujas mães consumiram diferentes concentrações de sementes de Senna occidentalis durante a gestação. São apresentadas as médias e os respectivos erros padrão através do método dos quadrados mínimos

Tabela 25 - Comprimento da cabeça (CCab), diâmetro da cabeça (DCab), comprimento do rádio (CRad) e comprimento da tíbia (CTIB) de cabritos cujas mães consumiram diferentes concentrações de sementes de Senna occidentalis durante a gestação. Médias e respectivos erros padrão através do método dos quadrados mínimos. ANOVA seguida de teste T de Student 
Tabela 26 - Comprimento do metacarpo (CMC), circunferência do metacarpo (CIMC) e circunferência do metatarso (CIMT) de cabritos cujas mães consumiram diferentes concentrações de sementes de Senna occidentalis durante a gestação. São apresentadas as médias e os respectivos erros padrão através do método dos quadrados mínimos. ANOVA seguida de teste T de Student.

Tabela 27 - Média do ganho de peso $(\mathrm{kg})$ de cabritos cujas mães consumiram ração contendo 0 , e $3 \%$ de sementes de Senna occidentalis durante a gestação. São apresentadas as médias e os respectivos erros padrão, através do método dos quadrados mínimos. ANOVA, seguida de teste "T" de Student

Tabela 28 - Níveis séricos de glicose ( $\mathrm{mg} / \mathrm{dl})$, aldolase (u/l), GGT (u/l) e AST (u/l) de cabritos cujas mães consumiram ração contendo 0 e $3 \%$ de sementes de Senna occidentalis durante a gestação. São apresentadas as médias e os respectivos erros padrão, através do método dos quadrados mínimos. ANOVA, seguida de teste "T" de Student

Tabela 29 - Níveis séricos de FA (u/l), CK (u/l) e LDH (u/l) de cabritos cujas mães consumiram ração contendo 0 e $3 \%$ de sementes de Senna occidentalis durante a gestação. São apresentadas as médias e os respectivos erros padrão, através do método dos quadrados mínimos. ANOVA, seguida de teste "T" de Student

Tabela 30 - Níveis séricos de proteína total $(\mathrm{mg} / \mathrm{dl})$, albumina $(\mathrm{g} / \mathrm{L})$, uréia $(\mathrm{mg} / \mathrm{dl})$ e creatinina $(\mathrm{u} / \mathrm{l})$ de cabritos cujas mães consumiram ração contendo 0 e $3 \%$ de sementes de Senna occidentalis durante a gestação. São apresentadas as médias e os respectivos erros padrão, através do método dos quadrados mínimos. ANOVA, seguida de teste "T" de Student

Tabela 31 - Altura corporal (AC), comprimento corporal (CC), perímetro torácico (PT) e comprimento da tíbia (CTib) de cabritos cujas mães consumiram ração contendo 0 e $3 \%$ de sementes de Senna occidentalis durante a gestação. São apresentadas as médias e os respectivos erros padrão, através do método dos quadrados mínimos. ANOVA, seguida de teste "T" de Student

Tabela 32 - Comprimento do rádio (CRad), comprimento do metatarso (CMT), comprimento do metacarpo (CMC) e comprimento da cabeça (CCab) de cabritos cujas mães consumiram ração contendo 0 e $3 \%$ de sementes de sementes de Senna occidentalis durante a gestação. São apresentadas as médias e os respectivos erros padrão. ANOVA, seguida de teste $T$ de Student

Tabela 33 - Diâmetro da cabeça (DCab), circunferência do metatarso (CIMT) e circunferência do metacarpo (CIMC) de cabritos cujas mães consumiram ração contendo 0 e $3 \%$ de sementes de Senna occidentalis durante a gestação. São apresentadas as médias e os respectivos erros padrão. ANOVA, seguida de teste $T$ de Student 
Tabela 34 - Labirinto progressivo realizado por cabritos cujas mães consumiram ração contendo 0 e $3 \%$ de sementes de Senna occidentalis durante a gestação. São apresentadas as médias e os respectivos erros padrão.

Tabela 35 - Labirinto em T (tempo total até a mãe) realizado por cabritos cujas mães consumiram ração contendo 0 e $3 \%$ de sementes de Senna occidentalis durante a gestação. São apresentadas as médias e os respectivos erros padrão

Tabela 36 - Labirinto médio realizado por cabritos cujas mães consumiram ração contendo 0 e $3 \%$ de sementes de Senna occidentalis durante a gestação. São apresentadas as médias e os respectivos erros padrão. PDIFF, seguida de teste $F$

Tabela 37 - Labirinto difícil realizado por cabritos cujas mães consumiram ração contendo 0 e $3 \%$ de sementes de Senna occidentalis durante a gestação. São apresentadas as médias e os respectivos erros padrão. PDIFF, seguida de teste $F$

Tabela 38 - Média do ganho de peso $(\mathrm{kg})$ mensal e total de cabritos cujas mães consumiram ração contendo 0 e $4 \%$ (LAC) de sementes de Senna occidentalis durante a lactação. São apresentadas as médias e os respectivos erros padrão através do método dos quadrados mínimos. ANOVA seguida de teste $\mathrm{T}$ de student

Tabela 39 - Níveis séricos de glicose, aldolase, GGT e AST de cabritos cujas mães consumiram ração contendo 0 e $4 \%$ (LAC) de sementes de Senna occidentalis durante a lactação. São apresentadas as médias e os respectivos erros padrão através do método dos quadrados mínimos. ANOVA seguida de teste T de student

Tabela 40 - Níveis séricos de FA (u/l), CK (u/l), LDH (u/l) e triglicerídeos (u/l) de cabritos cujas mães consumiram ração contendo 0 e $4 \%$ (LAC) de sementes de Senna occidentalis durante a lactação. São apresentadas as médias e os respectivos erros padrão através do método dos quadrados mínimos. ANOVA, seguida de teste "T" de Student.

Tabela 41 - Níveis séricos de proteína total (mg/dl), albumina $(\mathrm{g} / \mathrm{L})$, uréia (mg/dl) e creatinina ( $\mathrm{u} / \mathrm{l})$ de cabritos cujas mães consumiram ração contendo 0 e $4 \%$ (LAC) de sementes de Senna occidentalis durante a lactação. São apresentadas as médias e os respectivos erros padrão através do método dos quadrados mínimos. ANOVA, seguida de teste "T" de Student

Tabela 42 - Níveis séricos de colesterol $(\mathrm{mg} / \mathrm{dl})$ de cabritos cujas mães consumiram ração contendo 0 e $4 \%$ (LAC) de sementes de Senna occidentalis durante a lactação. São apresentadas as médias e os respectivos erros padrão através do método dos quadrados mínimos. ANOVA, seguida de teste "T" de Student....

Tabela 43 - Altura corporal (AC), comprimento corporal (CC), perímetro torácico (PT) e comprimento da tíbia (CTib) de cabritos cujas mães consumiram ração contendo 0 e $4 \%$ (LAC) de sementes 
de Senna occidentalis durante a lactação. São apresentadas as médias e os respectivos erros padrão através do método dos quadrados mínimos. ANOVA seguida de teste T de Student.

Tabela 44 - Comprimento do rádio (CRad), comprimento do metatarso (CMT), comprimento do metacarpo (CMC) e comprimento da cabeça (CCab) de cabritos cujas mães consumiram ração contendo 0 e $4 \%$ (LAC) de sementes de Senna occidentalis durante a lactação. São apresentadas as médias e os respectivos erros padrão através do método dos quadrados mínimos. ANOVA seguida de teste $\mathrm{T}$ de Student

Tabela 45 - Diâmetro da cabeça (DCab), circunferência do metatarso (CIMT) e circunferência do metacarpo (CIMC) de cabritos cujas mães consumiram ração contendo 0 e $4 \%$ (LAC) de sementes de sementes de Senna occidentalis durante a lactação. São apresentadas as médias e os respectivos erros padrão 


\section{LISTA DE ABREVIATURAS E SIGLAS}

So

Senna occidentalis

D daltons

CEPTOX......... Centro de Pesquisa em Toxicologia veterinária

$\mathrm{kg}$ quilograma

VPT Departamento de Patologia Veterinária

FMVZ Faculdade de Medicina Veterinária e Zootecnia

USP Universidade de São Paulo

ALB albumina

ALD. aldolase

AST aspartato amino transferase

CREAT creatinina

CK. creatina quinase

GGT gama glutamil transferase

FA fofatase alcalina

LDH. lactato desidrogenase

PT proteína total

PBS tampão fosfato salina

$\mathrm{KOH}$ Hidróxido de potássio

$\mathrm{CH} 3 \mathrm{OH}$ metanol

$\mathrm{HNO} 3$ ácido nítrico

PMSG gonadotrofina coriônica da égua prenhe eCG gonadotrofina coriônica eqüina

UI. unidades internacionais

VCM Departamento de Clínica Médica

VPS Departamento de Medicina Veterinária Preventiva e Saúde Animal MAP acetato de medroxiprogesterona

$\mathrm{ml}$ mililitro

MF movimento fetal

FC freqüência cardíaca

CCC Comprimento Craniocaudal

DBP diâmetro biparietal

DA diâmetro abdominal

DT diâmetro torácico

AC altura corporal

$\mathrm{CC}$ comprimento corporal

PT perímetro torácico

CCab comprimento da cabeça

DCab diâmetro da cabeça

CRAD comprimento do rádio

CTIB comprimento da tíbia

CMC comprimento do metacarpo

CMT comprimento do metatarso

CIMC circunferência do metacarpo

CIMT circunferência do metatarso

SNC sistema nervoso central 


\section{SUMÁRIO}

1 INTRODUÇÃO

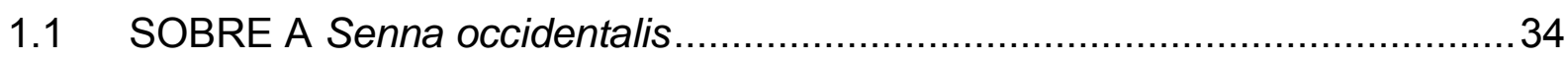

1.2 SOBRE A TOXICOLOGIA DO DESENVOLVIMENTO …...................................

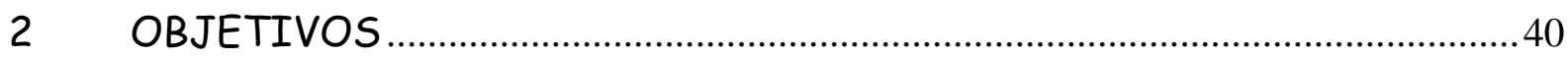

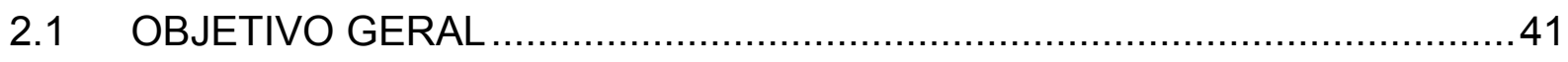

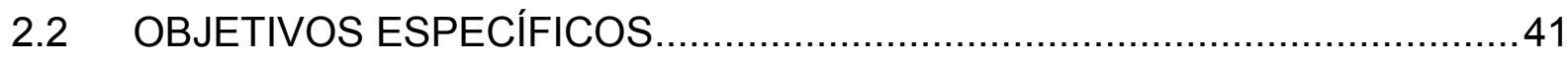

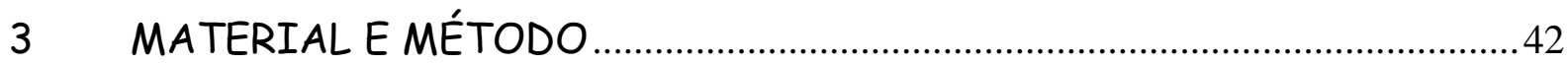

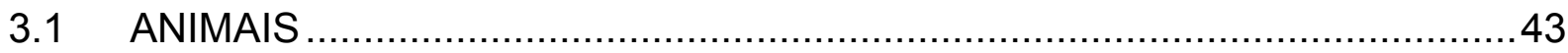

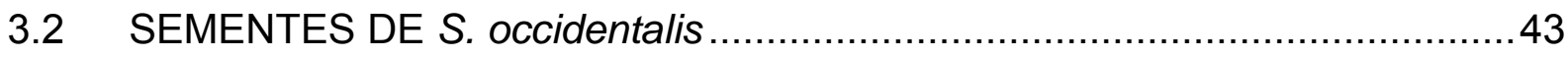

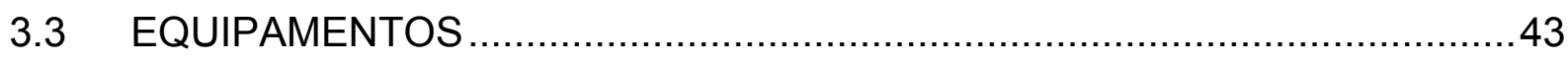

3.4 REAGENTES, SOLUÇÕES e FÁRMACOS ............................................... 44

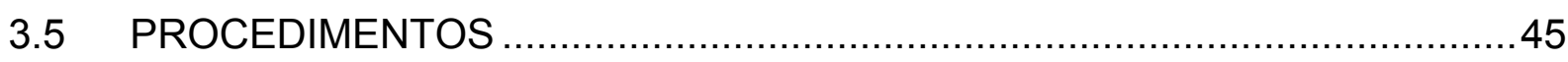

3.5.1 Administração de S. occidentalis para Caprinos.....................................45

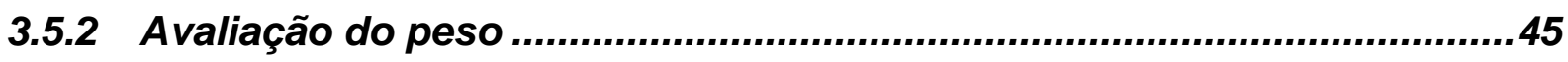

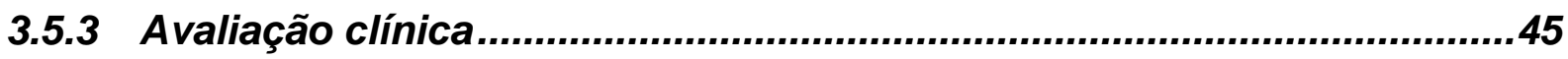

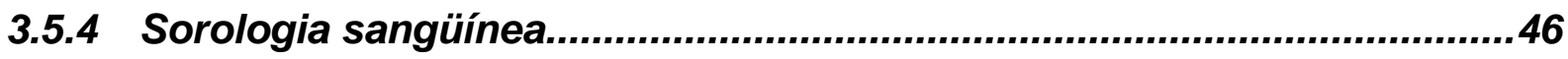

3.5.5 Indução do estro por esponjas impregnadas com progestágenos ........46

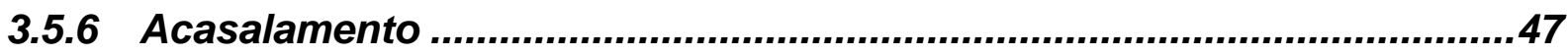

3.5.7 Dosagens de enzimas e componentes sangüíneos ................................47

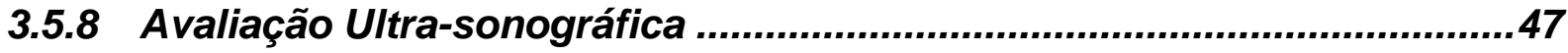

3.5.9 Avaliação de anomalias e/ou malformações fetais .................................50

3.5.10 Avaliação morfométrica corpórea de filhotes ........................................50

3.5.11 Estudo comportamental ......................................................................52

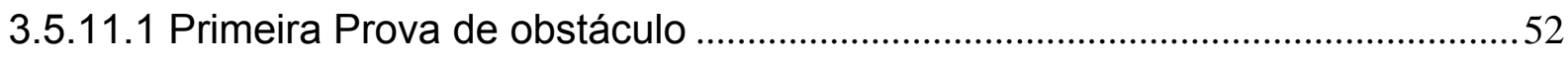

3.5.11.2 Segunda prova de obstáculo............................................................................ 
3.5.11.3 Terceira prova de obstáculos 54

3.5.11.4 Quarta prova de obstáculos. Labirinto em T (“T Maze”).................................55

3.5.11.4.1 Para quando havia uma cabra somente. A própria mãe ..............................57

3.5.11.4.2 Para quando havia duas cabras. A mãe e uma outra cabra .......................57

3.5.11.5 Quinta prova de obstáculos. Labirinto médio ("Lashley Maze”) ......................57

3.5.11.6 Sexta prova de obstáculos. Labirinto "Hebb-Williams Maze" .........................58

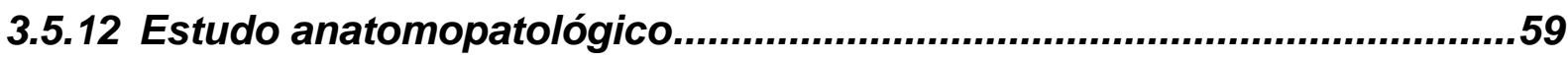

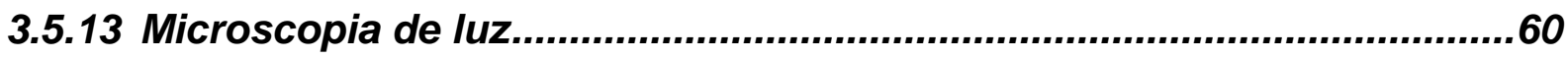

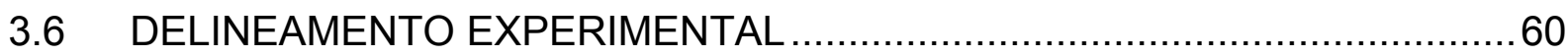

3.6.1 Experimento 1: Estudo dos efeitos tóxicos produzidos pela S. occidentalis em cabras durante a gestação..........................................6 60

3.6.2 Experimento 2: Estudo dos efeitos tóxicos produzidos pela S. occidentalis administrado a cabras lactantes..........................................61

3.6.3 Experimento 3: Estudo dos efeitos tóxicos produzidos pela S. occidentalis. Avaliação do desenvolvimento físico e comportamental da prole.

3.6.4 Experimento 4: Estudo dos efeitos tóxicos produzidos pela S. occidentalis administrado a cabras durante a lactação. Avaliação dos lactentes

3.6.5 Experimento 5: Estudo químico do leite de cabras que consumiram 4\% de sementes de $S$. occidentalis. Pesquisa da presença de antraquinonas

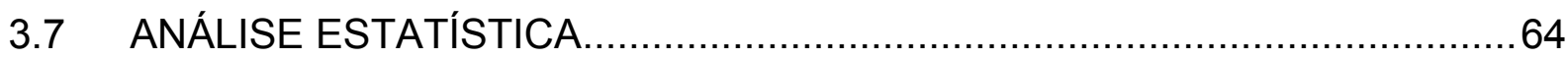

$4 \quad$ RESULTADOS

4.1 EXPERIMENTO 1: ESTUDO DOS EFEITOS TÓXICOS PRODUZIDOS PELA S. occidentalis EM CABRAS DURANTE A GESTAÇÃO ......................67

4.1.1 Resultados das cabras pertencentes aos grupos So1, So2 e So4.........67

4.1.2 Resultados das cabras pertencentes ao Grupo So3 ..............................85

4.2 EXPERIMENTO 2: ESTUDO DOS EFEITOS TÓXICOS PRODUZIDOS PELA S. occidentalis ADMINISTRADO A CABRAS LACTANTES

4.3 EXPERIMENTO 3: ESTUDO DOS EFEITOS TÓXICOS PRODUZIDOS PELA S. occidentalis. AVALIAÇÃO DO DESENVOLVIMENTO FÍSICO E COMPORTAMENTAL DA PROLE 
4.3.1 Resultados dos filhotes provenientes das cabras pertencentes aos grupos So1 e So2

4.3.2 Resultados dos filhotes provenientes das cabras pertencentes aos grupo So3

4.4 EXPERIMENTO 4: ESTUDO DOS EFEITOS TÓXICOS PRODUZIDOS PELA S. occidentalis ADMINISTRADO A CABRAS DURANTE A LACTAÇÃO. AVALIAÇÃO DOS LACTENTES

4.5 EXPERIMENTO 5: ESTUDO QUÍMICO DO LEITE DE CABRAS QUE CONSUMIRAM 4\% DE SEMENTES DE S. OCCIDENTALIS. PESQUISA DA PRESENÇA DE ANTRAQUINONAS

5 DISCUSSÃO

6 CONCLUSÕES

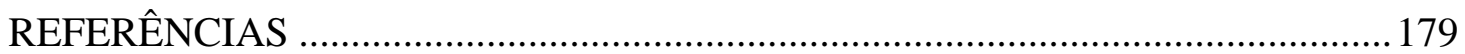




\section{PRÓLOGO}

O presente trabalho de pesquisa é a continuação de nossa Dissertação de Mestrado, intitulada "Estudo dos Efeitos Tóxicos Produzidos Pela Administração Prolongada de Sementes de Senna occidentalis. Avaliação em Ratos e Caprinos". Assim, a partir daquele estudo, foi possível obter informações sobre os efeitos tóxicos da administração prolongada, em concentrações baixas, desta planta, na espécie caprina, dados estes até então não disponíveis na literatura. Visa-se, agora, estudar os efeitos da exposição à $S$. occidentalis nesta mesma espécie, durante o período perinatal. 


\section{INTRODUÇÃO}

1866 D. CERQUEIRA Reminiscências da campanha do Paraguai. Ed. esp. fl 136: [...]A nossa vida em campanha não era tão má como se pensa vulgarmente. O Costa Matos achou perto do nosso acampamento, muito fedegoso, e fez uma excelente colheita de vagens maduras. Debulhou-as, moeu-as e fez um magnífico café, que adoçamos com um pouco de açúcar mascavado já melando. Havia muitos meses que não tomávamos senão mate. Foi uma delícia [...] (CERQUEIRA, 1980). 


\subsection{SOBRE A Senna occidentalis}

A Senna occidentalis (L.) Link (sin. Cassia occidentalis), é uma planta tóxica da família Fabaceae-Caesalpinoideae (Leguminosae). Esta planta pode ser encontrada em quase todo o território nacional, em pastagens e culturas de cereais como milho, sorgo, trigo e soja (O'HARA et al., 1969; COLVIN et al., 1986). Possui vários nomes vulgares, tais como fedegoso, mata-pasto verdadeiro, mamangá, sene, cigarreira, lava-pratos, pajamarioba, pajemarioba, mangerioba, entre outros (HOEHENE, 1939; JOLY, 1977; CRUZ, 2000).

De acordo com Lorenzi (1991), a S. occidentalis (Figura 1):

[...]é uma planta perene, subarbustiva, lenhosa, ramificada, medindo de 1-2 metros de altura, com reprodução por sementes. As folhas são alternas, compostas, paripinadas, com 4-6 pares de folíolos glabros de 6-7 $\mathrm{cm}$ de comprimento. As inflorescências são axilares e terminais, em racemos com poucas flores pediceladas e de coloração amarelo-ouro. Os frutos são formados dentro de vagens achatadas, mais ou menos retas, de coloração marrom, com 10-14 cm de comprimento. Esta leguminosa floresce no período de setembro a outubro e frutifica no período de fevereiro a abril.

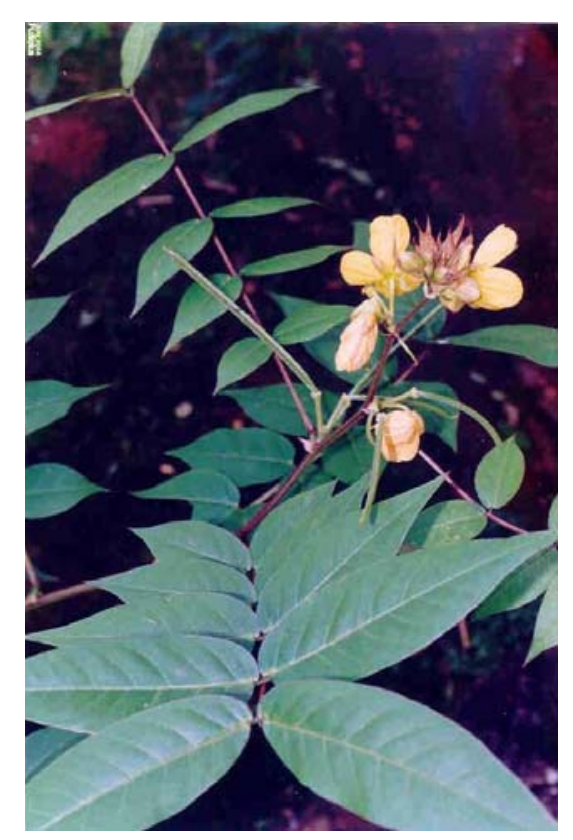

Figura 1 - Senna occidentalis 
Como a S. occidentalis cresce junto às plantações, esta planta pode, além de competir com nutrientes úteis aos cereais, contaminá-los com suas sementes durante a coleta mecânica. Caso não haja separação adequada dos tipos de sementes, principalmente através da peneiragem e separação por densidade, as sementes desta planta invasora de cultura poderão vir a compor parte do produto final destinado à alimentação tanto animal como humana, acarretando um desbalanço nutricional, além do risco de incluir nesta dieta algum componente tóxico que poderá ser previamente conhecido, ou não. Embora a semente seja responsabilizada pelas intoxicações mais severas, outras partes da S. occidentalis, como as folhas, caules e vagens, são consideradas tóxicas (DOLAHITE; HENSON, 1965).

Os casos de intoxicação espontânea pela S. occidentalis foram relatados em bovinos (HENSON et al., 1965; PIERCE; O'HARA, 1967; BARROS et al., 1990) e eqüínos (BROCQ-ROSSEAU; BRUERE, 1925; MOUSSU, 1925). Além disto, alguns trabalhos foram realizados, reproduzindo-se experimentalmente a intoxicação em animais como bovinos (DOLLAHITE; HENSON, 1965; HENSON; DOLLAHITE, 1966; MERCER et al., 1967; ROGERS; GIBSON; REICHMANN, 1979; BARROS et al., 1990); suínos (COLVIN et al., 1986; MARTINS et al., 1986), eqüinos (IRIGOYEN et al., 1991), ovinos (DOLLAHITE; HENSON, 1965), caprinos (DOLLAHITE; HENSON, 1965; SULIMAN; WASFI; ADAM, 1982; BARBOSA-FERREIRA, 2003), leporinos (DOLLAHITE; HENSON, 1965; O'HARA; PIERCE, 1974a,b; TASAKA et al., 2000), ratos (WEG, 2001; BARBOSA-FERREIRA et al., 2005) e aves (SIMPSON; DAMRON; HARMS, 1971; CAVALIERI et al., 1997; HARAGUCHI et al., 1998).

Os dados de intoxicação natural, bem como nos trabalhos experimentais mostram que os sintomas caracterizam-se principalmente por doença afebril, abatimento, tremores musculares, diarréia, incoordenação motora e morte, nas diferentes espécies estudadas.

Os achados de necropsia, nas diferentes espécies animais, revelam como principais lesões as degenerações do músculo esquelético e cardíaco (O'HARA; PIERCE, 1974a,b; ROGERS; GIBSON; REICHMANN, 1979; HERBERT et al., 1983; CAVALIERI, 1997), alterações hepáticas e renais (TASAKA et al., 2000; BARBOSAFERREIRA, 2003). Além destas, uma pesquisa realizada neste laboratório, no qual foram administradas diferentes concentrações de sementes de S. occidentalis, a ratos, mostrou que esta planta também pode promover alterações no sistema 
nervoso central - SNC (BARBOSA-FERREIRA et al., 2005). Entretanto, os locais onde as lesões se apresentam com maior gravidade são variáveis de acordo com a espécie, assim, a miopatia degenerativa da musculatura esquelética e cardíaca prevalece entre os bovinos e aves (BARROS et al., 1990; HARAGUCHI et al., 1998); por outro lado, em leporinos foi observada lesão mais grave em musculatura cardíaca associada a alterações hepáticas significantes (TASAKA et al., 2000).

Há muito se pesquisa sobre o princípio ativo tóxico da S. occidentalis. Os primeiros estudos apontavam a albumina como o princípio ativo tóxico (MOUSSU, 1925). Por outro lado, Hebert et al. (1983) sugeriram ser a toxina de natureza polar, por exemplo, uma proteína. Já Graziano et al. (1983), sugeriram que um dos princípios ativos poderia ser de natureza protéica, estável ao aquecimento, e outro, termo lábil, tais como os derivados da antraquinona. No entanto, Lewis e Shibamoto (1989), verificaram a presença de princípios em extratos orgânicos contendo quinonas e também em suspensões aquosas das sementes da planta tóxica Senna obtusifolia, que, igualmente, apresentaram miopatias em animais intoxicados. No entanto, só recentemente conseguiu-se determinar, de fato, qual seria o princípio ativo tóxico da S. occidentalis. Assim, Haraguchi et al. (1996), isolaram a diantrona, uma antraquinona e, por meio de avaliação biológica em aves, confirmaram ser, de fato, esta antraquinona a principal fitotoxina presente na planta.

Procurando-se compreender o mecanismo de ação tóxico da S. occidentalis Cavaliere et al. (1997) verificaram, à microscopia eletrônica, atrofia de fibras musculares, com alargamento da mitocôndria e armazenamento de lipídeos; o estudo histoquímico revelou moderada quantidade de fibras oxidase negativas. Estes mesmos autores propuseram, então, que o mecanismo de ação tóxico baseiase no desacoplamento da fosforilação oxidativa mitocondrial, portanto, este princípio ativo agiria diretamente sobre o metabolismo desta organela.

Devido ao peso molecular da diantrona (450 D), formulou-se a hipótese desta molécula atravessar a barreira hematoencefálica, podendo, desta maneira, acarretar danos ao SNC. Assim, em um dos experimentos de nossa Dissertação de Mestrado (BARBOSA-FERREIRA, 2003), propôs-se verificar os efeitos desta planta no sistema nervoso central de ratos intoxicados (4\% de sementes de S. occidentalis na ração), sendo que, de fato, os dados revelaram lesão também neste tecido. Portanto, além das alterações em outros órgãos descritos anteriormente, sugere-se que também o SNC seja bastante sensível às lesões produzidas por esta 
antraquinona.

\subsection{SOBRE A TOXICOLOGIA DO DESENVOLVIMENTO}

Segundo Pérez-Landeiro et al. (2002) as alterações morfológicas, bioquímicas ou funcionais induzidas durante a prenhez que é detectada durante a gestação, no nascimento ou posteriormente, é definida como teratogênese ou dismorfogênese. Estas alterações podem ser classificadas em maiores como, por exemplo, a focomelia, que se caracteriza pela aproximação ou encurtamento dos membros do feto, ou aquelas ditas menores, como alterações comportamentais (ROGERS; KAVLOCK, 2001).

A toxicologia do desenvolvimento se refere a uma área de conhecimento relativamente nova, apesar de ser oriunda da teratologia, que foi antigamente relacionada às alterações apenas de ordem estrutural, uma vez que os estudos nesta área restringiam-se somente alterações na morfologia, ou seja, aquelas esqueléticas ou viscerais (ERIKSSON, 2007). No entanto, atualmente está bem estabelecido que as alterações no concepto podem ser tanto estruturais como funcionais e estas podem ser iniciadas em qualquer período entre a fertilização e a maturação pós-natal (WILSON, 1977) Portanto, o termo teratologia passou a ser utilizado como sinônimo da toxicologia do desenvolvimento, abrangendo não só as anormalidades morfológicas, mas também as manifestações no retardo de crescimento, as alterações funcionais, comportamentais e/ou morte da prole (ROGERS; KAVLOCK, 2001).

A preocupação quanto à exposição da gestante aos possíveis efeitos tóxicos sobre o embrião ou no desenvolvimento do feto começou em meados do século $\mathrm{XX}$, pois anteriormente se acreditava que a placenta era uma barreira eficaz contra organismos exógenos, entretanto esta idéia foi derrubada quando se identificou a síndrome da rubéola congênita (GREGG, 1941) em que a mãe portadora desta doença poderia conceber filhos com malformações devido à livre passagem do vírus, causador desta afecção, através da placenta e afetando assim o feto (WEBSTER, 1998). No entanto, foi após o "desastre da talidomida", um medicamento utilizado como sedativo por mulheres grávidas, responsável pelo 
aparecimento de severas alterações no feto, é que a toxicologia do desenvolvimento tomou grande impulso. Assim, a partir deste fato, houve uma revolução na maneira de pensar em relação aos riscos do uso de substâncias durante a gestação, demonstrando que a exposição do feto a xenobióticos durante os períodos críticos do desenvolvimento poderia produzir danos irreversíveis (PÉREZ-LANDERO et al., 2002). A partir de então, começaram a se desenvolver testes eficazes de avaliação de risco da exposição a substâncias durante o período gestacional. Os primeiros testes de avaliação de risco, referentes à toxicologia reprodutiva, foram iniciados, nos Estados Unidos, há mais de 40 anos. Atualmente, são realizados três protocolos para avaliação in vivo: o Segmento I que é aquele que cobre o período de préacasalamento até a implantação; o Segmento II, cuja denominação anterior era "teste de teratogenicidade", sendo atualmente este adotado pelas principais agências que normatizam a avaliação de risco, e é aquele no qual se avalia o efeito da substância química da implantação até o final da organogênese e o Segmento III que compreende a avaliação do final da gestação até o desenvolvimento pós-natal (DASTON; SEED, 2007).

A principal preocupação na avaliação de risco do impacto das diferentes substâncias químicas no desenvolvimento é que haja a extrapolação correta dos dados obtidos; neste sentido, um dos maiores desafios para as agências de regulamentação de avaliação de risco é, a partir dos dados obtidos em ratos, extrapolá-los para os seres humanos. Seguindo-se este mesmo raciocínio, deve-se supor que a extrapolação de dados de uma espécie monogástrica, como ratos, para uma outra espécie ruminante deve ser feita com muito maior precaução, já que o rúmen é, sabidamente, um local que desempenha importante papel na farmacocinética e metabolismo dos diferentes xenobióticos; por exemplo, o antihelmíntico albendazole, causa embriotoxicidade somente em ruminantes, pois o composto teratógeno é o seu metabólito, um derivado sulfóxido, o qual é gerado exclusivamente por poligástricos (DELATOUR et al., 1981).

Por outro lado sabe-se que a mortalidade pré-natal e o nascimento de fetos teratogênicos são importantes causas de perdas econômicas na criação animal (PANTER et al., 1992). Assim sendo, e objetivando-se avaliar os possíveis efeitos teratogênicos das diferentes substâncias químicas (medicamentos, toxinas e contaminantes ambientais, entre outros) é altamente desejável que sejam realizados estudos no sentido de se estabelecer um protocolo de avaliação de teratogenicidade 
especificamente para ruminantes, utilizando-se a espécie caprina como modelo animal.

Portanto, o presente trabalho tem como escopo introduzir novos parâmetros para avaliação de teratogenicidade em ruminantes no protocolo que tem sido proposto por este grupo, sendo que, no presente estudo, foram incorporados dados de observações relativas ao desenvolvimento físico e neurocomportamental da prole de cabras submetidas à intoxicação experimental com Senna occidentalis durante a gestação. 


\section{OBJETIVOS}

1618 Diálogo das Grandezas do Brasil ii. fl.53: [...] muito fasil que he o que se costuma fazer nesta terra tomaõ hu piqueno de tabaquo por outro nome erua santa em falta de outra erua que chamaõ pajemarioba ${ }^{1}$ - epizada com summo de limaõ metem hua piquena cantidade della no seso do enfermo ese está doente do bicho lhe causa grande ardor e pello contrario naõ tem nehu ou caze nada, e esta erua pizada com o sumo de limaõ cura tambe grandemete amesma enfermidade (CUNHA, 1999).

\footnotetext{
${ }^{1}$ Pajamarioba s.f. Var.: pajemarioba, pagémarioba, pajé merioba, paimarioba [< T. pajemari'oua 'Fedegoso']. Planta da família das leguminosas; fedegoso (CUNHA, 1999).
} 


\subsection{OBJETIVO GERAL}

Avaliar os possíveis efeitos tóxicos produzidos pelas sementes de $S$. occidentalis, em diferentes concentrações, na cabra e em suas proles, durante o período perinatal.

\subsection{OBJETIVOS ESPECÍFICOS}

- Estudar os possíveis efeitos tóxicos promovidos pela S. occidentalis em cabras expostas durante o período de gestação;

- Estudar, por meio de análise ultrassonográfica uterina, os possíveis efeitos fetotóxicos promovidos pelas sementes de $S$. occidentalis administrada a cabras expostas durante o período de gestação;

- Propor parâmetros para avaliação durante a lactação, tanto física como neurocomportamental, do desenvolvimento da prole de cabras expostas à $S$. occidentalis no período gestacional;

- Avaliar o desenvolvimento da prole lactente de cabras as quais foram expostas à S. occidentalis durante o período de lactação;

- Identificar a possível presença do princípio ativo da S. occidentalis no leite de cabras intoxicadas com sementes de planta. 


\section{MATERIAL E MÉTODO}

c 1763 J. S. JOSÉ Viagem ao Gram-Pará in RIH, IX (1869) 204: [Na villa de Santarém] Há pagé marioba, cujas folhas ou raízes cozidas são admiráveis nos defluxos e diuphoreticas, e outras muitas (CUNHA, 1999). 


\subsection{ANIMAIS}

Foram utilizadas cabras nulíparas, meio sangue Saanen com aproximadamente 12 meses de idade, pesando $33 \mathrm{~kg} \mathrm{em}$ média, no início do experimento e um macho reprodutor, meio sangue Saanen. Os animais foram alojados em baias coletivas, nas instalações do Centro de Pesquisa em Toxicologia Veterinária (CEPTOX) do Campus Administrativo de Pirassununga da Universidade de São Paulo, Pirassununga, SP.

Os animais receberam como alimento capim Napier sp, cana-de-açúcar (Sacharum officinarum L.) e sal mineral, ad libitum, além de ração comercial produzida no próprio Campus Administrativo de Pirassununga da Universidade de São Paulo, Pirassununga, SP.

\subsection{SEMENTES DE S. occidentalis}

As sementes de S. occidentalis foram colhidas de uma plantação no Centro de Pesquisa em Toxicologia Veterinária (CEPTOX) do Departamento de Patologia Veterinária (VPT) da Faculdade de Medicina Veterinária e Zootecnia da Universidade de São Paulo (FMVZ/USP), Campus de Pirassununga, SP. A. S. occidentalis foi identificada pela Dra. Maria Eneida Fidalgo do Instituto Botânico de São Paulo, SP, Brasil e encontra-se sob o número SP-363817, depositado no mesmo Instituto.

\subsection{EQUIPAMENTOS}

- Aparelho de Ultra-som (US) Pie-Medical - Nutri cell - Scanner 100, Mod. Falco (transdutores linear e convexo, 5.0 / 7.0 MHz);

- Tronco de contenção para cabras; 
- Máquina de tosquia (Golden A-5 Clipper - Oster $囚$ )

- Aparelho de leitura automática de bioquímica CELM SBA-200 (CELM®, Brasil);

- Microscópio de luz modelo Nikkon;

- Fita métrica;

- Liquidificador industrial para trituração de grãos;

- Misturador horizontal de rosca sem fim (Marconi, mod. 206).

- Botijão de nitrogênio líquido (marca MVE, modelo XC-20.)

- Placas de plástico impregnada com sílica-gel 60 GF254 (Merck®);

- Rota-evaporador modelo 802 (Fisatom Equipamentos Científicos Ltda).

- Aparelho de cromatografia líquida de alta eficiência (Shimadzu Corporation, Kyoto, Japan);

- Centrífuga refrigerada (Eppendorf®, modelo 5810R)

\subsection{REAGENTES, SOLUÇÕES e FÁRMACOS}

Kits para determinação de albumina, aldolase, aspartato aminotransferase (AST), creatinaquinase (CK), gama glutamil transferase (GGT), fosfatase alcalina $(F A)$, glicose, lactato desidrogenase $(\mathrm{LDH})$, proteína total (PT), creatinina, uréia bilirrubina total, colinesterase, triglicerídios, formol a 4\% e 10 e tampão fosfato salina (PBS). Hidróxido de potássio $(\mathrm{KOH})$, metanol $(\mathrm{CH} 3 \mathrm{OH})$ e ácido nítrico (HNO3). Esponja de acetato embebida com 60m de medroxiprogesterona (MAP-Syntex S.A.), novormon ${ }^{\circledR}$ - Syntex S.A. Preparação altamente purificada de gonadotrofina coriônica da égua prenhe (PMSG) + gonadotrofina coriônica eqüina (eCG), Ciosin® Coopers Brasil Ltda. Cloprostenol sódico (análogo da protagalndiona F2a). 


\subsection{PROCEDIMENTOS}

Foram realizados os procedimentos experimenais conforme os itens 3.5 .1 ao 3.5.12 relacionados a seguir.

\subsubsection{Administração de S. occidentalis para Caprinos}

Devido à possibilidade de inativação do princípio ativo pelo aquecimento e conseqüente perda de toxicidade das sementes quando da trituração em moinho de facas, realizou-se o procedimento a frio, assim as sementes de $S$. occidentalis foram imersas em nitrogênio liquido e, a seguir, trituradas em liquidificador comum, sendo posteriormente adicionadas à ração comercial na proporção de 1, 2, 3 e 4\%. Estas misturas foram homogeneizadas em misturador (Hobart mod. H-600).

Estas rações, com diferentes concentrações de sementes de $S$. occidentalis foram fornecidas, logo pela manhã (entre $8-9 h$ ), aos animais pertencentes aos distintos grupos experimentais, a saber: So1, So2, So3 e So4, durante o período de gestação, misturadas à ração, cuja quantidade diária administrada foi de 1,5\% de peso vivo. Às cabras pertencentes ao grupo LAC, foi fornecida a mesma quantidade de ração, contendo $4 \%$ de sementes da planta somente durante a lactação. Aos animais pertencentes ao grupo foi fornecido somente ração comercial na mesma proporção. Para todos os animais, tanto do grupo controle como experimentais, a dieta foi complementada com cana-de-açúcar, capim Napier e sal mineral.

\subsubsection{Avaliação do peso}

A avaliação do peso tanto das cabras como de seus filhotes foi realizada semanalmente, sempre com os animais em jejum, entre 8:00 e 9:00h, sendo os animais pesados individualmente.

\subsubsection{Avaliação clínica}


A avaliação clinica, tanto das cabras como de suas proles, foi realizada semanalmente, no período matutino, sempre entre 8:00 e 9:00h. Foram avaliados visualmente o estado corporal geral, coloração de mucosas, bem como avaliação dermatológica e observação de alterações comportamentais, além de mensuração da temperatura corpórea.

\subsubsection{Sorologia sangüínea}

Antes dos procedimentos relativos ao acasalamento o sangue de todos os animais foi coletado para análise de doenças infecciosas, de importância na reprodução, a saber: toxoplasmose, analisado no Serviço de Laboratório Clínico do Departamento de Clínica Médica (VCM/FMVZ/USP), leptospirose, brucelose e micoplasmose analisadas no Laboratório de Zoonoses Bacterianas do Departamento de Medicina Veterinária Preventiva e Saúde Animal (VPS/FMVZ/USP).

\subsubsection{Indução do estro por esponjas impregnadas com progestágenos}

Para se ter uma homogeneidade no período gestacional, as cabras receberam tratamento hormonal para a indução do estro. Para tanto, foi empregado o procedimento proposto por Traldi (1994), utilizando uma esponja impregnada com $60 \mathrm{mg}$ de acetato de medroxiprogesterona (MAP) que permanece no interior da vagina por 10 dias. Dois dias antes do final deste tratamento (dia 8), administra-se pela via intramuscular $250 \mathrm{UI}(1,0 \mathrm{ml})$, por animal, de Norvormon® e 0,3 ml de Ciosin ${ }^{\circ}$, que promoverão o crescimento folicular. No $10^{\circ}$ dia retira-se a esponja e após cerca de 24-48 horas as cabras entraram no cio, podendo, então, serem cobertas. 


\subsubsection{Acasalamento}

As cabras foram fecundadas por meio de monta natural; todas foram cobertas pelo mesmo reprodutor, permitindo-se que este macho realizasse até, no máximo, 4 coberturas/dia, para que não houvesse a possibilidade de redução da fertilidade do bode. As cabras que foram acasaladas até as 11:00h da manhã foram consideradas como se estivessem no dia 1 da gestação; aquelas cabras que foram cobertas após este horário, foram consideradas como se estivessem no dia 0 da gestação. Este esquema foi adotado para não haver um número grande de animais submetidos à avaliação ultra-sonográfica no mesmo dia.

\subsubsection{Dosagens de enzimas e componentes sangüíneos}

O sangue das cabras foi coletado por punção da veia jugular, sempre no período matutino, entre 8:00 e 9:00h, tanto das mães, como dos filhotes. As coletas foram realizadas com seringas sem anticoagulante para obtenção do soro.

As dosagens de glicose, GGT, AST, LDH, FA, CK, albumina, proteína, aldolase, colinesterase, uréia e creatinina, foram feitas por meio de "kits" comerciais específicos e de espectrofotômetro automático (CELM SBA-200). Trata-se de métodos enzimáticos, colorimétricos e cinéticos. O sangue dos filhotes foi coletado a partir do quinto dia de nascimento, por punção da veia jugular. Além das análises citadas acima, dosou-se o nível de triglicerídios.

\subsubsection{Avaliação Ultra-sonográfica}

A avaliação ultra-sonográfica para detecção de prenhez foi realizada a cada 24 horas, do $24^{\circ}$ ao $27^{\circ}$ dia após cobertura, pela via transretal até a visualização de vesícula embrionária e pulsação cardíaca (Figura $2 \mathrm{~A}$ ). Uma vez detectada a prenhez, as mensurações fetais começaram no $35^{\circ}$ dia em relação ao movimento 
fetal (MF), freqüência cardíaca (FC), mensuração do Comprimento Craniocaudal (CCC - Figura 2B) que compreende a distância determinada por uma linha entre a parte anterior do crânio (osso occipital) até a base da cauda (primeira vértebra coccígea - KAHN, 1994); no $69^{\circ}$ foi mensurado, também, o diâmetro biparietal (DBP - Figura 2C), determinado pela maior distância entre os ossos biparietais que se apresentarem hiperecogênicos, contrastando internamente com o córtex cerebral que se apresentará de forma hipoecogênica (KAHN, 1994); no $63^{\circ}$ dia também se mensurou o diâmetro abdominal (DA - Figura 2D), determinado pela maior distância entre os bordos do tronco, obtido em corte horizontal ou transversal, na altura entre a última costela e o cordão umbilical (CHAVEZ MORENO; STEINMANN CHAVEZ; BICKHARDT, 1996) além do diâmetro torácico (DT - Figura 2E), que foi obtido medindo-se a distância entre as bordas ecogênicos de duas costelas, em corte horizontal, na altura do coração (CHAVEZ MORENO; STEINMANN CHAVEZ; BICKHARDT, 1996). Estas mensurações foram realizadas no $35^{\circ}$ dia pela vias transretal e abdominal e, somente pela via abdominal, no $43^{\circ}$ e $69^{\circ}$ dia de gestação.

O procedimento para as mensurações foi realizado da seguinte maneira: no momento do exame pela via transretal, depois de conter o animal, o operador aplicou sobre o reto da cabra o gel para ultra-som $\left(\right.$ BioGel $^{\circledR}$ ) para lubrificar o esfíncter anal, facilitando o subseqüente esvaziamento da parte final do reto. Posteriormente, o gel foi colocado sobre o transdutor linear, o qual foi então introduzido no reto até que fosse possível a visualização de um dos cornos uterinos. Nesse momento, girou-se o transdutor em um ângulo de $90^{\circ}$ no sentido horário e $180^{\circ}$ no sentido oposto até que todo trato reprodutivo pudesse ser explorado (SCHRICK et al., 1993). Já no exame abdominal, os animais foram depilados na região abdominal utilizando uma máquina de tosquia provida de lâmina $n^{\circ}$. 40 . Os animais foram contidos em estação, e posteriormente aplicou-se gel sobre o transdutor convexo e sobre a região depilada, para promover o contato íntimo com a pele do animal. Por meio de manipulação do transdutor, são feitos a mensuração fetal e os demais parâmetros. Os animais foram submetidos a jejum hídrico e alimentar antes do início dos procedimentos.

No caso de ter sido constatada gestação gemelar, considerou-se a média dos dois embriões/fetos, uma vez que é sabido que o número de fetos não influencia suas medidas nos $2 / 3$ iniciais de gestação (GONZÁLES DE BULNES et al., 1998). 

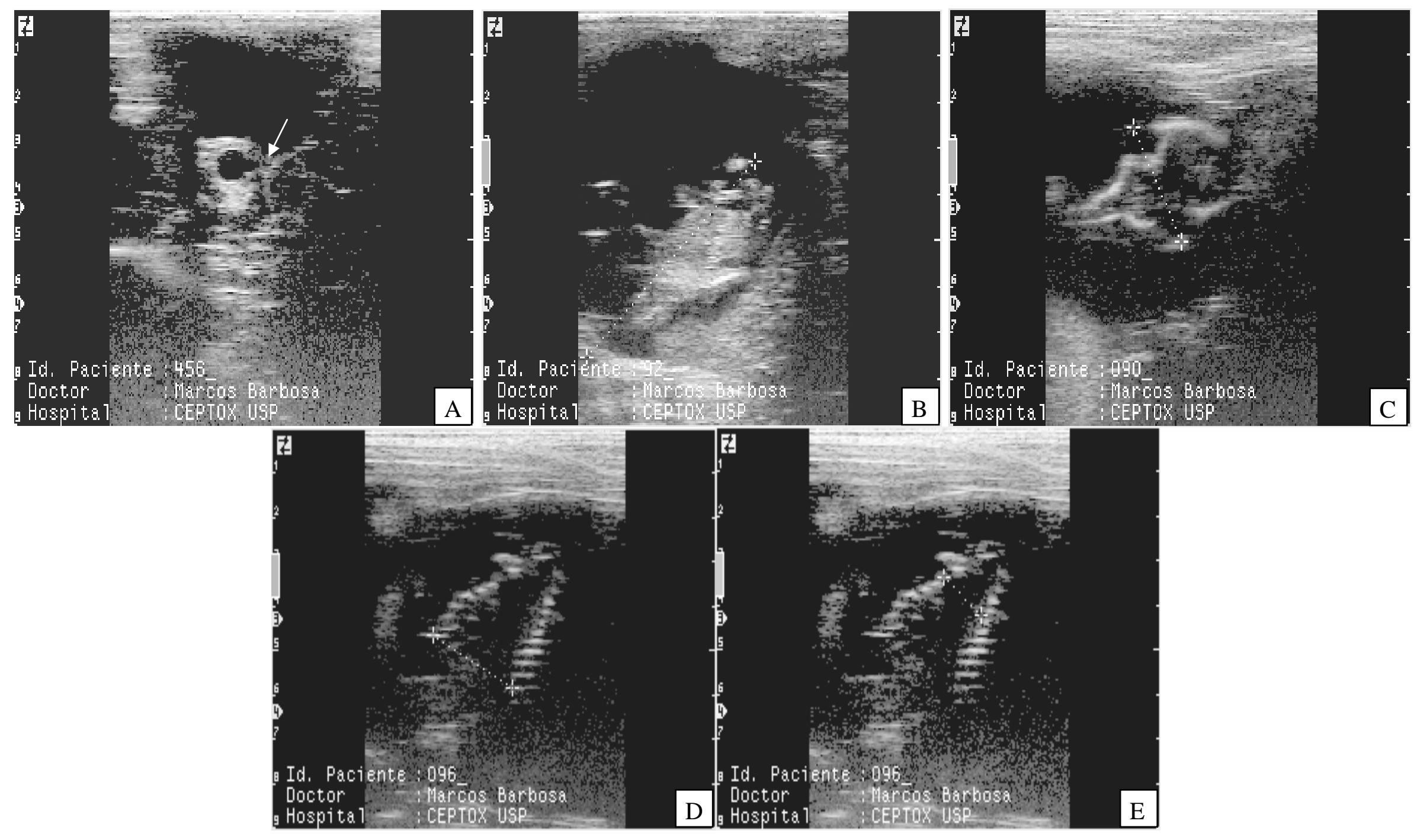

Figura 2 - Imagens ultrassonográficas de caprinos. A) Diagnóstico de gestação, evidenciando as vesículas embrionárias e o coração (seta); B) CCC, $43^{\circ}$ dia; C) DBP, $69^{\circ}$ dia; D) DA, $69^{\circ} \mathrm{dia}$; E) DT, $69^{\circ} \mathrm{dia}$ 


\subsubsection{Avaliação de anomalias elou malformações fetais}

Após o nascimento e identificação do sexo, foram realizados exames minuciosos para constatar a conformação e o posicionamento dos olhos, boca, crânio, mandíbula, membros anteriores e posteriores, cauda e pele, além da presença de perfuração anal, entre outras possíveis malformações e/ou anomalias externas.

\subsubsection{Avaliação morfométrica corpórea de filhotes}

Foram realizadas as seguintes mensurações, conforme proposto por Arrayet et al. (2002): altura corporal (AC), do chão até o ponto mais alto da escápula; comprimento corporal (CC), mensurado da ponta do ombro (processo acrônimo da escápula) ao túbero do ísquio; perímetro torácico (PT), mensurado logo atrás das escápulas, em torno do tórax; comprimento da cabeça (CCab), desde o osso occipital até o espelho nasal; diâmetro da cabeça (DCab), atrás da borda caudal das mandíbulas, logo atrás das orelhas; comprimento do rádio (CRAD), do processo olécrano à junta intercarpal (articulatio mediocarpea); comprimento da tíbia (CTIB), mensurados da crista tibial à superfície flexora da região tíbia-fíbula; comprimento do metacarpo (CMC), mensurado na superfície cranial, desde a superfície proximal do metacarpo até a superfície distal do metacarpo, na articulação metacarpo-falangeal; comprimento do metatarso (CMT), na superfície cranial, da região externa do calcâneo à articulação metatarso-falangeal, na superfície metatarsal; circunferência do metacarpo (CIMC) e circunferência do metatarso (CIMT), mensuradas no ponto mais próximo da diáfise, (Figura 3). Estas mensurações foram realizadas para determinar a velocidade de crescimento dos filhotes em cada intervalo. Todas as medidas foram realizadas do lado esquerdo do corpo, usando-se uma fita métrica. 


\begin{tabular}{|l|l|}
\hline Altura corporal & $(1)$ \\
\hline Comprimento corporal & $(2)$ \\
\hline Perimetro torácico & $(3)$ \\
\hline Comprimento da cabeça & $(4)$ \\
\hline Diâmetro da cabeça & $(5)$ \\
\hline Comprimento do rádio & $(6)$ \\
\hline Comprimento da tíbia & $(7)$ \\
\hline Comprimento do metacarpo & $(8)$ \\
\hline Coprimento do metatarso & $(9)$ \\
\hline Circunferência do metacarpo & $(10)$ \\
\hline Circunferência do metatarso & $(11)$ \\
\hline
\end{tabular}

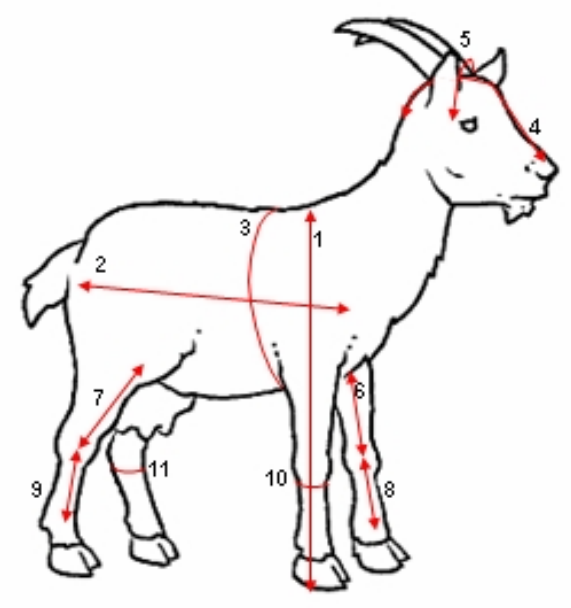

Figura 3 - Locais onde foram realizadas as mensurações corporais. 


\subsubsection{Estudo comportamental}

Os itens 3.5.11.1 ao 3.5.11.6 relacionam os protocolos para avaliação de comportamento de cabritos no período pós-natal, utilizados no presene trabalho.

\subsubsection{Primeira Prova de obstáculo}

Objetivo: Aprendizado. O neonato deve atender ao chamado da mãe e ter a capacidade de ir até ela. Assim, o filhote deve sair de dentro de uma caixa com janela, pela qual se vê a mãe, e caminhar até ela. A distância da caixa até o local onde a mãe se encontrava foi de $2,5 \mathrm{~m}$, tendo uma linha riscada no chão, dividindo a áreas em duas metades, esquerda e direita (Figura 4).

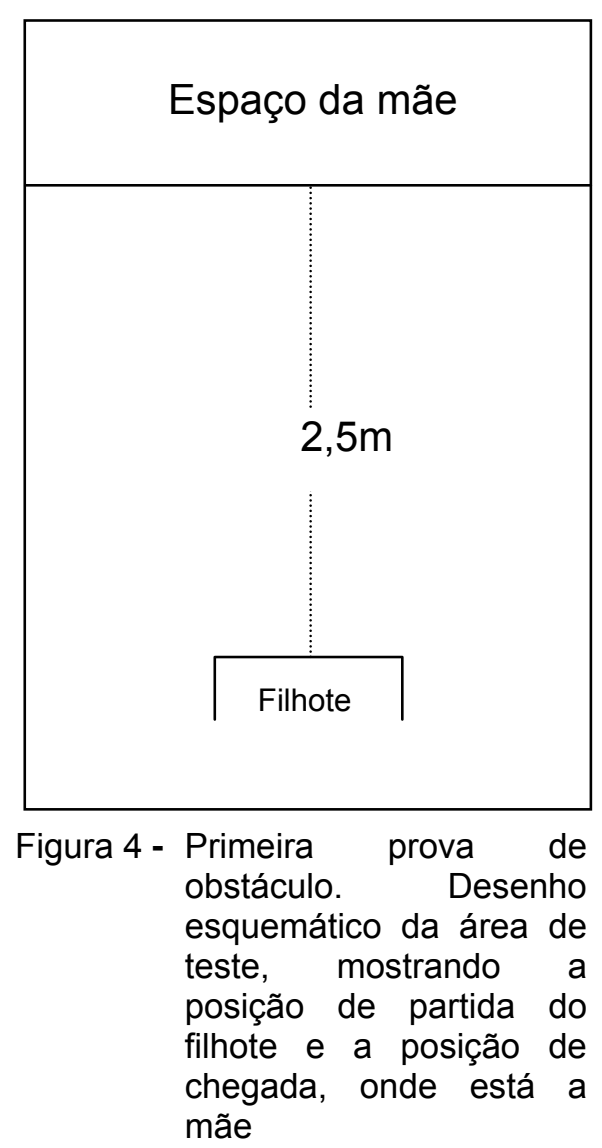


Foram anotados os seguintes parâmetros:

- Tempo de saída da caixa;

- Tempo de partida;

- Tempo de chegada;

- Lado pelo qual o filhote saiu da caixa (lado da mãe, ou outro lado);

- Se o filhote cruzou a frente da caixa (em caso de ter cruzado a linha que separa a arena em dois campos).

Este teste foi realizado às $12 \mathrm{~h}$ de vida e repetido às $24 \mathrm{~h}$ após o nascimento. Se o animal não foi capaz de realizá-lo em $12 \mathrm{~h}$, outra tentativa foi realizada novamente com $24 \mathrm{~h}$, repetindo-se com $36 \mathrm{~h}$ pós-nascimento todo o procedimento. Foram realizadas três sessões em cada teste.

\subsubsection{Segunda prova de obstáculo}

Nesta fase uma segunda cabra foi incluída no teste. Assim, esta nova fêmea e a mãe do recém-nascido permaneceram em lados opostos da arena ao mesmo tempo (Figura 5). O objetivo deste teste foi o de observar a capacidade de reconhecimento da mãe pelo filhote. Para evitar vícios as cabras foram trocadas de lado a cada sessão do teste.

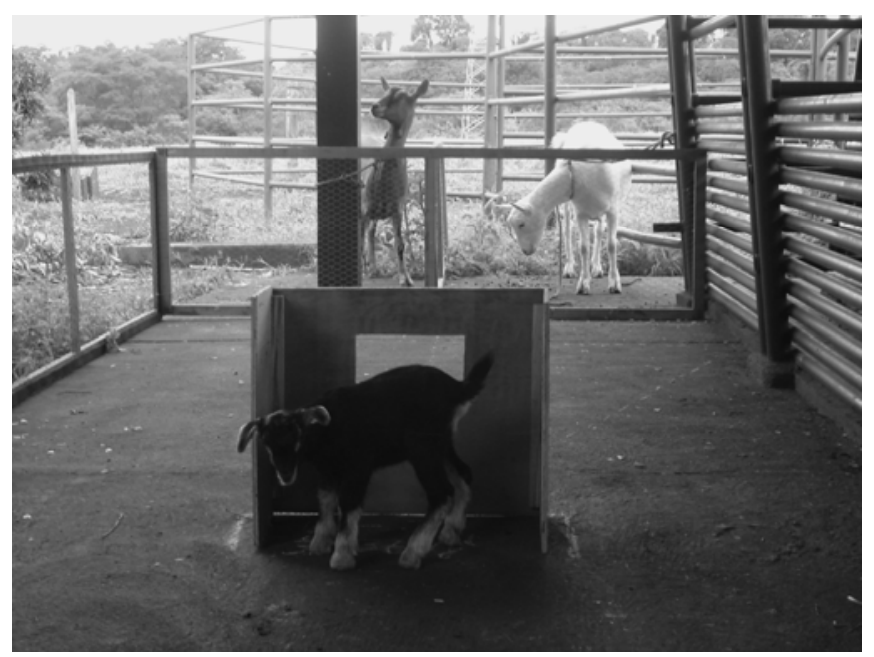

Figura 5 - Prova de obstáculos com duas mães. Fotografia do teste, em primeiro plano o local onde o filhote é colocado no início do teste e, ao fundo, como ficam dispostas as mães. 
Foram anotados os seguintes parâmetros:

- Tempo de saída da caixa;

- Tempo de partida;

- Tempo de chegada;

- Lado pelo qual o filhote saiu da caixa (lado da mãe, ou outro lado);

- Se o filhote cruzou a frente da caixa (em caso de ter cruzado a linha que separa a arena em dois campos);

- Se o filhote caminhou diretamente até a mãe ou confundiu-a com a outra fêmea.

Neste teste foram realizadas três sessões em cada teste, realizados às $12 \mathrm{~h}$ e $24 \mathrm{~h}$ de vida. Se o animal não foi capaz de realizá-lo em $12 \mathrm{~h}$, este teste foi repetido $24 \mathrm{~h}$ após o nascimento, repetindo-o com 36h.

\subsubsection{Terceira prova de obstáculos}

Trata-se, de um corredor, levando à mãe, no qual são colocados tapumes, de maneira que se criem obstáculos em ziguezague. Estes tapumes são adicionados progressivamente, formando um labirinto, como ilustrado pela a Figura 6.

Foram realizados três dias de teste, acrescentando-se a cada dia um obstáculo, assim, no terceiro dia de testes, o animal deveria contornar os três obstáculos para chegar até a mãe.

Foram anotados os seguintes parâmetros:

- Tempo de saída de trás do obstáculo;

- Tempo de partida;

- Tempo de chegada até a mãe;

- Tempo que o animal pode ter despendido explorando o ambiente.

Foram realizadas três sessões em cada teste. 
Os testes foram realizados em três etapas, a saber, no $2^{\circ}, 4^{\circ}$ e $6^{\circ}$ dia de idade.
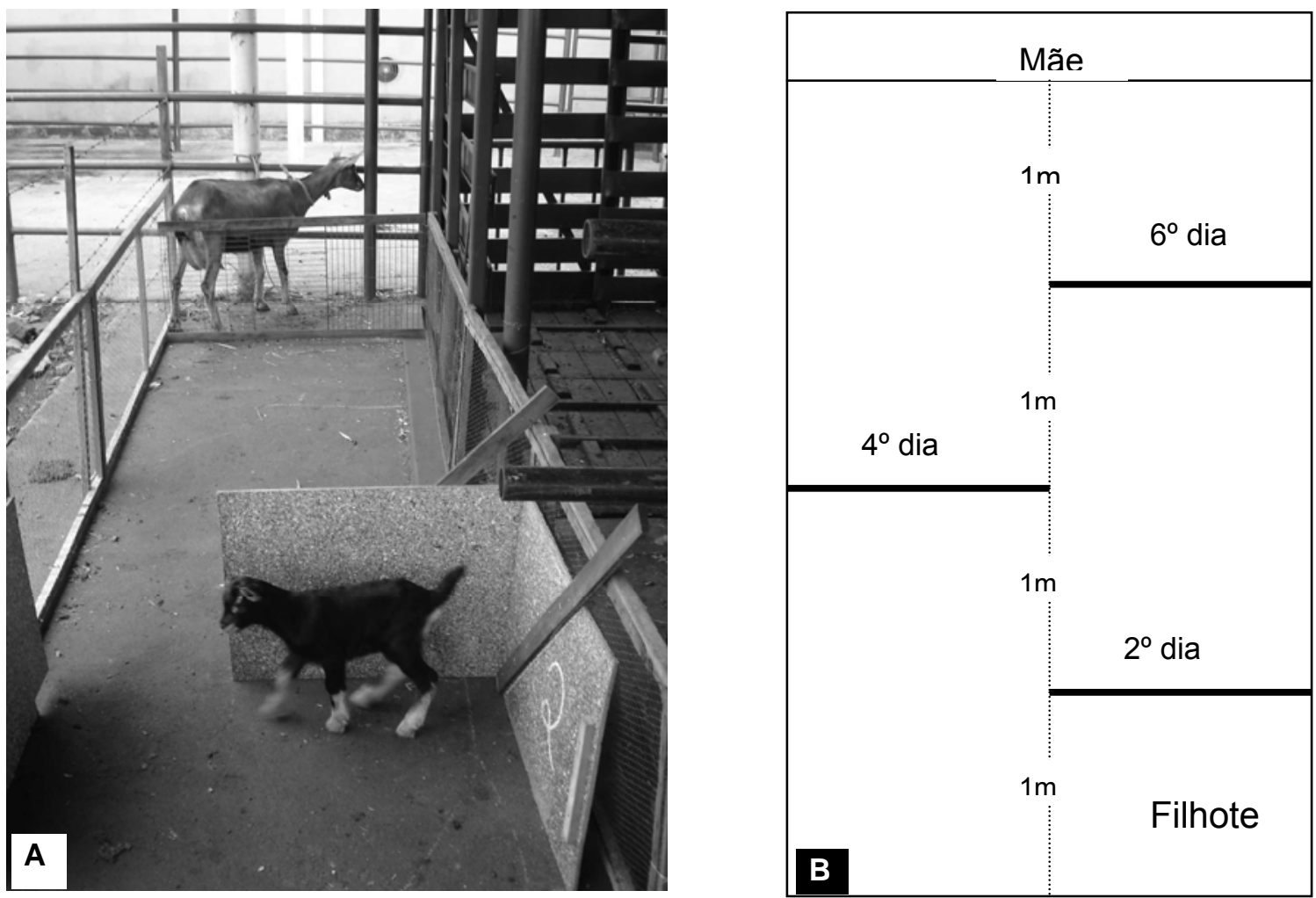

Figura 6 - Fotografia do labirinto progressivo durante o segundo dia de idade, apresentando o primeiro obstáculo (A). Esquema do labirinto e disposição da mãe e seu filhote (B)

\subsubsection{Quarta prova de obstáculos. Labirinto em T (“T Maze”)}

Trata-se de uma estrutura construída com placas de madeira compensada, medindo aproximadamente 120 x $90 \mathrm{~cm}$ dispostas em corredores em forma de T (Figura 7). Os filhotes não podam ver acima das paredes da estrutura. Neste teste, com grau de dificuldade fácil, o objetivo é que o animal percorra os corredores, para chegar até sua mãe, da maneira mais rápida. 

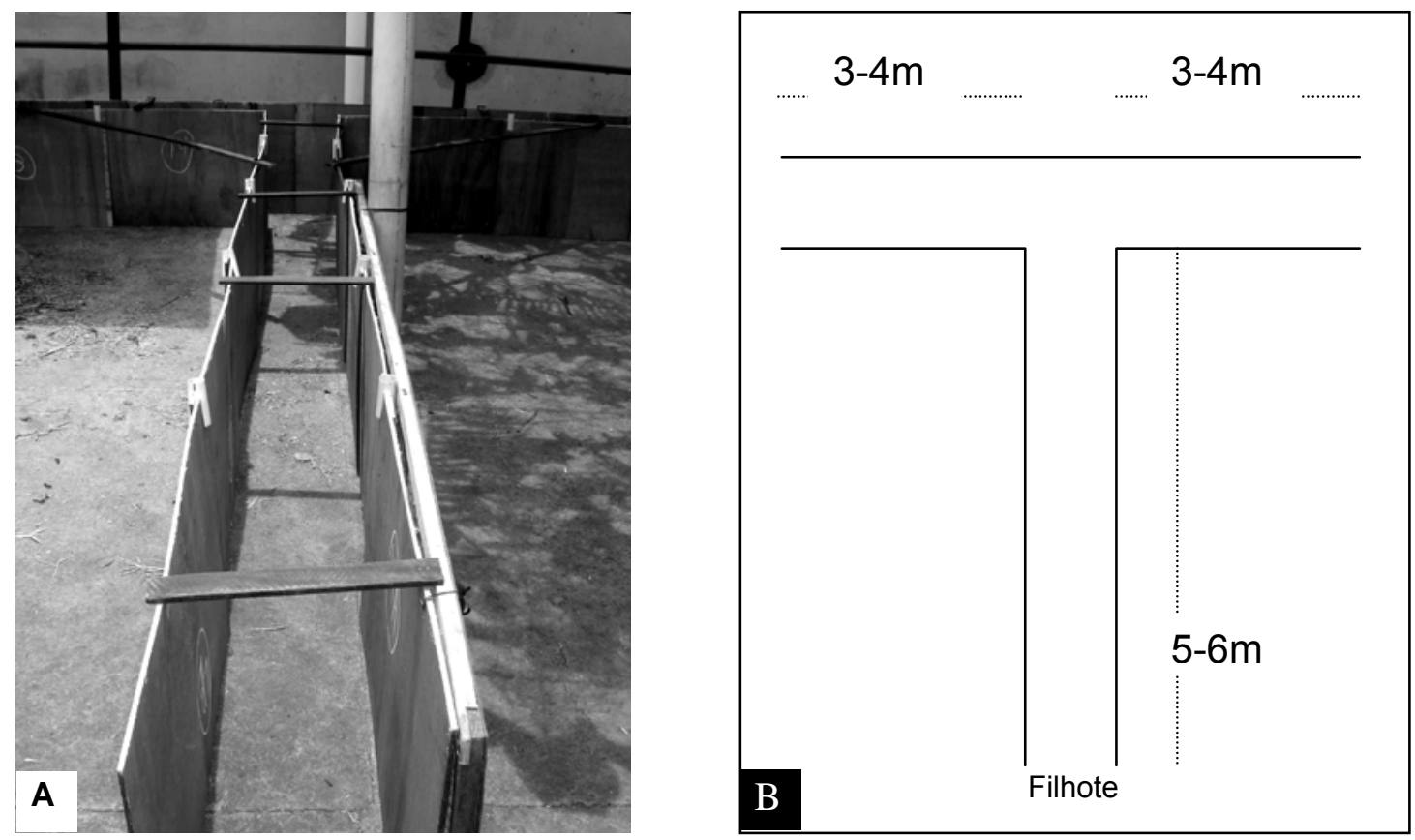

Figura 7 - Labirinto em T, fotografia $(A)$ e desenho esquemático, com as dimensões, da área de teste $(B)$

Os filhotes foram privados do contato com as mães pelo menos quatro horas antes do início do teste. No momento da realização do teste, colocou-se a mãe em contato com o respectivo filhote por breves segundos, tanto para ela saber que ele estaria por perto e começar a chamá-lo, como para que o filhote percebesse que sua mãe estaria próxima e, assim, estar sensibilizado para atender aos seus chamados. O teste foi dividido em duas etapas:

1. Na primeira etapa, a mãe foi colocada em um dos braços do labirinto, sendo invertida sua posição na segunda sessão e novamente invertida na terceira sessão.

2. Na segunda etapa utilizaram-se duas cabras paridas, a própria mãe e outra cabra, que estivesse em outra baia e com filhote de mesma idade. Em cada sessão do teste, estas fêmeas eram trocadas de posição. Assim, a cabra que estava no braço esquerdo, foi trocada pela outra que estivesse no braço direito e vice versa, a cada sessão, até o fim do teste.

Foram anotados os seguintes parâmetros: 
3.5.11.4.1 Para quando havia uma cabra somente. A própria mãe

- Tempo de chegada até a bifurcação;

- Escolha do braço (mãe ou oposto);

- Tempo de chegada até a mãe.

3.5.11.4.2 Para quando havia duas cabras. A mãe e uma outra cabra

- Tempo de chegada até a bifurcação;

- Escolha do braço (mãe ou oposto);

- Tempo de chegada até a mãe;

- Escolha de outra cabra (tempo de chegada).

O teste foi realizado na $6^{a}, 8^{a}$ e $10^{a}$ semana de idade. Foram realizadas três sessões em cada teste.

3.5.11.5 Quinta prova de obstáculos. Labirinto médio ("Lashley Maze")

Este teste, com grau de dificuldade média, tratava-se de um labirinto composto por corredores paralelos, construídos com placas de madeira compensada medindo $120 \times 90 \mathrm{~cm}$ (Figura 8), no qual os filhotes deveriam aprender que, seguindo os corredores chegariam até suas mães. Esperava-se que estes animais alcançassem suas mães cada vez mais rapidamente, a cada repetição dos testes, de modo que, ao fim do experimento, os filhotes chegassem às suas mães percorrendo o menor trajeto. 

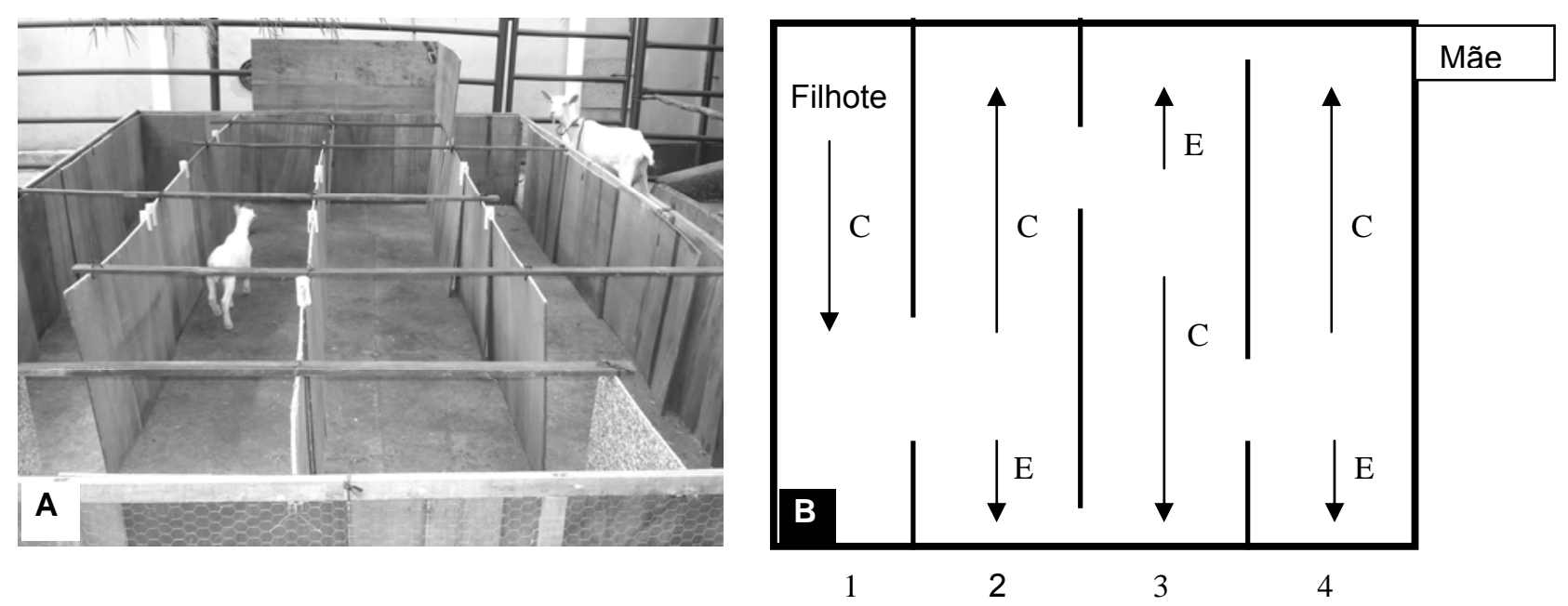

Figura 8 - Labirinto médio ("Lashley Maze"). Fotografia apresentando um filhote no segundo braço (A). Desenho esquemático, com as dimensões, da área de teste e os respectivos corredores $(B)$

Foram anotados os seguintes parâmetros:

- Número de vezes que o filhote foi para o lugar certo e o lugar errado;

- Tempo de permanência em cada corredor;

- O tempo final do experimento;

- Tempo total.

O teste foi realizado na $6^{a}, 8^{a}$ e $10^{a}$ semana de idade. Foram realizadas três sessões em cada teste.

\subsubsection{Sexta prova de obstáculos. Labirinto "Hebb-Williams Maze"}

Neste teste com grau de dificuldade difícil, os filhotes deveriam aprender o meio mais rápido de chegar até suas mães, percorrendo o labirinto, conforme ilustrado na figura 9. Esperava-se que o animal aprendesse o trajeto mais curto a cada repetição do teste, de modo que, ao fim do experimento, os filhotes chegassem às suas mães percorrendo o menor trajeto. 


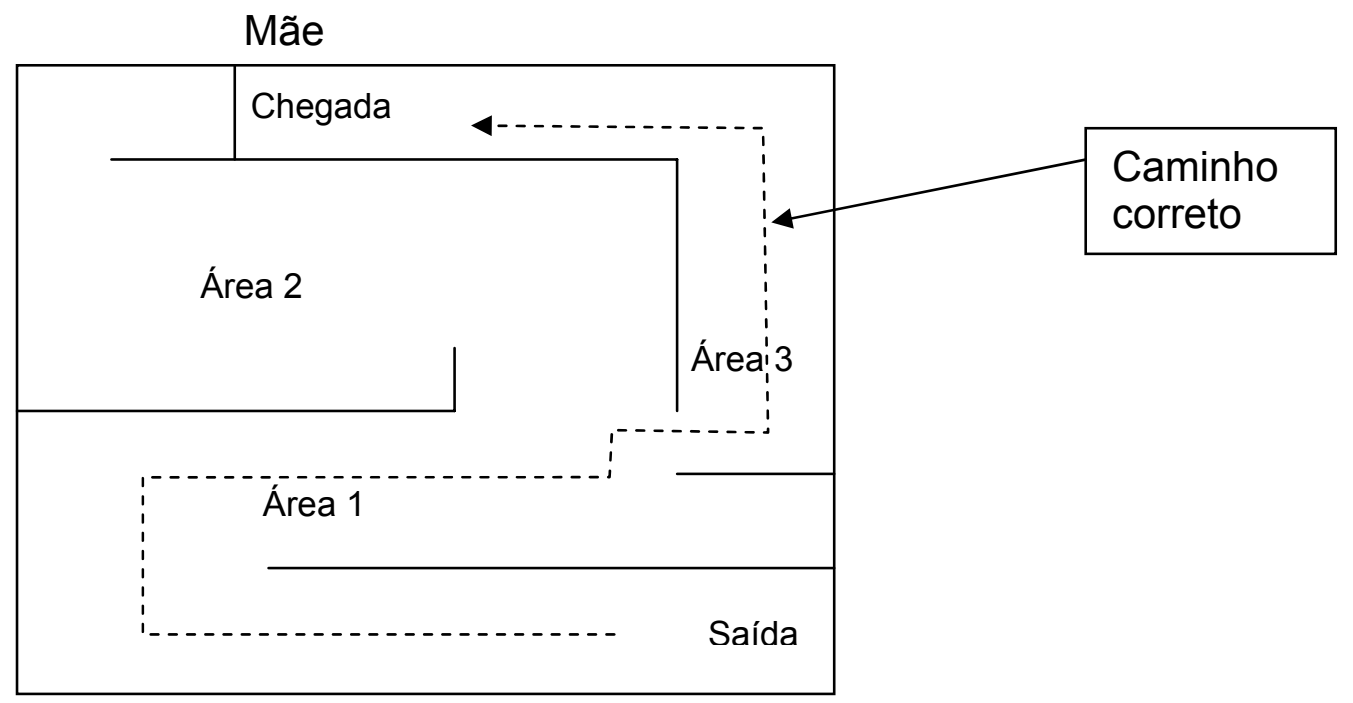

Figura 9 - Labirinto difícil ("Hebb-Williams Maze"). Desenho esquemático, com as dimensões, da área de teste

Foram anotados os seguintes parâmetros:

- Número de vezes que o filhote foi para o lugar certo e o lugar errado;

- Tempo de permanência em cada área;

- O tempo final do experimento;

- Tempo total para chegar até a mãe.

O teste foi realizado na $6^{a}, 8^{a}$ e $10^{a}$ semana de idade. Foram realizadas três sessões em cada teste.

\subsubsection{Estudo anatomopatológico}

Ao final dos experimentos, tanto as mães como os filhotes foram abatidos e submetidos à necropsia, quando se avaliou o aspecto geral dos órgãos e possíveis alterações macroscópicas. Em seguida procedeu-se à coleta de fragmentos representativos do cérebro, cerebelo, medula espinhal, nervo ciático além de amostras de fígado, rim, baço, pulmão, músculos esqueléticos (tibial, peitoral e diafragmático) e miocárdio. 
No caso de morte durante o experimento, foram realizados os mesmos procedimentos para coleta de material para estudo histopatológico.

\subsubsection{Microscopia de luz}

Os fragmentos provenientes da coleta à necropsia, tanto das mães quanto dos filhotes, foram fixados em formol a 10\%; posteriormente, o material foi emblocado, cortado e corado com hematoxilina-eosina, para observação de possíveis alterações à microscopia óptica, utilizou-se também a coloração Sudan Black para evidenciação de possíveis depósitos de gordura em alguns tecidos específicos.

\subsection{DELINEAMENTO EXPERIMENTAL}

Os delineamentos experimentais estão separados em relação ao período gestacional e, posteriormente, em relação ao período pós-parto.

\subsubsection{Experimento 1: Estudo dos efeitos tóxicos produzidos pela $S$. occidentalis em cabras durante a gestação}

Foram utilizadas 21 cabras nulíparas, divididas em quatro grupos: um controle e três experimentais. Estas fêmeas foram acasaladas conforme procedimento descrito nos itens 3.5 .5 e 3.5.6. A partir do $27^{\circ}$ dia pós-coito, as fêmeas provenientes dos grupos experimentais receberam as diferentes concentrações das sementes de S. occidentalis na ração: 1\% $(n=5)$, denominado grupo So1; $2 \%(n=5)$, denominado grupo So2 e 4\% $(n=6)$, denominado grupo So4; as cabras do grupo controle $(n=5)$ receberam apenas ração comercial. Quinzenalmente, foi coletado o sangue dos animais para a realização da dosagem bioquímica conforme item 3.5.7. A avaliação ultra-sonográfica foi realizada a cada 24 
horas do $24^{\circ}$ ao $27^{\circ}$ dia pós-cobertura, para confirmação da prenhez e para as mensurações fetais nos dias 35,43 e 69 , conforme procedimento descrito no item 3.5.8.

Posteriormente, foi necessário realizar um outro experimento, no qual os animais do grupo experimental receberam uma concentração menor de $S$. occidentalis na ração. Neste experimento, foram utilizadas 12 cabras nulíparas, divididas em dois grupos iguais, sendo um controle, que consumiu somente ração comercial e outro grupo, denominado So3, no qual as fêmeas receberam ração contendo $3 \%$ de sementes de S. occidentalis. Os procedimentos subseqüentes foram idênticos àqueles descritos para o experimento da administração das diferentes concentrações de S. occidentalis na gestação.

\subsubsection{Experimento 2: Estudo dos efeitos tóxicos produzidos pela $S$. occidentalis administrado a cabras lactantes}

Foram utilizadas cinco cabras nulíparas, acasaladas conforme procedimento descrito nos itens 3.5.5 e 3.5.6. Estas fêmeas receberam ração contendo a concentração de $4 \%$ de sementes de $S$. occidentalis (grupo LAC), imediatamente após o nascimento de seus filhotes, até o desmame, aos quatro meses de idade da prole. As fêmeas que pertenciam ao grupo controle durante a gestação, naquele experimento no qual se realizou a administração de sementes de $S$. occidentalis nas concentrações de $1 \%, 2 \%$ e $4 \%$, serviram também como animais controle durante esta fase de lactação, já que estas aquelas não receberam, em nenhum período, as sementes da planta. Quinzenalmente, foi coletado o sangue de todas as lactantes para a realização da bioquímica sérica, conforme o item 3.5.7. Ao final do experimento, estas cabras foram abatidas, quando então foram coletadas amostras de coleta de fragmentos representativos do cérebro, cerebelo, medula espinhal, nervo ciático além de amostras de fígado, rim, baço, pulmão, músculos esqueléticos (tibial peitoral e diafragmático) e miocárdio para o estudo histopatológico, conforme descrito nos itens 3.5 .12 e 3.5.13. 


\subsubsection{Experimento 3: Estudo dos efeitos tóxicos produzidos pela $S$.} occidentalis. Avaliação do desenvolvimento físico e comportamental da prole

No dia do nascimento, todos os filhotes provenientes dos grupos controle, So1, So2 e So3 foram avaliados cuidadosamente para identificação de possíveis malformações, conforme descrito no item 3.5.9 e avaliados durante quatro meses por meio de mensurações corporais, conforme descrito no item 3.5.10. Estes filhotes foram pesados semanalmente até o dia do abate (em torno do $120^{\circ}$ dia de vida), quando então foram coletadas amostras dos diferentes tecidos para o estudo histopatológico, conforme descrito nos itens 3.5.12 e 3.5.13. Foi coletado sangue para análise bioquímica, conforme o item 3.5.7, a cada quinze dias. Aqueles filhotes provenientes do grupo So3 foram ainda submetidos à avaliação neurocomportamental durante 3 meses, conforme descrito no item 3.5.11.

\subsubsection{Experimento 4: Estudo dos efeitos tóxicos produzidos pela $S$. occidentalis administrado a cabras durante a lactação. Avaliação dos lactentes}

Os filhotes de mães tratadas com ração contendo a concentração de $4 \%$ de sementes de S. occidentalis durante a lactação foram avaliados imediatamente após o nascimento para pesquisa de anomalias físicas, conforme o item 3.5.9. Estes filhotes foram então avaliados utilizando-se o mesmo protocolo de avaliação dos neonatos, conforme descrito nos itens 3.5.7, 3.5.10, 3.5.12 e 3.5.13.

\subsubsection{Experimento 5: Estudo químico do leite de cabras que consumiram 4\% de sementes de S. occidentalis. Pesquisa da presença de antraquinonas}

Foram coletadas, no dia do parto, amostras de colostro proveniente de duas cabras que consumiram ração contendo $2 \%$ e $4 \%$ de sementes de S. occidentalis na gestação, contendo, respectivamente 200 e 180ml além de quatro amostras de leite, 
oriundas de diferentes cabras do grupo LAC, colhidas na $3^{\mathrm{a}}, 9^{\mathrm{a}}, 12^{\mathrm{a}}$ e $15^{\mathrm{a}}$ semana de lactação. Estas amostras foram homogeneizadas e, subseqüentemente, uma alíquota contendo $250 \mathrm{ml}$ da mistura foi retirada e congelada em freezer comum, a $20^{\circ} \mathrm{C}$ até serem enviadas para a análise química. Estas amostras foram denominadas A1 (colostro 2\%), A2 (colostro 4\%) e A3 (leite de cabras LAC).

A estas amostras adicionou-se metanol com 0 intuito de realizar a precipitação de proteínas lácteas (desproteinização). Após este procedimento, as amostras foram centrifugadas a $4000 \mathrm{rpm} / 21^{\circ} \mathrm{C}$ em centrífuga refrigerada para completa separação da proteína precipitada; em seguida, as soluções foram concentradas totalmente em rota-evaporador, a $40^{\circ} \mathrm{C}$, sob pressão reduzida, para obtenção de respectivos resíduos secos.

Os resíduos secos das amostras $A 1, A 2$ e A3, além de uma fração obtida do extrato de sementes da planta contendo antraquinonas, empregada como padrão $(\mathrm{P})$, foram submetidas à cromatografia de camada delgada (CCD). Para tal foram usadas placas de plástico impregnadas com sílica-gel 60 GF254 (Merck®) e desenvolvidas no sistema de solventes constituídos por acetato de etila:metanol:água (77:13:10). As placas foram visualizadas em UV e as manchas foram detectadas através de três métodos: vapores de iodo; revelações com solução metanólica de hidróxido de potássio $(\mathrm{CH} 3 \mathrm{OH}+\mathrm{KOH})$ a $10 \%$; e ácido nítrico (HNO3) a $100 \%$. A presença de antraquinonas é evidenciada por manchas de coloração marrom no primeiro método e de coloração rósea, nos dois últimos métodos. Em seguida, após a revelação, foi calculado o fator de retenção $\mathrm{Rf}$ de cada mancha detectada. O Rf é a distância da origem (local de aplicação da amostra) até o centro da mancha na placa cromatográfica, dividido pela distância total percorrida pela fase móvel (COLLINS et al., 1997).

Os resíduos das amostras $\mathrm{A} 3$ e $\mathrm{P}$ foram aplicados em CLAE (cromatografia líquida de alta eficiência) empregando coluna RP-C18; a fase móvel utilizada foi solução metanol:água (3:1), no sistema isocrático, usando detector de UV em 254 $\mathrm{nm}$, com fluxo de $1 \mathrm{ml} / \mathrm{min}$, volume de injeção de $20 \mu \mathrm{l}$. 


\subsection{ANÁLISE ESTATÍSTICA}

Os resultados são expressos pelo método dos quadrados mínimos (LS means e SE do LS means).

O peso corporal das fêmeas e as variáveis sangüíneas foram analisados estatisticamente usando um modelo misto linear entre os tratamentos; os sujeitos experimentais foram "aninhados" por tratamentos e mensurações repetidas em relação ao tempo (Proc Mixed of SAS). Os principais efeitos significantes $(P<0.05)$ são seguidos da media usando o teste "T" de Student. O peso inicial das fêmeas foi incluído como covariável. As variáveis dos filhotes, no modelo misto linear, foram similares às usadas para as mães, em relação ao tratamento, sexo e tempo, com todas as possíveis interações. O peso corporal dos filhotes foi analisado em relação ao sexo e tempo.

Todos os testes comportamentais foram analisados não paramétricamente, com nível de significância $P<0,10$. Quanto ao teste "Labirinto em T" as variáveis "tempo até a bifurcação" (mãe no primeiro braço e depois no segundo braço do labirinto como testes separados) foram analisadas como completamente aleatórios e como se fossem dois tratamentos diferentes. O modelo incluiu tratamento (controles vs. Tratados), com animais individualmente "aninhados" com os tratamentos e mensurações repetidas. Os animais foram fatores aleatórios na análise de modelo linear e misturado, usando os procedimentos SAS (SAS Inst. Inc., Cary, NC; Version 9.1 for Windows). A variável independente primária foi o tempo para chegar ao ponto de decisão (bifurcação) ou à mãe. A matriz de variância-covariância foi escolhida por um processo interativo em que a melhor adequação foi escolhida baseada no critério de Schwarz Bayesian. O composto do modelo de covariância e simetria foi tipicamente a estrutura de melhor adequação. Por ser um experimento com $\mathrm{N}$ não balanceado, utilizou-se o método dos quadrados mínimos (LSMeans em inglês) ao invés de médias não ajustadas. A opção PDIFF no SAS foi utilizada para testar as interações significantes se o teste $F$ para os principais efeitos ou interações foi significante $(P<0,05)$. Para os estudos de regressão e correlação foram utilizados todos os animais.

A análise estatística realizada para os labirintos médio e difícil foi realizada em relação a mensurações repetidas duplas (2x), com dois fatores de tempo: lab e 
sessão. Foram avaliados o tempo e percentagem de tempo em cada braço do labirinto, além do tempo total para chegar ao fim do labirinto.

Os dados foram submetidos à análise de variância, teste $F$, estudos de regressão e correlações, e as médias, comparadas pelo teste "Pdiff", utilizando o programa estatístico SAS (SAS, 2005). Para os estudos de regressão e correlação, foram utilizados todos os animais, com exceção dos mortos ao nascimento. 
Resultados 66

\section{RESULTADOS}

c 1767 J. DANIEL Tesouro do Rio Amazonas in RIH, III. (1841) 291: [Ha muitos outros modos de suadouros muito usados na America] Cozem em um tacho ou panella bastantemente grande algumas hervas medicinaes como são mocura caa, pajé, merioba, e muitas outras aperientes; [...] (CUNHA, 1999). 


\subsection{EXPERIMENTO 1: ESTUDO DOS EFEITOS TÓXICOS PRODUZIDOS PELA S. occidentalis EM CABRAS DURANTE A GESTAÇÃO}

Nesta sessão são apresentados os resultados da mães durante a gestação. divididos entre os grupos controle e experimentais So1, So2 e So4 no item 4.1.1. E os grupos controle e So3 no item 4.1.2.

\subsubsection{Resultados das cabras pertencentes aos grupos So1, So2 e So4}

Não se observou nenhum sinal de intoxicação durante o período do tratamento. Entretanto, duas fêmeas do grupo So4 tiveram morte fetal, entre o $27^{\circ} \mathrm{e}$ $35^{\circ}$ dias de gestação. Além disso, uma fêmea pertencente a este mesmo grupo morreu próximo ao parto, adicionalmente outra fêmea So4 teve o seu filhote morto logo após o nascimento. Finalmente, um filhote deste grupo nasceu bastante debilitado (Tabela 7).

Em relação ao peso médio mensal destes animais, as análises de covariância realizadas (ANCOVA) revelaram não haver diferenças significantes $(P>0.05)$, entre os valores obtidos nos diferentes grupos (Tabela 1 e Figura 10).

Quanto aos níveis séricos de albumina, a ANOVA revelou haver diferenças significantes $(P<0,05)$ no segundo e quarto mês de gestação. $O$ subseqüente teste "T" de Student, após o uso do método dos quadrados mínimos (LSM) revelou haver diminuição significante na interação tratamento $x$ tempo, nos níveis desta substância nos animais provenientes dos grupos So2 e So4, durante quarta semana de gestação e diminuição significante na $18^{\mathrm{a}}$ semana de gestação em relação às cabras pertencentes ao grupo So4 ( $F=4,59$ e $D F=6 / 26 ; P<0,05)$. Tabela 2 e figura 11.

A comparação dos dados relativos à atividade da enzima colinesterase, entre os diferentes grupos, revelou haver diferença significante na $4^{\mathrm{a}}$ e $12^{\mathrm{a}}$ semanas do experimento $(F=2,88, D F=6 / 25 ; P<0,05)$. A aplicação do teste "T" mostrou haver diminuição significante na atividade desta enzima, naqueles animais do grupo So2 durante a $4^{a}$ semana de gestação, além de diminuição na $12^{a}$ semana, nas cabras pertencentes aos grupos So1 e So2, quando comparados com aqueles resultados 
obtidos dos animais do grupo controle (Tabela 2 e Figura 11).

A tabela 2 mostra e a figura 11 ilustra os dados referentes à atividade sérica da enzima aldolase destas cabras, a análise da variância utilizada revelou haver diferenças significantes $(P<0,05)$, na $12^{a}$ semana de gestação. Após o LSM, o teste "T" de Student revelou diminuição significante nos níveis desta enzima, naqueles animais do grupo So2 e So4, quando comparados com aqueles resultados obtidos dos animais do grupo controle $(F=4,59$ e $D F=6 / 26 ; P<0,05)$.

Em relação aos níveis de creatinina, a ANOVA revelou haver diferenças significantes neste parâmetro $(F=4,88 ; D F=6 / 26 ; p<0,05)$. A aplicação do teste "T de Student, após o LSM mostrou haver aumento significante na atividade desta enzima, naqueles animais do grupo So2 durante a $4^{\mathrm{a}}$ semana de gestação, além de diminuição durante a $12^{\text {a }}$ semana nas cabras pertencentes ao grupo So4, quando comparados com aqueles resultados obtidos dos animais do grupo controle (Tabela 2 e Figura 11).

Quando submetidos ao teste ANOVA, os parâmetros bioquímicos de glicose, GGT, AST, LDH, CK, proteína total e uréia não revelaram alterações significantes $(P>0.05)$, em todos os grupos experimentais em relação ao grupo controle (Tabelas 3 e 4 e Figuras 12 e 13).

A avaliação das mensurações ultra-sonográficas, quando submetidas à ANOVA, revelou haver diferença significante no parâmetro FC, o subseqüente teste "T" indicou diferença significante ( $F=2.58 ; D F=6 / 25 ; p<0,05)$, no $69^{\circ}$ dia de gestação, entre os animais do grupo $1 \%$ em relação aos animais do grupo controle. Entretanto a análise estatística revelou não haver qualquer alteração significante $(P>0.05)$, nos parâmetros MF, CCC, DA, DT e DBP observados (Tabelas 5 e 6 e Figuras 14 e 15).

À necropsia, a cabra que morreu no final da gestação, apresentou estrias esbranquiçadas, caracterizando necrose no músculo cardíaco; fígado com aspecto de noz-moscada, além de líquido amniótico com pigmentação amarelada. A análise histológica dos tecidos desta cabra revelou lesões como vacuolização de hepatócitos (Figura 16 A e B); em rim foi observada vacuolização das células dos túbulos contornados proximais (Figura $16 \mathrm{C}$ e D); vacuolização e necrose em musculatura esquelética (Figura $17 \mathrm{~A}$ e B), vacuolização edema e necrose em musculatura cardíaca (Figura 17 C e D), além de lesões em nervo ciático, caracterizado por tumefação axonal e câmaras de digestão em bainha de mielina (Figura 18). 
Tabela 1 - Parâmetros reprodutivos de mães tratadas com sementes de S. occidentalis do $27^{\circ}$ dia de gestação até o parto

\begin{tabular}{|c|c|c|c|c|}
\hline \multirow{2}{*}{ Parâmetros } & \multicolumn{4}{|c|}{ Sementes de Senna occidentalis (\%) } \\
\hline & 0 & 1 & 2 & 4 \\
\hline $\begin{array}{l}\text { Número de cabras prenhes / cabras } \\
\text { cobertas }\end{array}$ & $5 / 5$ & $4 / 5$ & $4 / 5$ & $6 / 6$ \\
\hline Morte embrionária & 0 & 0 & 0 & 2 \\
\hline Mortalidade de cabras & 0 & 0 & 0 & 1 \\
\hline Duração da gestação (dias $\pm S E M)$ & $144.4 \pm 0.5$ & $147.8 \pm 0.9$ & $147.3 \pm 0.9$ & $148.0 \pm 1.5$ \\
\hline Filhotes vivos & 7 & 5 & 5 & 3 \\
\hline Machos & $4(57.1)^{a}$ & $3(60.0)$ & $3(60.0)$ & $1(33.3)$ \\
\hline Fêmeas & $3(42.9)$ & $2(40.0)$ & $2(40.0)$ & $2(66.7)$ \\
\hline Mortalidade de filhotes (pós parto) & 0 & 0 & 0 & $1(33.3)$ \\
\hline Gêmeos & $4(57.1)$ & $2(40.0)$ & $2(40.0)$ & 0 \\
\hline Filhotes debilitados $^{b}$ & 0 & $2(40.0)$ & 0 & $1(33.3)$ \\
\hline
\end{tabular}

am parêntese, percentagens.

${ }^{b}$ Filhote debilitado refere-se a observações subjetivas quanto à dificuldade de permanecer em pé e mamar logo após o nascimento. 
Tabela 2 - Peso médio $(\mathrm{kg})$ inicial, final e total de cabras que consumiram diferentes concentrações de sementes de Senna occidentalis durante a gestação. São apresentados as médias e os respectivos erros padrão, pelo método dos quadrados mínimos. ANOVA, seguida de teste T de Student

\begin{tabular}{lcccc}
\hline \multirow{2}{*}{ Dias de coleta } & \multicolumn{4}{c}{ Sementes de Senna occidentalis (\%) } \\
\cline { 2 - 5 } $27^{\circ}$ & $\mathbf{0}$ & $\mathbf{1}$ & $\mathbf{2}$ & $\mathbf{4}$ \\
$146^{\circ}$ & $33,07 \pm 3,73(5)^{\mathrm{a}}$ & $33,17 \pm 1,67(4)$ & $33,11 \pm 2,69(4)$ & $35,49 \pm 3,68(4)$ \\
Total & $47,52 \pm 4,02(5)$ & $44,70 \pm 2,48(4)$ & $47,57 \pm 4,07(4)$ & $43,82 \pm 4,32(4)$ \\
\hline a & $14,45 \pm 3,88(5)$ & $11,52 \pm 2,07(4)$ & $14,46 \pm 3,38(4)$ & $8,375 \pm 4,00(4)$ \\
\hline
\end{tabular}

${ }^{a}$ entre parênteses o número de animais estudados. 

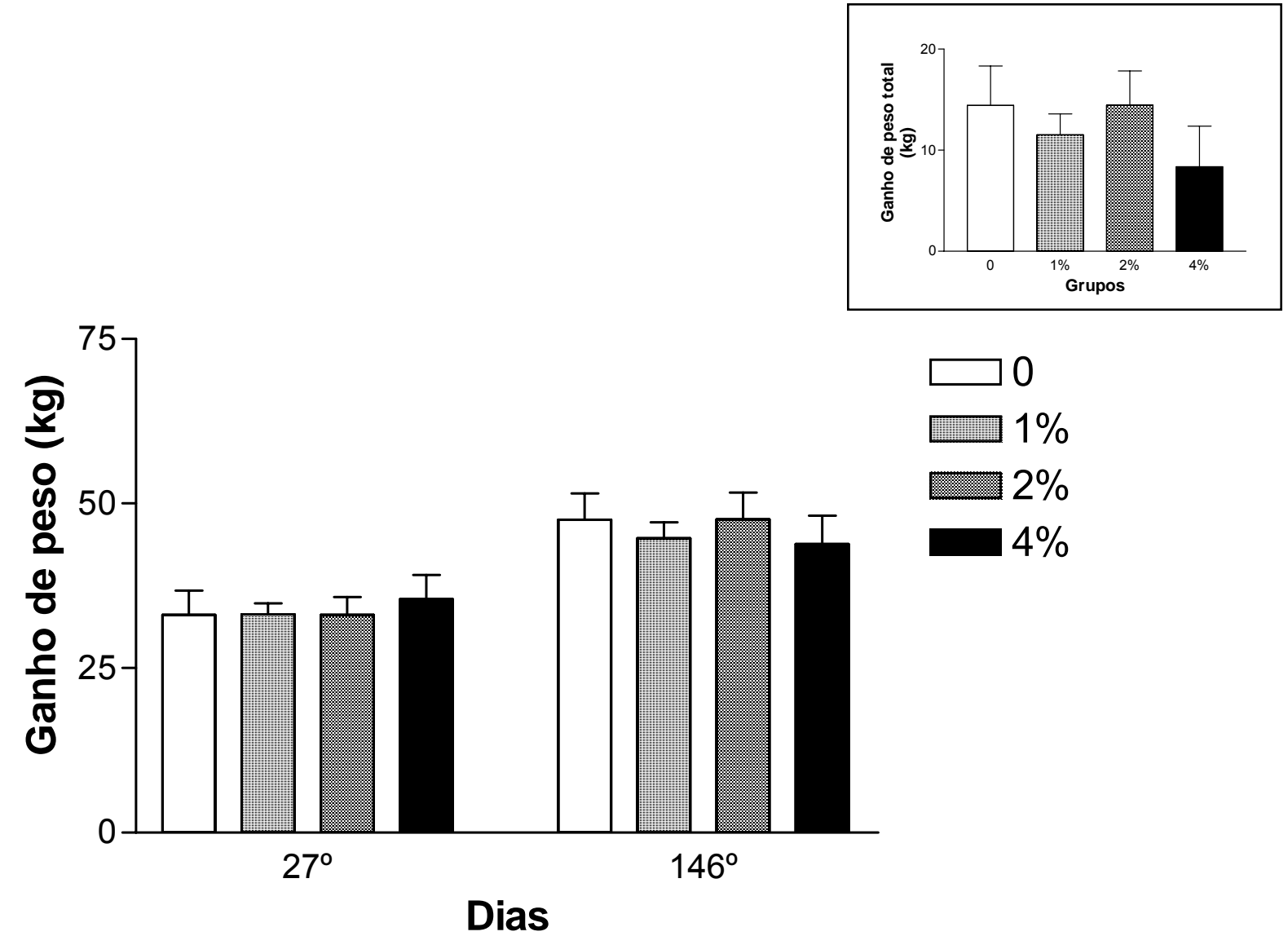

Figura 10 - Peso médio $(\mathrm{kg})$ inicial, final e total (quadro) de cabras que consumiram diferentes concentrações de sementes de Senna occidentalis durante a gestação. São apresentadas as médias e os respectivos erros padrão 
Tabela 3 - Níveis séricos de albumina $(\mathrm{g} / \mathrm{l})$, colinesterase $(\mathrm{u} / \mathrm{l})$, Aldolase $(\mathrm{u} / \mathrm{l})$ e creatinina $(\mathrm{u} / \mathrm{l})$ de cabras que consumiram diferentes concentrações de sementes de Senna occidentalis durante a gestação. São apresentadas as médias e os respectivos erros padrão, pelo método dos quadrados mínimos. ANOVA, seguida de teste T de Student

\begin{tabular}{|c|c|c|c|c|c|}
\hline \multirow{2}{*}{ Substâncias } & \multirow{2}{*}{$\begin{array}{c}\text { Datas de } \\
\text { coleta }^{\mathrm{a}}\end{array}$} & \multicolumn{4}{|c|}{ Sementes de Senna occidentalis (\%) } \\
\hline & & 0 & 1 & 2 & 4 \\
\hline \multirow{3}{*}{$\begin{array}{l}\text { Albumina } \\
(\mathrm{g} / \mathrm{l})\end{array}$} & 4 & $2,88 \pm, 014(5)^{b}$ & $2,81 \pm 0,17(4)$ & $2,33 \pm 0,17(4)$ * & $2,22 \pm 0,20(4)$ \\
\hline & 12 & $2,61 \pm 0,14(5)$ & $2,30 \pm 0,17(4)$ & $2,85 \pm 0,17(4)$ & $3,17 \pm 0,20(4)$ \\
\hline & 18 & $2,66 \pm 0,14(5)$ & $2,63 \pm 0,17(4)$ & $2,18 \pm 0,17(4)$ * & $2,26 \pm 0,20(4)$ \\
\hline \multirow{3}{*}{$\begin{array}{c}\text { Colinesterase } \\
\text { (UI) }\end{array}$} & 4 & $1,00 \pm 0,12(5)$ & $0,94 \pm 0,14(4)$ & $0,45 \pm 0,14(4) *$ & $0,94 \pm 0,17(4)$ \\
\hline & 12 & $1,12 \pm 0,12(5)$ & $0,41 \pm 0,17(4)$ * & $0,61 \pm 0,14(4) *$ & $0,95 \pm 0,17(4)$ \\
\hline & 18 & $0,87 \pm 0,12(5)$ & $0,80 \pm 0,90(4)$ & $0,83 \pm 0,14(4)$ & $0,90 \pm 0,17(4)$ \\
\hline \multirow{3}{*}{$\begin{array}{c}\text { Aldolase } \\
(\mathrm{U} / \mathrm{I})\end{array}$} & 4 & $14,33 \pm 2,76(5)$ & $11,16 \pm 3,38(4)$ & $21,90 \pm 3,38(4)$ & $13,89 \pm 3,90(4)$ \\
\hline & 12 & $5,77 \pm 1,45(5)$ & $4,05 \pm 0,96(4)$ & $2,80 \pm 0,96(4)$ * & $2,5 \pm 1,11(4)$ * \\
\hline & 18 & $8,59 \pm 0,94(5)$ & $5,90 \pm 1,55(4)$ & $11,16 \pm 1,36(4)$ & $8,01 \pm 1,57(4)$ \\
\hline \multirow{3}{*}{$\begin{array}{l}\text { Creatinina } \\
\quad(\mathrm{U} / \mathrm{l})\end{array}$} & 4 & $0,78 \pm 0,07(5)$ & $0,88 \pm 0,09(4)$ & $1,06 \pm 0,09(4) *$ & $1,11 \pm 0,10(4)$ * \\
\hline & 12 & $1,20 \pm 0,07(5)$ & $1,18 \pm 0,09(4)$ & $1,06 \pm 0,09(4)$ * & $0,73 \pm 0,10(4)$ * \\
\hline & 18 & $1,20 \pm 0,07(5)$ & $1,18 \pm 0,09(4)$ & $1,13 \pm 0,09(4)$ & $1,11 \pm 0,10(4)$ \\
\hline
\end{tabular}

b entre parênteses o número de animais estudados.

* Difere significantemente $(P<0,05)$. Anova, seguido de teste T de Student. Os dados são apresentados através do método dos quadrados mínimos. 

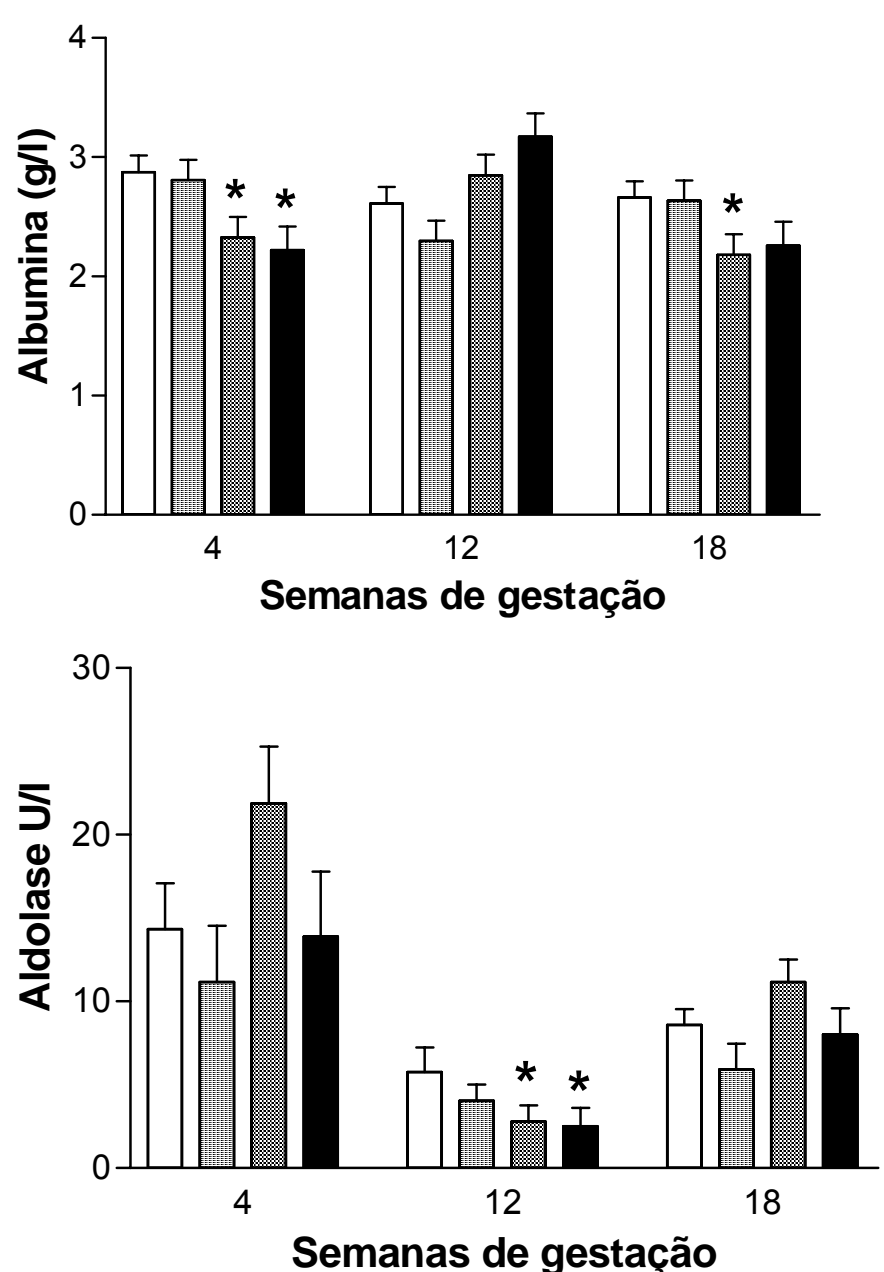
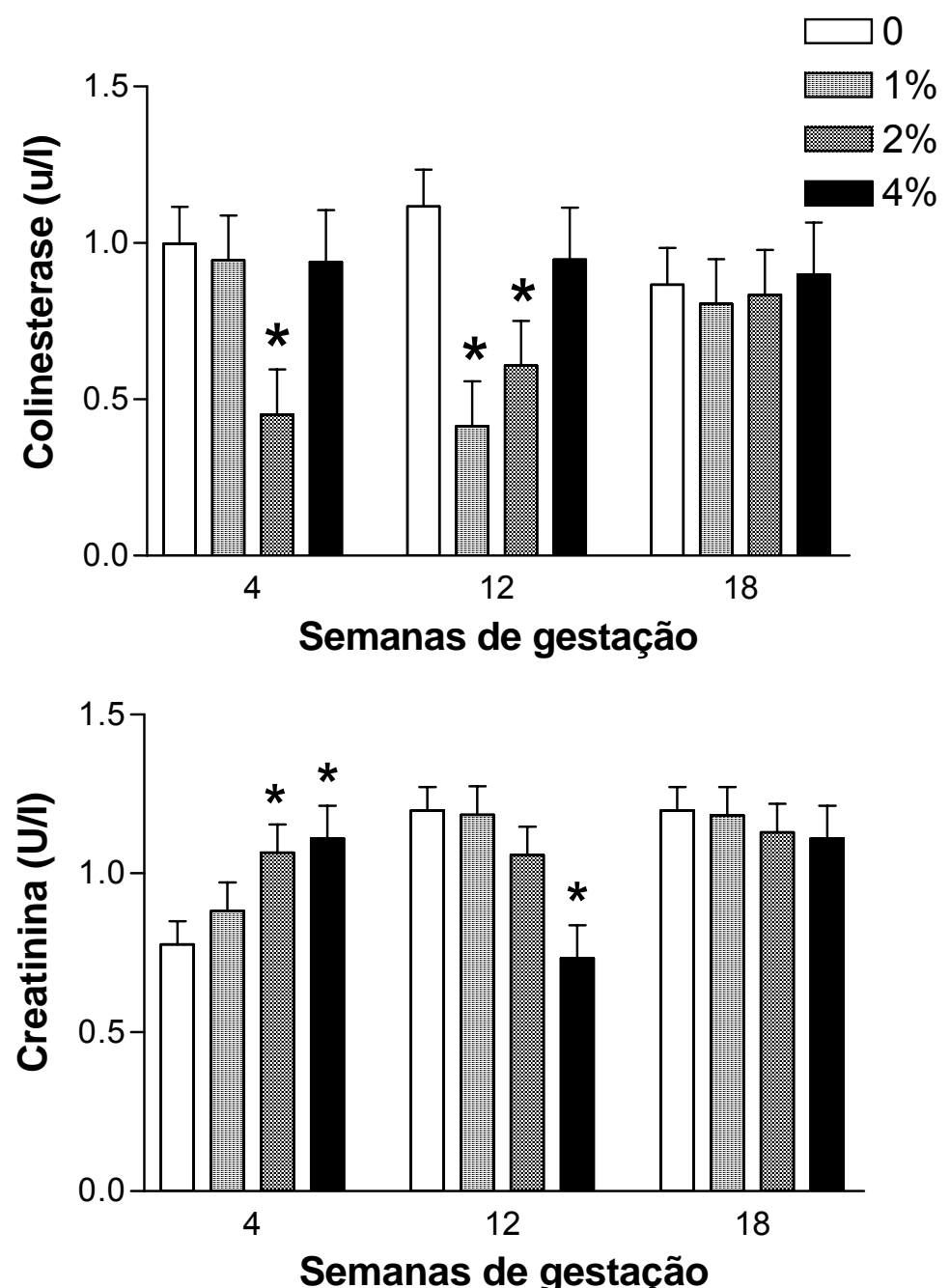

${ }^{*} \mathrm{P}<0,05$. Análise da variância ANOVA, seguida de teste $T$ de Student

Figura 11 - Níveis séricos de albumina (g/L), colinesterase (U/L), aldolase (U/L) e creatinina (U/L) de cabras que consumiram diferentes concentrações de sementes de Senna occidentalis durante a gestação. São apresentadas as médias e os respectivos erros padrão. Os dados são apresentados através do método dos quadrados mínimos 
Tabela 4 - Níveis séricos de glicose (mg/dl), GGT (u/l), AST (u/l) e LDH (u/l) de cabras que consumiram diferentes concentrações de sementes de Senna occidentalis durante a gestação. São apresentadas as médias e os respectivos erros padrão, pelo método dos quadrados mínimos. ANOVA, seguida de teste T de Student

\begin{tabular}{|c|c|c|c|c|c|}
\hline \multirow{2}{*}{ Substâncias } & \multirow{2}{*}{$\begin{array}{c}\text { Datas de } \\
\text { coleta }^{a}\end{array}$} & \multicolumn{4}{|c|}{ Sementes de Senna occidentalis (\%) } \\
\hline & & 0 & 1 & 2 & 4 \\
\hline \multirow{3}{*}{$\begin{array}{l}\text { Glicose } \\
\text { (mg/dl) }\end{array}$} & 4 & $43,36 \pm 11,10(5)^{b}$ & $25,58 \pm 10,83(4)$ & $35,54 \pm 5,17(4)$ & $37,76 \pm 5,00(4)$ \\
\hline & 12 & $36,95 \pm 7,74(5)$ & $35,84 \pm 8,99(4)$ & $39,36 \pm 2,84(4)$ & $28,46 \pm 23,62(4)$ \\
\hline & 18 & $28,67 \pm 10,79(5)$ & $29,00 \pm 2,62(4)$ & $26,76 \pm 2,58(4)$ & $33,85 \pm 23,99(4)$ \\
\hline \multirow{3}{*}{$\begin{array}{l}\text { GGT } \\
(\mathrm{U} / \mathrm{l})\end{array}$} & 4 & $49,58 \pm 3,20(5)$ & $53,49 \pm 9,10(4)$ & $49,65 \pm 5,36(4)$ & $49,84 \pm 6,36(4)$ \\
\hline & 12 & $48,99 \pm 2,30(5)$ & $47,13 \pm 6,41(4)$ & $49,29 \pm 2,54(4)$ & $45,87 \pm 7,90(4)$ \\
\hline & 18 & $28,67 \pm 10,79(5)$ & $29,00 \pm 2,62(4)$ & $26,76 \pm 2,58(4)$ & $33,85 \pm 2,40(4)$ \\
\hline \multirow{3}{*}{$\begin{array}{l}\text { AST } \\
(U / I)\end{array}$} & 4 & $31,99 \pm 2,14(5)$ & $34,86 \pm 2,78(4)$ & $34,15 \pm 3,78(4)$ & $34,90 \pm 4,77(4)$ \\
\hline & 12 & $30,27 \pm 1,29(5)$ & $30,10 \pm 2,62(4)$ & $27,49 \pm 1,06(4)$ & $29,98 \pm 1,26(4)$ \\
\hline & 18 & $30,65 \pm 1,73(5)$ & $35,46 \pm 11,30(4)$ & $31,77 \pm 4,82(4)$ & $33,95 \pm 1,46(4)$ \\
\hline \multirow{3}{*}{$\begin{array}{l}\mathrm{LDH} \\
(\mathrm{U} / \mathrm{I})\end{array}$} & 4 & $382,10 \pm 39,72(5)$ & $390,58 \pm 51,04(4)$ & $380,47 \pm 20,10(4)$ & $426,34 \pm 132,05(4)$ \\
\hline & 12 & $279,28 \pm 18,64(5)$ & $322,43 \pm 35,36(4)$ & $333,52 \pm 76,07(3)$ & $302,21 \pm 8815(4)$ \\
\hline & 18 & $281,70 \pm 10,60(5)$ & $281,29 \pm 21,31(4)$ & $312,68 \pm 29,82(4)$ & $329,20 \pm 79,86(4)$ \\
\hline
\end{tabular}

a meses da gestação, quando as cabras começaram a ser mensuradas, logo após a detecção da prenhez.
b entre parênteses o número de animais estudados. 

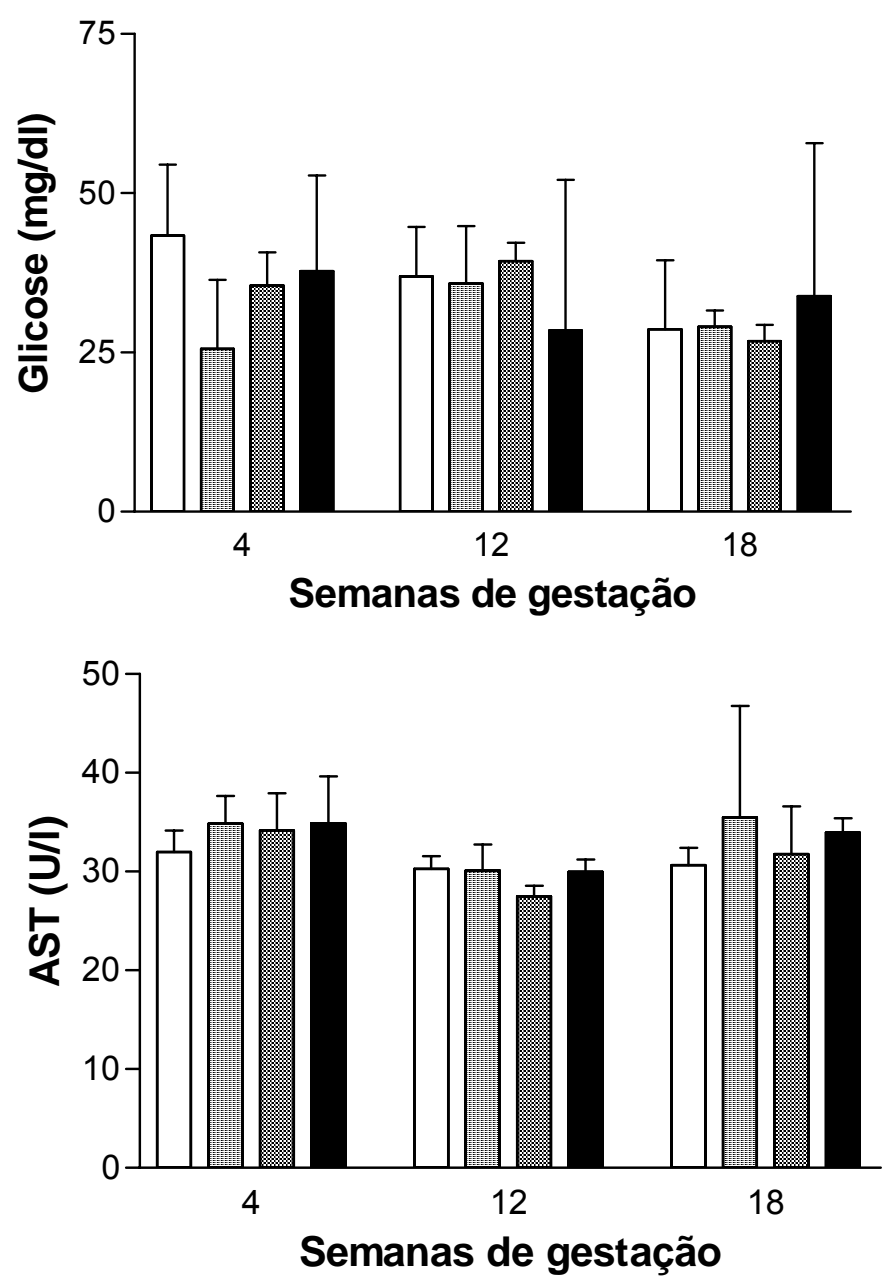
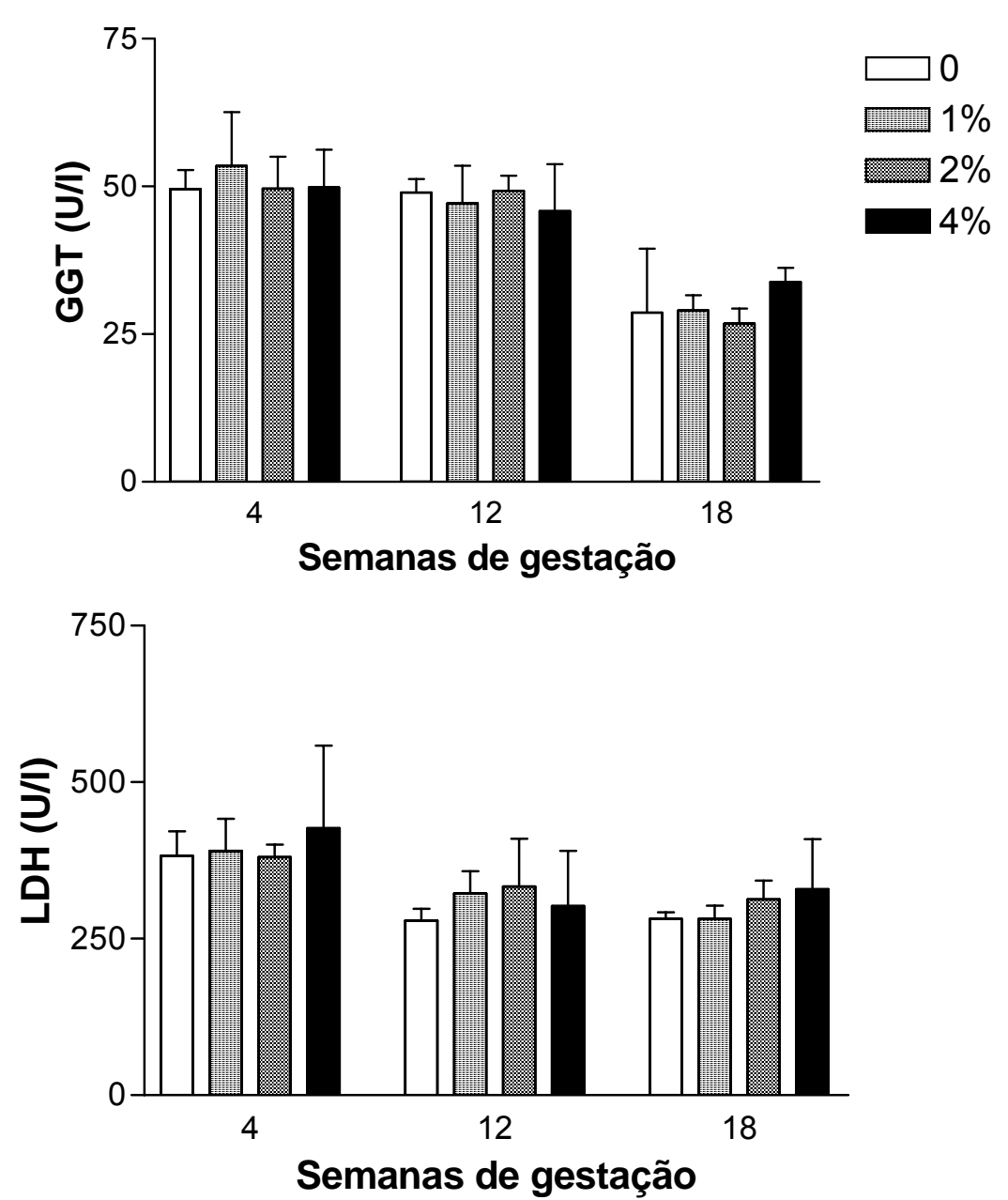

Figura 12 - Níveis séricos de glicose (mg/dl), GGT (u/l), AST (u/l) e LDH (u/l) de cabras que consumiram diferentes concentrações de sementes de Senna occidentalis durante a gestação. São apresentadas as médias e os respectivos erros padrão. Análise da variância ANOVA, seguida de teste T de Student. Os dados são apresentados através do método dos quadrados mínimos 
Tabela 5 - Níveis séricos de CK (U/L), proteína $(\mathrm{g} / \mathrm{dl})$ e uréia $(\mathrm{mg} / \mathrm{dl})$ de cabras que consumiram diferentes concentrações de sementes de Senna occidentalis durante a gestação São apresentadas as médias e os respectivos erros padrão, pelo método dos quadrados mínimos. ANOVA, seguida de teste T de Student

\begin{tabular}{|c|c|c|c|c|c|}
\hline \multirow{2}{*}{ Substâncias } & \multirow{2}{*}{$\begin{array}{c}\text { Datas de } \\
\text { coleta }^{\mathrm{a}}\end{array}$} & \multicolumn{4}{|c|}{ Sementes de Senna occidentalis (\%) } \\
\hline & & 0 & 1 & 2 & 4 \\
\hline \multirow{3}{*}{$\begin{array}{l}\text { CK } \\
(\mathrm{U} / \mathrm{I})\end{array}$} & 4 & $22,70 \pm 3,62(5)^{b}$ & $23,30 \pm 3,90(4)$ & $25,30 \pm 6,90(4)$ & $36,43 \pm 24,63(4)$ \\
\hline & 12 & $18,62 \pm 2,22(5)$ & $18,89 \pm 2,34(4)$ & $19,23 \pm 0,90(4)$ & $24,30 \pm 4,00(4)$ \\
\hline & 18 & $18,32 \pm 2,22(5)$ & $19,23 \pm 2,02(4)$ & $18,21 \pm 2,34(4)$ & $17,54 \pm 2,34(4)$ \\
\hline \multirow{3}{*}{$\begin{array}{l}\text { Proteína } \\
\text { (g/dl) }\end{array}$} & 4 & $6,90 \pm 0,91(5)$ & $7,04 \pm 0,56(4)$ & $7,51 \pm 1,03(4)$ & $8,85 \pm 4,86(4)$ \\
\hline & 12 & $6,05 \pm 0,41(5)$ & $7,10 \pm 0,67(4)$ & $6,22 \pm 0,63(4)$ & $4,17 \pm 3,90(4)$ \\
\hline & 18 & $6,70 \pm 0,66(5)$ & $5,61 \pm 0,91(4)$ & $7,94 \pm 1,84(4)$ & $4,93 \pm 3,40(4)$ \\
\hline \multirow{3}{*}{$\begin{array}{l}\text { Uréia } \\
\text { (mg/dl) }\end{array}$} & 4 & $29,0 \pm 9,30(5)$ & $23,33 \pm 8,90(4)$ & $38,35 \pm 3,85(4)$ & $5,56 \pm 12,73(4)$ \\
\hline & 12 & $37,67 \pm 6,52(5)$ & $24,58 \pm 2,84(4)$ & $22,91 \pm 3,16(4)$ & $18,89 \pm 2,55(4)$ \\
\hline & 18 & $28,70 \pm 3,80(5)$ & $27,10 \pm 3,16(4)$ & $28,33 \pm 3,70(4)$ & $27,80 \pm 3,85(4)$ \\
\hline
\end{tabular}



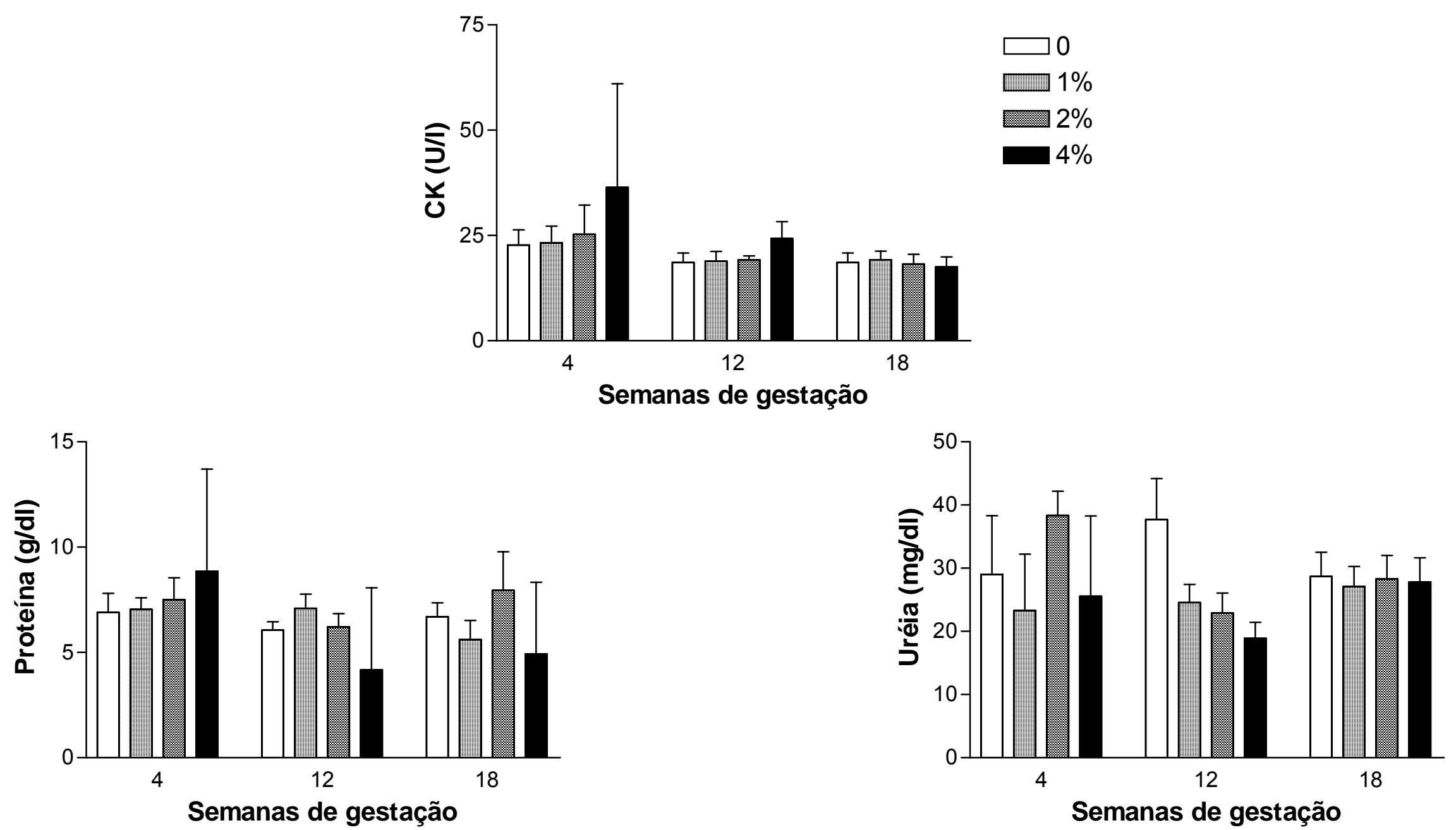

Figura 13 - Níveis séricos de CK (U/L), proteína $(\mathrm{g} / \mathrm{dl})$ e uréia $(\mathrm{mg} / \mathrm{dl})$ de cabras que consumiram diferentes concentrações de sementes de Senna occidentalis durante a gestação. São apresentadas as médias e os respectivos erros padrão. Análise da variância ANOVA, seguida de teste $\mathrm{T}$ de Student. Os dados são apresentados através do método dos quadrados mínimos 
Tabela 6 - Parâmetros ultrassonográficos de cabras que consumiram diferentes concentrações de sementes de Senna occidentalis durante a gestação. Freqüência cardíaca (FC), movimento fetal (MF) e comprimento crânio caudal (CCC). São apresentadas as médias e os respectivos erros padrão, pelo método dos quadrados mínimos. ANOVA, seguida de teste T de Student

\begin{tabular}{|c|c|c|c|c|c|}
\hline \multirow{2}{*}{ Mensurações } & \multirow{2}{*}{ Datas de coleta ${ }^{a}$} & \multicolumn{4}{|c|}{ Sementes de Senna occidentalis (\%) } \\
\hline & & 0 & 1 & 2 & 4 \\
\hline \multirow{3}{*}{$\begin{array}{c}\text { FC } \\
(\min )\end{array}$} & $35^{\circ}$ & $116.6 \pm 12.03(5)^{b}$ & $150.0 \pm 13.52(4)$ & $149.0 \pm 13.52(4)$ & $140.7 \pm 15.62(4)$ \\
\hline & $43^{\circ}$ & $153.2 \pm 11.04$ & $140.0 \pm 13.52(4)$ & $152.0 \pm 13.52(4)$ & $165.7 \pm 15.62(4)$ \\
\hline & $69^{\circ}$ & $154.0 \pm 11.04(5)$ & $90.10 \pm 13.52(4)$ * & $146.0 \pm 13.52(4)$ & $157.3 \pm 15.62(4)$ \\
\hline \multirow{3}{*}{$\begin{array}{c}\text { MF } \\
(\min )\end{array}$} & $35^{\circ}$ & $0.80 \pm 1.78(5)$ & $0.00 \pm 0,00(4)$ & $1.00 \pm 2.00(4)$ & $0.00 \pm 0.00(4)$ \\
\hline & $43^{\circ}$ & $3.40 \pm 0.89(5)$ & $5.50 \pm 3.00(4)$ & $6.00 \pm 2.83(4)$ & $3.70 \pm 2.52(4)$ \\
\hline & $69^{\circ}$ & $5.20 \pm 2.30(5)$ & $4.75 \pm 2.99(4)$ & $3.50 \pm 2.52(4)$ & $6.00 \pm 2.83(4)$ \\
\hline \multirow{2}{*}{$\begin{array}{l}\text { CCC } \\
(\mathrm{cm})\end{array}$} & $35^{\circ}$ & $1.82 \pm 0.33(5)$ & $2.16 \pm 0.26(4)$ & $1.65 \pm 0.49(4)$ & $1.79 \pm 0.43(4)$ \\
\hline & $43^{\circ}$ & $4.98 \pm 0.88(5)$ & $4.90 \pm 0.57(4)$ & $4.74 \pm 0.72(4)$ & $4.70 \pm 0.48(4)$ \\
\hline
\end{tabular}

* Difere significantemente do controle. Anova seguida de teste T de student.
a dias da gestação, quando as cabras começaram a ser mensuradas, logo após a deteç̧ão da prenhez.
b entre parênteses o número de animais estudados. 

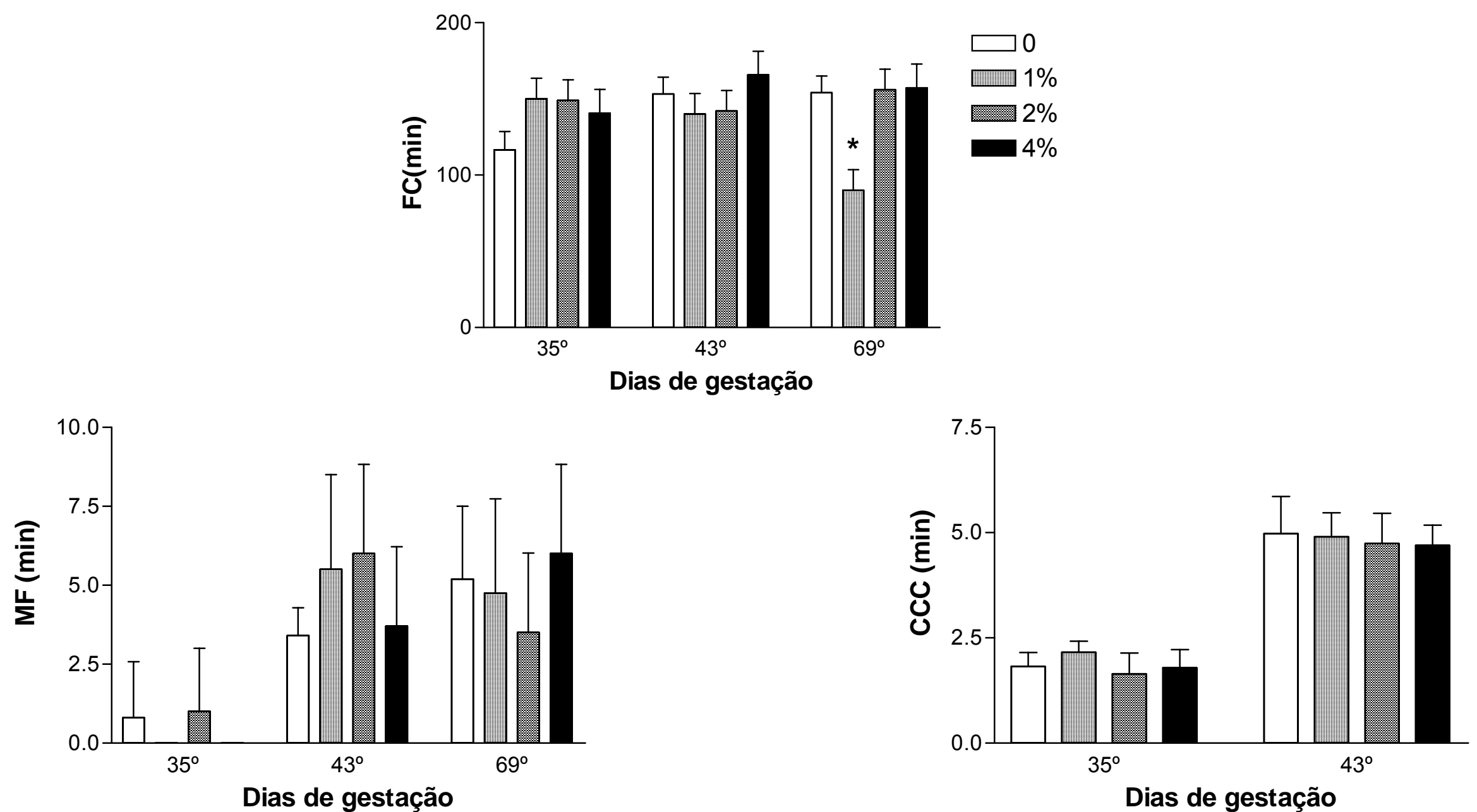

*Difere significantemente do controle.

Figura 14 - Parâmetros ultrassonográficos de cabras que consumiram diferentes concentrações de sementes de Senna occidentalis durante a gestação. Freqüência cardíaca (FC), movimento fetal (MF) e comprimento crânio caudal (CCC). São apresentados as médias e os respectivos erros padrão. ANOVA, seguida de teste T de Student. Dados apresentados pelo método dos quadrados mínimos 
Tabela 7 - Parâmetros ultrassonográficos de cabras que consumiram diferentes concentrações de sementes de Senna occidentalis durante a gestação. Diâmetro abdominal (DA), diâmetro torácico (DT) e diâmetro biparietal (DBP). São apresentadas as médias e os respectivos erros padrão, pelo método dos quadrados mínimos. ANOVA, seguida de teste T de Student

\begin{tabular}{cccccc}
\hline \multirow{2}{*}{ Medidas } & Datas de coleta $^{\mathrm{a}}$ & \multicolumn{4}{c}{ Sementes de Senna occidentalis (\%) } \\
\cline { 3 - 6 } & DA & $\mathbf{0}$ & $\mathbf{1}$ & $\mathbf{2}$ & $\mathbf{4}$ \\
$(\mathrm{cm})$ & $69^{\circ}$ & $2.10 \pm 0.19(5)$ & $2.03 \pm 0.26(4)$ & $2.00 \pm 0.46(4)$ & $2.13 \pm 0.04(4)$ \\
DT & & & & & \\
$(\mathrm{cm})$ & $69^{\circ}$ & $1.30 \pm 0.11(5)$ & $1.27 \pm 0.12(4)$ & $1.52 \pm 0.52(4)$ & $1.53 \pm 0.15(4)$ \\
DBP & $69^{\circ}$ & $1.98 \pm 0.14(5)$ & $2.15 \pm 0.18(4)$ & $2.10 \pm 0.20(4)$ & $1.99 \pm 0.10(4)$ \\
$(\mathrm{CM})$ & & & & & \\
\hline
\end{tabular}

a dias da gestação, quando as cabras começaram a ser mensuradas, logo após a detecção da prenhez. 

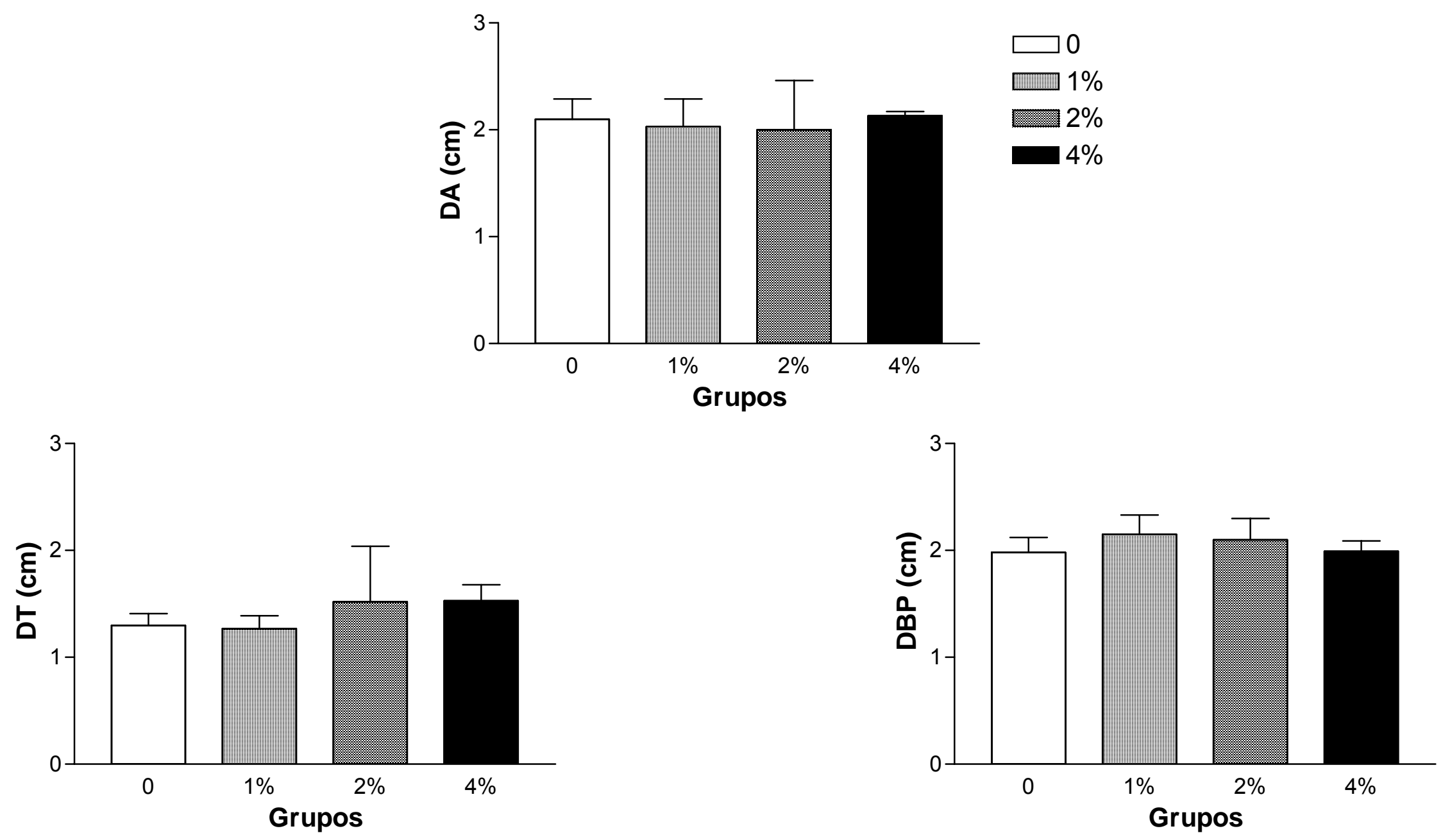

Figura 15 - Parâmetros ultrassonográficos de cabras que consumiram diferentes concentrações de sementes de Senna occidentalis durante o $69^{\circ}$ dia da gestação. Diâmetro abdominal (DA), diâmetro torácico (DT) e diâmetro biparietal (DBP). São apresentadas as médias e os respectivos erros padrão. ANOVA, seguida de teste T de Student. Dados apresentados pelo método dos quadrados mínimos 

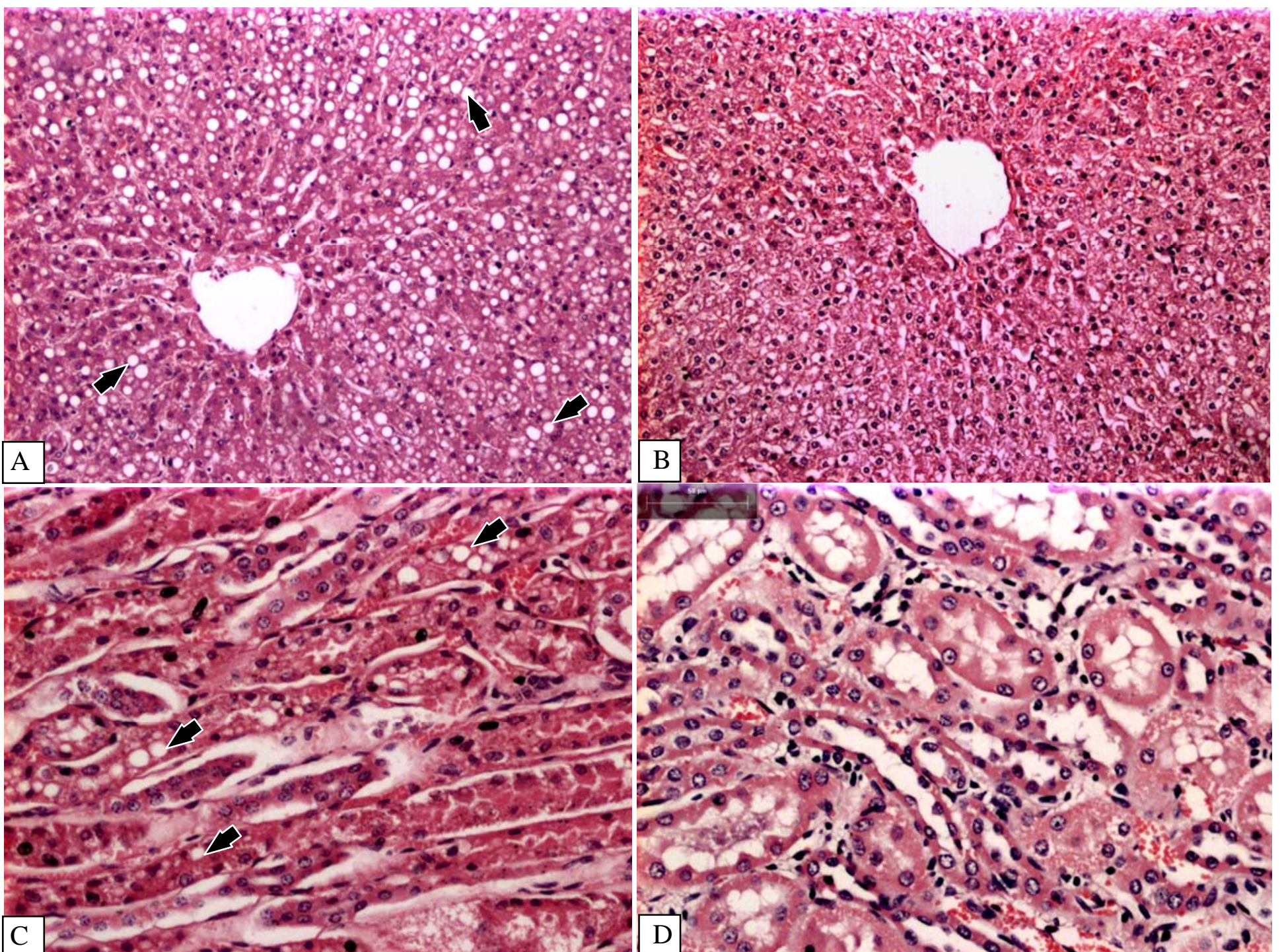

Figura 16 - Fotomicrografia de luz de fígado de cabra, pertencente ao grupo So4 (A) e grupo controle (B), evidencia-se severa vacuolização de hepatócitos (setas), HE, A: 10x. Rim de cabra, pertencente ao grupo So4 (C) e controle (D). Evidencia-se discreta vacuolização de endotélio de túbulo contornado (setas), HE, A: 20x 

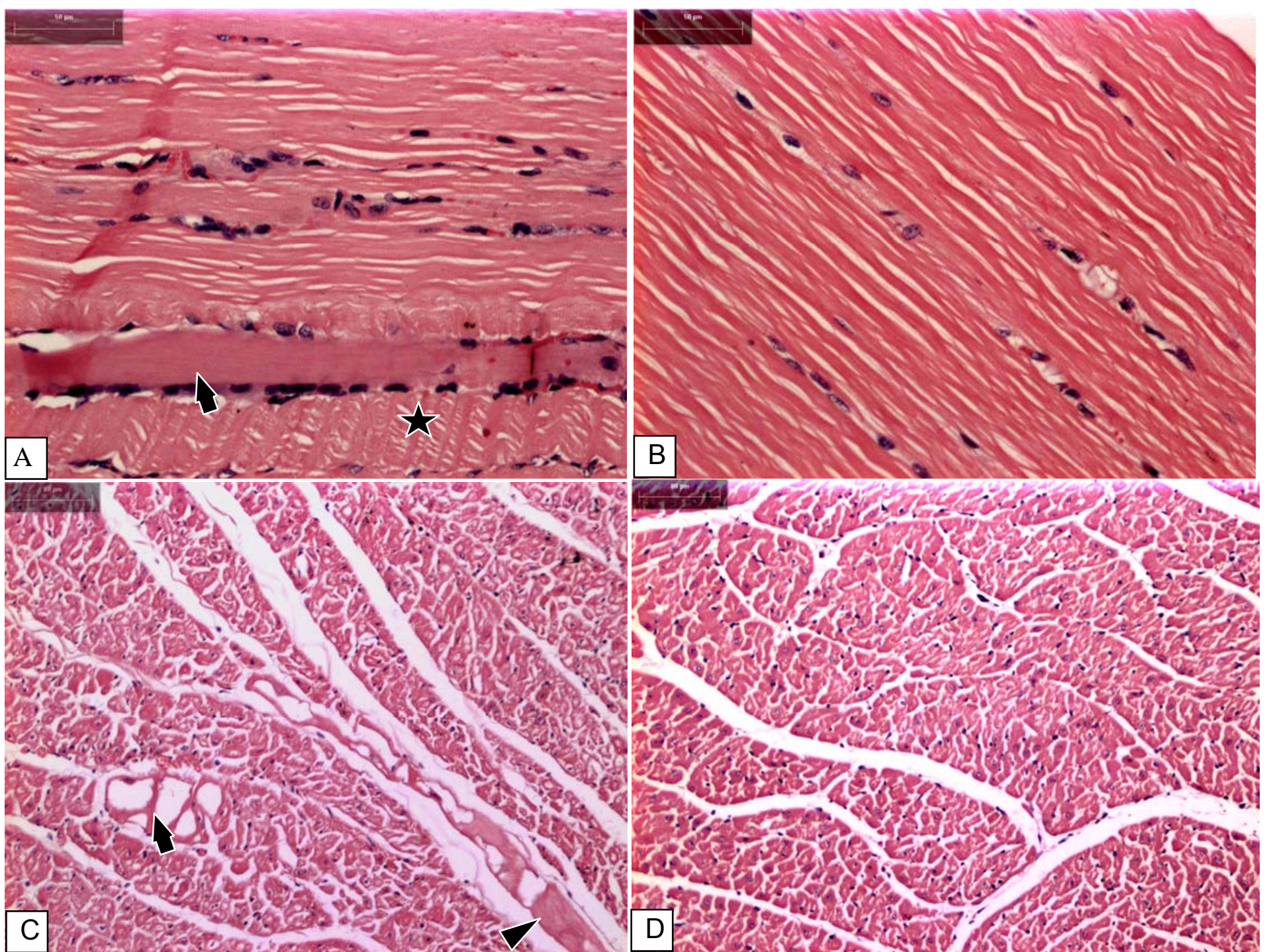

Figura 17 - Fotomicrografia de luz tumefação (seta), e afrouxamento de fibras (estrela), HE, A: 20x. Músculo cardíaco de cabra do grupo So4 (C) e controle (D). Evidencia-se, edema intersticial e vacuolização (seta), necrose, e tumefação (cabeça de seta) HE, A: 20x 

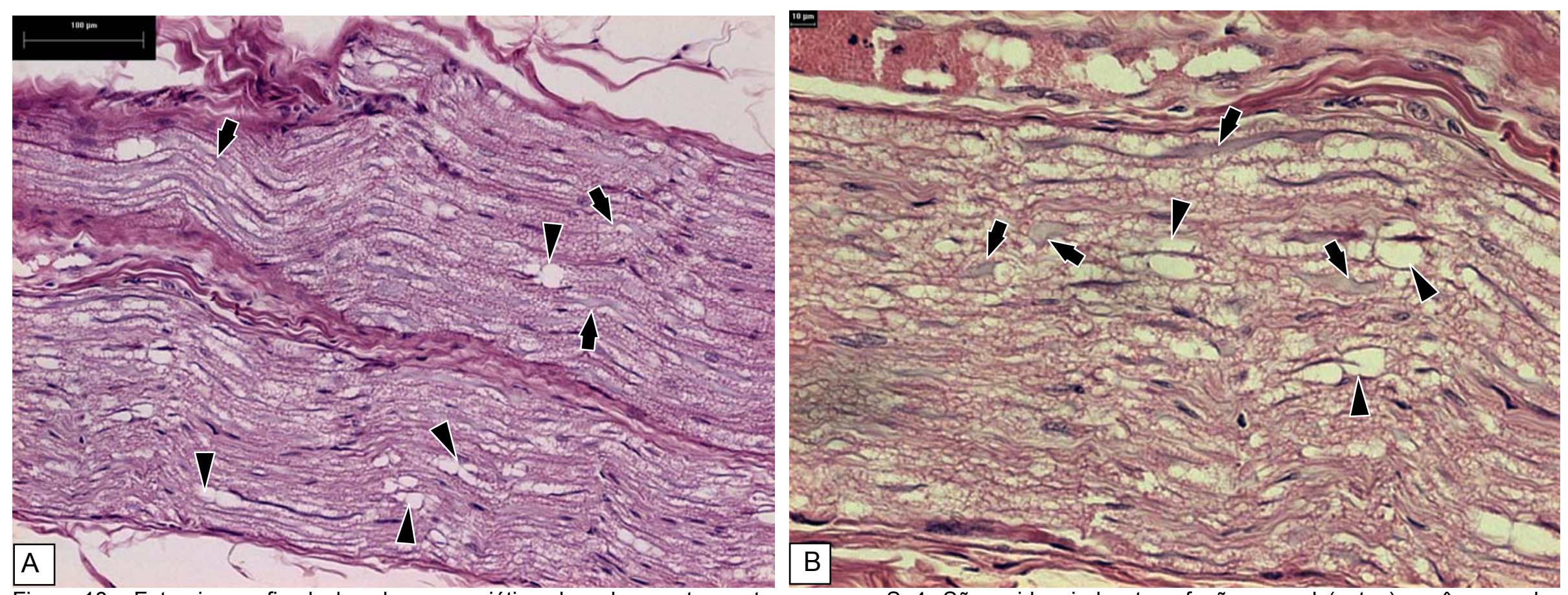

Figura 18 - Fotomicrografia de luz de nervo ciático de cabra pertencente ao grupo So4. São evidenciadas tumefação axonal (setas) e câmaras de digestão em bainha de mielina (cabeças de seta). HE, A: 10x (A) e 20X (B) 


\subsubsection{Resultados das cabras pertencentes ao Grupo So3}

Não foram observadas alterações clínicas durante todo o período gestacional.

A tabela 8 mostra os principais eventos relacionados à gestação das fêmeas do grupo controle e So3. Não houve nenhuma alteração durante a gestação.

Em relação ao peso médio inicial e final das cabras pertencentes ao grupo So3, as análises de covariância realizadas (ANCOVA) revelaram não haver diferenças significantes entre os valores obtidos dos diferentes grupos (Tabela 9 e Figura 19). Quanto ao peso total, a análise não paramétrica pelo teste MannWhitney, teste $P$ de duas vias, não pareado, revelou haver diferença significante entre os dois grupos $(U=24,0 ; P=0,0095$, medianas 12,54/2,40) (Tabela 9 e Figura 19).

Quanto aos níveis séricos de albumina, proteína, colesterol e triglicerídeos, a ANOVA revelou não haver diferenças significantes $(P>0,05)$ durante a gestação (Tabela 10 e Figura 20).

A tabela 11 mostra e a figura 21 ilustra os dados referentes à concentração sérica de glicose, da atividade sérica das enzimas GGT, AST e LDH destas cabras, a análise da variância utilizada revelou NÃO haver diferenças significantes $(P>0,05)$.

Em relação à atvidade das enzimas $\mathrm{CK}$, FA, e aos níveis de creatinina e uréia, a análise estatística revelou NÃO haver diferença significante $(P>0,05)$ (Tabela 12 e Figura 22).

A avaliação das mensurações ultra-sonográficas, quando submetidas à ANOVA, não revelou haver diferenças significantes em todos os parâmetros avaliados (Tabelas 13 e 14 e Figuras 23 e 24). 
Tabela 8 - Parâmetros reprodutivos de cabras que consumiram ração contendo 0 e $3 \%$ de sementes de Senna occidentalis durante a gestação. São apresentadas as médias, respectivos erros padrão e porcentagens dos principais eventos

\begin{tabular}{|c|c|c|}
\hline \multirow{2}{*}{ Parâmetros } & \multicolumn{2}{|c|}{ Sementes de Senna occidentalis (\%) } \\
\hline & 0 & 3 \\
\hline Número de cabras prenhes / cabras cobertas & $5 / 5$ & $5 / 5$ \\
\hline Morte embrionária & 0 & 0 \\
\hline Mortalidade de cabras & 0 & 0 \\
\hline Duração da gestação (dias $\pm S E M)$ & $146,2 \pm 0,5$ & $147,1 \pm 1,0$ \\
\hline Filhotes vivos & 8 & 7 \\
\hline Machos & $6(75,00)^{a}$ & $2(28,57)$ \\
\hline Fêmeas & $2(25,00)$ & $5(71,43)$ \\
\hline Mortalidade de filhotes (pós parto) & 0 & 0 \\
\hline Gêmeos & $3(37,50)$ & $2(28,57)$ \\
\hline Filhotes debilitados $^{b}$ & 0 & 0 \\
\hline
\end{tabular}

Em parêntese, percentagens.

${ }^{6}$ Filhotes debilitados: refere-se a observações subjetivas quanto à dificuldade de permanecer em pé e mamar logo após o nascimento. 
Tabela 9 - Peso médio $(\mathrm{kg})$ inicial, final e total de cabras que consumiram ração contendo 0 e $3 \%$ de sementes de Senna occidentalis durante a gestação. São apresentadas as médias e os respectivos erros padrão, pelo método dos quadrados mínimos.

\begin{tabular}{ccc}
\hline \multirow{2}{*}{ Dias de coleta } & \multicolumn{2}{c}{ Sementes de Senna occidentalis (\%) } \\
\cline { 2 - 3 } & $\mathbf{0}$ & $\mathbf{3}$ \\
\hline $27^{\circ}$ & $33,15 \pm 2,53(4)^{\mathrm{a}}$ & $36,57 \pm 2,07(6)$ \\
$146^{\circ}$ & $47,12 \pm 2,53(4)$ & $43,58 \pm 2,07(6)$ \\
Total & $13,97 \pm 3,80(4)$ & $7,02 \pm 2,13(6){ }^{*}$ \\
\hline
\end{tabular}

* diferença significante.Análise não paramétrica, Mann-Witney, teste $P$ de duas vias. $P=0,0095$
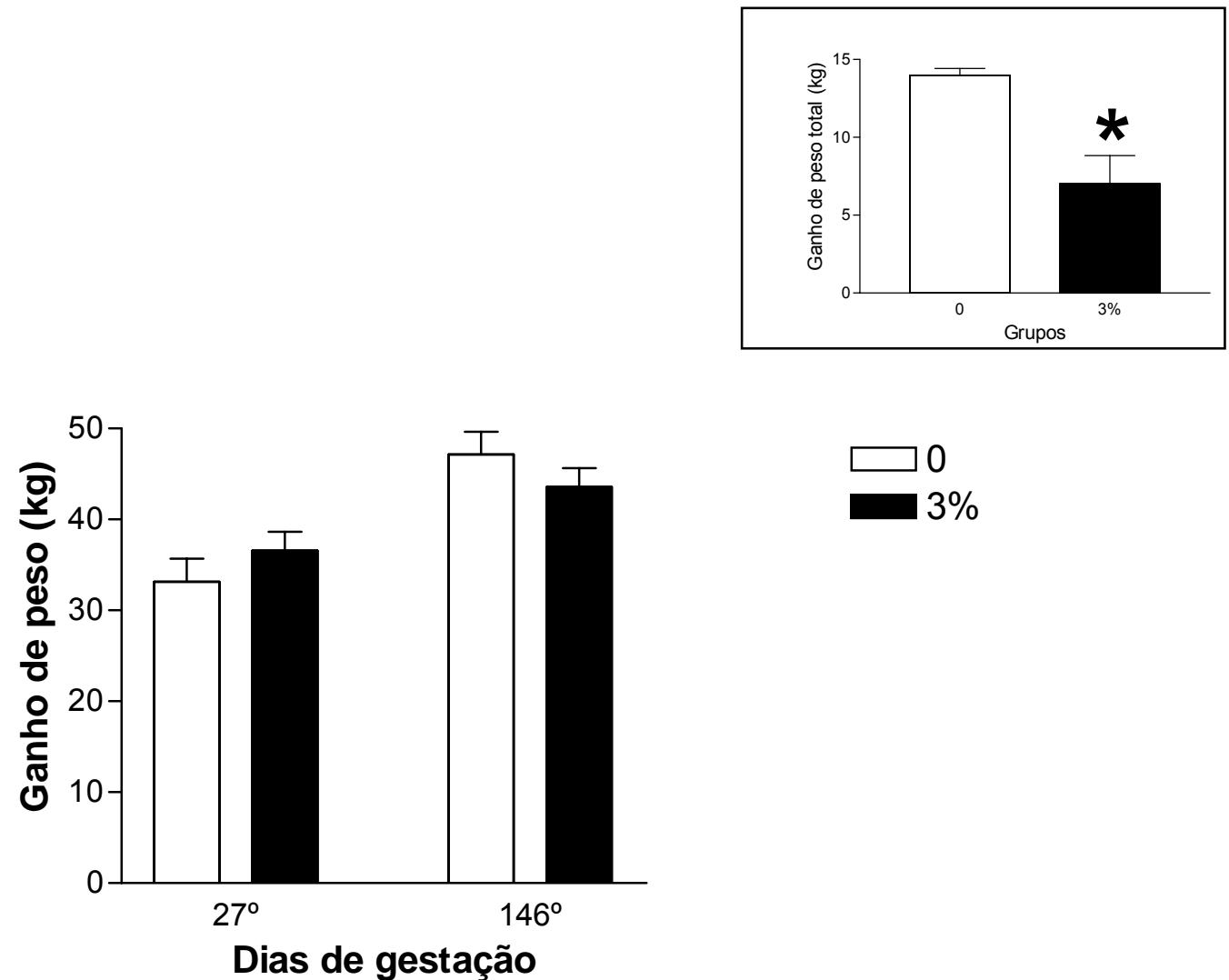

* diferença significante.Análise não paramétrica, Mann-Witney, teste $P$ de duas vias. $P=0,0095$

Figura 19 - Média do ganho de peso (kg) inicial, final e total (quadro) de cabras que consumiram ração contendo 0 e $3 \%$ de sementes de Senna occidentalis durante a gestação. São apresentadas as médias e os respectivos erros padrão, pelo método dos quadrados mínimos. 
Tabela 10 - Níveis séricos de albumina ( $\mathrm{g} / \mathrm{l})$, proteína ( $\mathrm{g} / \mathrm{dl})$, colesterol (u/l) e triglicerídeos (mg/dl), de cabras que consumiram ração contendo 0 e $3 \%$ de sementes de Senna occidentalis durante a gestação. São apresentadas as médias e os respectivos erros padrão, pelo método dos quadrados mínimos. ANOVA, seguida de teste $T$ de Student

\begin{tabular}{|c|c|c|c|}
\hline \multirow{2}{*}{ Substâncias } & \multirow{2}{*}{$\begin{array}{l}\text { Datas de } \\
\text { coleta }^{\mathrm{a}}\end{array}$} & \multicolumn{2}{|c|}{ Sementes de Senna occidentalis (\%) } \\
\hline & & 0 & $3 \%$ \\
\hline \multirow{3}{*}{$\begin{array}{l}\text { Albumina } \\
(\mathrm{g} / \mathrm{l})\end{array}$} & 4 & $3,30 \pm 0,09(4)^{b}$ & $3,27 \pm 0,08(6)$ \\
\hline & 12 & $3,28 \pm 0,09(4)$ & $3,06 \pm 0,08(6)$ \\
\hline & 18 & $3,32 \pm 0,12(3)$ & $2,80 \pm 0,08(3)$ \\
\hline \multirow{4}{*}{$\begin{array}{l}\text { Proteína } \\
(\mathrm{g} / \mathrm{dl})\end{array}$} & 4 & $6,78 \pm 0,18(4)$ & $6,57 \pm 0,18(6)$ \\
\hline & 12 & $6,74 \pm 0,18(4)$ & $6,22 \pm 0,18(6)$ \\
\hline & 18 & $6,88 \pm 0,26(3)$ & $5,81 \pm 0,26(3)$ \\
\hline & 4 & $106,97 \pm 12,16(4)$ & $109,53 \pm 9,93(6)$ \\
\hline \multirow[t]{2}{*}{ Colesterol (mg/dl) } & 12 & $113,00 \pm 12,16(4)$ & $93,39 \pm 9,93(6)$ \\
\hline & 18 & $92,19 \pm 13,35(3)$ & $96,47 \pm 12,63(3)$ \\
\hline \multirow{3}{*}{$\begin{array}{l}\text { Triglicerídeos } \\
\qquad(\mathrm{mg} / \mathrm{dl})\end{array}$} & 4 & $41,09 \pm 21,50(4)$ & $46,27 \pm 15,22(6)$ \\
\hline & 12 & $85,10 \pm 18,64(4)$ & $97,87 \pm 15,22(6)$ \\
\hline & 18 & $38,69 \pm 21,50(3)$ & $101,09 \pm 21,42(3)$ \\
\hline
\end{tabular}



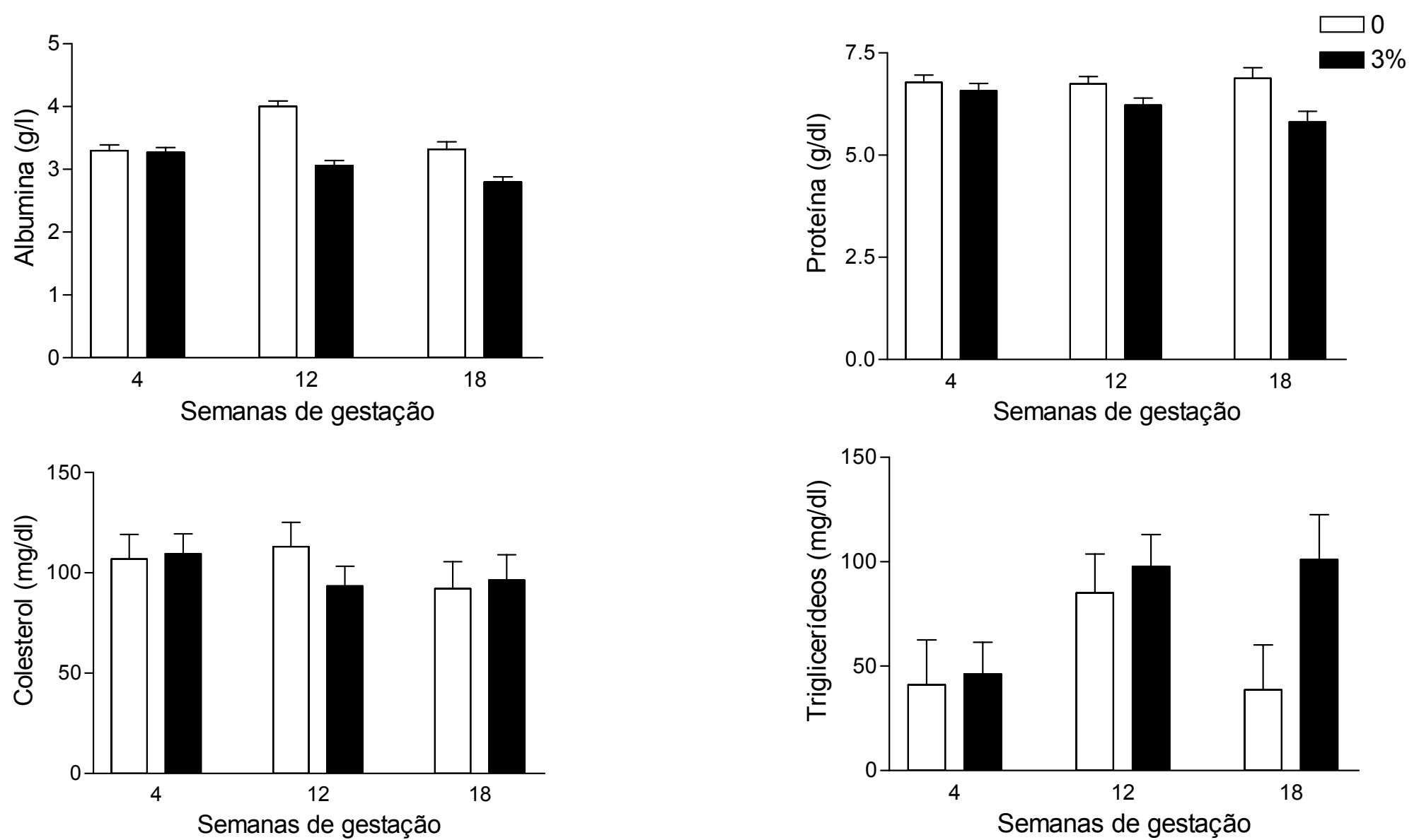

Figura 20 - Níveis séricos de albumina ( $\mathrm{g} / \mathrm{l})$, proteína $(\mathrm{g} / \mathrm{dl})$, colesterol $(\mathrm{mg} / \mathrm{dl})$ e triglicerídeos $(\mathrm{mg} / \mathrm{dl})$, de cabras que consumiram ração contendo 0 e $3 \%$ de sementes de Senna occidentalis durante a gestação. São apresentadas as médias e os respectivos erros padrão, pelo método dos quadrados mínimos. ANOVA, seguida de teste T de Student 
Tabela 11 - Níveis séricos de glicose (mg/dl), e atividade de GGT (u/l), AST (u/l) e LDH (u/l) de cabras que consumiram ração contendo 0 e $3 \%$ de sementes de Senna occidentalis durante a gestação. São apresentadas as médias e os respectivos erros padrão, pelo método dos quadrados mínimos. ANOVA, seguida de teste T de Student

\begin{tabular}{cccc}
\hline \multirow{2}{*}{ Substâncias } & $\begin{array}{c}\text { Datas de } \\
\text { coleta }^{\mathrm{a}}\end{array}$ & \multicolumn{2}{c}{ Sementes de Senna occidentalis (\%) } \\
\cline { 3 - 4 } Glicose & 4 & $\mathbf{0}$ & $\mathbf{3}$ \\
(mg/dl) & 12 & $46,05 \pm 9,82(4)^{\mathrm{b}}$ & $70,24 \pm 9,82(6)$ \\
& 18 & $45,05 \pm 9,82(4)$ & $46,09 \pm 9,82(6)$ \\
& & $17,91 \pm 13,80(3)$ & $33,32 \pm 13,71(3)$ \\
GGT & 4 & $18,09 \pm 1,83(4)$ & $17,20 \pm 1,49(6)$ \\
$(\mathrm{U} / \mathrm{l})$ & 12 & $18,29 \pm 1,83(4)$ & $16,90 \pm 1,49(6)$ \\
& 18 & $19,15 \pm 1,97(3)$ & $16,26 \pm 1,82(3)$ \\
& & & \\
AST & 4 & $73,70 \pm 7,49(4)$ & $70,73 \pm 6,12(6)$ \\
$(\mathrm{U} / \mathrm{l})$ & 12 & $76,82 \pm 7,49(4)$ & $79,45 \pm 6,12(6)$ \\
& 18 & $83,10 \pm 8,33(3)$ & $77,34 \pm 7,99(3)$ \\
& & & $467,17 \pm 68,60(6)$ \\
LDH & 4 & $517,25 \pm 84,02(4)$ & $476,83 \pm 68,60(6)$ \\
$(\mathrm{U} / \mathrm{ll})$ & 12 & $418,75 \pm 84,02(4)$ & $463,16 \pm 81,34(3)$
\end{tabular}



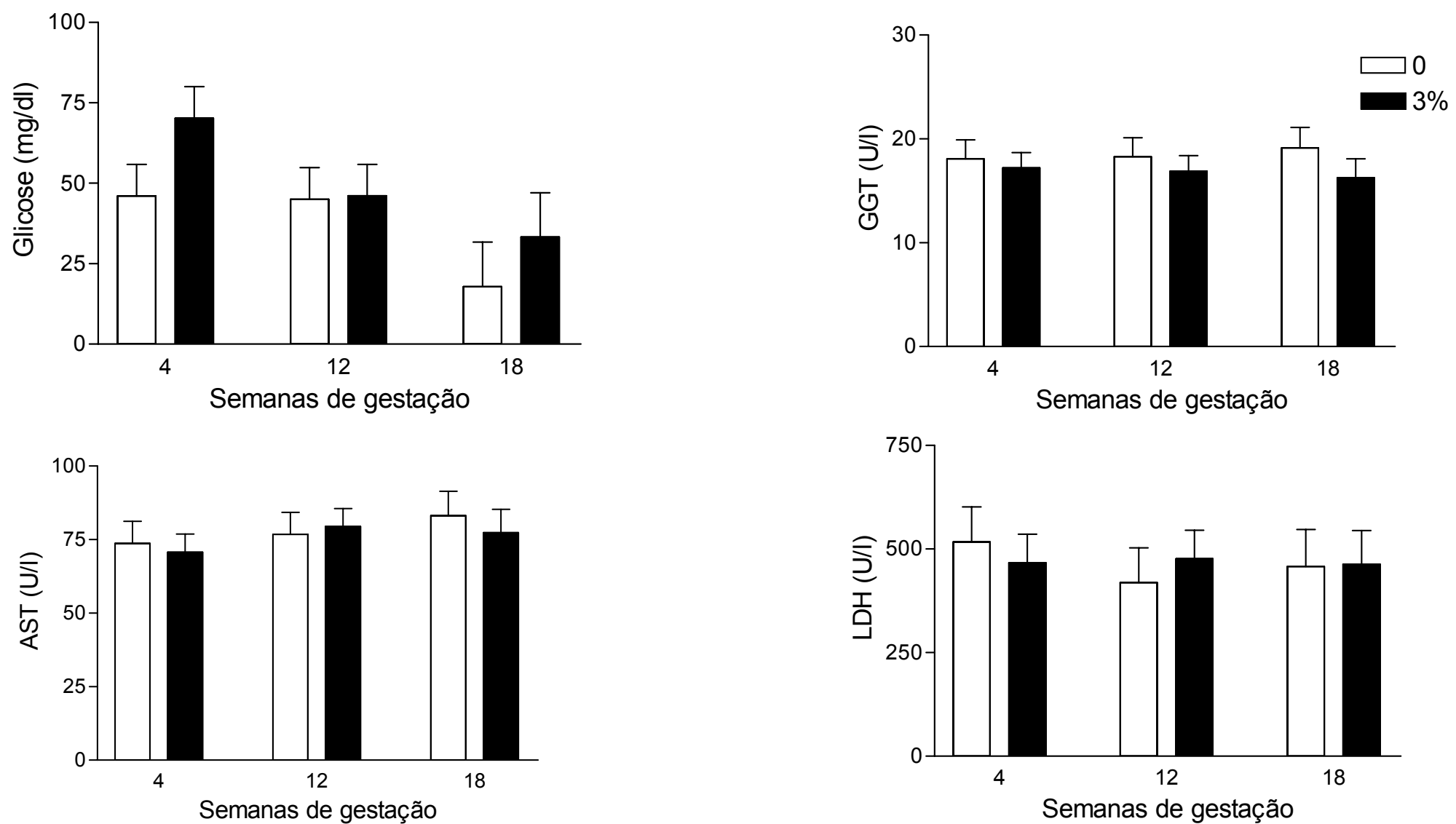

Figura 21 - Níveis séricos de glicose (mg/dl), e atividade de GGT (U/l), AST (U/l) e LDH (U/l) de cabras que consumiram ração contendo 0 e $3 \%$ de sementes de Senna occidentalis durante a gestação. São apresentadas as médias e os respectivos erros padrão, pelo método dos quadrados mínimos. ANOVA, seguida de teste T de Student 
Tabela 12 - Atividade sérica de CK (U/l), FA (U/l) e níveis séricos de creatinina (U/l) e uréia (mg/dl) de cabras que consumiram ração contendo 0 e $3 \%$ de sementes de Senna occidentalis durante a gestação. São apresentadas as médias e os respectivos erros padrão, pelo método dos quadrados mínimos. ANOVA, seguida de teste T de Student

\begin{tabular}{|c|c|c|c|}
\hline \multirow{2}{*}{ Substâncias } & \multirow{2}{*}{ Datas de coleta ${ }^{a}$} & \multicolumn{2}{|c|}{ Sementes de Senna occidentalis (\%) } \\
\hline & & 0 & 3 \\
\hline \multirow{3}{*}{$\begin{array}{l}\text { CK } \\
(\mathrm{U} / \mathrm{I})\end{array}$} & 4 & $35,62 \pm 6,15(4)^{b}$ & $41,02 \pm 5,02(6)$ \\
\hline & 12 & $35,82 \pm 6,15(4)$ & $37,62 \pm 5,02(6)$ \\
\hline & 18 & $34,48 \pm 7,10(3)$ & $30,90 \pm 1,82(3)$ \\
\hline \multirow{3}{*}{$\begin{array}{l}\text { FA } \\
(\mathrm{U} / \mathrm{I})\end{array}$} & 4 & $811,25 \pm 145,56(4)$ & $634,50 \pm 118,85(6)$ \\
\hline & 12 & $873,50 \pm 145,56(4)$ & $472,17 \pm 118,85(6)$ \\
\hline & 18 & $147,61 \pm 165,00(3)$ & $285,83 \pm 161,86(3)$ \\
\hline \multirow{3}{*}{$\begin{array}{l}\text { Creatinina } \\
\quad(U / I)\end{array}$} & 4 & $1,21 \pm 0,06(4)$ & $0,99 \pm 0,05(6)$ \\
\hline & 12 & $1,15 \pm 0,06(4)$ & $1,04 \pm 0,05(6)$ \\
\hline & 18 & $1,40 \pm 0,07(3)$ & $1,06 \pm 0,07(3)$ \\
\hline \multirow{3}{*}{$\begin{array}{l}\text { Uréia } \\
\text { (mg/dl) }\end{array}$} & 4 & $33,06 \pm 4,54(4)$ & $45,04 \pm 3,70(6)$ \\
\hline & 12 & $42,10 \pm 4,54(4)$ & $44,55 \pm 3,70(6)$ \\
\hline & 18 & $40,63 \pm 5,13(3)$ & $38,15 \pm 5,02(3)$ \\
\hline
\end{tabular}

a meses da gestação, quando as cabras começaram a ser mensuradas, logo após a detecção da prenhez.

${ }^{b}$ entre parênteses o número de animais estudados. 

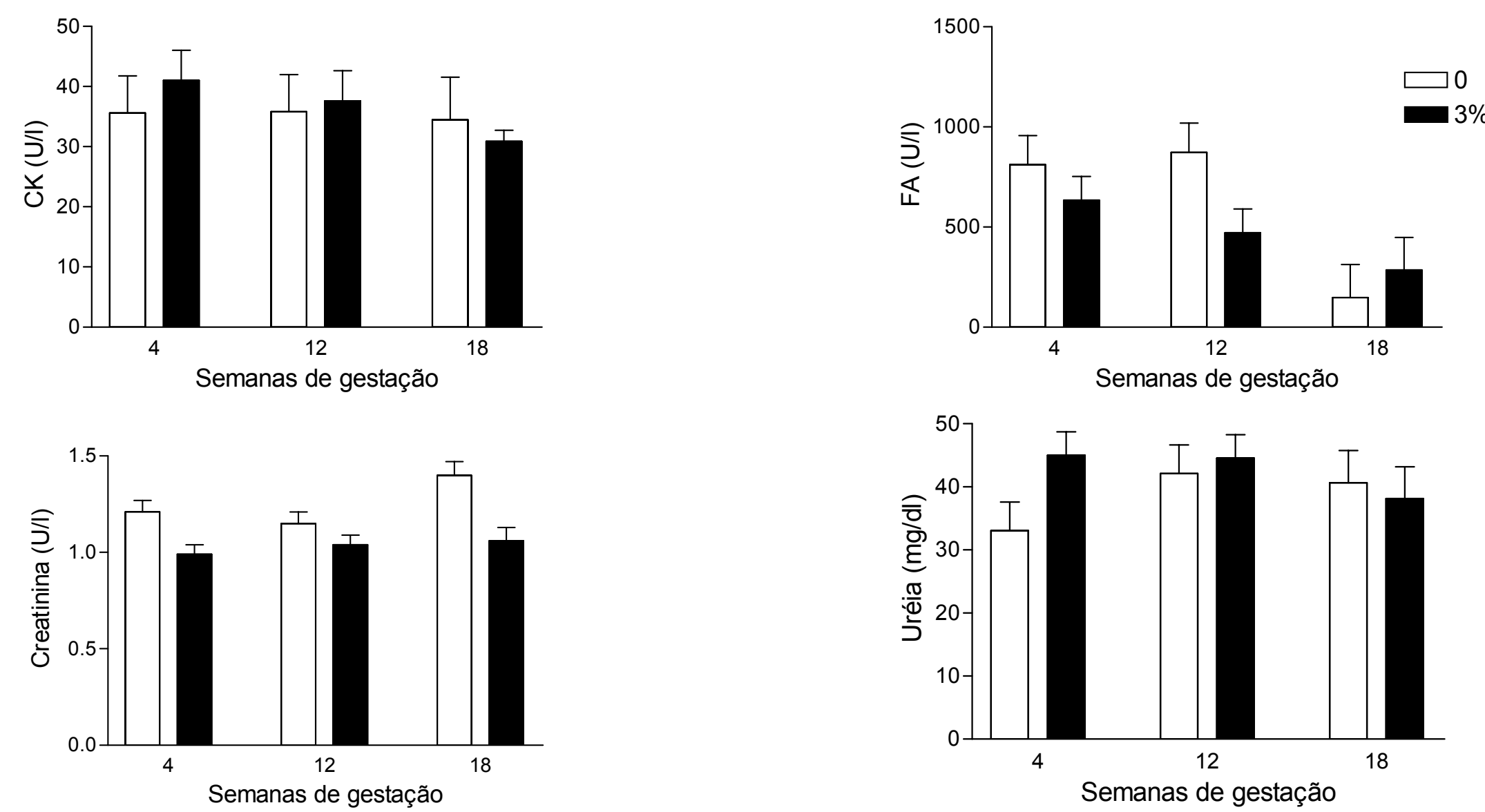

Figura 22 - Atividade sérica de CK (U/l), FA (U/l) e níveis séricos de creatinina (U/l) e uréia (mg/dl) de cabras que consumiram ração contendo 0 e $3 \%$ de sementes de Senna occidentalis durante a gestação. São apresentadas as médias e os respectivos erros padrão, pelo método dos quadrados mínimos. ANOVA, seguida de teste T de Student 
Tabela 13 - Parâmetros ultra-sonográficos de cabras que consumiram ração contendo 0 e $3 \%$ de sementes de Senna occidentalis durante a gestação. Freqüência cardíaca (FC), movimento fetal (MF) e comprimento crânio caudal (CCC). São apresentadas as médias e os respectivos erros padrão, pelo método dos quadrados mínimos. ANOVA seguida de teste $T$ de Student

\begin{tabular}{cccc}
\hline \multirow{2}{*}{ Mensurações } & $\begin{array}{c}\text { Datas de coleta } \\
\text { (dias) }\end{array}$ & \multicolumn{2}{c}{ Sementes de Senna occidentalis (\%) } \\
\cline { 3 - 4 } & $35^{\circ}$ & $\mathbf{0}$ & $\mathbf{3}$ \\
FC & $43^{\circ}$ & $141,25 \pm 8,77(4)^{\mathrm{b}}$ & $149,33 \pm 7,16(6)$ \\
& $69^{\circ}$ & $165,00 \pm 8,77(4)$ & $160,17 \pm 7,16(6)$ \\
& & $158,50 \pm 8,77(4)$ & $142,00 \pm 7,16(6)$ \\
MF & $35^{\circ}$ & & \\
$(\min )$ & $43^{\circ}$ & $0,75 \pm 0,75(4)$ & $0,50 \pm 0,61(6)$ \\
& $69^{\circ}$ & $3,00 \pm 0,75(4)$ & $2,50 \pm 0,61(6)$ \\
CCC & $35^{\circ}$ & $3,25 \pm 0,75(4)$ & $2,50 \pm 0,61(6)$ \\
$(\mathrm{cm})$ & $43^{\circ}$ & $1,45 \pm 0,29(4)$ & $1,86 \pm 0,24(6)$ \\
\hline
\end{tabular}

a dias da gestação, quando as cabras começaram a ser mensuradas, logo após a detecção da prenhez.

entre parênteses o número de animais estudados. 

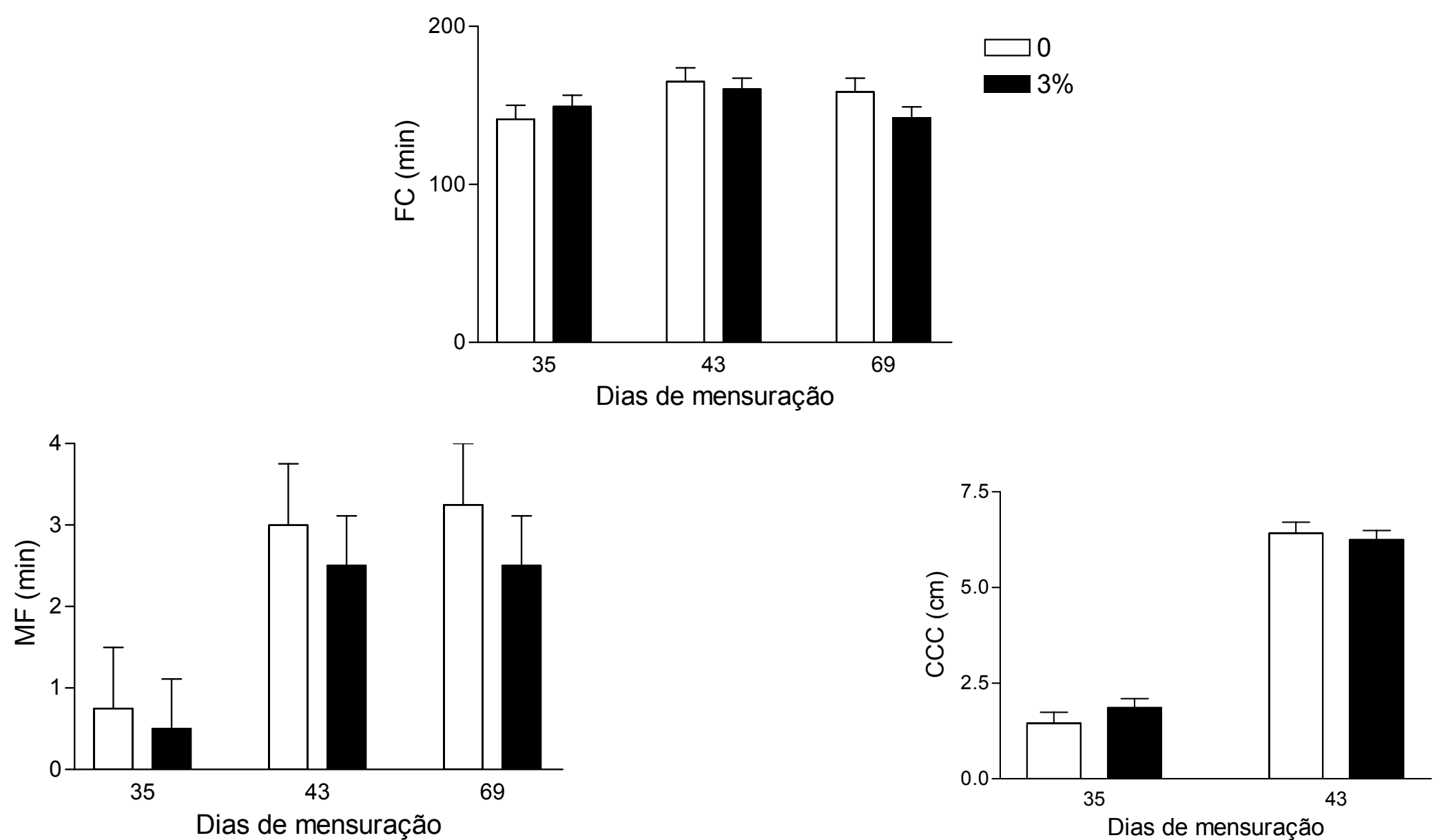

Figura 23 - Parâmetros ultrassonográficos de cabras que consumiram ração contendo 0 e $3 \%$ de sementes de Senna occidentalis durante a gestação. Freqüência cardíaca (FC), movimento fetal (MF) e comprimento crânio caudal (CCC). São apresentadas as médias e os respectivos erros padrão, pelo método dos quadrados mínimos. ANOVA, seguida de teste T de Student 
Tabela 14 - Parâmetros ultrassonográficos de cabras que consumiram ração contendo 0 e $3 \%$ de sementes de Senna occidentalis durante a gestação. Diâmetro abdominal (DA), diâmetro torácico (DT) e diâmetro biparietal (DBP). São apresentadas as médias e os respectivos erros padrão, pelo método dos quadrados mínimos. ANOVA seguida de teste T de Student

\begin{tabular}{cccc}
\hline \multirow{2}{*}{ Medidas } & Datas de coleta $^{\mathrm{a}}$ & \multicolumn{2}{c}{ Sementes de Senna occidentalis (\%) } \\
\cline { 3 - 4 } & & $\mathbf{0}$ & $\mathbf{3}$ \\
\hline DA & $43^{\circ}$ & $1,70 \pm 0,31(4)^{\mathrm{b}}$ & $1,83 \pm 0,25(6)$ \\
$(\mathrm{cm})$ & $69^{\circ}$ & $2,34 \pm 0,31(4)$ & $2,60 \pm 0,25(6)$ \\
& & & \\
DT & $43^{\circ}$ & $1,78 \pm 0,81(4)$ & $1,58 \pm 0,07(6)$ \\
$(\mathrm{cm})$ & $69^{\circ}$ & $1,78 \pm 0,81(4)$ & $1,58 \pm 0,07(6)$ \\
DBP & $43^{\circ}$ & $1,33 \pm 0,92(4)$ & $1,62 \pm 0,07(6)$ \\
$(\mathrm{CM})$ & $69^{\circ}$ & $2,58 \pm 0,92(4)$ & $2,35 \pm 0,07(6)$ \\
\hline adias da gestação, quando as cabras começaram a ser mensuradas, logo após a deteccão da prenhez.
\end{tabular}

a dias da gestação, quando as cabras começaram a ser mensuradas, logo após a detecção da prenhez. 

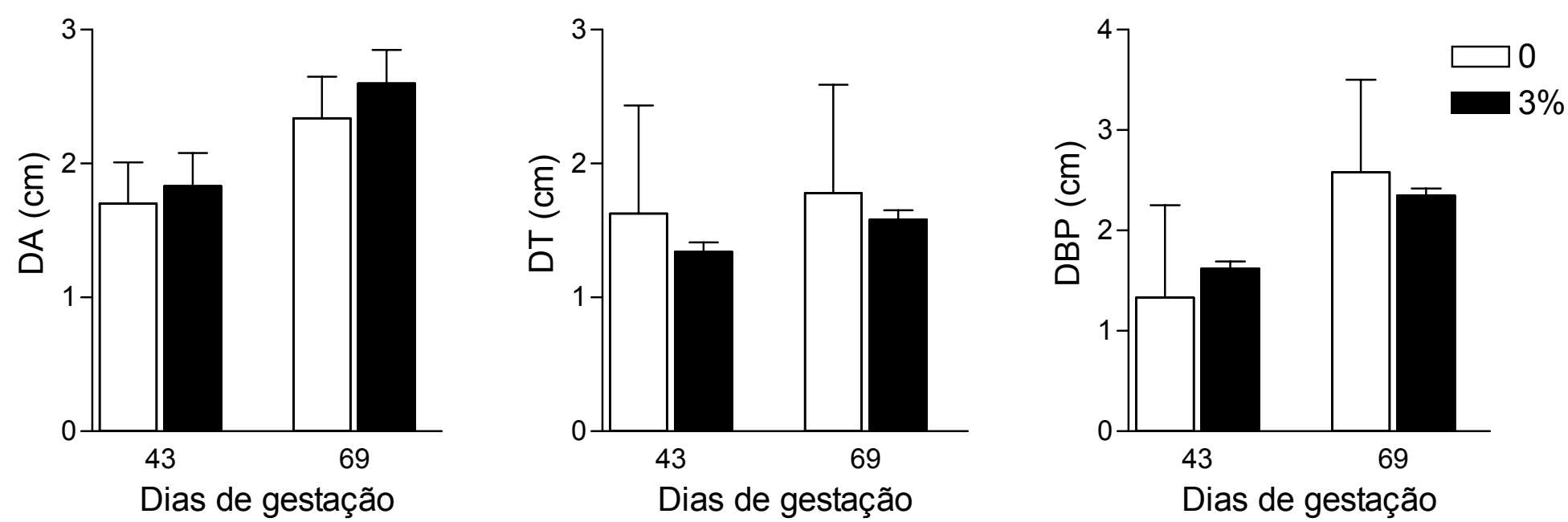

Figura 24 - Parâmetros ultrassonográficos de cabras que consumiram ração contendo 0 e $3 \%$ de sementes de Senna occidentalis durante a gestação. Diâmetro abdominal (DA), diâmetro torácico (DT) e diâmetro biparietal (DBP). São apresentadas as médias e os respectivos erros padrão, pelo método dos quadrados mínimos. ANOVA, seguida de teste $T$ de Student 


\subsection{EXPERIMENTO 2: ESTUDO DOS EFEITOS TÓXICOS PRODUZIDOS PELA S. occidentalis ADMINISTRADO A CABRAS LACTANTES}

Em relação ao peso médio mensal destes animais, as análises de covariância realizadas (ANCOVA) revelaram não haver diferenças significantes $(P>0,05)$, entre os valores obtidos dos diferentes grupos, (Tabela 15 e Figura 25).

A ANOVA revelou NÃO haver diferenças significantes $(P>0,05)$ em nenhum dos parâmetros bioquímicos avaliados (Tabelas 16 a 18 e Figuras 26 a 28).

Não se observou nenhum sintoma de intoxicação por S. occidentalis durante o período do experimento.

A análise histológica dos tecidos das mães do grupo LAC revelou haver lesões discretas, pouco severas e focais das células epiteliais dos túbulos contornados proximais (Figura 29 A e B), necrose focal com desorganização de sarcolema, edema e invasão de células inflamatórias em musculatura esquelética (Figura $29 \mathrm{C}$ e D), além de necrose focal com edema intersticial e tumefação de fibra muscular cardíaca (Figura 30). 
Tabela 15 - Ganho de peso médio $(\mathrm{kg})$ inicial, final e total de cabras que receberam ração contendo 0 e $4 \%$ de sementes de Senna occidentalis durante a lactação. São apresentadas as médias e os respectivos erros padrão, pelo método dos quadrados mínimos. ANCOVA, seguida de teste T de Student

\begin{tabular}{lcc}
\hline \multirow{2}{*}{ Dias de coleta } & \multicolumn{2}{c}{ Grupos } \\
\cline { 2 - 3 } & Controle & LAC \\
\hline $27^{\circ}$ & $33,07 \pm 3,76(4)^{\mathrm{a}}$ & $32,40 \pm 1,48(4)$ \\
$146^{\circ}$ & $47,52 \pm 4,02(4)$ & $49,26 \pm 3,10(4)$ \\
Total & $14,46 \pm 3,84(4)$ & $16,86 \pm 2,13(4)$ \\
\hline
\end{tabular}
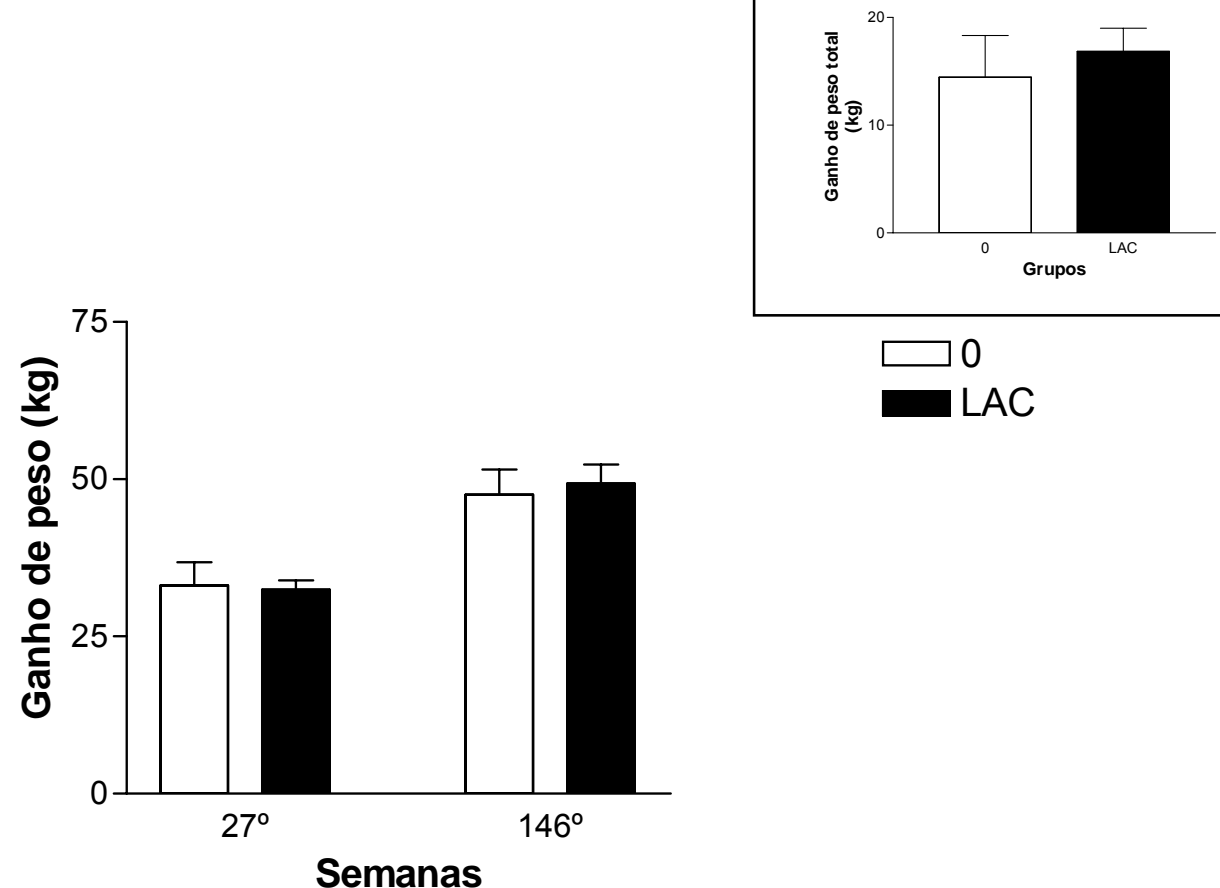

Figura 25 - Pesos médios $(\mathrm{kg})$ iniciais, finais e totais (quadro) de cabras que receberam ração contendo 0 e $4 \%$ de sementes de Senna occidentalis durante a lactação. São apresentadas as médias e os respectivos erros padrão, pelo método dos quadrados mínimos. ANCOVA, seguida de teste T de Student 
Tabela 16 - Níveis séricos de albumina $(\mathrm{g} / \mathrm{l})$, colesterol $(\mathrm{u} / \mathrm{l})$, uréia $(\mathrm{mg} / \mathrm{dl})$ e creatinina $(\mathrm{u} / \mathrm{l})$ de cabras que receberam ração contendo 0 e $4 \%$ de sementes de Senna occidentalis durante a lactação. São apresentados as médias e os respectivos erros padrão. ANOVA, seguida de teste $T$ de Student. Os dados são apresentados através do método dos quadrados mínimos

\begin{tabular}{cccc}
\hline \multirow{2}{*}{ Substâncias } & $\begin{array}{c}\text { Datas de } \\
\text { coleta }^{\mathrm{a}}\end{array}$ & \multicolumn{2}{c}{ Sementes de Senna occidentalis (\%) } \\
\cline { 3 - 4 } & 1 & $2,99 \pm 0,30(4)^{\mathrm{b}}$ & LAC \\
\hline $\begin{array}{c}\text { Albumina } \\
\text { (g/l) }\end{array}$ & 5 & $3,85 \pm 0,30(4)$ & $3,85 \pm 0,30(4)$ \\
& 8 & $3,99 \pm 0,30(4)$ & $3,66 \pm 0,30(4)$ \\
& 1 & $68,7 \pm 23,6(4)$ & $97,2 \pm 23,6(4)$ \\
Colesterol (u/l) & 5 & $152,0 \pm 23,6(4)$ & $107,7 \pm 23,6(4)$ \\
& 8 & $173,7 \pm 23,6(4)$ & $111,4 \pm 23,6(4)$ \\
Uréia & & & $17,99 \pm 5,15(4)$ \\
(mg/dl) & 1 & $31,61 \pm 5,15(4)$ & $28,71 \pm 5,15(4)$ \\
& 5 & $31,32 \pm 5,15(4)$ & $17,61 \pm 5,15(4)$ \\
& 8 & $38,92 \pm 5,15(4)$ & $1,01 \pm 0,07(4)$ \\
Creatinina & & & $0,86 \pm 0,07(4)$ \\
(u/l) & 1 & $0,84 \pm 0,07(4)$ & $0,95 \pm 0,07(4)$ \\
\hline
\end{tabular}



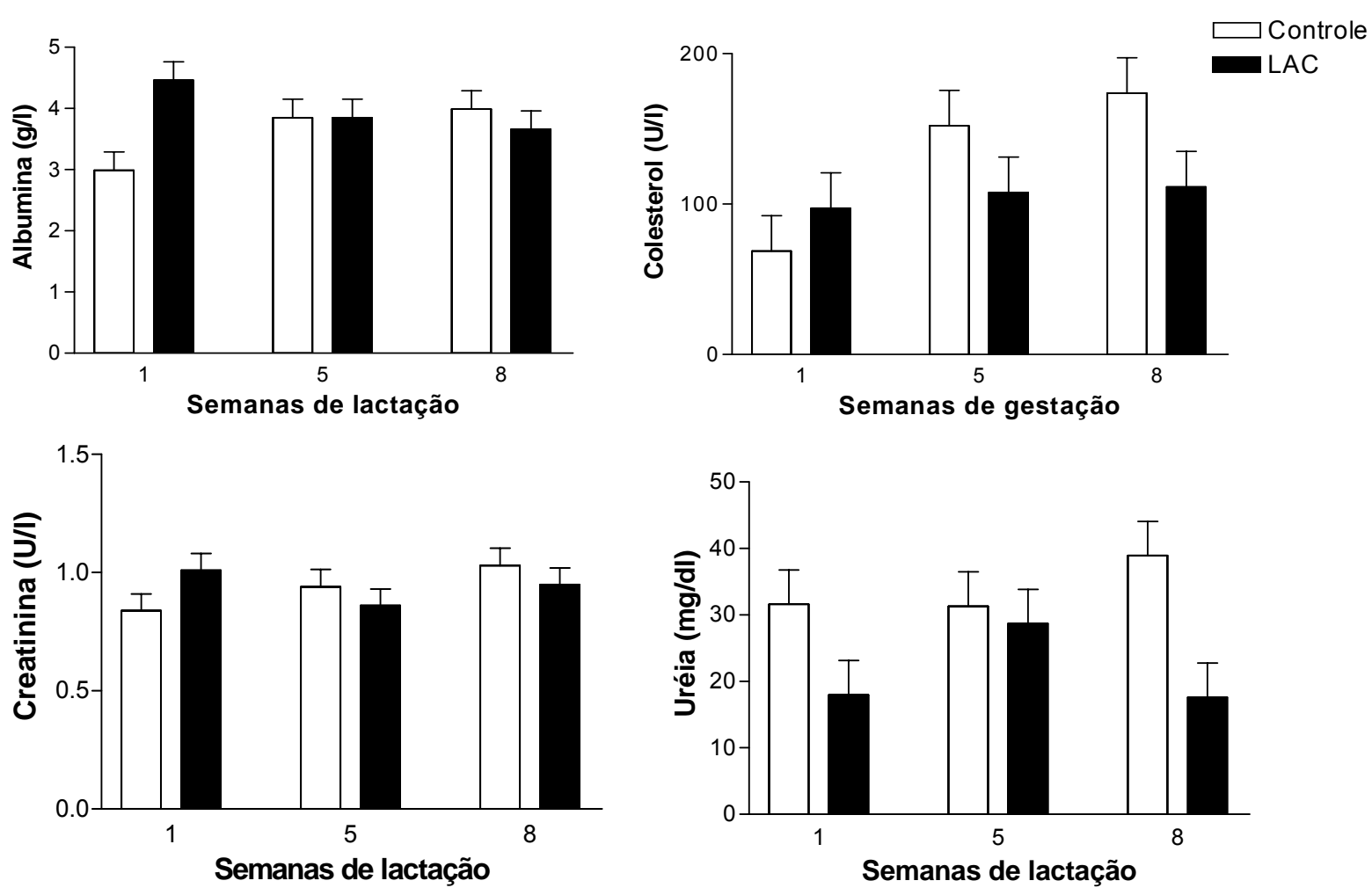

Figura 26 - Níveis séricos de albumina (g/l), colesterol (U/l), aldolase (U/I) e creatinina (U/l) de cabras que consumiram ração contendo 0 e $4 \%$ de sementes de Senna occidentalis durante a lactação. São apresentadas as médias e os respectivos erros padrão. ANOVA, seguida de teste $T$ de Student. Os dados são apresentados através do método dos quadrados mínimos 
Tabela 17 - Níveis séricos de glicose (mg/dl), GGT (u/l), AST (u/l) e LDH (u/l) de cabras que consumiram ração contendo 0 e $4 \%$ de sementes de Senna occidentalis durante a lactação. São apresentadas as médias e os respectivos erros padrão. ANOVA, seguida de teste $T$ de Student. Os dados são apresentados através do método dos quadrados mínimos

\begin{tabular}{cccc}
\hline \multirow{2}{*}{ Substâncias } & $\begin{array}{c}\text { Datas de } \\
\text { coleta }^{\mathrm{a}}\end{array}$ & \multicolumn{2}{c}{ Sementes de Senna occidentalis (\%) } \\
\cline { 2 - 4 } Glicose & 1 & $36,49 \pm 5,6(4)^{\mathrm{b}}$ & $31,42 \pm 5,6(4)$ \\
(mg/dl) & 5 & $32.56 \pm 5,6(4)$ & $39,05 \pm 5,6(4)$ \\
& 8 & $64,55 \pm 5,6(4)$ & $49,11 \pm 5,6(4)$ \\
GGT & 1 & $43,90 \pm 3,99(4)$ & $45,65 \pm 3,99(4)$ \\
(U/l) & 5 & $68,08 \pm 3,99(4)$ & $59,17 \pm 3,99(4)$ \\
& 8 & $77,47 \pm 3,99(4)$ & $68,72 \pm 3,99(4)$ \\
AST & 1 & & \\
(U/l) & 5 & $74,77 \pm 8,95(4)$ & $84,40 \pm 8,95(4)$ \\
& 8 & $85,90 \pm 8,95(4)$ & $118,65 \pm 8,95(4)$ \\
& & $90,75 \pm 8,95(4)$ & $102,28 \pm 8,95(4)$ \\
LDH & 1 & & $157,5 \pm 74,0(4)$ \\
$(U / I)$ & 5 & $143,2 \pm 74,0(4)$ & $249,5 \pm 74,0(4)$ \\
& 8 & $360,5 \pm 74,0(4)$ & $267,7 \pm 74,0(4)$ \\
\hline
\end{tabular}



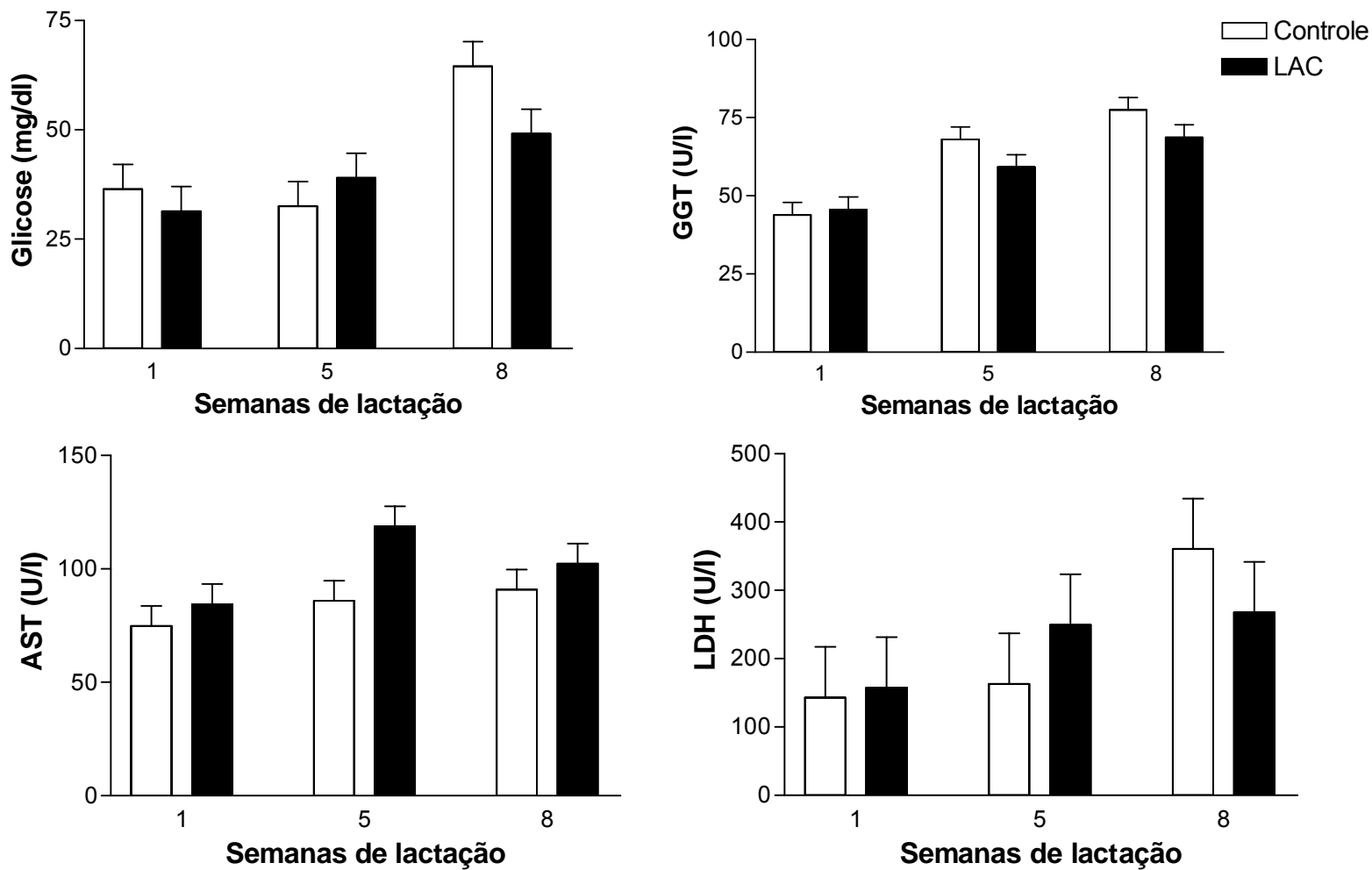

Figura 27 - Níveis séricos de glicose (mg/dl), GGT (u/l), AST (u/l) e LDH (u/l) de cabras que consumiram ração contendo 0 e $4 \%$ de sementes de Senna occidentalis durante a lactação. São apresentadas as médias e os respectivos erros padrão. ANOVA, seguida de teste $T$ de Student. Os dados são apresentados através do método dos quadrados mínimos 
Tabela 18 - Níveis séricos de CK (U/l), proteína (g/dl) e uréia (mg/dl) de cabras que consumiram ração contendo 0 e $4 \%$ de sementes de Senna occidentalis durante a lactação. São apresentados as médias e os respectivos erros padrão. ANOVA, seguida de teste T de Student. Os dados são apresentados através do método dos quadrados mínimos

\begin{tabular}{cccc}
\hline \multirow{2}{*}{ Substâncias } & \begin{tabular}{c} 
Datas de $^{*}$ coleta $^{\mathrm{a}}$ \\
\cline { 2 - 4 }
\end{tabular} & \multicolumn{2}{c}{ Sementes de Senna occidentalis (\%) } \\
\cline { 3 - 4 } CK & 1 & $19,5 \pm 5,3(4)^{\mathrm{b}}$ & $24,25 \pm 5,3(4)$ \\
$(\mathrm{U} / \mathrm{l})$ & 5 & $26,25 \pm 5,3(4)$ & $22,00 \pm 5,3(4)$ \\
& 8 & $42,00 \pm 5,3(4)$ & $29,25 \pm 5,3(4)$ \\
& & & \\
Proteína & 1 & $4,71 \pm 0,32(4)$ & $5,05 \pm 0,32(4)$ \\
(g/dl) & 5 & $5,95 \pm 0,32(4)$ & $5,95 \pm 0,32(4)$ \\
& 8 & $6,49 \pm 0,32(4)$ & $6,26 \pm 0,32(4)$ \\
Aldolase & 1 & $4,84 \pm 1,0(4)$ & $3,05 \pm 1,0(4)$ \\
(u/l) & 5 & $5,57 \pm 1,2(4)$ & $3,91 \pm 1,0(4)$ \\
& 8 & $7,02 \pm 1,0(4)$ & $5,49 \pm 1,0(4)$ \\
\hline
\end{tabular}

Semanas da lactação,

b entre parênteses o número de animais estudados. 

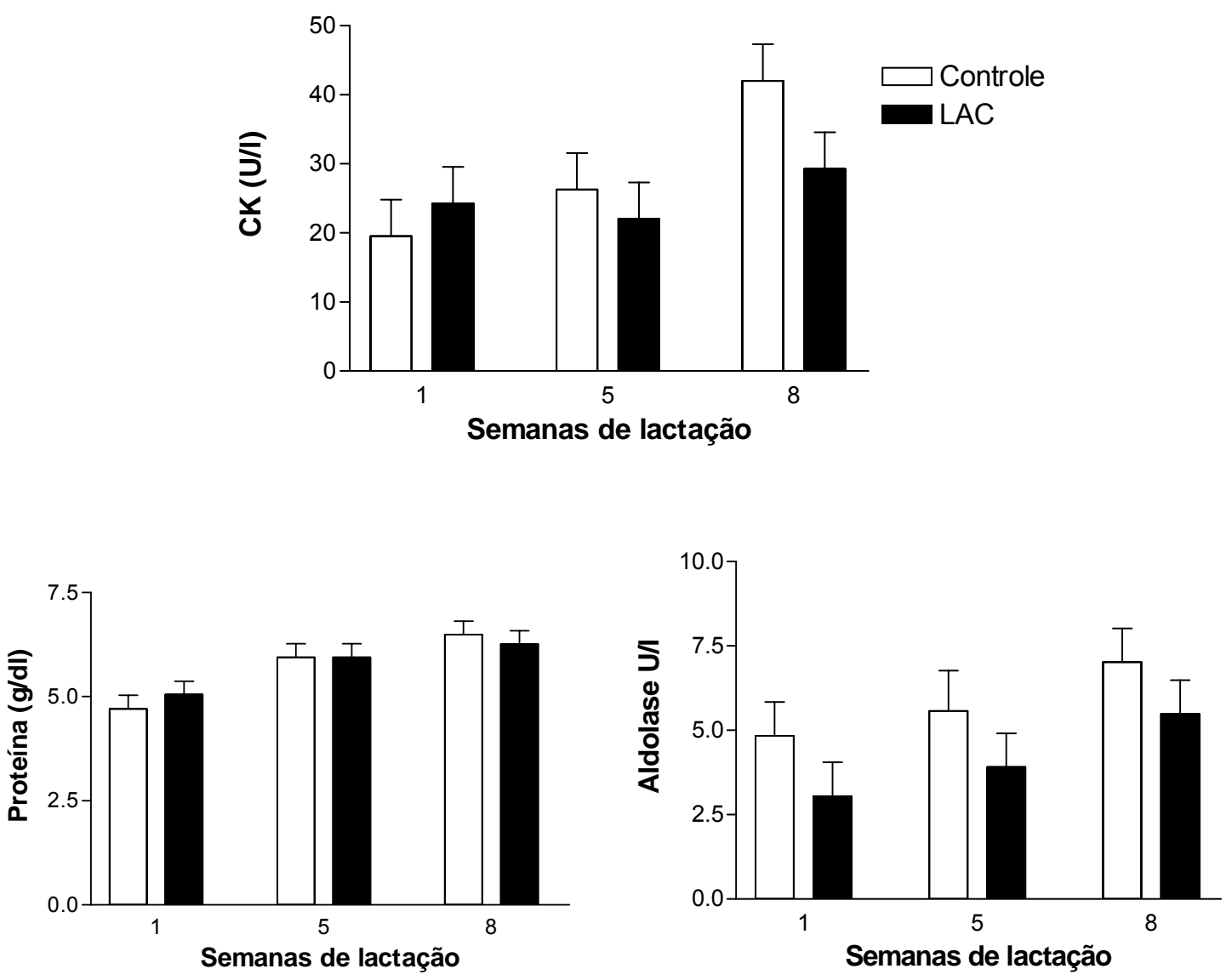

Figura 28- Níveis séricos de CK (U/l), proteína $(\mathrm{g} / \mathrm{dl})$ e aldolase $(\mathrm{mg} / \mathrm{dl})$ de cabras que consumiram ração contendo 0 e $4 \%$ de sementes de Senna occidentalis durante a lactação. São apresentadas as médias e os respectivos erros padrão. ANOVA, seguida de teste $T$ de Student. Os dados são apresentados através do método dos quadrados mínimos 


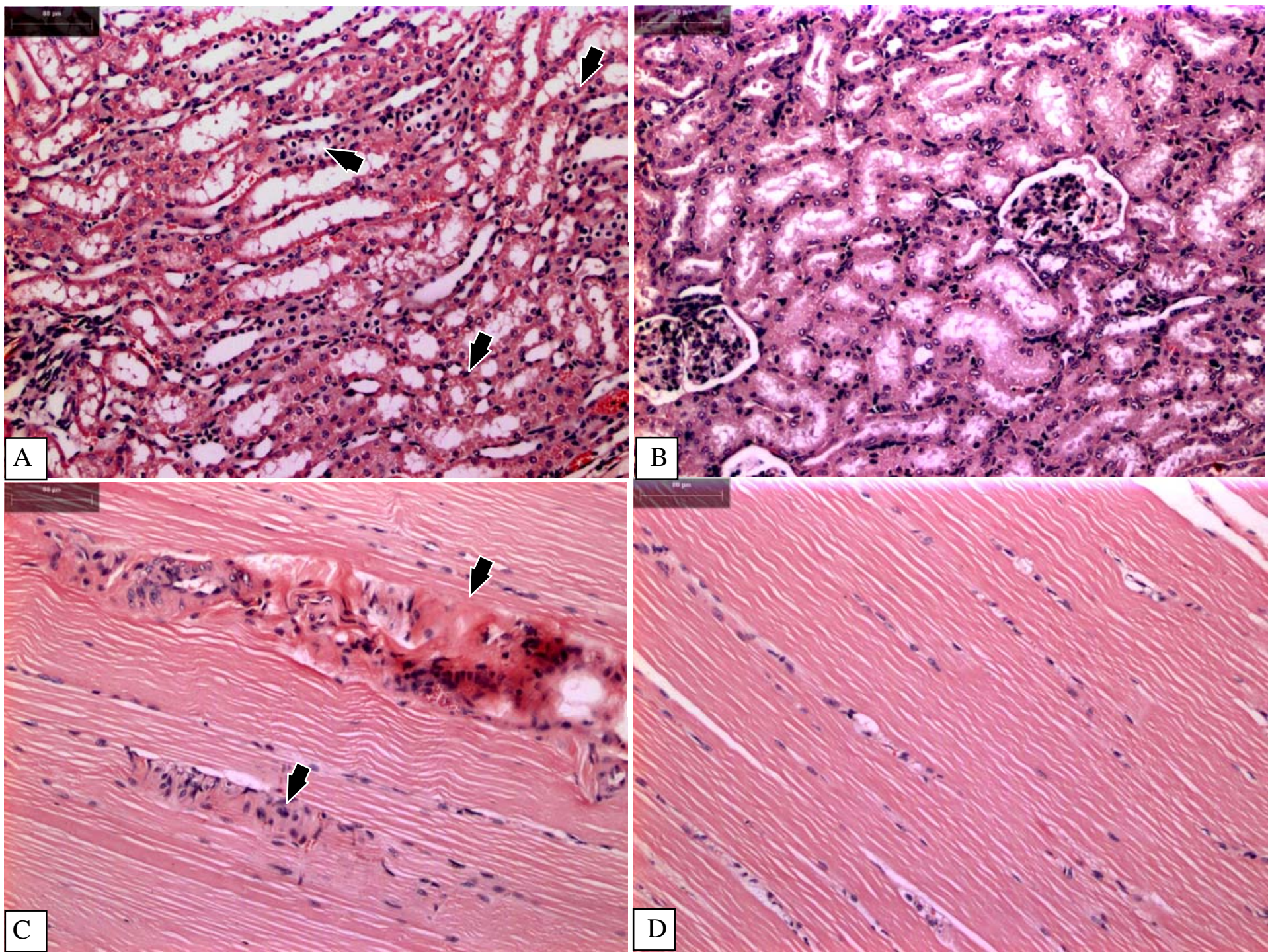

Figura 29 - Fotomicrografia de luz de rim de cabra, pertencente ao grupo LAC (A) e controle (B). Evidencia-se discreta vacuolização de epitélio de túbulo contornado (setas), HE, A: 20x. Músculo esquelético de cabra, pertencente ao grupo LAC (C) e controle (D), evidencia-se necrose com desorganização de sarcolema (setas), HE, A: 10x 


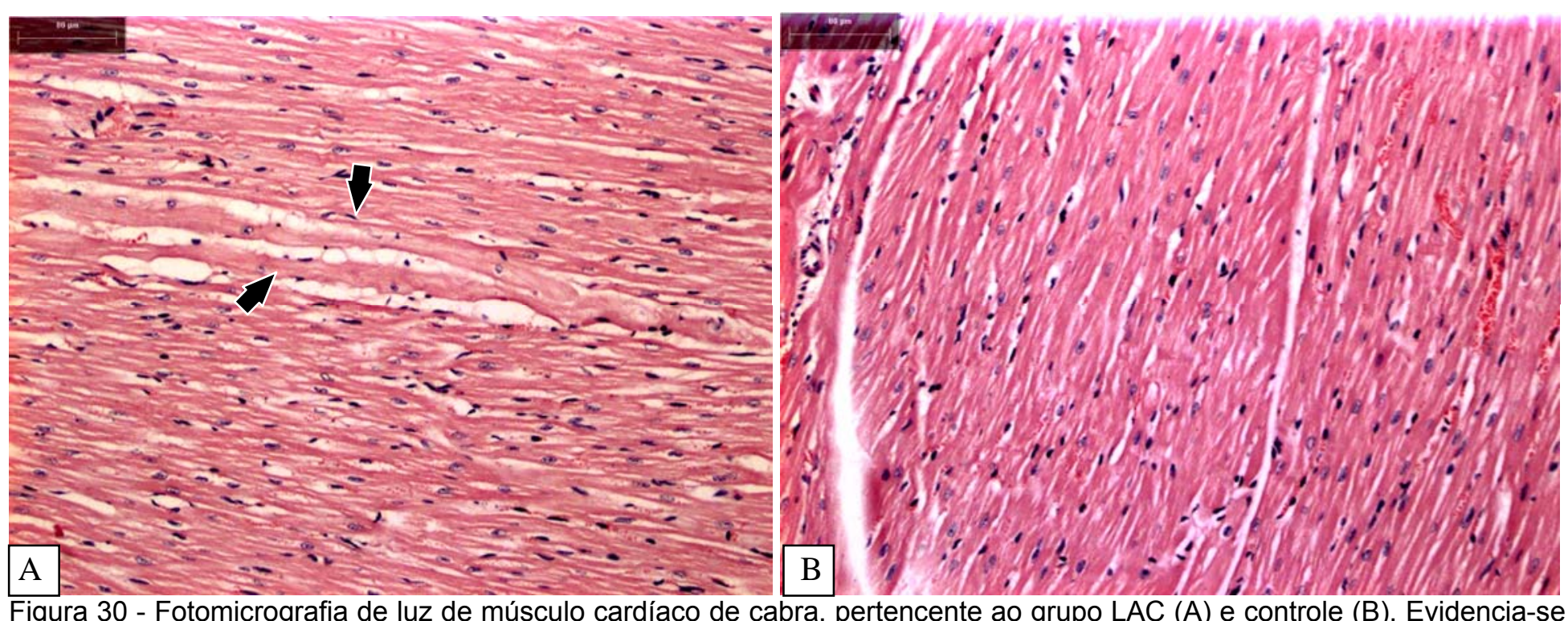

Figura 30 - Fotomicrografia de luz de músculo cardíaco de cabra, pertencente ao grupo LAC (A) e controle (B). Evidencia-se necrose focal com edema intersticial e tumefação de fibra muscular (setas), HE, A: 20x 


\subsection{EXPERIMENTO 3: ESTUDO DOS EFEITOS TÓXICOS PRODUZIDOS PELA S.} occidentalis. AVALIAÇÃO DO DESENVOLVIMENTO FÍSICO E COMPORTAMENTAL DA PROLE

Nesta sessão são apresentados os resultados dos filhotes de mães intoxicadas durante a gestação, divididos entre os grupos controle e experimentais So1e So2 no item 4.3.1. E os grupos controle e So3 no item 4.3.2.

\subsubsection{Resultados dos filhotes provenientes das cabras pertencentes aos grupos So1 e So2}

A tabela 19 mostra e a figura 31 ilustra o ganho de peso total da prole dos grupos So1 e So2. A análise de variância revelou não haver diferença significante $(P>0,05)$ entre os valores dos diferentes grupos durante o período de 4 meses após o nascimento.

Quanto aos níveis séricos de glicose, a ANOVA revelou haver diferenças significantes $(P<0,05)$ no segundo e quarto mês de gestação. $O$ subseqüente teste "T" de Student, após o uso do método dos quadrados mínimos (LSM) revelou haver diminuição significante na interação tratamento $x$ tempo, nos níveis desta substância nos animais provenientes do grupo So1 durante o primeiro mês após o nascimento, quando comparado aos animais do grupo controle $(F=3.57$ e $D F=6 / 11 ; P<0,05)$ (Tabela 20 e Figura 32).

Quanto à atividade sérica da enzima aldolase destes filhotes, a análise da variância utilizada revelou haver diferenças significantes $(P<0,05)$, nos meses 2 , 3 e 4 de observação. Após o LSM, o teste "T" de Student revelou diminuição significante na atividade desta enzima, naqueles animais do grupo So1, durante o segundo mês, aumento significante nos animais pertencentes ao grupo So2, durante o terceiro mês e diminuição neste mesmo grupo durante o quarto mês, quando comparados com aqueles resultados obtidos dos animais do grupo controle $(F=5.34$ e $D F=6 / 11$; 
$P<0,05)$ (Tabela 20 e Figura 32).

Em relação à atividade sérica da enzima GGT destes filhotes, a análise da variância utilizada revelou haver diferença significante $(P<0,05)$, no primeiro mês de observação. Após a aplicação do LSM, o teste "T" de Student revelou aumento significante $(F=4.76$ e $D F=6 / 11 ; P<0,05)$ na atividade desta enzima, naqueles animais do grupo So2 (Tabela 20 e Figura 32).

Quando submetidos ao teste ANOVA, os parâmetros bioquímicos de AST (Tabela 20 e Figura 32)LDH, FA, CK, triglicerídeos, proteína total, albumina, uréia, colinesterase, e creatinina, não revelaram alterações significantes $(P>0.05)$, em todos os grupos experimentais em relação ao grupo controle, FA, CK, LDH e triglicerídeos (Tabela 21 e Figura 33), proteína total, albumina, uréia, creatinina (Tabela 22 e Figura 34) e colinesterase (Tabela 23 e Figura 35), não revelaram alterações significantes $(P>0.05)$, em todos os grupos experimentais em relação ao grupo controle.

A avaliação da morfometria corporal, quando submetidas à ANOVA, revelou haver diferença significante no parâmetro $\mathrm{CMT}$, o subseqüente teste $\mathrm{T}$ de student indicou diferença significante $(F=2,35 ; D F=8 / 44 ; P<0,05)$, logo após o nascimento e no primeiro mês de idade, em relação aos animais pertencentes ao grupo So2, além de diferença significante entre os animais do grupo So1 e os animais do grupo controle, durante o segundo mês de mensuração (Tabela 24 e Figura 36).

Em relação a AC, CC, PT (Tabela 24 e Figura 39), CCab, DCab, CRad, CTIB (Tabela 25 e Figura 37), CMC, CIMC, CIMT (Tabela 26 e Figura 38), a análise estatística revelou não haver qualquer diferença significante $(P>0,05)$ nestes parâmetros morfométricos. 
Tabela 19 - Pesos médios $(\mathrm{kg})$ de cabritos filhos de cabras que consumiram ração contendo diferentes concentrações $(0,1 \%$ e $2 \%)$ de sementes de Senna occidentalis durante a gestação. São apresentadas as médias e os respectivos erros padrão. Análise da variância ANOVA, seguida de LSM e teste "T" de Student

\begin{tabular}{cccc}
\hline \multirow{2}{*}{ Meses de coleta } & \multicolumn{3}{c}{ Sementes de Senna occidentalis (\%) } \\
\cline { 2 - 4 } & $\mathbf{0}$ & $\mathbf{1}$ & $\mathbf{2}$ \\
\hline $0^{\mathrm{a}}$ & $4,06 \pm 0,31(7)^{\mathrm{b}}$ & $3,28 \pm 0,37(5)$ & $2,77 \pm 0,37(5)$ \\
1 & $8,71 \pm 0,44(7)$ & $7,96 \pm 0,53(5)$ & $8,00 \pm 0,53(5)$ \\
2 & $12,76 \pm 1,38(7)$ & $11,47 \pm 1,65(5)$ & $13,55 \pm 1,65(5)$ \\
3 & $17,17 \pm 2,09(7)$ & $15,81 \pm 2,50(5)$ & $18,85 \pm 2,50(5)$ \\
4 & $19,83 \pm 2,49(7)$ & $19,61 \pm 2,97(5)$ & $23,79 \pm 2,97(5)$ \\
\hline${ }^{a}$ peso ao nascer & & &
\end{tabular}

b entre parênteses o número de animais estudados.

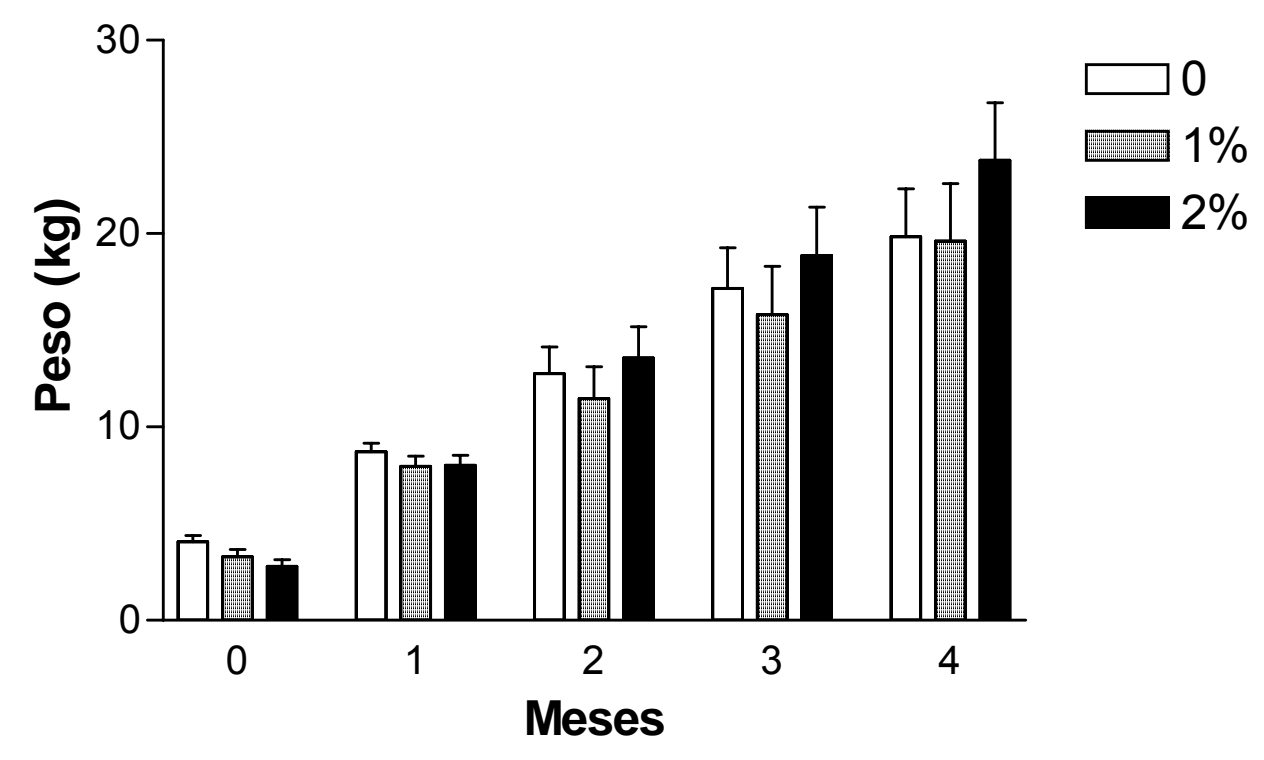

Figura 31 - Pesos médios $(\mathrm{kg})$ de cabritos filhos de cabras que consumiram ração contendo diferentes concentrações $(0,1 \%$ e $2 \%)$ de sementes de Senna occidentalis durante a gestação. São apresentadas as médias e os respectivos erros padrão. Análise da variância ANOVA, seguida de LSM e teste "T" de Student 
Tabela 20 - Níveis séricos de glicose (mg/dl), aldolase (u/l), GGT (u/l) e AST (u/l) de cabritos cujas mães consumiram diferentes concentrações de sementes de Senna occidentalis durante a gestação. São apresentadas as médias e os respectivos erros padrão. Análise da variância ANOVA, seguida de teste "T" de Student. Os dados são apresentados através do método dos quadrados mínimos

\begin{tabular}{|c|c|c|c|c|}
\hline \multirow{2}{*}{ Substâncias } & \multirow{2}{*}{$\begin{array}{l}\text { Datas de } \\
\text { coleta }^{a}\end{array}$} & \multicolumn{3}{|c|}{ Sementes de Senna occidentalis (\%) } \\
\hline & & 0 & 1 & 2 \\
\hline \multirow{4}{*}{$\begin{array}{l}\text { Glicose } \\
\text { (mg/dl) }\end{array}$} & 1 & $79,98 \pm 2,89(5)^{b}$ & $65,97 \pm 3,45(4) *$ & $81,18 \pm 3,45(4)$ \\
\hline & 2 & $71,63 \pm 6,98(5)$ & $59,25 \pm 8,34(4)$ & $79,88 \pm 8,34(4)$ \\
\hline & 3 & $54,80 \pm 5,29(5)$ & $43,16 \pm 6,64(4)$ & $66,45 \pm 6,33(4)$ \\
\hline & 4 & $45,81 \pm 4,65(5)$ & $45,49 \pm 5,56(4)$ & $43,88 \pm 5,56(4)$ \\
\hline \multirow{4}{*}{$\begin{array}{l}\text { Aldolase } \\
\quad(\mathrm{U} / \mathrm{I})\end{array}$} & 1 & $14,36 \pm 1,52(5)$ & $13,60 \pm 1,82(4)$ & $13,96 \pm 1,82(4)$ \\
\hline & 2 & $14,62 \pm 1,45(5)$ & $9,44 \pm 1,74(4)$ * & $17,81 \pm 1,74(4)$ \\
\hline & 3 & $10,69 \pm 1,44(5)$ & $12,12 \pm 1,21(4)$ & $16,57 \pm 1,13(4)$ * \\
\hline & 4 & $15,82 \pm 1,99(5)$ & $10,80 \pm 2,38(4)$ & $7,60 \pm 2,38(4) *$ \\
\hline \multirow{4}{*}{$\begin{array}{l}\text { GGT } \\
(\mathrm{U} / \mathrm{I})\end{array}$} & 1 & $109,38 \pm 9,75(5)$ & $131,12 \pm 11,60(4)$ & $175,87 \pm 11,6(4)$ * \\
\hline & 2 & $78,80 \pm 9,75(5)$ & $76,07 \pm 11,66(4)$ & $72,33 \pm 11,6(4)$ \\
\hline & 3 & $67,89 \pm 9,75(5)$ & $80,01 \pm 12,30(4)$ & $76,72 \pm 11,6(4)$ \\
\hline & 4 & $75,21 \pm 9,75(5)$ & $68,33 \pm 11,6(4)$ & $68,75 \pm 11,6(4)$ \\
\hline \multirow{4}{*}{$\begin{array}{l}\text { AST } \\
(\mathrm{U} / \mathrm{I})\end{array}$} & 1 & $52,60 \pm 9,67(5)$ & $47,04 \pm 20,19(4)$ & $86,83 \pm 12,44(4)$ \\
\hline & 2 & $63,23 \pm 10,46(5)$ & $65,68 \pm 17,04(4)$ & $65,05 \pm 16,46(4)$ \\
\hline & 3 & $48,12 \pm 9,41(5)$ & $65,08 \pm 7,25(4)$ & $66,21 \pm 6,24(4)$ \\
\hline & 4 & $62,40 \pm 18,31(5)$ & $60,97 \pm 7,17(4)$ & $64,32 \pm 6,88(4)$ \\
\hline
\end{tabular}



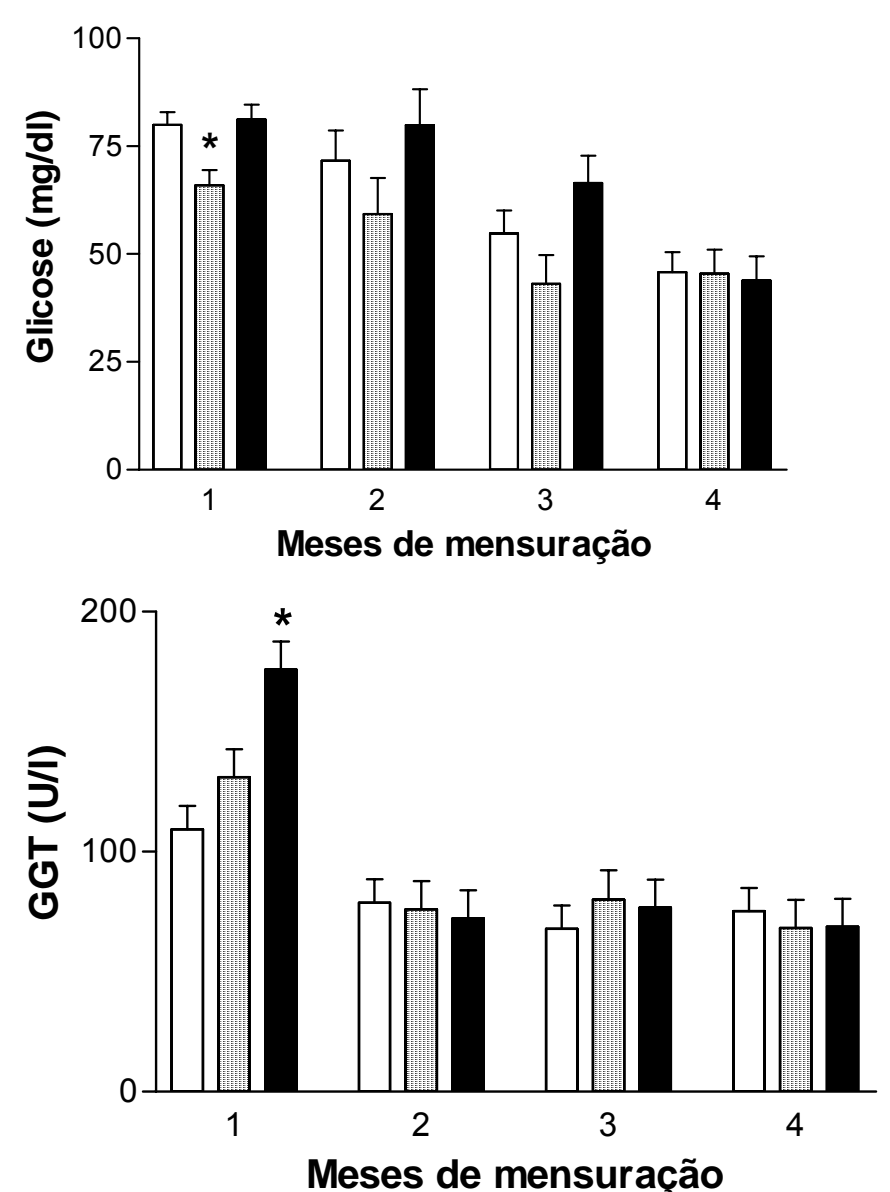
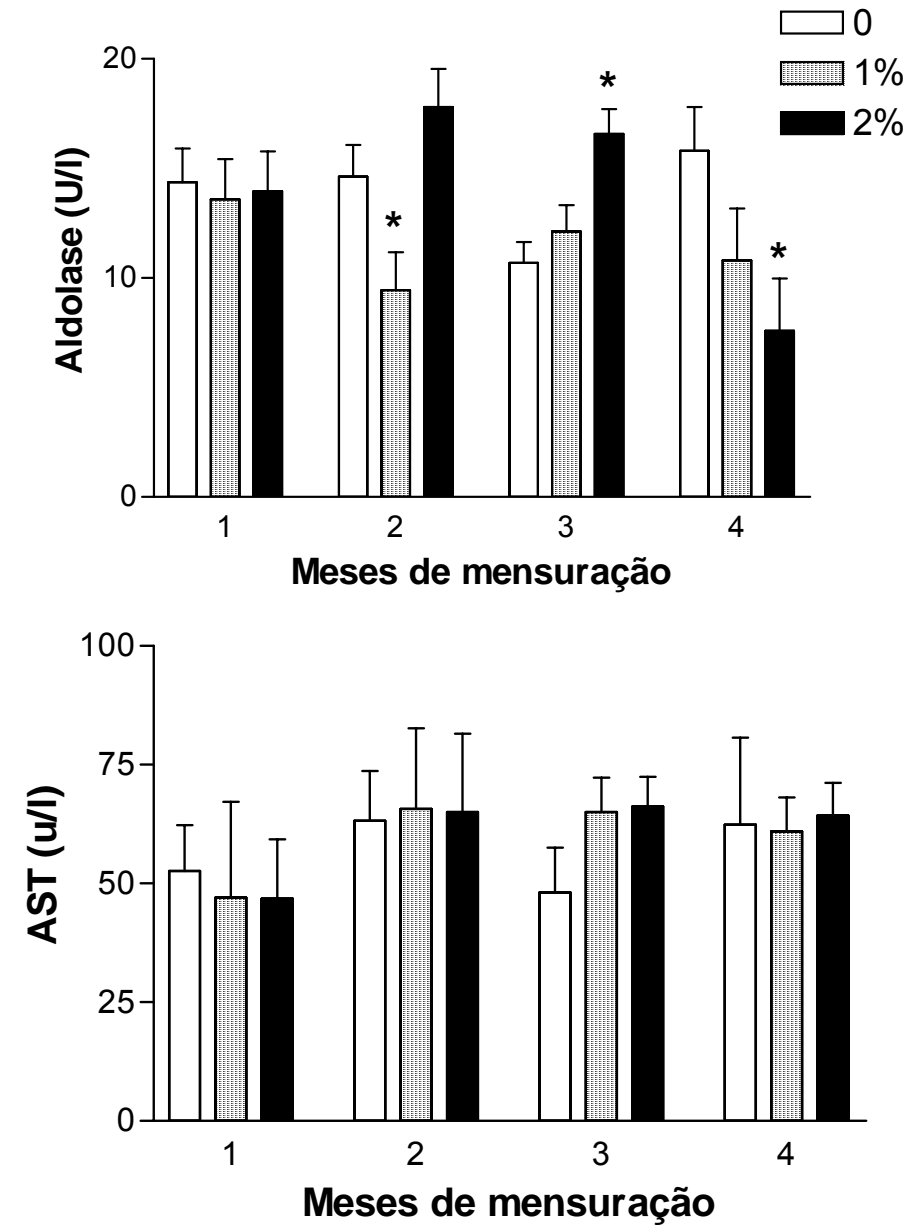

*Difere significantemente $(P<0,05)$. Anova, seguido de teste $T$ de Student.

Figura 32 - Níveis séricos de glicose (mg/dl), aldolase (u/l), GGT (u/l) e AST (u/l) de cabritos cujas mães consumiram diferentes concentrações de sementes de Senna occidentalis durante a gestação. São apresentadas as médias e os respectivos erros padrão. Análise da variância ANOVA, seguida de teste $T$ de Student. Os dados são apresentados através do método dos quadrados mínimos 
Tabela 21 - Níveis séricos de FA (u/l), CK (u/l), LDH (u/l) e triglicerídeos (u/l) de cabritos cujas mães consumiram diferentes concentrações de sementes de Senna occidentalis durante a gestação. São apresentadas as médias e os respectivos erros padrão. Os dados são apresentados através do método dos quadrados mínimos

\begin{tabular}{|c|c|c|c|c|}
\hline \multirow[t]{2}{*}{ Substâncias } & \multirow[t]{2}{*}{ Datas de coleta $^{\mathrm{a}}$} & \multicolumn{3}{|c|}{ Sementes de Senna occidentalis (\%) } \\
\hline & & 0 & 1 & 2 \\
\hline \multirow{4}{*}{$\begin{array}{l}\mathrm{FA} \\
(\mathrm{U} / \mathrm{l})\end{array}$} & 1 & $297,91 \pm 34.43(7)^{\mathrm{b}}$ & $257,15 \pm 41,16(5)$ & $261,120 \pm 41,16(5)$ \\
\hline & 2 & $306,70 \pm 57.59(7)$ & $307,78 \pm 68,83(5)$ & $271,520 \pm 68,83(5)$ \\
\hline & 3 & $226,66 \pm 37.72(7)$ & $209,40 \pm 46,21(5)$ & $211,430 \pm 45,08(5)$ \\
\hline & 4 & $255,68 \pm 70.04(7)$ & $221,27 \pm 83,72(5)$ & $178,680 \pm 83,72(5)$ \\
\hline \multirow{4}{*}{$\begin{array}{l}\text { CK } \\
(\mathrm{U} / \mathrm{I})\end{array}$} & 1 & $37,49 \pm 13,69(7)$ & $28,08 \pm 15,38(5)$ & $23,58 \pm 15,38(5)$ \\
\hline & 2 & $89,54 \pm 12,87(7)$ & $126,75 \pm 15,38(5)$ & $70,83 \pm 15,38(5)$ \\
\hline & 3 & $88,25 \pm 12,87(7)$ & $135,95 \pm 16,74(5)$ & $124,75 \pm 15,38(5)$ \\
\hline & 4 & $113,58 \pm 12,87(7)$ & $143,42 \pm 15,38(5)$ & $149,42 \pm 15,38(5)$ \\
\hline \multirow{4}{*}{$\begin{array}{l}\text { LDH } \\
(\mathrm{U} / \mathrm{l})\end{array}$} & 1 & $584,29 \pm 110,88(7)$ & $623,50 \pm 132,52(5)$ & $652,33 \pm 132,52(5)$ \\
\hline & 2 & $879,50 \pm 139,27(7)$ & $557,92 \pm 166,46(5)$ & $659,25 \pm 166,46(5)$ \\
\hline & 3 & $420,00 \pm 85,93(7)$ & $544,71 \pm 108,33(5)$ & $638,08 \pm 102,71(5)$ \\
\hline & 4 & $597,92 \pm 90,81(7)$ & $602,25 \pm 108,54(5)$ & $704,42 \pm 108,54(5)$ \\
\hline \multirow{4}{*}{$\begin{array}{l}\text { Triglicerídeos } \\
\text { (U/I) }\end{array}$} & 1 & $71,18 \pm 10,50(7)$ & $74,64 \pm 12,55(5)$ & $75,36 \pm 12,54(5)$ \\
\hline & 2 & $56,82 \pm 9,62(7)$ & $68,41 \pm 11,49(5)$ & $56,01 \pm 11,50(5)$ \\
\hline & 3 & $46,63 \pm 11,15(7)$ & $59,73 \pm 13,66(5)$ & $32,60 \pm 13,32(5)$ \\
\hline & 4 & $48,62 \pm 7,86(7)$ & $72,72 \pm 9,40(5)$ & $45,41 \pm 9,40(5)$ \\
\hline
\end{tabular}



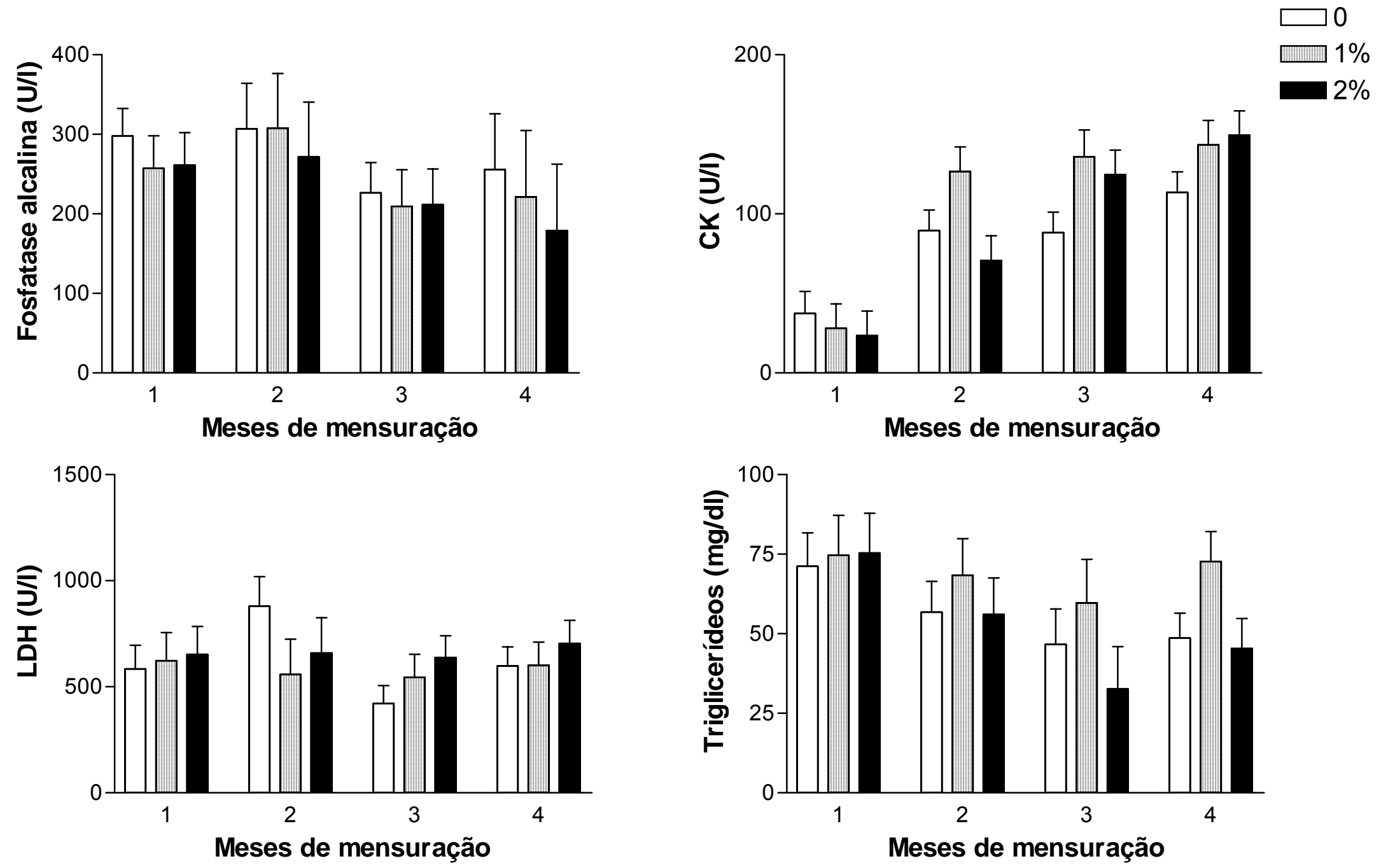

Figura 33 - Níveis séricos de FA (u/l), CK (u/l), LDH (u/l) e triglicerídeos (u/l) de cabritos cujas mães consumiram diferentes concentrações de sementes de Senna occidentalis durante a gestação. São apresentadas as médias e os respectivos erros padrão. Análise da variância ANOVA, seguida de teste "T" de Student. Os dados são apresentados através do método dos quadrados mínimos 
Tabela 22 - Níveis séricos de proteína total $(\mathrm{mg} / \mathrm{dl})$, albumina $(\mathrm{g} / \mathrm{l})$, uréia $(\mathrm{mg} / \mathrm{dl})$ e creatinina $(\mathrm{u} / \mathrm{l})$ de cabritos cujas mães consumiram diferentes concentrações de sementes de Senna occidentalis durante a gestação. São apresentadas as médias e os respectivos erros padrão. Os dados são apresentados através do método dos quadrados mínimos

\begin{tabular}{|c|c|c|c|c|}
\hline \multirow{2}{*}{ Substâncias } & \multirow{2}{*}{$\begin{array}{c}\text { Datas de } \\
\text { coleta }^{\mathrm{a}}\end{array}$} & \multicolumn{3}{|c|}{ Sementes de Senna occidentalis (\%) } \\
\hline & & 0 & 1 & 2 \\
\hline \multirow{4}{*}{$\begin{array}{l}\text { Proteína total } \\
\qquad(\mathrm{mg} / \mathrm{dl})\end{array}$} & 1 & $5.72 \pm 0.21(7)^{b}$ & $4.80 \pm 0.26(5)$ & $5.27 \pm 0.26(5)$ \\
\hline & 2 & $5.90 \pm 0.61(7)$ & $5.42 \pm 0.73(5)$ & $5.39 \pm 0.73(5)$ \\
\hline & 3 & $4.99 \pm 0.19(7)$ & $5.35 \pm 0.24(5)$ & $5.48 \pm 0.23(5)$ \\
\hline & 4 & $5.88 \pm 0.31(7)$ & $5.93 \pm 0.37(5)$ & $6.29 \pm 0.37(5)$ \\
\hline \multirow{4}{*}{$\begin{array}{l}\text { Albumina } \\
(\mathrm{g} / \mathrm{l})\end{array}$} & 1 & $3.00 \pm 0.12(7)$ & $2.64 \pm 0.15(5)$ & $2.51 \pm 0.15(5)$ \\
\hline & 2 & $3.83 \pm 0.30(7)$ & $3.47 \pm 0.36(5)$ & $3.56 \pm 0.36(5)$ \\
\hline & 3 & $3.42 \pm 0.16(7)$ & $3.22 \pm 0.20(5)$ & $3.70 \pm 0.19(5)$ \\
\hline & 4 & $3.64 \pm 0.24(7)$ & $3.24 \pm 0.29(5)$ & $3.74 \pm 0.29(5)$ \\
\hline \multirow{4}{*}{$\begin{array}{l}\text { Uréia } \\
\text { (mg/dl) }\end{array}$} & 1 & $54.83 \pm 5.86(7)$ & $50.20 \pm 7.01(5)$ & $36.56 \pm 7.01(5)$ \\
\hline & 2 & $63.66 \pm 5.86(7)$ & $72.95 \pm 7.01(5)$ & $31.67 \pm 7.01(5)$ \\
\hline & 3 & $39.36 \pm 5.86(7)$ & $35.241 \pm 7.60$ & $29.36 \pm 7.01(5)$ \\
\hline & 4 & $31.85 \pm 5.86(7)$ & $27.84 \pm 7.01(5)$ & $31.15 \pm 7.01(5)$ \\
\hline \multirow{4}{*}{$\begin{array}{c}\text { Creatinina } \\
(\mathrm{U} / \mathrm{I})\end{array}$} & 1 & $1.23 \pm 0.11(7)$ & $1.22 \pm 0.13(5)$ & $0.86 \pm 0.13(5)$ \\
\hline & 2 & $1.32 \pm 0.14(7)$ & $1.18 \pm 0.17(5)$ & $1.08 \pm 0.17(5)$ \\
\hline & 3 & $0.99 \pm 0.08(7)$ & $0.10 \pm 0.10(5)$ & $1.02 \pm 0.10(5)$ \\
\hline & 4 & $1.06 \pm 0.10(7)$ & $0.93 \pm 0.12(5)$ & $1.04 \pm 0.12(5)$ \\
\hline
\end{tabular}



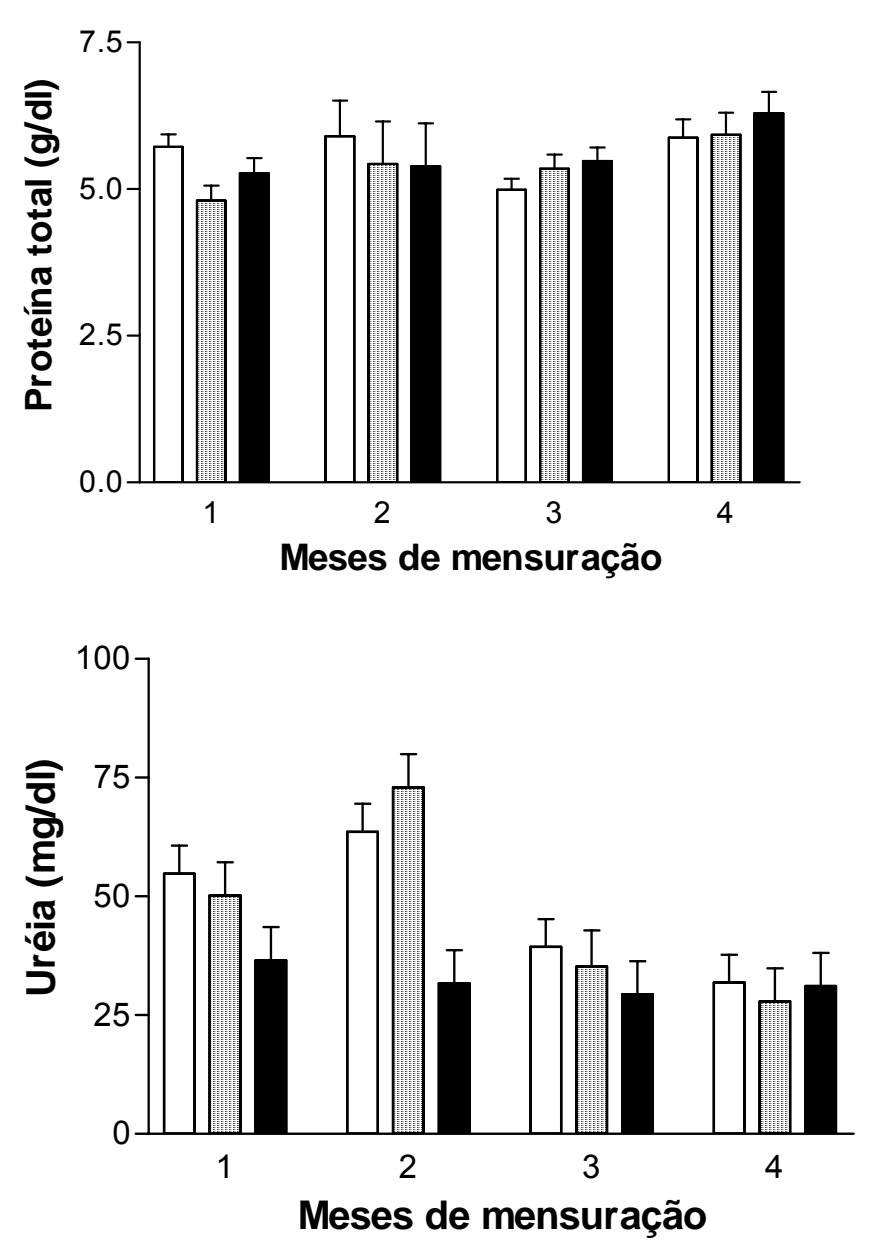
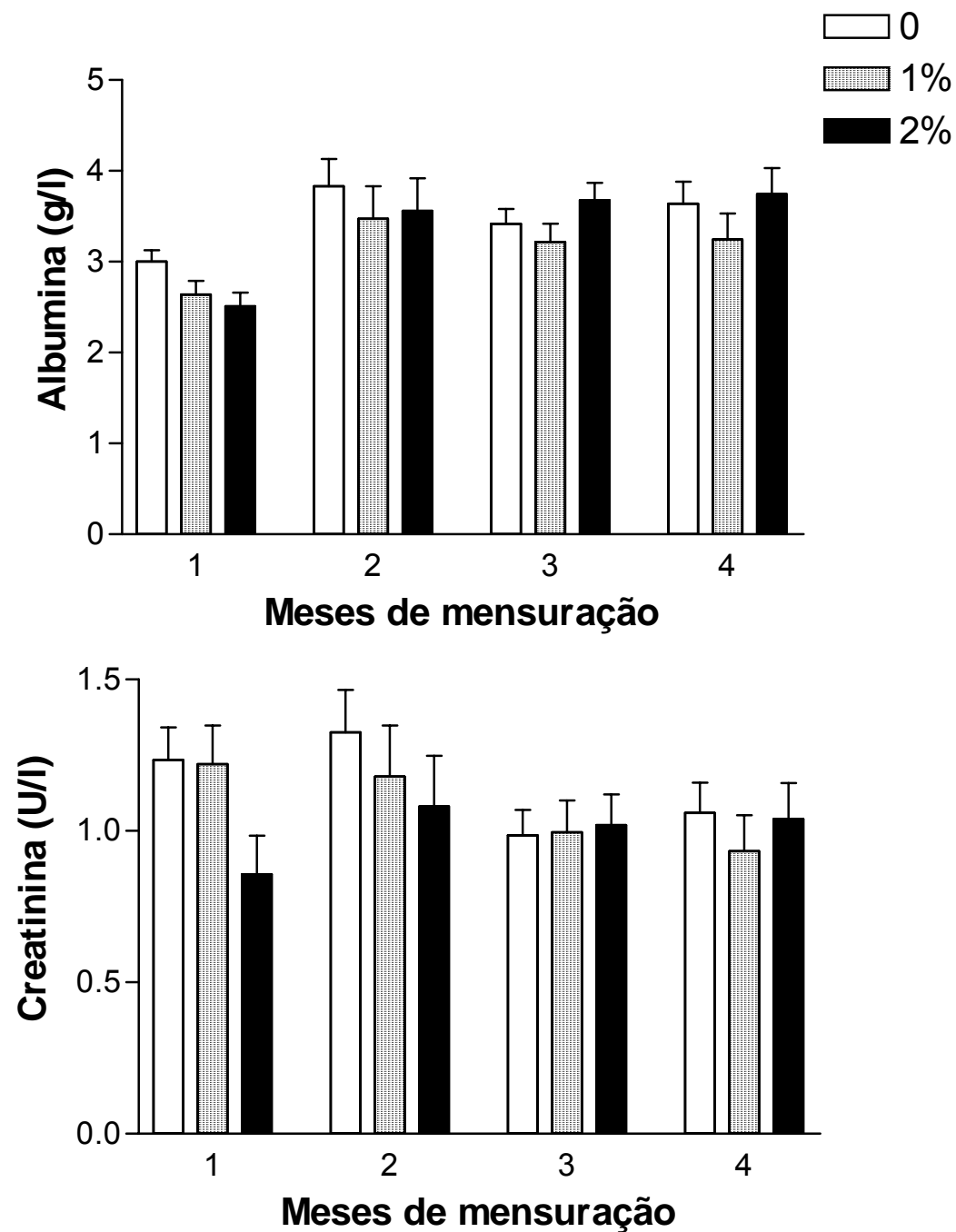

Figura 34 - Níveis séricos de proteína total $(\mathrm{mg} / \mathrm{dl})$, albumina $(\mathrm{g} / \mathrm{l})$, uréia $(\mathrm{mg} / \mathrm{dl})$ e creatinina $(\mathrm{u} / \mathrm{l})$ de cabritos cujas mães consumiram diferentes concentrações de sementes de Senna occidentalis durante a gestação. São apresentadas as médias e os respectivos erros padrão. ANOVA, seguida de teste T de Student. Os dados são apresentados através do método dos quadrados mínimos 
Tabela 23 - Níveis séricos de colinesterase (u/l) de cabritos cujas mães consumiram diferentes concentrações de sementes de Senna occidentalis durante a gestação. São apresentadas as médias e os respectivos erros padrão. Os dados são apresentados através do método dos quadrados mínimos

\begin{tabular}{ccccc}
\hline \multirow{2}{*}{ Substâncias } & \begin{tabular}{c} 
Datas de $^{\text {coleta }}{ }^{\mathbf{a}}$ \\
\cline { 2 - 5 }
\end{tabular} & $\mathbf{0}$ & $\mathbf{1}$ & $\mathbf{2}$ \\
\hline \multirow{3}{*}{ Colinesterase } & 1 & $178,31 \pm 16,85(7)^{\mathbf{b}}$ & $197,32 \pm 20,13(5)$ & $190,22 \pm 20,13(5)$ \\
(U/I) & 2 & $291,24 \pm 38,26(7)$ & $207,38 \pm 46,16(5)$ & $187,28 \pm 46,16(5)$ \\
& 3 & $198,26 \pm 30,68(7)$ & $169,08 \pm 37,91(5)$ & $168,33 \pm 36,67(5)$ \\
& 4 & $216,67 \pm 34,73(7)$ & $279,71 \pm 41,51(5)$ & $237,54 \pm 41,51(5)$ \\
\hline
\end{tabular}

${ }^{a}$ logo após o nascimento até o quarto mês de vida.

${ }^{b}$ entre parênteses o número de animais estudados.

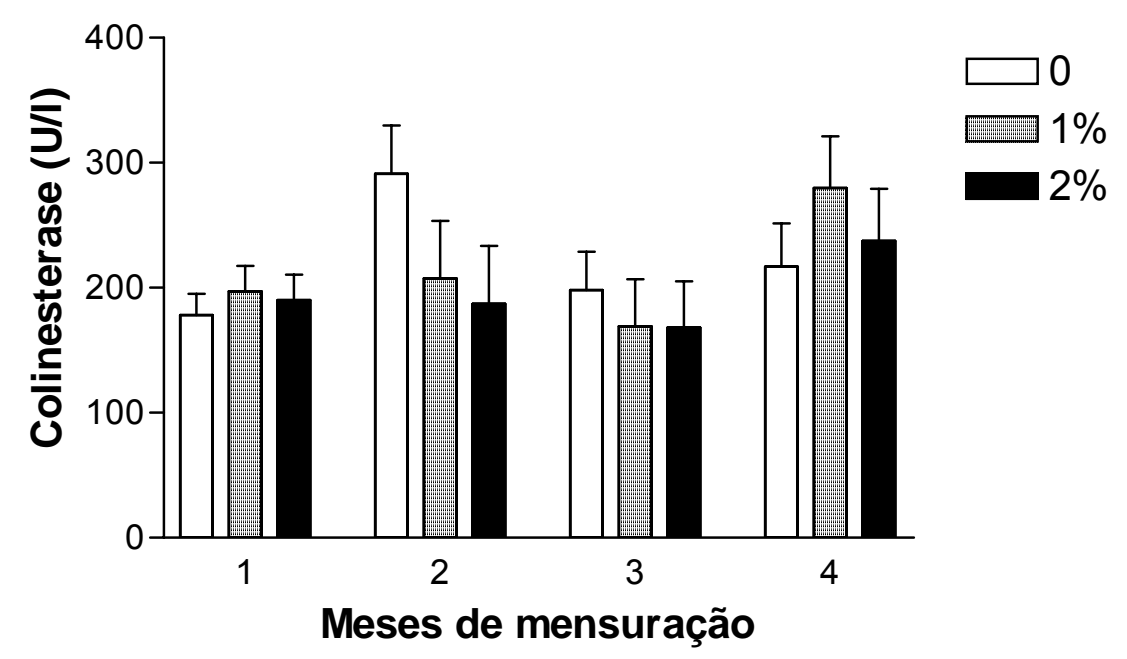

Figura 35 - Níveis séricos de colinesterase (u/l) de cabritos cujas mães consumiram diferentes concentrações de sementes de Senna occidentalis durante a gestação. São apresentadas as médias e os respectivos erros padrão. Os dados são apresentados através do método dos quadrados mínimos 
Tabela 24 - Comprimento do metatarso (CMT), altura corporal (AC), comprimento corporal (CC) e perímetro torácico $(\mathrm{PT})$ de cabritos cujas mães consumiram diferentes concentrações de sementes de Senna occidentalis durante a gestação. São apresentadas as médias e os respectivos erros padrão através do método dos quadrados mínimos

\begin{tabular}{|c|c|c|c|c|}
\hline \multirow{2}{*}{$\begin{array}{l}\text { Parâmetros } \\
\text { (cm) }\end{array}$} & \multirow{2}{*}{$\begin{array}{l}\text { Datas de } \\
\text { coleta }^{a}\end{array}$} & \multicolumn{3}{|c|}{ Sementes de Senna occidentalis (\%) } \\
\hline & & 0 & 1 & 2 \\
\hline \multirow{5}{*}{ CMT } & 0 & $10,93 \pm 0,32(7)^{\mathbf{b}}$ & $10,16 \pm 0,38(5)$ & $9,50 \pm 0,38(5)$ * \\
\hline & 1 & $11,83 \pm 0,38(7)$ & $11,08 \pm 0,45(5)$ & $12,01 \pm 0,46(5)$ * \\
\hline & 2 & $12,37 \pm 0,25(7)$ & $11,70 \pm 0,30(5)$ * & $12,04 \pm 0,30(5)$ \\
\hline & 3 & $12,85 \pm 0,33(7)$ & $12,33 \pm 0,40(5)$ & $12,75 \pm 0,40(5)$ \\
\hline & 4 & $13,19 \pm 0,41(7)$ & $13,12 \pm 0,50(5)$ & $13,25 \pm 0,50(5)$ \\
\hline \multirow{5}{*}{$\mathrm{AC}$} & 0 & $35,04 \pm 1,60(7)$ & $34,92 \pm 1,91(5)$ & $33,75 \pm 1,91(5)$ \\
\hline & 1 & $44,58 \pm 1,92(7)$ & $40,75 \pm 2,30(5)$ & $41,33 \pm 1,40(5)$ \\
\hline & 2 & $48,00 \pm 1,90(7)$ & $45,87 \pm 2,25(5)$ & $46,33 \pm 1,93(5)$ \\
\hline & 3 & $51,55 \pm 1,55(7)$ & $49,75 \pm 1,85(5)$ & $51,08 \pm 1,98(5)$ \\
\hline & 4 & $53,17 \pm 1,80(7)$ & $53,00 \pm 2,12(5)$ & $54,42 \pm 2,09(5)$ \\
\hline \multirow{5}{*}{$\mathrm{CC}$} & 0 & $32,02 \pm 1.00(7)$ & $31.37 \pm 1.20(5)$ & $28.17 \pm 1.20(5)$ \\
\hline & 1 & $41,12 \pm 1.60(7)$ & $40.70 \pm 1.91(5)$ & $38.58 \pm 1.91(5)$ \\
\hline & 2 & $46,33 \pm 1.73(7)$ & $43.92 \pm 2.07(5)$ & $45.42 \pm 2.07(5)$ \\
\hline & 3 & $49,12 \pm 1.78(7)$ & $51.17 \pm 2.12(5)$ & $50.50 \pm 2.12(5)$ \\
\hline & 4 & $51.62 \pm 2.06(7)$ & $51.92 \pm 2.47(5)$ & $54.42 \pm 2.47(5)$ \\
\hline \multirow{5}{*}{ PT } & 0 & $36,42 \pm 1,37(7)$ & $35,42 \pm 1,64(5)$ & $33,25 \pm 20,13(5)$ \\
\hline & 1 & $47,70 \pm 1,64(7)$ & $44,5 \pm 1,96(5)$ & $44,87 \pm 46,16(5)$ \\
\hline & 2 & $53,52 \pm 2,16(7)$ & $50,17 \pm 2,58(5)$ & $54.21 \pm 2.58$ \\
\hline & 3 & $58,81 \pm 2,78(7)$ & $54,92 \pm 3,25(5)$ & $64.00 \pm 3.32(5)$ \\
\hline & 4 & $61,08 \pm 2,64(7)$ & $59,75 \pm 2,95$ & $66.00 \pm 2.95$ \\
\hline
\end{tabular}

* Difere significantemente do controle. Anova seguida de teste T de Studen

${ }^{a}$ logo após o nascimento até o quarto mês de vida.

${ }^{\mathrm{b}}$ entre parênteses o número de animais estudados. 

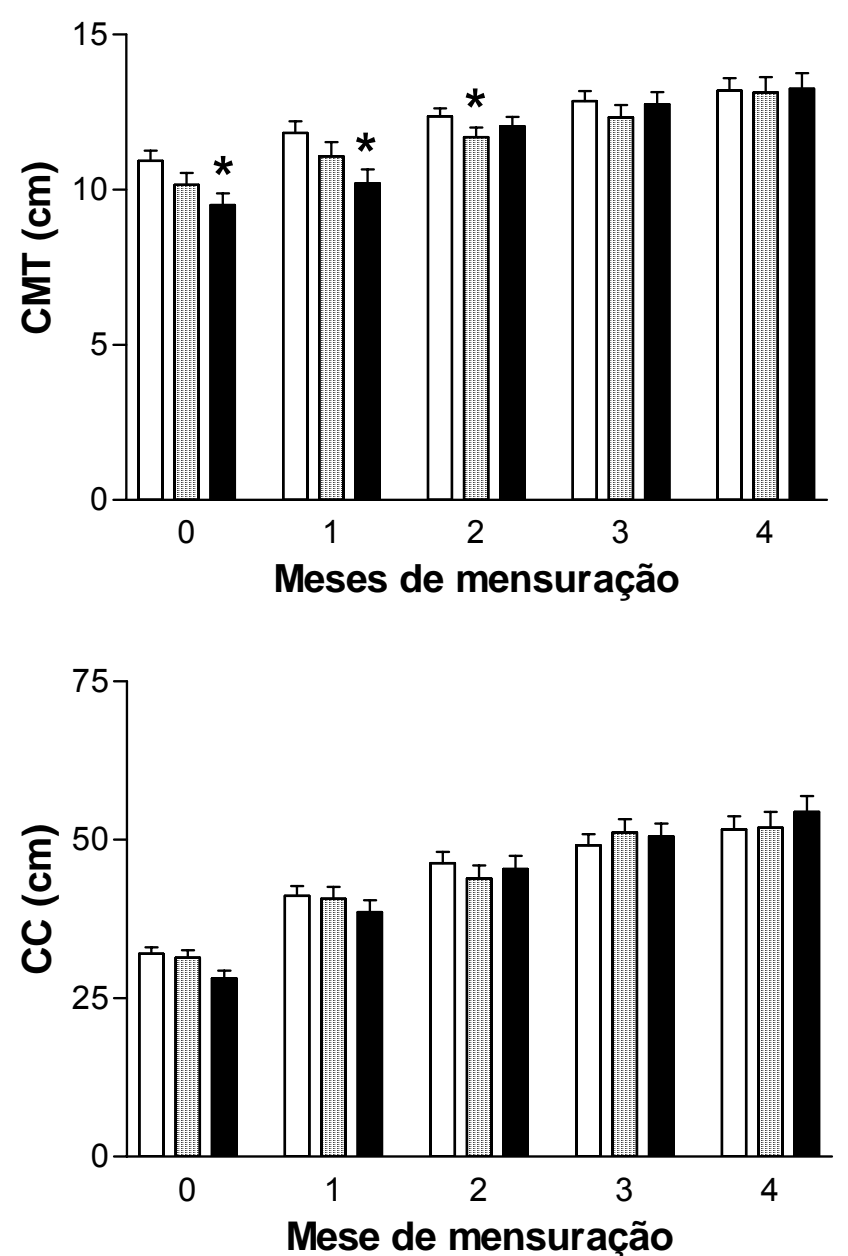
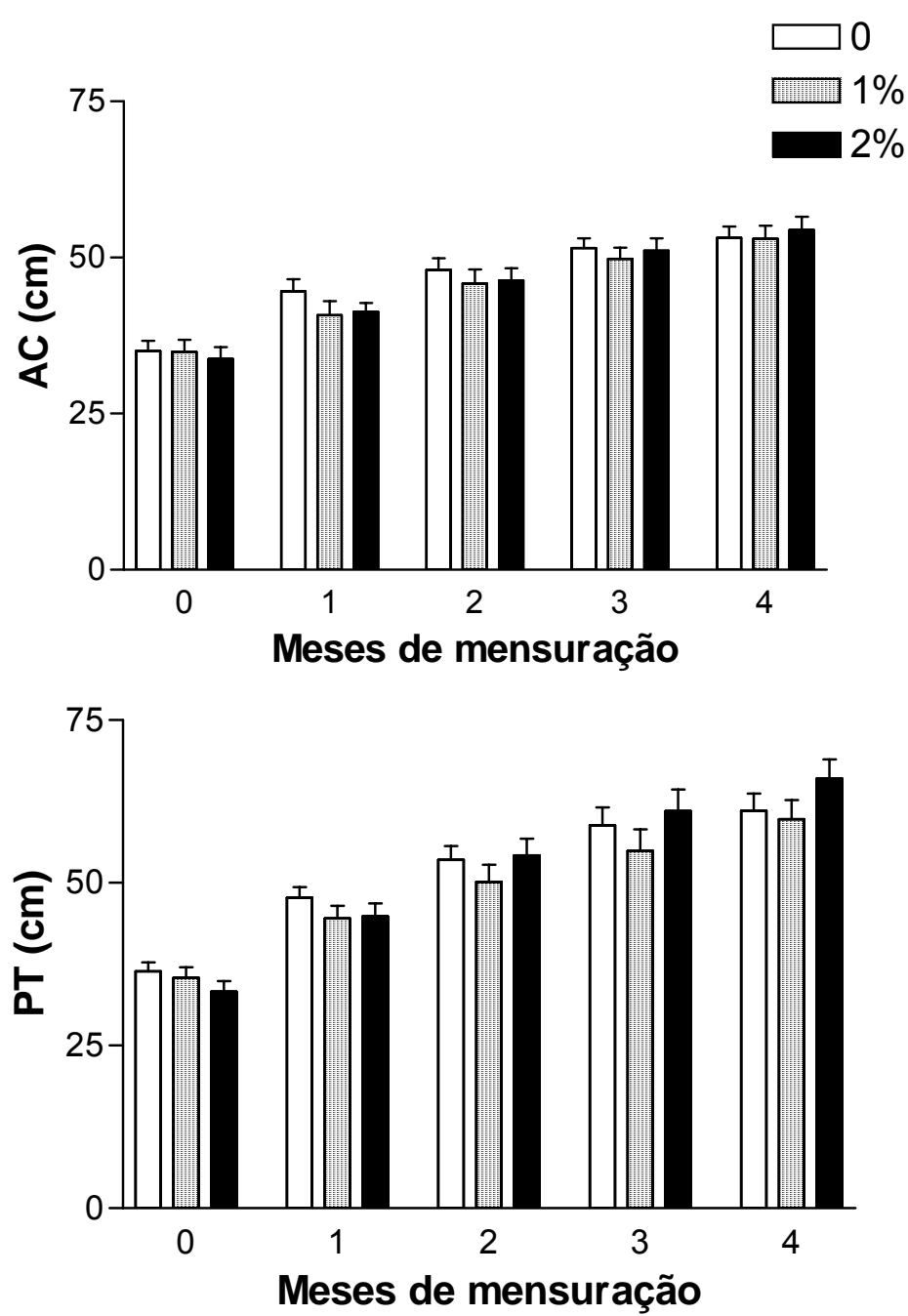

*Difere significantemente $(\mathrm{P}<0,05)$. Anova, seguido de teste $T$ de Student.

Figura 36 - Comprimento do metatarso (CMT), altura corporal (AC), comprimento corporal (CC) e perímetro torácico (PT) de cabritos cujas mães consumiram diferentes concentrações de sementes de Senna occidentalis durante a gestação. São apresentadas as médias e os respectivos erros padrão, através do método dos quadrados mínimos. 
Tabela 25 - Comprimento da cabeça (CCab), diâmetro da cabeça (DCab), comprimento do rádio (CRad) e comprimento da tíbia (CTIB) de cabritos cujas mães consumiram diferentes concentrações de sementes de Senna occidentalis durante a gestação. Médias e respectivos erros padrão através do método dos quadrados mínimos. ANOVA seguida de teste T de Student

\begin{tabular}{|c|c|c|c|c|}
\hline \multirow{2}{*}{$\begin{array}{l}\text { Parâmetros } \\
\text { (cm) }\end{array}$} & \multirow{2}{*}{$\begin{array}{l}\text { Datas de } \\
\text { coleta }^{a}\end{array}$} & \multicolumn{3}{|c|}{ Sementes de Senna occidentalis (\%) } \\
\hline & & 0 & 1 & 2 \\
\hline \multirow{5}{*}{$\begin{array}{l}\text { CCab } \\
(\mathrm{cm})\end{array}$} & 0 & $16.56 \pm 0,40(7)^{b}$ & $16,78 \pm 0,48(5)$ & $16,10 \pm 0,48(5)$ \\
\hline & 1 & $20,38 \pm 0,76(7)$ & $20,92 \pm 0,91(5)$ & $20,42 \pm 0,91(5)$ \\
\hline & 2 & $23,08 \pm 0,79(7)$ & $23,75 \pm 0,95(5)$ & $23,46 \pm 0,95(5)$ \\
\hline & 3 & $24,98 \pm 0,86(7)$ & $24,54 \pm 1,03(5)$ & $25,33 \pm 1,06(5)$ \\
\hline & 4 & $25,27 \pm 0,72(7)$ & $27,17 \pm 0,86(5)$ & $27,00 \pm 0,86(5)$ \\
\hline \multirow{5}{*}{$\begin{array}{l}\text { DCab } \\
(\mathrm{cm})\end{array}$} & 0 & $10.79 \pm 0.35(7)$ & $11.58 \pm 0.43(5)$ & $11.5 \pm 0.43(5)$ \\
\hline & 1 & $13.83 \pm 0.38(7)$ & $13.67 \pm 0.46(5)$ & $14.12 \pm 0.46(5)$ \\
\hline & 2 & $16.06 \pm 0.55(7)$ & $14.87 \pm 0.65(5)$ & $15.55 \pm 0.65(5)$ \\
\hline & 3 & $16.50 \pm 0.39(7)$ & $15.62 \pm 0.46(5)$ & $16.70 \pm 0.46(5)$ \\
\hline & 4 & $17.50 \pm 0.71(7)$ & $17.17 \pm 0.84(5)$ & $16.83 \pm 0.85(5)$ \\
\hline \multirow{5}{*}{$\begin{array}{l}\text { CRad } \\
(\mathrm{cm})\end{array}$} & 0 & $11.31 \pm 0.41(7)$ & $11.12 \pm 0.49(5)$ & $10.25 \pm 0.49(5)$ \\
\hline & 1 & $13.29 \pm 0.48(7)$ & $12.29 \pm 0.58(5)$ & $12.00 \pm 0.58(5)$ \\
\hline & 2 & $13.98 \pm 0.49(7)$ & $13.71 \pm 0.58(5)$ & $14.30 \pm 0.58(5)$ \\
\hline & 3 & $15.08 \pm 0.63(7)$ & $14.54 \pm 0.57(5)$ & $15.21 \pm 0.57(5)$ \\
\hline & 4 & $15.56 \pm 0.49(7)$ & $15.29 \pm 0.75(5)$ & $16.33 \pm 0.75(5)$ \\
\hline \multirow{5}{*}{$\begin{array}{l}\text { CTIB } \\
(\mathrm{cm})\end{array}$} & 0 & $12.37 \pm 0.34(7)$ & $12.70 \pm 0.40(5)$ & $11.67 \pm 0.40(5)$ \\
\hline & 1 & $15.30 \pm 0.58(7)$ & $14.58 \pm 0.70(5)$ & $13.87 \pm 0.69(5)$ \\
\hline & 2 & $16.56 \pm 0.57(7)$ & $15.71 \pm 0.68(5)$ & $16.04 \pm 0.67(5)$ \\
\hline & 3 & $18.27 \pm 0.62(7)$ & $17.42 \pm 0.74(5)$ & $18.29 \pm 0.74(5)$ \\
\hline & 4 & $19.12 \pm 0.75(7)$ & $18.25 \pm 0.90$ & $20.50 \pm 0.99(5)$ \\
\hline
\end{tabular}



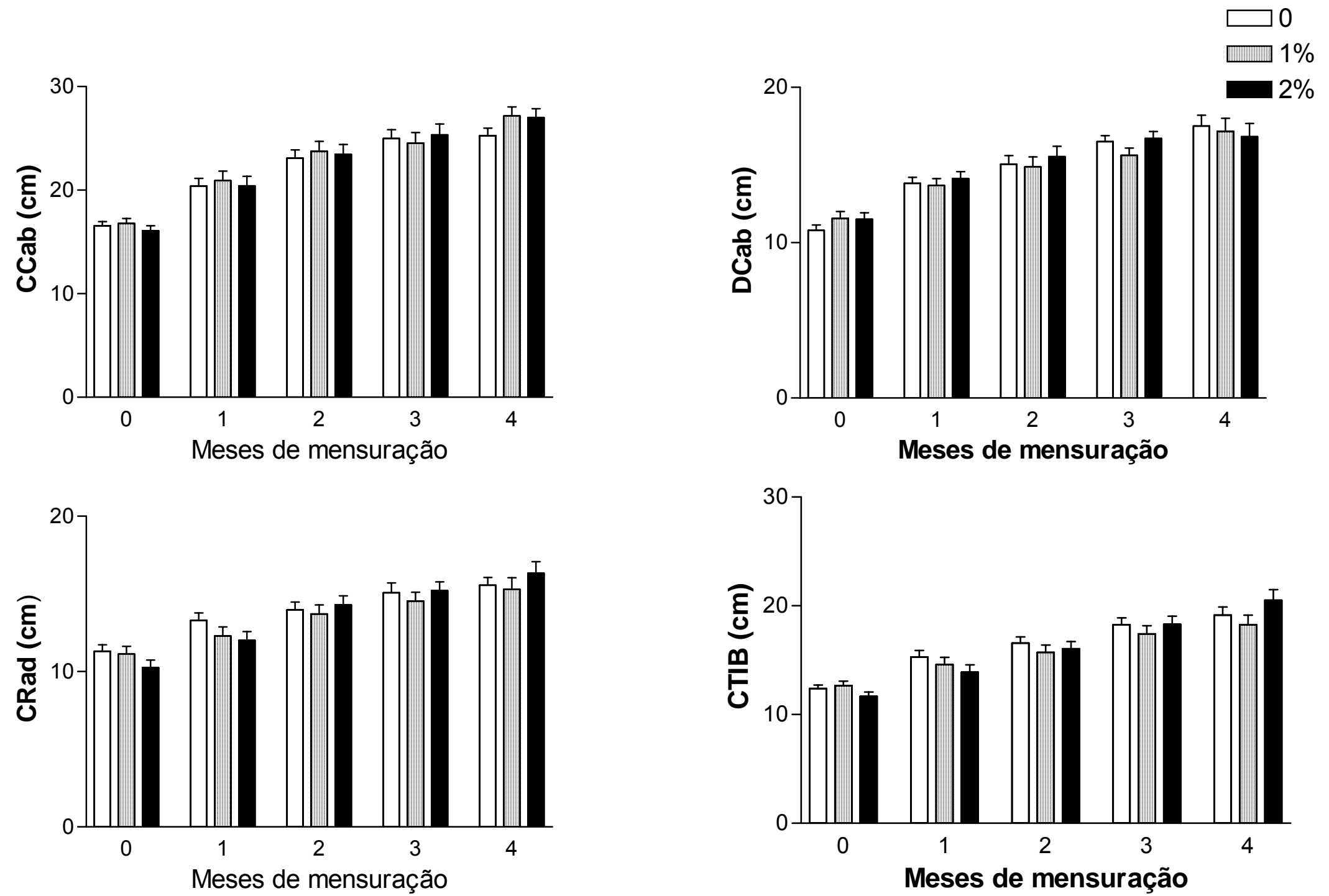

Figura 37 - Comprimento da cabeça (CCab), diâmetro da cabeça (DCab), comprimento do rádio (CRad) e comprimento da tíbia (CTIB) de cabritos cujas mães consumiram diferentes concentrações de sementes de Senna occidentalis durante a gestação. Médias e respectivos erros padrão através do método dos quadrados mínimos. ANOVA seguida de teste T de Student 


\begin{tabular}{|c|c|c|c|c|}
\hline \multirow{2}{*}{$\begin{array}{l}\text { Parâmetros } \\
\text { (cm) }\end{array}$} & \multirow{2}{*}{$\begin{array}{l}\text { Datas de } \\
\text { coleta }^{a}\end{array}$} & \multicolumn{3}{|c|}{ Sementes de Senna occidentalis (\%) } \\
\hline & & 0 & 1 & 2 \\
\hline \multirow{5}{*}{$\begin{array}{l}\text { CMC } \\
(\mathrm{cm})\end{array}$} & 0 & $8.71 \pm 0.37(7)^{\mathbf{b}}$ & $8.79 \pm 0.45(5)$ & $8.21 \pm 0.44(5)$ \\
\hline & 1 & $10.06 \pm 0.47(7)$ & $9.29 \pm 0.56(5)$ & $8.71 \pm 0.56(5)$ \\
\hline & 2 & $10.50 \pm 0.46(7)$ & $10.37 \pm 0.55(5)$ & $10.00 \pm 0.55(5)$ \\
\hline & 3 & $11.23 \pm 0.37(7)$ & $10.62 \pm 0.44(5)$ & $11.04 \pm 0.44(5)$ \\
\hline & 4 & $11.85 \pm 0.47(7)$ & $11.29 \pm 0.56(5)$ & $11.62 \pm 0.56(5)$ \\
\hline \multirow{5}{*}{$\begin{array}{l}\text { CIMC } \\
(\mathrm{cm})\end{array}$} & 0 & $8.71 \pm 0.37(7)$ & $8.80 \pm 0.45(5)$ & $8.21 \pm 0.44(5)$ \\
\hline & 1 & $10.06 \pm 0.47(7)$ & $9.29 \pm 00.57(5)$ & $8.70 \pm 0.56(5)$ \\
\hline & 2 & $10.05 \pm 0.46(7)$ & $10.37 \pm 0.55(5)$ & $10.00 \pm 0.55(5)$ \\
\hline & 3 & $11.23 \pm 0.37(7)$ & $10.62 \pm 0.44(5)$ & $11.04 \pm 0.45(5)$ \\
\hline & 4 & $11.85 \pm 0.47(7)$ & $11.29 \pm 0.56(5)$ & $11.62 \pm 0.56(5)$ \\
\hline \multirow{5}{*}{$\begin{array}{l}\text { CIMT } \\
(\mathrm{cm})\end{array}$} & 0 & $7.25 \pm 0.33(7)$ & $6.87 \pm 0.40(5)$ & $6.08 \pm 0.40(5)$ \\
\hline & 1 & $7.44 \pm 0.31(7)$ & $7.21 \pm 0.37(5)$ & $6.63 \pm 0.38(5)$ \\
\hline & 2 & $7.46 \pm 0.25(7)$ & $7.83 \pm 0.31(5)$ & $7.54 \pm 0.31(5)$ \\
\hline & 3 & $7.54 \pm 0.23(7)$ & $8.17 \pm 0.27(5)$ & $8.00 \pm 0.27(5)$ \\
\hline & 4 & $7.90 \pm 0.21(7)$ & $8.42 \pm 0.25(5)$ & $8.21 \pm 0.25(5)$ \\
\hline
\end{tabular}



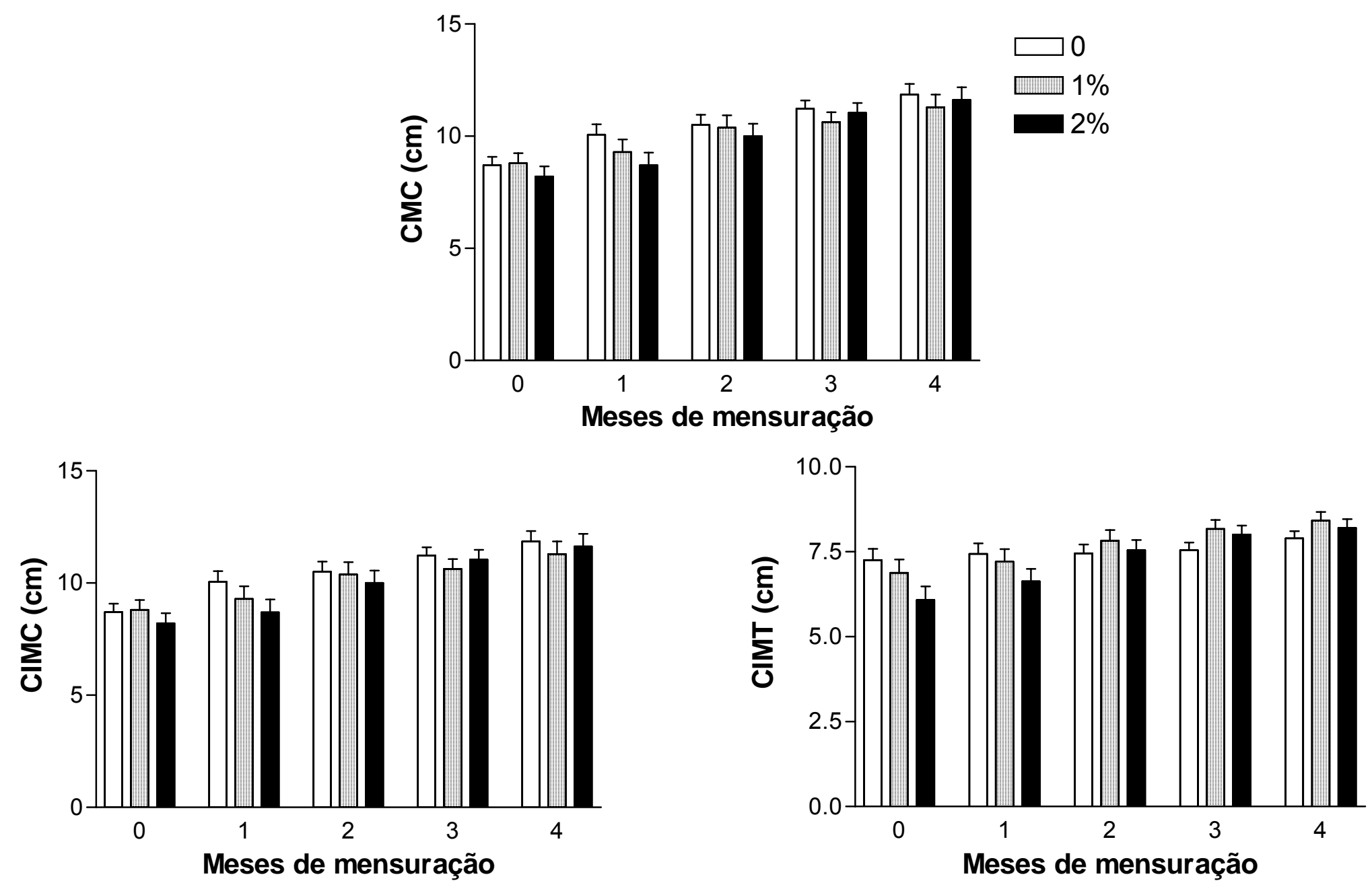

Figura 38- Comprimento do metacarpo (CMC), circunferência do metacarpo (CIMC) e circunferência do metatarso (CIMT) de cabritos cujas mães consumiram diferentes concentrações de sementes de Senna occidentalis durante a gestação. São apresentadas as médias e os respectivos erros padrão através do método dos quadrados mínimos. ANOVA seguida de teste T de Student 


\subsubsection{Resultados dos filhotes provenientes das cabras pertencentes aos grupo So3}

Em relação aos filhotes do grupo So3, a tabela 27 mostra e a figura 39 ilustra o ganho de peso mensal e total destes animais. A análise de variância revelou não haver diferença significante $(P>0,05)$ entre os valores dos diferentes grupos durante o período de 4 meses após o nascimento.

Quanto aos níveis séricos de glicose e a atividade sérica de aldolase, GGT e AST a ANOVA revelou não haver diferenças significantes $(P>0,05)$ nestes parâmetros Tabela 28 e Figura 40. O mesmo foi observado para FA, CK e LDH. Tabela 29 e figura 41. Também não foram observadas diferenças significantes $(P>0,05)$ para proteína total, albumina, uréia e creatinina (Tabela 30 e Figura 42).

A avaliação da morfometria corporal, quando submetidas à ANOVA, revelou não haver diferença significante nos parâmetros altura, comprimento corporal, comprimento torácico e comprimento da tíbia (Tabela 31 e Figura 43).

Quando submetidas à ANOVA o parâmetros CRad, CMT, CMC e CCab não tiveram diferenças significantes $(P>0,05)$. Tabela 32 e Figura 44. O mesmo foi observado para os parâmetros DCab, CIMT e CIMC (Tabela 33 e Figura 45).

Quanto aos testes comportamentais destes filhotes, não foi possível a realização dos testes mais precoces, uma vez que os filhotes, tanto do grupo controle como experimental, se deitavam e assim permaneciam durante longos minutos. Portanto, a primeira e segunda provas de obstáculo não foram realizadas.

Quanto à terceira prova de obstáculos, "Labirinto progressivo", a ANOVA revelou haver grande diferença $(P<0,10)$, entre as sessões. Assim, o teste $T$ revelou haver diferenças significantes entre as sessões 2 e 3 e a primeira em todas os dias do experimento, sessão $1(F=3,51$; $D F=2 / 12 ; P=0,06)$, sessão $2(F=7,87$; $D F=2 / 13$; $\mathrm{P}=0,006)$, sessão $3(\mathrm{~F}=4,19$; $\mathrm{DF}=2 / 14 ; \mathrm{P}=0,04)$ (Tabela 34 e Figura 46).

Quanto ao teste "Labirinto em T" com uma cabra somente, a mãe, (T1 e T2) houve interação tratamento versus repetições $(P=0,09)$. Os filhotes do grupo controle chegaram até suas mães em um tempo mais curto do que os do grupo So3 no teste $\mathrm{T} 1$, na primeira seção de três repetições $(\mathrm{F}=2,61 ; \mathrm{DF}=2 / 24 ; \mathrm{P}=0,09)$, no entanto, à medida que foram realizadas as outras duas repetições, este tempo de chegada às mães foi diminuindo pelos filhotes do grupo So3 (dados não mostrados). Desta 
maneira, estes dados parecem indicar que os filhotes do grupo experimental aprenderam rapidamente como chegar às suas mães, apesar de haver uma defasagem no início do teste. Em relação ao teste "Labirinto em T" com duas cabras (T3 e T4), os filhotes provenientes do grupo controle chegaram até suas mães em um tempo muito menor que os filhotes provenientes do grupo So3, no teste T3. A ANOVA revelou haver diferença significante $(P<0,10)$ entre os tempos de chegada entre os grupos. O subseqüente teste $T$ revelou que os filhotes do grupo So3 gastaram um tempo maior para chegar às suas mães, $(F=13,77 ; D F=1 / 12 ; P<0,10)$ (Tabela 35 e Figura 47).

Quanto à escolha dos cabritos em seguir pelo braço das mães ou o outro braço, não houve diferenças significantes $(P>0,10)$ nas escolhas.

Em relação ao labirinto médio, "Lashley Maze", Não houve diferenças significantes $(P>0,10)$ em relação aos tratamentos e o tempo. Os filhotes adquiriram maior velocidade em sem mover dentro do labirinto e cometendo menos erros à medida que os testes eram realizados mensalmente. Entretanto os tratamentos não influenciaram Nos parâmetros avaliados (Tabela 36 e Figura 48).

A tabela 37 mostra e a figura 49 ilustra os resultados dos testes no labirinto de difícil "Hebb-Williams Maze", a análise estatística revelou haver diferenças significantes $(P<0,10)$ entre os grupos experimentais na sexta semana de idade. As diferenças entre os grupos foram observadas nas três sessões realizadas, em relação à área 1 do labirinto $(F=4,14 ; D F=2 / 35$; $\mathrm{P}<0,02)$. 
Tabela 27 - Média do ganho de peso $(\mathrm{kg})$ de cabritos cujas mães consumiram ração contendo 0 , e $3 \%$ de sementes de Senna occidentalis durante a gestação. São apresentadas as médias e os respectivos erros padrão, através do método dos quadrados mínimos. ANOVA, seguida de teste "T" de Student

\begin{tabular}{ccc}
\hline \multirow{2}{*}{ Meses de coleta } & \multicolumn{2}{c}{ Sementes de Senna occidentalis (\%) } \\
\cline { 2 - 3 } & $\mathbf{0}$ & $\mathbf{3}$ \\
\hline $0^{\mathrm{a}}$ & $2,98 \pm 0,98(8)^{\mathrm{b}}$ & $2,44 \pm 1,30(7)$ \\
1 & $6,27 \pm 0,98(8)$ & $6,63 \pm 1,30(7)$ \\
2 & $9,02 \pm 0,98(8)$ & $8,29 \pm 1,30(7)$ \\
3 & $13,68 \pm 0,98(8)$ & $10,19 \pm 1,30(7)$ \\
4 & $12,62 \pm 0,98(8)$ & $13,00 \pm 1,30(7)$ \\
Total & $13,44 \pm 1,76(7)$ & $10,74 \pm 0,93(7)$ \\
\hline
\end{tabular}

peso ao nascer

b entre parênteses o número de animais estudados.
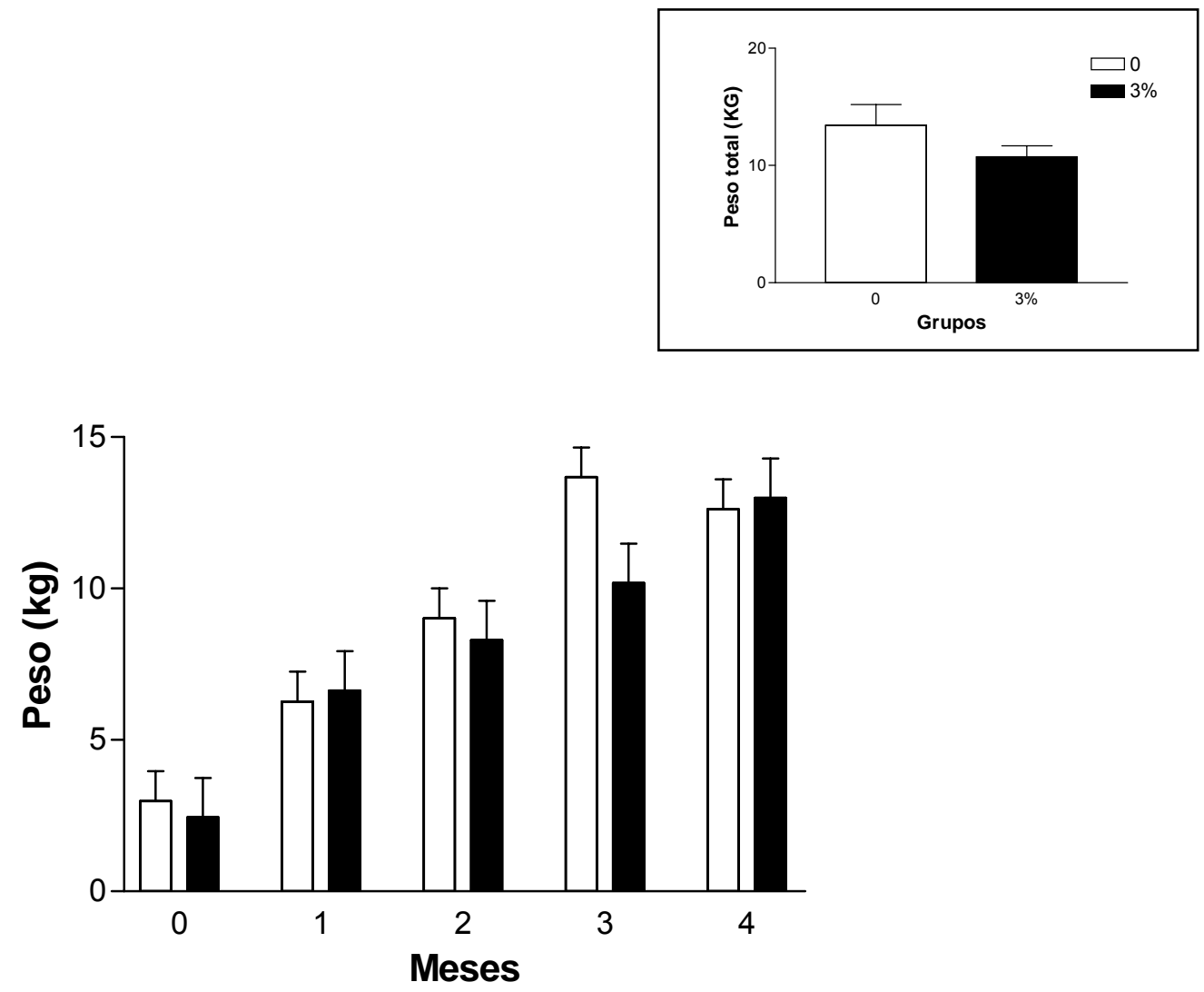

Figura 39 - Peso médio e total (quadro), de cabritos cujas mães consumiram ração contendo 0 e $3 \%$ de sementes de Senna occidentalis durante a gestação. São apresentadas as médias e os respectivos erros padrão, através do método dos quadrados mínimos. ANOVA, seguida de teste "T" de Student 
Tabela 28 - Níveis séricos de glicose ( $\mathrm{mg} / \mathrm{dl})$, aldolase (u/l), GGT (u/l) e AST (u/l) de cabritos cujas mães consumiram ração contendo 0 e $3 \%$ de sementes de Senna occidentalis durante a gestação. São apresentadas as médias e os respectivos erros padrão, através do método dos quadrados mínimos. ANOVA, seguida de teste "T" de Student

\begin{tabular}{|c|c|c|c|}
\hline \multirow{2}{*}{ Substâncias } & \multirow{2}{*}{ Datas de coleta ${ }^{a}$} & \multicolumn{2}{|c|}{ Sementes de Senna occidentalis (\%) } \\
\hline & & 0 & 3 \\
\hline \multirow{4}{*}{$\begin{array}{l}\text { Glicose } \\
\text { (mg/dl) }\end{array}$} & 1 & $84,62 \pm 7,93(8)^{b}$ & $99,42 \pm 10,50(7)$ \\
\hline & 2 & $81,15 \pm 7,93(8)$ & $72,06 \pm 10,50(7)$ \\
\hline & 3 & $61,81 \pm 8,13(7)$ & $58,57 \pm 10,64(6)$ \\
\hline & 4 & $63,64 \pm 7,93(8)$ & $79,01 \pm 10,50(7)$ \\
\hline \multirow{4}{*}{$\begin{array}{l}\text { Aldolase } \\
\quad(\mathrm{U} / \mathrm{I})\end{array}$} & 1 & $12,18 \pm 1,77(8)$ & $17,78 \pm 2,35(7)$ \\
\hline & 2 & $13,57 \pm 1,77(8)$ & $14,92 \pm 2,35(7)$ \\
\hline & 3 & $10,85 \pm 1,82(7)$ & $14,38 \pm 2,38(6)$ \\
\hline & 4 & $11,51 \pm 1,77(8)$ & $12,66 \pm 2,35(7)$ \\
\hline \multirow{4}{*}{$\begin{array}{l}\text { GGT } \\
(\mathrm{U} / \mathrm{I})\end{array}$} & 1 & $37,03 \pm 5,56(8)$ & $32,63 \pm 7,36(7)$ \\
\hline & 2 & $45,71 \pm 5,56(8)$ & $24,78 \pm 7,36(7)$ \\
\hline & 3 & $44,17 \pm 5,70(7)$ & $30,94 \pm 7,47(6)$ \\
\hline & 4 & $43,51 \pm 5,56(8)$ & $29,73 \pm 7,36(7)$ \\
\hline \multirow{4}{*}{$\begin{array}{l}\text { AST } \\
\mathrm{U} / \mathrm{I})\end{array}$} & 1 & $56,99 \pm 8,15(8)$ & $68,94 \pm 10,79(7)$ \\
\hline & 2 & $75,43 \pm 8,15(8)$ & $98,06 \pm 10,79(7)$ \\
\hline & 3 & $99,10 \pm 8,15(8)$ & $106,25 \pm 10,79(7)$ \\
\hline & 4 & $108,34 \pm 8,15(8)$ & $132,2 \pm 10,79(7)$ \\
\hline
\end{tabular}

${ }^{a}$ Logo após o nascimento até o quarto mês de vida. 

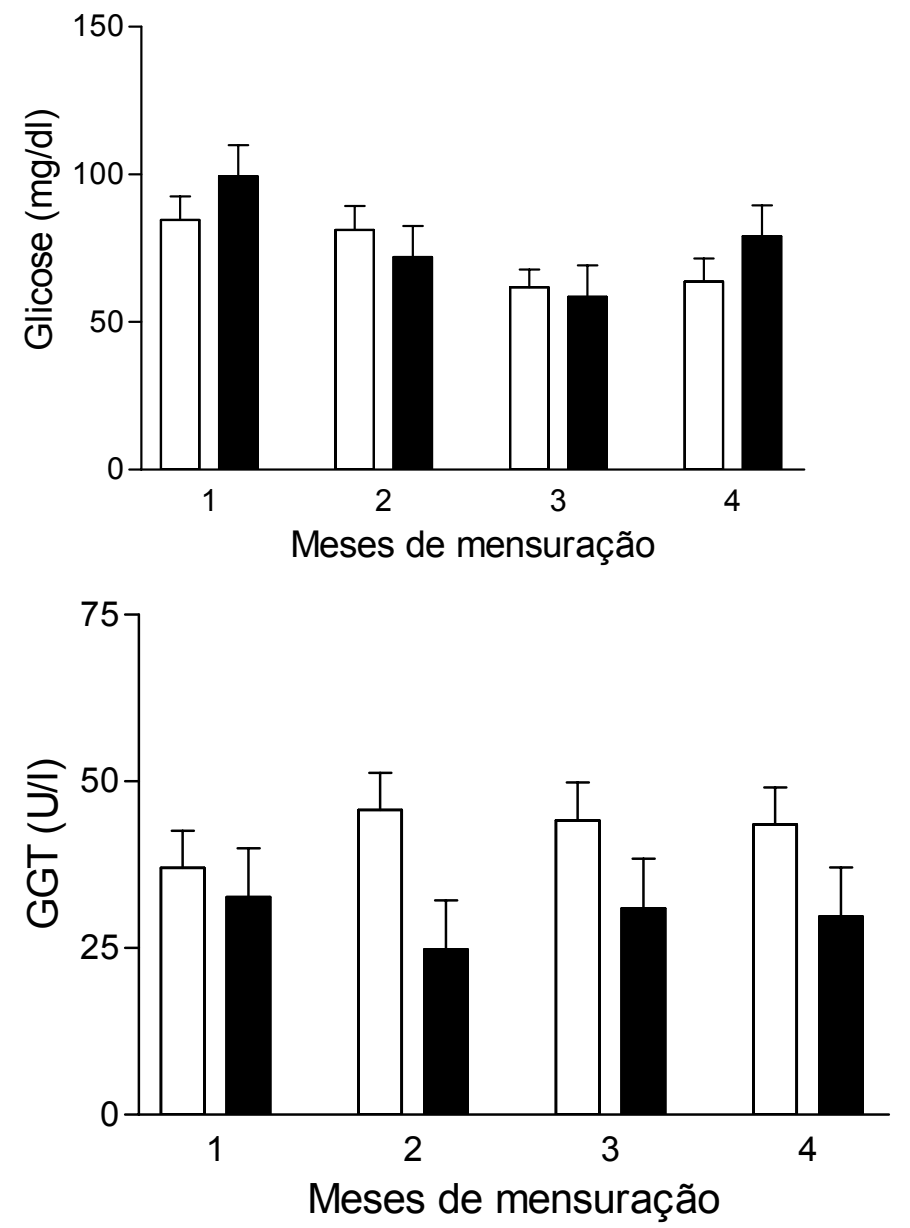
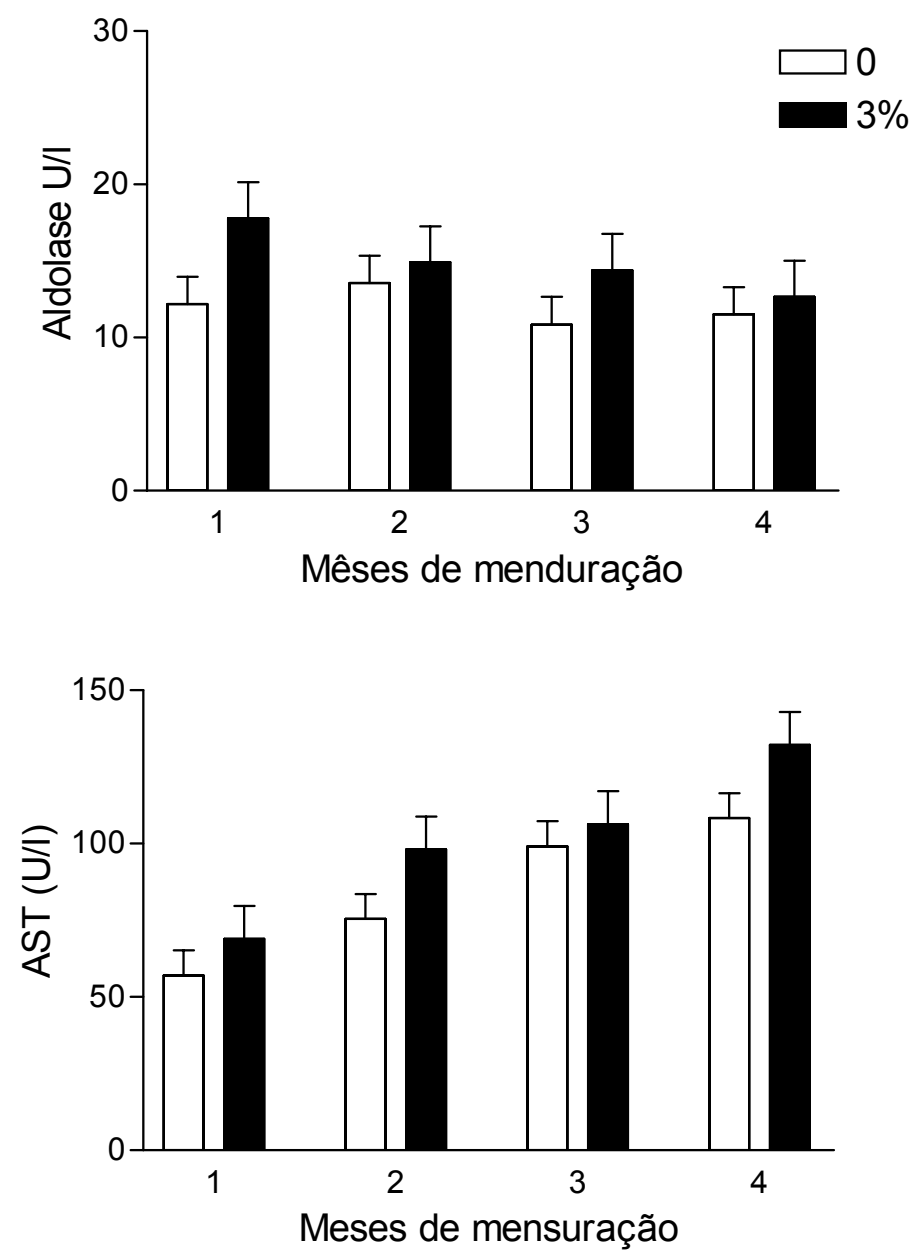

Figura 40 - Níveis séricos de glicose (mg/dl), aldolase (u/l), GGT (u/l) e AST (u/l) de cabritos de cabritos cujas mães consumiram ração contendo 0 e $3 \%$ de sementes de Senna occidentalis durante a gestação. São apresentadas as médias e os respectivos erros padrão, através do método dos quadrados mínimos. ANOVA, seguida de teste "T" de Student 
Tabela 29 - Níveis séricos de FA (u/l), CK (u/l) e LDH (u/l) de cabritos cujas mães consumiram ração contendo 0 e $3 \%$ de sementes de Senna occidentalis durante a gestação. São apresentadas as médias e os respectivos erros padrão, através do método dos quadrados mínimos. ANOVA, seguida de teste "T" de Student

\begin{tabular}{cccc}
\hline \multirow{2}{*}{ Substâncias } & $\begin{array}{c}\text { Datas de } \\
\text { coleta }^{\mathrm{a}}\end{array}$ & \multicolumn{2}{c}{ Sementes de Senna occidentalis (\%) } \\
\cline { 3 - 4 } & 1 & $\mathbf{0}$ & $\mathbf{3}$ \\
$\mathrm{FA}$ & 2 & $220,16 \pm 38,22(8)^{\mathrm{b}}$ & $270,70 \pm 50,57(7)$ \\
$(\mathrm{U} / \mathrm{l})$ & 3 & $244,88 \pm 38,22(8)$ & $243,65 \pm 50,57(7)$ \\
& 4 & $160,25 \pm 39,09(7)$ & $164,12 \pm 51,23(6)$ \\
& 1 & $182,51 \pm 38,22(8)$ & $149,88 \pm 50,57(7)$ \\
$\mathrm{CK}$ & 2 & $40,65 \pm 15,16(8)$ & $48,91 \pm 20,05(7)$ \\
$(\mathrm{U} / \mathrm{l})$ & 3 & $77,28 \pm 15,16(8)$ & $117,20 \pm 20,05(7)$ \\
& 4 & $59,81 \pm 15,53(7)$ & $138,36 \pm 20,34(6)$ \\
& & $40,13 \pm 15,16(8)$ & $58,39 \pm 20,05(7)$ \\
& 1 & $667,50 \pm 82,54(8)$ & $843,50 \pm 109,19(7)$ \\
LDH & 2 & $563,08 \pm 82,54(8)$ & $547,83 \pm 109,19(7)$ \\
$(\mathrm{U} / \mathrm{ll})$ & 3 & $190,50 \pm 84,29(7)$ & $367,26 \pm 110,52(6)$ \\
& 4 & $253,58 \pm 82,54(8)$ & $201,75 \pm 109,19(7)$ \\
\hline
\end{tabular}

Logo após o nascimento até o quarto mês de vida 

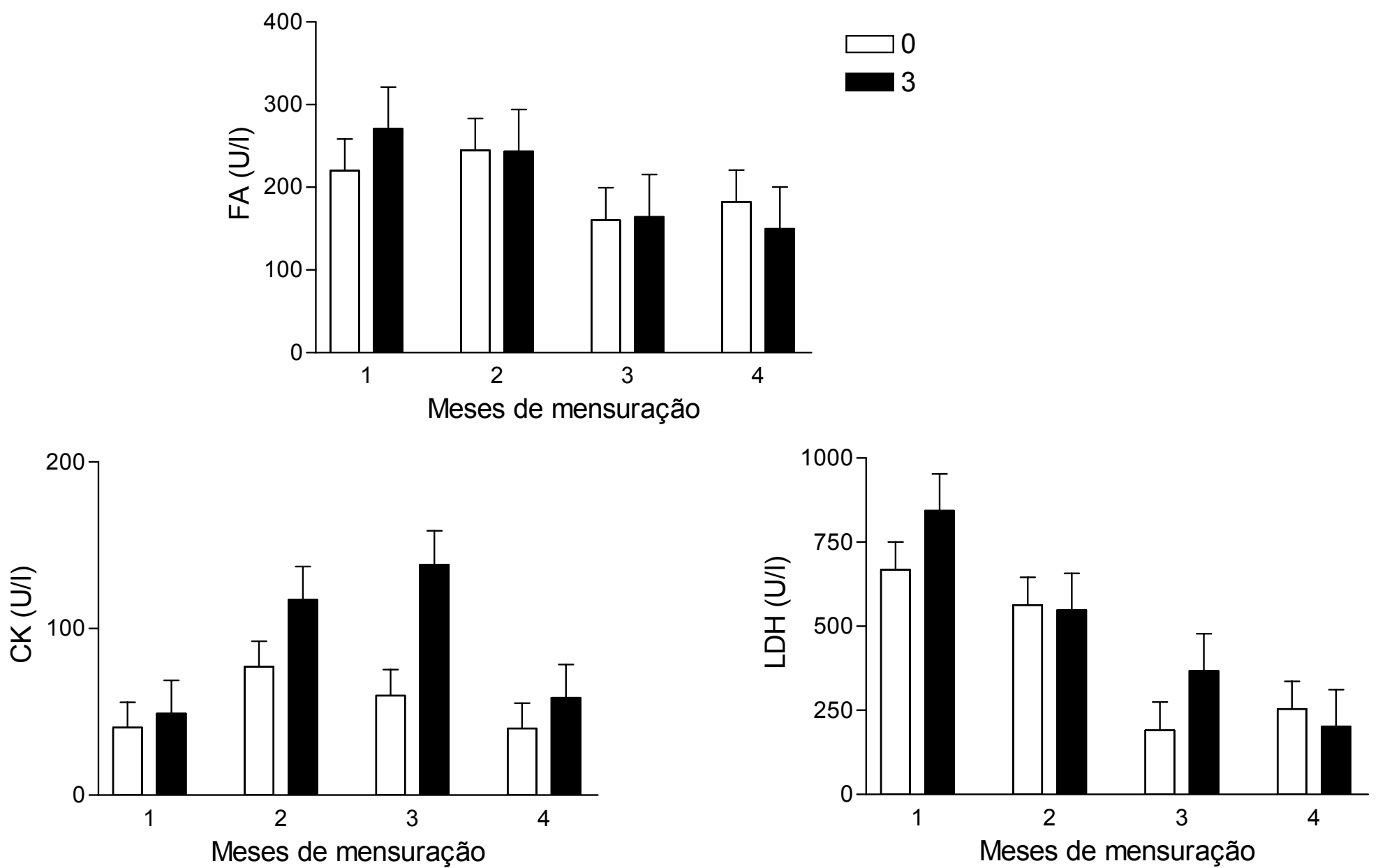

Figura 41- Níveis séricos de FA (u/l), CK (u/l) E LDH (u/l) de cabritos de cabritos cujas mães consumiram ração contendo 0 e $3 \%$ de Senna occidentalis durante a gestação. São apresentadas as médias e os respectivos erros padrão, através do método dos quadrados mínimos. ANOVA, seguida de teste "T" de Student 
Tabela 30 - Níveis séricos de proteína total (mg/dl), albumina (g/L), uréia (mg/dl) e creatinina (u/l) de cabritos cujas mães consumiram ração contendo 0 e $3 \%$ de sementes de Senna occidentalis durante a gestação. São apresentadas as médias e os respectivos erros padrão, através do método dos quadrados mínimos. ANOVA, seguida de teste "T" de Student

\begin{tabular}{|c|c|c|c|}
\hline \multirow{2}{*}{ Substâncias } & \multirow{2}{*}{ Datas de coleta ${ }^{a}$} & \multicolumn{2}{|c|}{ Sementes de Senna occidentalis (\%) } \\
\hline & & 0 & 3 \\
\hline \multirow{4}{*}{$\begin{array}{l}\text { Proteína total } \\
\qquad(\mathrm{mg} / \mathrm{dl})\end{array}$} & 1 & $8,28 \pm 0,68(8)^{b}$ & $6,99 \pm 0,90(7)$ \\
\hline & 2 & $3,11 \pm 0,68(8)$ & $4,44 \pm 0,90(7)$ \\
\hline & 3 & $3,58 \pm 0,70(7)$ & - \\
\hline & 4 & $5,19 \pm 0,68(8)$ & $3,50 \pm 0,90(7)$ \\
\hline \multirow{4}{*}{$\begin{array}{l}\text { Albumina } \\
\text { (g/l) }\end{array}$} & 1 & $2,80 \pm 0,42(8)$ & $2,94 \pm 0,55(7)$ \\
\hline & 2 & $2,99 \pm 0,42(8)$ & $3,21 \pm 0,55(7)$ \\
\hline & 3 & $3,76 \pm 0,43(7)$ & $3,35 \pm 0,56(6)$ \\
\hline & 4 & $3,47 \pm 0,42(8)$ & $4,38 \pm 0,55(7)$ \\
\hline \multirow{4}{*}{$\begin{array}{l}\text { Uréia } \\
\text { (mg/dl) }\end{array}$} & 1 & $29,75 \pm 4,16(8)$ & $16,58 \pm 5,50(7)$ \\
\hline & 2 & $20,50 \pm 4,16(8)$ & $26,43 \pm 5,50(7)$ \\
\hline & 3 & $32,52 \pm 4,25(7)$ & $26,05 \pm 5,57(6)$ \\
\hline & 4 & $47,76 \pm 4,16(8)$ & $44,80 \pm 5,50(7)$ \\
\hline \multirow{4}{*}{$\begin{array}{l}\text { Creatinina } \\
\quad(U / I)\end{array}$} & 1 & $0,72 \pm 0,09(8)$ & $0,67 \pm 0,13(7)$ \\
\hline & 2 & $0,61 \pm 0,09(8)$ & $0,62 \pm 0,13(7)$ \\
\hline & 3 & $0,33 \pm 0,10(7)$ & $0,58 \pm 0,13(6)$ \\
\hline & 4 & $0,20 \pm 0,09(8)$ & $0,17 \pm 0,13(7)$ \\
\hline
\end{tabular}



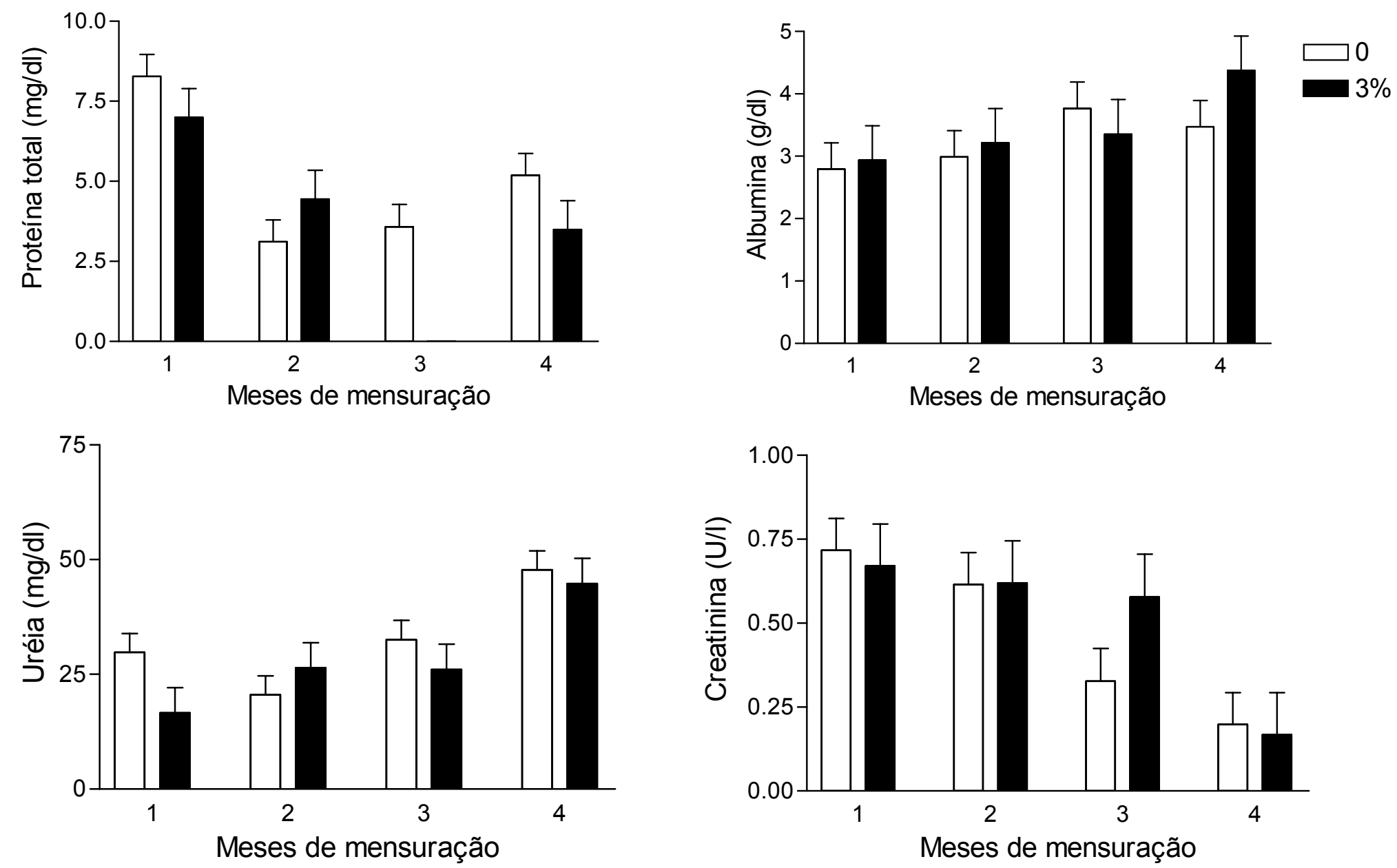

Figura 42 - Níveis séricos de proteína total (mg/dl), albumina $(\mathrm{g} / \mathrm{l})$, uréia $(\mathrm{mg} / \mathrm{dl})$ e creatinina (u/l) de cabritos cujas mães consumiram ração contendo 0 e $3 \%$ de sementes de Senna occidentalis durante a gestação. São apresentadas as médias e os respectivos erros padrão, através do método dos quadrados mínimos. ANOVA, seguida de teste "T" de Student 
Tabela 31 - Altura corporal (AC), comprimento corporal (CC), perímetro torácico (PT) e comprimento da tíbia (CTib) de cabritos cujas mães consumiram ração contendo 0 e $3 \%$ de sementes de Senna occidentalis durante a gestação. São apresentadas as médias e os respectivos erros padrão, através do método dos quadrados mínimos. ANOVA, seguida de teste "T" de Student

\begin{tabular}{|c|c|c|c|}
\hline \multirow{2}{*}{$\begin{array}{l}\text { Parâmetros } \\
\text { (cm) }\end{array}$} & \multirow{2}{*}{ Datas de coleta ${ }^{a}$} & \multicolumn{2}{|c|}{ Sementes de Senna occidentalis (\%) } \\
\hline & & 0 & 1 \\
\hline \multirow{5}{*}{ Altura } & 0 & $34,04 \pm 1,53(8)^{\mathbf{b}}$ & $33,83 \pm 2,02(7)$ \\
\hline & 1 & $38,50 \pm 1,53(8)$ & $37,50 \pm 2,02(7)$ \\
\hline & 2 & $45,00 \pm 1,53(8)$ & $42,42 \pm 2,02(7)$ \\
\hline & 3 & $45,50 \pm 1,53(8)$ & $45,50 \pm 2,02(7)$ \\
\hline & 4 & $48,54 \pm 1,53(8)$ & $48,29 \pm 2,02(7)$ \\
\hline \multirow{5}{*}{$\mathrm{CC}$} & 0 & $30,08 \pm 1,48(8)$ & $27,79 \pm 1,95(7)$ \\
\hline & 1 & $36,25 \pm 1,48(8)$ & $34,33 \pm 1,95(7)$ \\
\hline & 2 & $40,37 \pm 1,48(8)$ & $39,42 \pm 1,95(7)$ \\
\hline & 3 & $42,87 \pm 1,48(8)$ & $40,75 \pm 1,95(7)$ \\
\hline & 4 & $44,70 \pm 1,48(8)$ & $44,25 \pm 1,95(7)$ \\
\hline \multirow{5}{*}{ PT } & 0 & $29,92 \pm 1,94(8)$ & $34,17 \pm 2,56(7)$ \\
\hline & 1 & $41,42 \pm 1,94(8)$ & $42,08 \pm 2,56(7)$ \\
\hline & 2 & $46,42 \pm 1,94(8)$ & $46,17 \pm 2,56(7)$ \\
\hline & 3 & $48,62 \pm 1,94(8)$ & $48,37 \pm 2,56(7)$ \\
\hline & 4 & $53,33 \pm 1,94(8)$ & $51,75 \pm 2,56(7)$ \\
\hline \multirow{5}{*}{ CTIB } & 0 & $12,04 \pm 0,59(8)$ & $11,33 \pm 0,78(7)$ \\
\hline & 1 & $12,96 \pm 0,59(8)$ & $12,54 \pm 0,78(7)$ \\
\hline & 2 & $14,25 \pm 0,59(8)$ & $14,50 \pm 0,78(7)$ \\
\hline & 3 & $15,58 \pm 0,59(8)$ & $15,75 \pm 0,78(7)$ \\
\hline & 4 & $16,70 \pm 0,59(8)$ & $16,29 \pm 0,78(7)$ \\
\hline
\end{tabular}



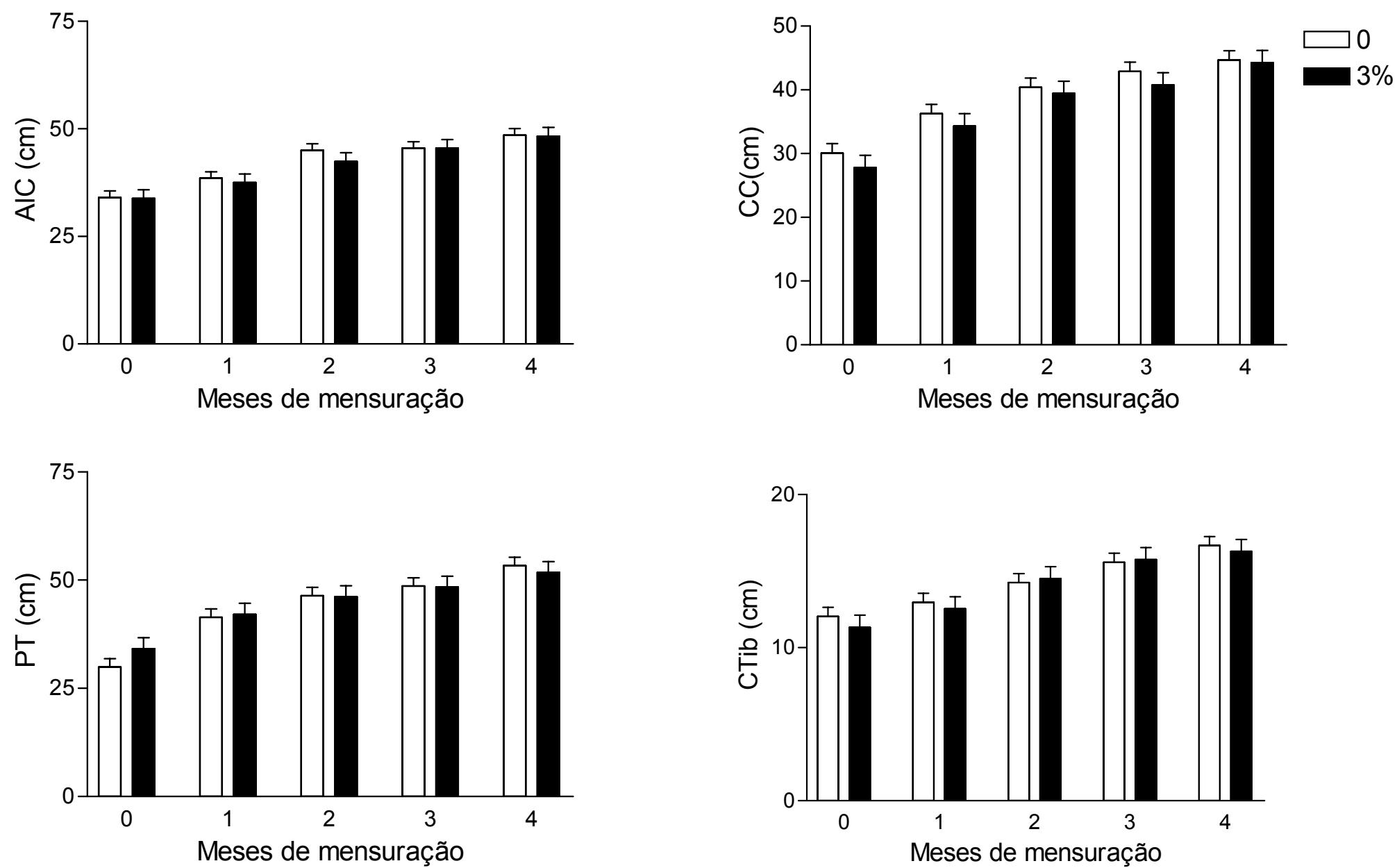

Figura 43 - Altura corporal (AC), comprimento corporal (CC), perímetro torácico (PT) e comprimento da tíbia (CTib) de cabritos cujas mães consumiram ração contendo 0 e $3 \%$ de sementes de Senna occidentalis durante a gestação. São apresentadas as médias e os respectivos erros padrão, através do método dos quadrados mínimos. ANOVA, seguida de teste "T" de Student 
Tabela 32 - Comprimento do rádio (CRad), comprimento do metatarso (CMT), comprimento do metacarpo (CMC) e comprimento da cabeça (CCab) de cabritos cujas mães consumiram ração contendo 0 e $3 \%$ de sementes de sementes de Senna occidentalis durante a gestação. São apresentadas as médias e os respectivos erros padrão. ANOVA, seguida de teste $T$ de Student

\begin{tabular}{|c|c|c|c|}
\hline \multirow{2}{*}{$\begin{array}{l}\text { Parâmetros } \\
\text { (cm) }\end{array}$} & \multirow{2}{*}{$\begin{array}{l}\text { Datas de } \\
\text { coleta }^{a}\end{array}$} & \multicolumn{2}{|c|}{ Sementes de Senna occidentalis (\%) } \\
\hline & & 0 & LAC \\
\hline & 0 & $9,58 \pm 0,54(8)^{b}$ & $9,71 \pm 0,72(7)$ \\
\hline & 1 & $11,04 \pm 0,54(8)$ & $11,12 \pm 0,72(7)$ \\
\hline \multirow[t]{5}{*}{ CRad } & 2 & $11,50 \pm 0,54(8)$ & $11,83 \pm 0,72(7)$ \\
\hline & 3 & $12,62 \pm 0,54(8)$ & $12,20 \pm 0,72(7)$ \\
\hline & 4 & $13,37 \pm 0,54(8)$ & $13,83 \pm 0,72(7)$ \\
\hline & 0 & $9,29 \pm 0,39(8)$ & $8,92 \pm 0,51(7)$ \\
\hline & 1 & $10,37 \pm 0,39(8)$ & $9,30 \pm 0,51(7)$ \\
\hline \multirow[t]{5}{*}{$\mathrm{CMT}$} & 2 & $10,62 \pm 0,39(8)$ & $9,71 \pm 0,51(7)$ \\
\hline & 3 & $11,50 \pm 0,39(8)$ & $10,62 \pm 0,51(7)$ \\
\hline & 4 & $11,62 \pm 0,39(8)$ & $11,79 \pm 0,51(7)$ \\
\hline & 0 & $7,33 \pm 0,42(8)$ & $7,54 \pm 0,55(7)$ \\
\hline & 1 & $8,42 \pm 0,42(8)$ & $7,87 \pm 0,55(7)$ \\
\hline \multirow[t]{5}{*}{ CMC } & 2 & $8,79 \pm 0,42(8)$ & $8,25 \pm 0,55(7)$ \\
\hline & 3 & $9,29 \pm 0,42(8)$ & $9,58 \pm 0,55(7)$ \\
\hline & 4 & $9,50 \pm 0,42(8)$ & $9,04 \pm 0,55(7)$ \\
\hline & 0 & $16,83 \pm 0,76(8)^{\mathbf{b}}$ & $15,37 \pm 1,00(7)$ \\
\hline & 1 & $19,17 \pm 0,76(8)$ & $18,67 \pm 1,00(7)$ \\
\hline \multirow[t]{3}{*}{ CCab } & 2 & $20,58 \pm 0,76(8)$ & $20,25 \pm 1,00(7)$ \\
\hline & 3 & $22,71 \pm 0,76(8)$ & $21,75 \pm 1,00(7)$ \\
\hline & 4 & $24,17 \pm 0,76(8)$ & $24,00 \pm 1,00(7)$ \\
\hline
\end{tabular}

a logo após o nascimento até o quarto mês de vida.

${ }^{\mathrm{b}}$ entre parênteses o número de animais avaliados. 

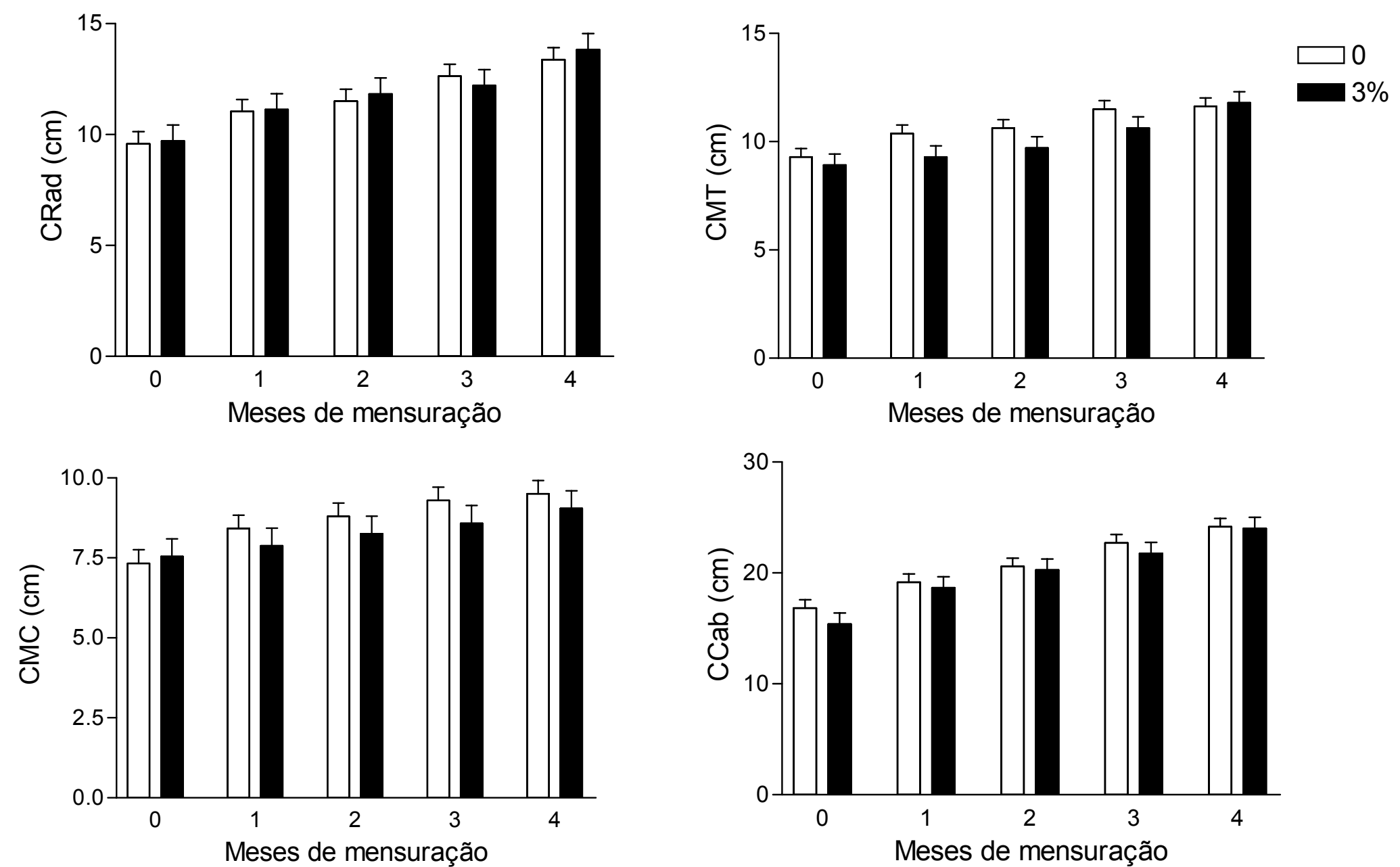

Figura 44 - Comprimento do rádio (CRad), comprimento do metatarso (CMT), comprimento do metacarpo (CMC) e comprimento da cabeça (CCab) de cabritos cujas mães consumiram ração contendo 0 e $3 \%$ de sementes de sementes de Senna occidentalis durante a gestação. São apresentadas as médias e os respectivos erros padrão. ANOVA, seguida de teste T de Student 
Tabela 33 - Diâmetro da cabeça (DCab), circunferência do metatarso (CIMT) e circunferência do metacarpo (CIMC) de cabritos cujas mães consumiram ração contendo 0 e $3 \%$ de sementes de Senna occidentalis durante a gestação. São apresentadas as médias e os respectivos erros padrão. ANOVA, seguida de teste T de Student

\begin{tabular}{cccc}
\hline $\begin{array}{c}\text { Parâmetros } \\
(\mathbf{c m})\end{array}$ & $\begin{array}{c}\text { Datas de } \\
\text { coleta }^{\mathbf{a}}\end{array}$ & \multicolumn{2}{c}{ Sementes de Senna occidentalis (\%) } \\
\cline { 3 - 4 } & 0 & $12,25 \pm 0,39(8)$ & LAC \\
\hline DCab & 1 & $13,00 \pm 0,39(8)$ & $12,75 \pm 0,52(7)$ \\
& 2 & $13,92 \pm 0,39(8)$ & $12,96 \pm 0,52(7)$ \\
& 3 & $14,67 \pm 0,39(8)$ & $14,42 \pm 0,52(7)$ \\
& 4 & $15,33 \pm 0,39(8)$ & $15,08 \pm 0,52(7)$ \\
& & & \\
CIMT & 0 & $5,79 \pm 0,23(8)$ & $5,50 \pm 0,31(7)$ \\
& 1 & $6,33 \pm 0,23(8)$ & $5,96 \pm 0,31(7)$ \\
& 3 & $6,67 \pm 0,23(8)$ & $6,17 \pm 0,31(7)$ \\
& 4 & $6,79 \pm 0,23(8)$ & $6,46 \pm 0,31(7)$ \\
& & $6,87 \pm 0,23(8)$ & $6,75 \pm 0,31(7)$ \\
CIMC & 0 & $5,78 \pm 0,24(8)$ & $5,19 \pm 0,31(7)$ \\
& 1 & $6,12 \pm 0,24(8)$ & $5,46 \pm 0,31(7)$ \\
& 2 & $6,62 \pm 0,24(8)$ & $6,12 \pm 0,31(7)$ \\
& 3 & $6,83 \pm 0,24(8)$ & $6,71 \pm 0,31(7)$ \\
& 4 & $6,92 \pm 0,24(8)$ & $6,96 \pm 0,31(7)$ \\
\hline
\end{tabular}

${ }^{a}$ logo após o nascimento até o quarto mês de vida.

${ }^{\mathrm{b}}$ entre parênteses o número de animais avaliados 

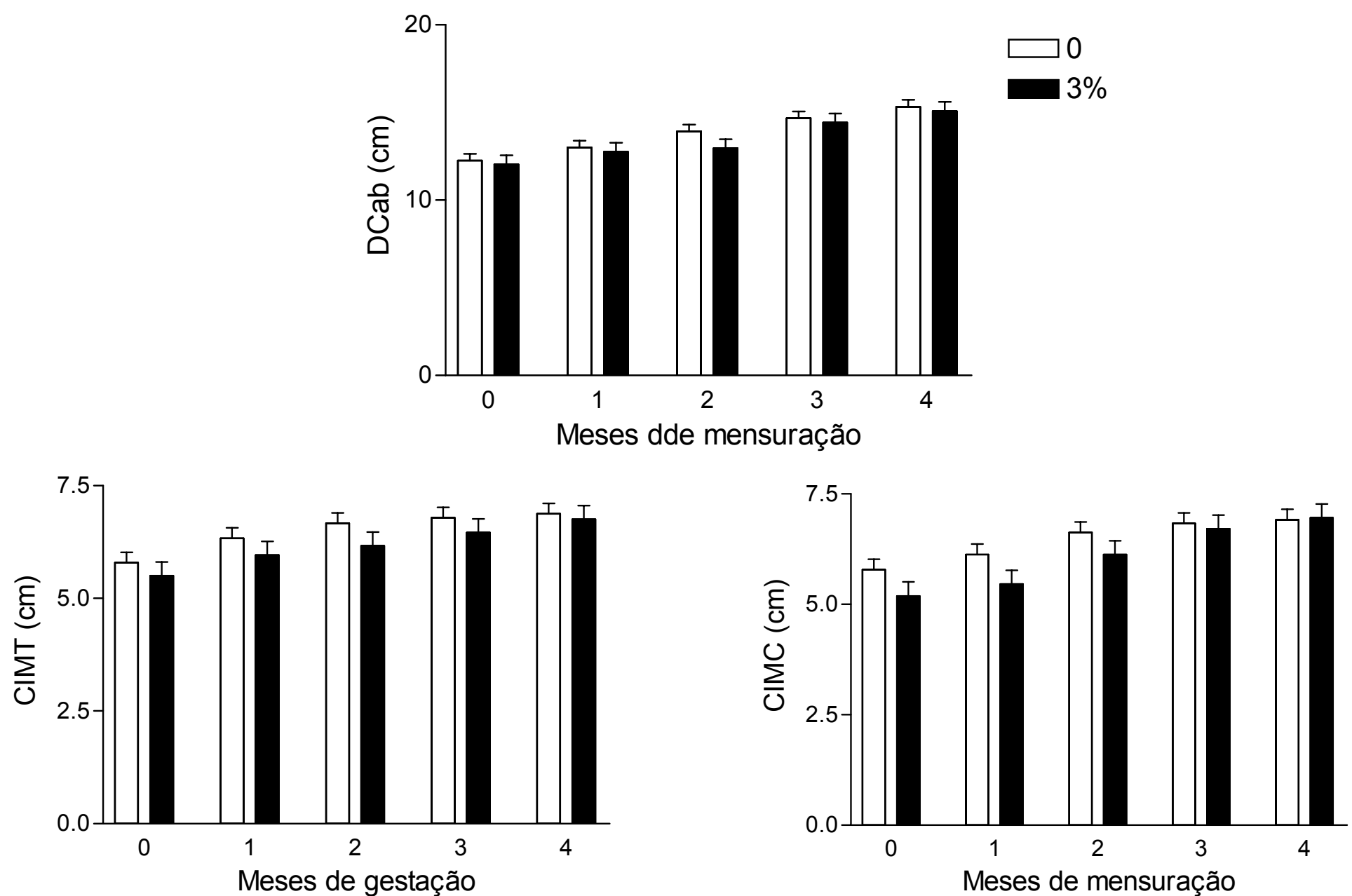

Figura 45 - Diâmetro da cabeça (DCab), circunferência do metatarso (CIMT) e circunferência do metacarpo (CIMC) de cabritos cujas mães consumiram ração contendo 0 e $3 \%$ de sementes de Senna occidentalis durante a gestação. São apresentadas as médias e os respectivos erros padrão. ANOVA, seguida de teste T de Student 
Tabela 34 - Labirinto progressivo realizado por cabritos cujas mães consumiram ração contendo 0 e $3 \%$ de sementes de Senna occidentalis durante a gestação. São apresentadas as médias e os respectivos erros padrão.

\begin{tabular}{|c|c|c|c|}
\hline \multirow{2}{*}{$\begin{array}{l}\text { Labirinto } \\
\text { Progressivo }\end{array}$} & \multirow{2}{*}{ Sessões } & \multicolumn{2}{|c|}{ Sementes de Senna occidentalis (\%) } \\
\hline & & 0 & 3 \\
\hline \multirow{3}{*}{$2^{\circ}$ dia } & $1^{\circ}$ & $52,50 \pm 11,40(8)^{a}$ & $50,00 \pm 28,94(7)$ \\
\hline & $2^{\circ}$ & $10,91 \pm 1,50(8)^{*}$ & $24,60 \pm 5,65(7)^{*}$ \\
\hline & $3^{\circ}$ & $7,55 \pm 1,97(8)^{*}$ & $22,33 \pm 5,81(4)^{*}$ \\
\hline \multirow{3}{*}{$4^{\circ}$ dia } & $1^{0}$ & $28,00 \pm 10,92(8)$ & $27,00 \pm 8,70(7)$ \\
\hline & $2^{\circ}$ & $10,75 \pm 4,98(8)^{*}$ & $9,50 \pm 2,02(6)^{*}$ \\
\hline & $3^{\circ}$ & $5,75 \pm 1,93(8)^{*}$ & $8,20 \pm 1,24(4)^{*}$ \\
\hline \multirow{3}{*}{$6^{\circ} \mathrm{dia}$} & $1^{\circ}$ & $29,26 \pm 8,98(8)$ & $36,21 \pm 16,52(7)$ \\
\hline & $2^{\circ}$ & $11,75 \pm 6,02(8)^{*}$ & $10,57 \pm 4,40(7)^{*}$ \\
\hline & $3^{\circ}$ & $6,75 \pm 2,06(8)^{*}$ & $7,29 \pm 2,30(7)^{*}$ \\
\hline \multirow{3}{*}{ Tempos totais } & $2^{\circ}$ dia & $23,66 \pm 4,96(8)^{a}$ & $24,24 \pm 13,47(7)$ \\
\hline & $4^{\circ}$ dia & $14,83 \pm 5,78(8)$ & $14,90 \pm 3,99(7)$ \\
\hline & $6^{\circ} \mathrm{dia}$ & $15,92 \pm 5,68(8)$ & $18,02 \pm 7,74(7)$ \\
\hline
\end{tabular}



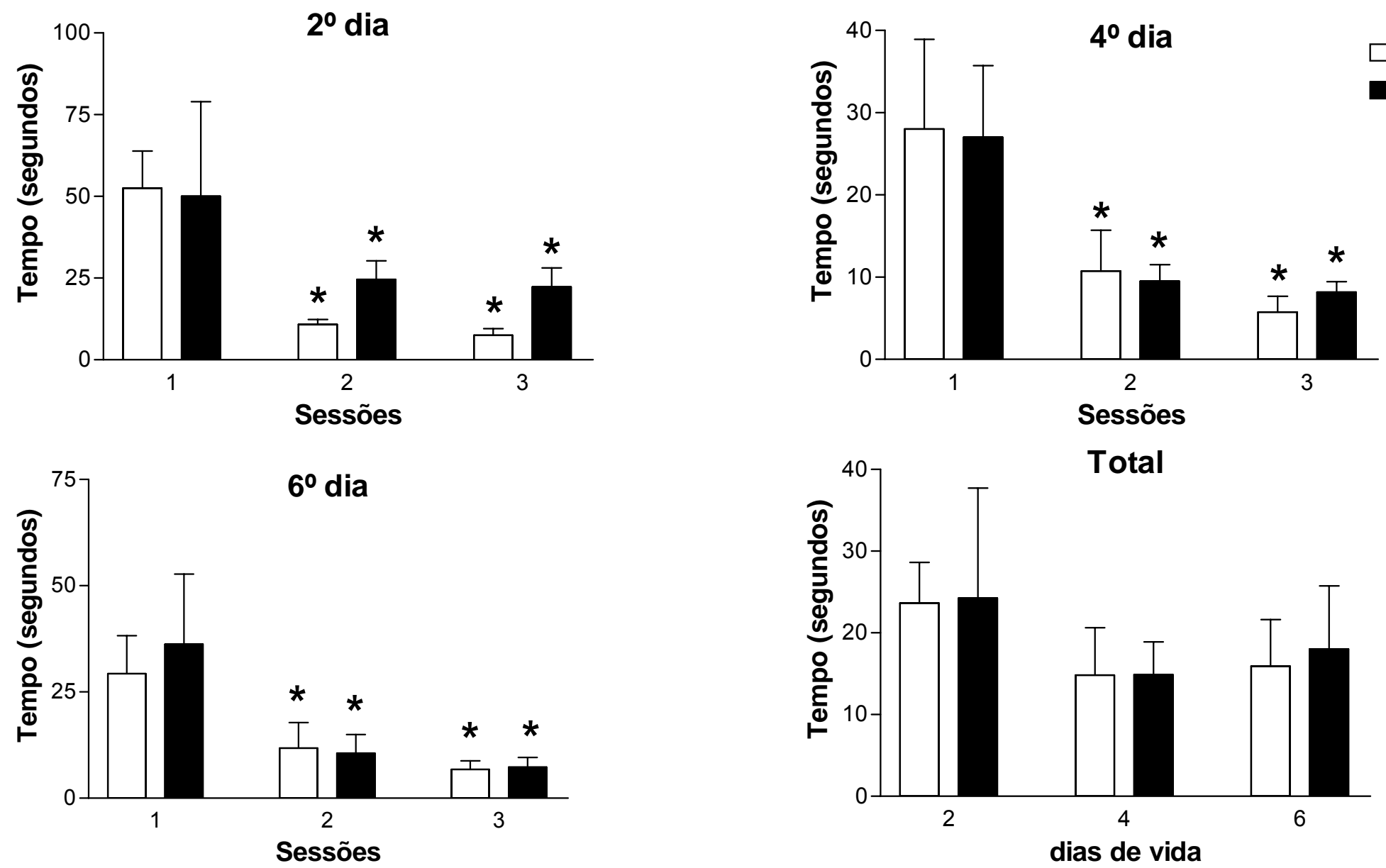

${ }^{*} P<0,10$, diferem da primeira sessão. PDIFF, seguida de teste $F$.

Figura 46 - Labirinto progressivo realizado por cabritos cujas mães consumiram ração contendo 0 e $3 \%$ de sementes de Senna occidentalis durante a gestação. São apresentadas as médias e os respectivos erros padrão. 
Tabela 35 - Labirinto em T (tempo total até a mãe) realizado por cabritos cujas mães consumiram ração contendo 0 e $3 \%$ de sementes de Senna occidentalis durante a gestação. São apresentadas as médias e os respectivos erros padrão

\begin{tabular}{cccc}
\hline \multirow{2}{*}{ Labirinto T } & \multirow{2}{*}{ Sessão } & \multicolumn{2}{c}{ Sementes de Senna occidentalis (\%) } \\
\cline { 3 - 4 } & & 0 & 3 \\
\hline \multirow{2}{*}{ Médias de todos } & T1 & $16,57 \pm 3,92(8)$ & $29,17 \pm 14,26(7)$ \\
os testes & T2 & $12,17 \pm 1,27(8)$ & $14,83 \pm 3,41(7)$ \\
& T3 & $8,30 \pm 1,13(8)$ & $27,08 \pm 8,97(7)^{*}$ \\
& T4 & $12,13 \pm 1,24(8)$ & $13,36 \pm 2,23(7)$ \\
\hline
\end{tabular}

a: número de animais avaliados.

${ }^{*} \mathrm{P}<0,10$, diferem da primeira sessão. PDIFF, seguida de teste $\mathrm{F}$.

T1= mãe sozinha em um dos braços; T2= mãe sozinha no outro braço; T3 mãe em um braço e outra cabra no outro, T4= mãe e outra cabra invertidas.

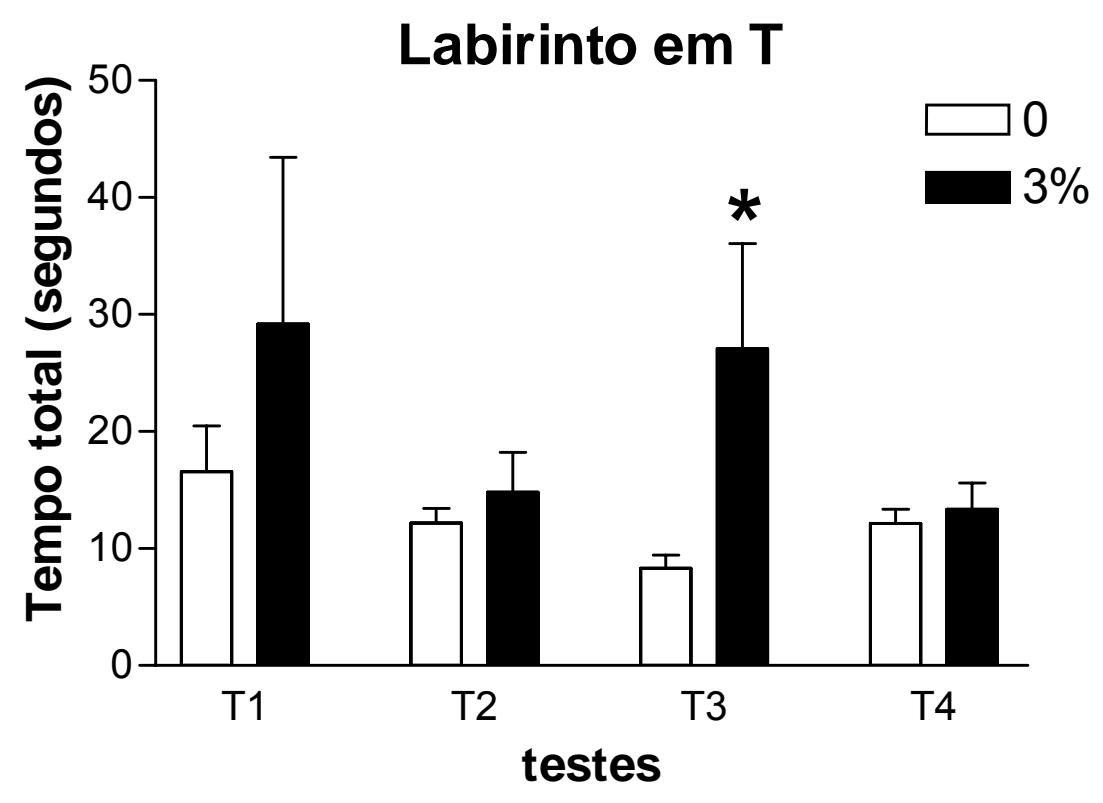

${ }^{*} \mathrm{P}<0,10$, diferem da primeira sessão. PDIFF, seguida de teste $\mathrm{F}$

Figura 47 - Labirinto em T (tempo total até a mãe) realizado por cabritos cujas mães consumiram ração contendo 0 e $3 \%$ de sementes de Senna occidentalis durante a gestação. São apresentadas as médias e os respectivos erros padrão. 
Tabela 36 - Labirinto médio realizado por cabritos cujas mães consumiram ração contendo 0 e $3 \%$ de sementes de Senna occidentalis durante a gestação. São apresentadas as médias e os respectivos erros padrão. PDIFF, seguida de teste $F$

\begin{tabular}{|c|c|c|c|}
\hline \multirow{2}{*}{ Labirinto M } & \multirow{2}{*}{ Áreas } & \multicolumn{2}{|c|}{ Sementes de Senna occidentalis (\%) } \\
\hline & & 0 & 3 \\
\hline \multirow{4}{*}{$6^{\mathrm{a}}$ semana } & $1^{\circ}$ corredor & $25,83 \pm 3,49(8)^{a}$ & $25,92 \pm 4,76(6)$ \\
\hline & $2^{\circ}$ corredor & $21,79 \pm 3,48(8)$ & $20,19 \pm 2,86(6)$ \\
\hline & $3^{\circ}$ corredor & $34,42 \pm 4,21(8)$ & $37,71 \pm 4,98(6)$ \\
\hline & $4^{\circ}$ corredor & $17,95 \pm 1,84(8)$ & $16,17 \pm 1,63(6)$ \\
\hline \multirow{4}{*}{$8^{a}$ semana } & $1^{\circ}$ corredor & $18,08 \pm 3,02(8)$ & $22,40 \pm 1,78(6)$ \\
\hline & $2^{\circ}$ corredor & $41,23 \pm 4,87(8)$ & $28,33 \pm 3,09(5)$ \\
\hline & $3^{\circ}$ corredor & $24,26 \pm 4,35(8)$ & $25,63 \pm 2,92(5)$ \\
\hline & $4^{\circ}$ corredor & $16,43 \pm 1,63(8)$ & $23,64 \pm 2,64(5)$ \\
\hline \multirow{4}{*}{$10^{a}$ semana } & $1^{\circ}$ corredor & $19,19 \pm 2,06(8)$ & $17,26 \pm 2,40(6)$ \\
\hline & $2^{\circ}$ corredor & $37,72 \pm 4,23(8)$ & $39,37 \pm 4,78(6)$ \\
\hline & $3^{\circ}$ corredor & $18,10 \pm 1,67(8)$ & $20,60 \pm 1,95(6)$ \\
\hline & $4^{\circ}$ corredor & $25,82 \pm 2,16(7)$ & $22,77 \pm 2,52(6)$ \\
\hline \multirow{3}{*}{ Tempos totais } & M1 & $29,84 \pm 5,00(8)$ & $30,77 \pm 9,37(6)$ \\
\hline & M2 & $26,53 \pm 4,33(8)$ & $14,24 \pm 1,84(6)$ \\
\hline & M3 & $17,62 \pm 2,25(8)$ & $28,06 \pm 7,78(6)$ \\
\hline
\end{tabular}



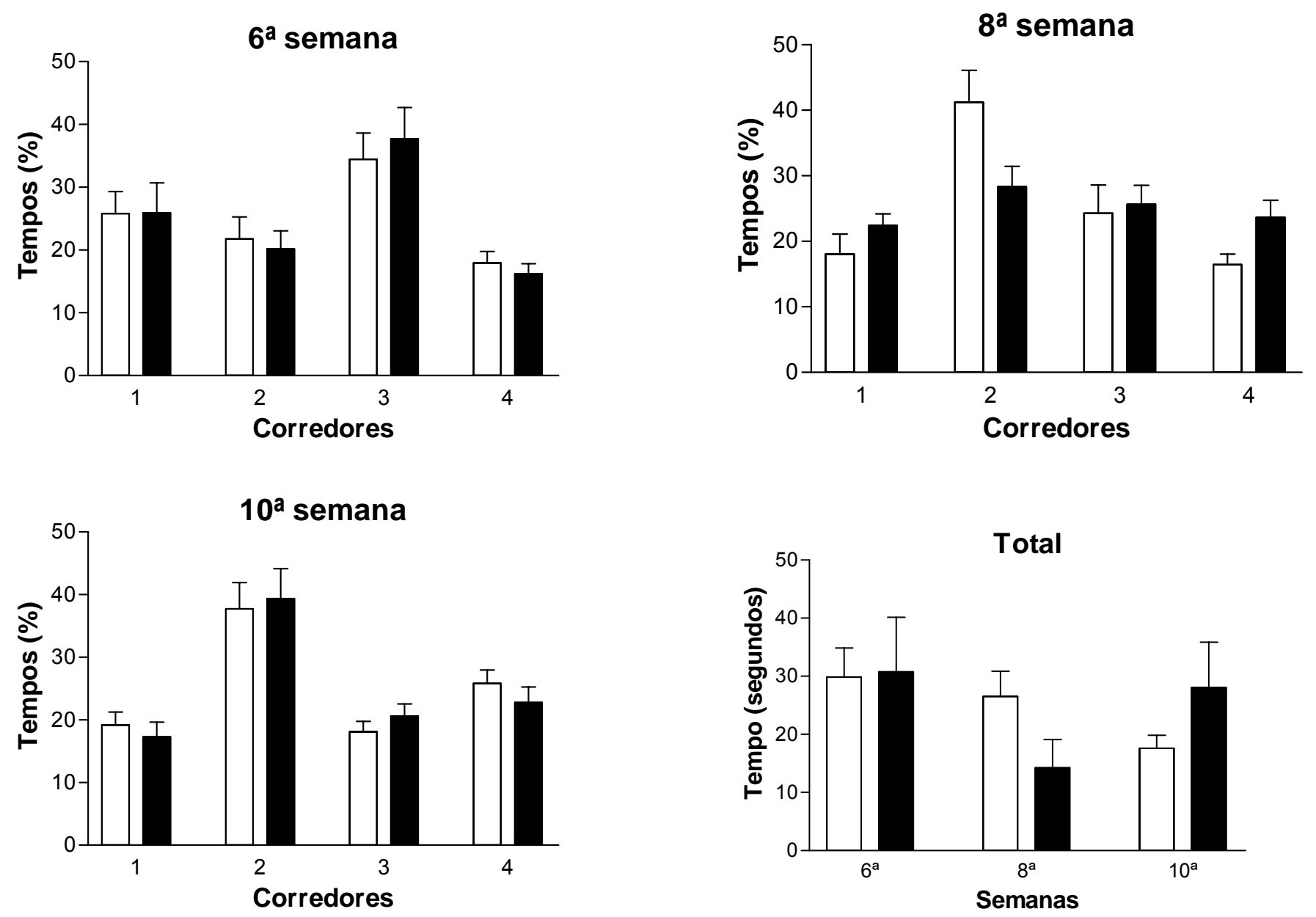

Figura 48 - Labirinto médio realizado por cabritos cujas mães consumiram ração contendo 0 e $3 \%$ de sementes de Senna occidentalis durante a gestação. São apresentadas as médias e os respectivos erros padrão. PDIFF, seguida de teste $\mathrm{F}$ 


Tabela 37 - Labirinto difícil realizado por cabritos cujas mães consumiram ração
contendo 0 e $3 \%$ de sementes de Senna occidentalis durante a
gestação. São apresentadas as médias e os respectivos erros
padrão. PDIFF, seguida de teste F

a: número de animais avaliados.

$* \mathrm{P}<0,10$, diferem da primeira sessão. $\mathrm{PDIFF}$, seguida de teste $\mathrm{F}$ 
$6^{\mathrm{a}}$ semana

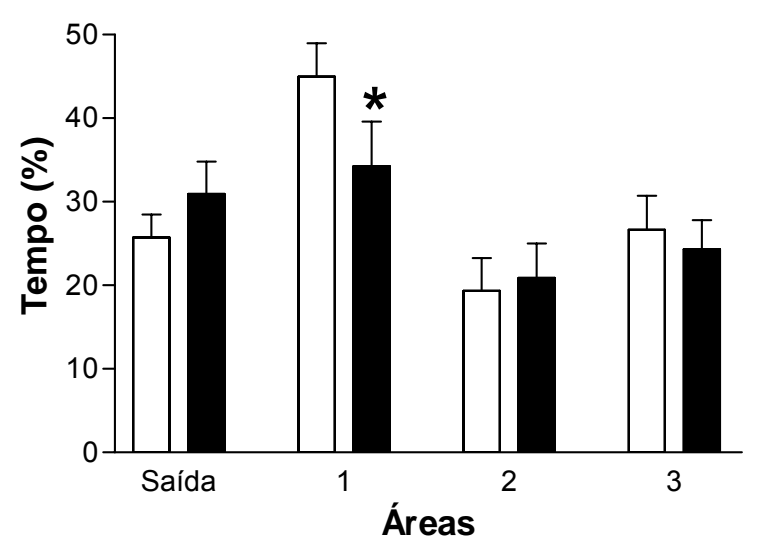

$10^{\mathrm{a}}$ semana

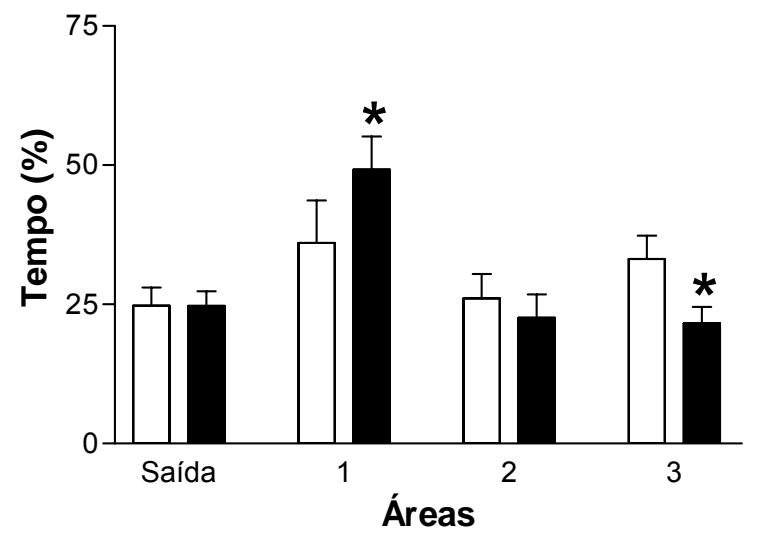

$8^{\mathrm{a}}$ semana

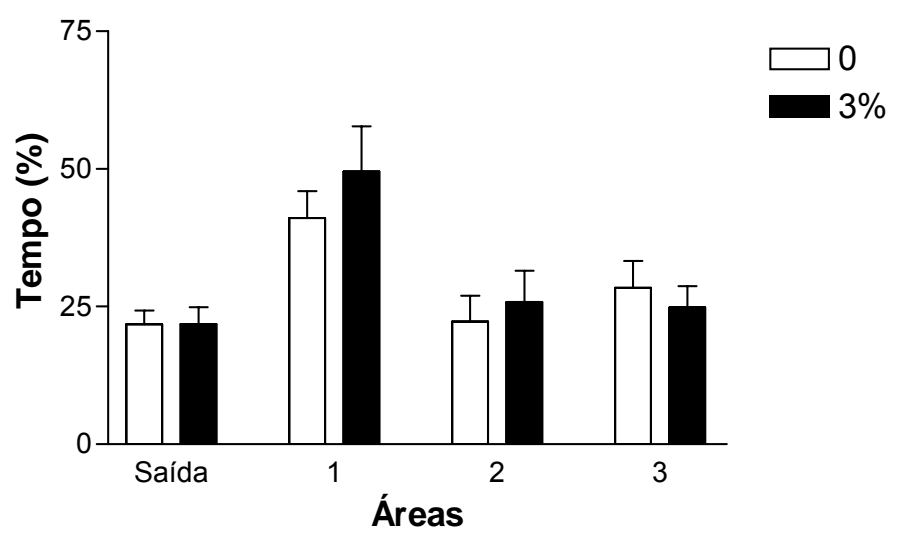

Labirinto difícil

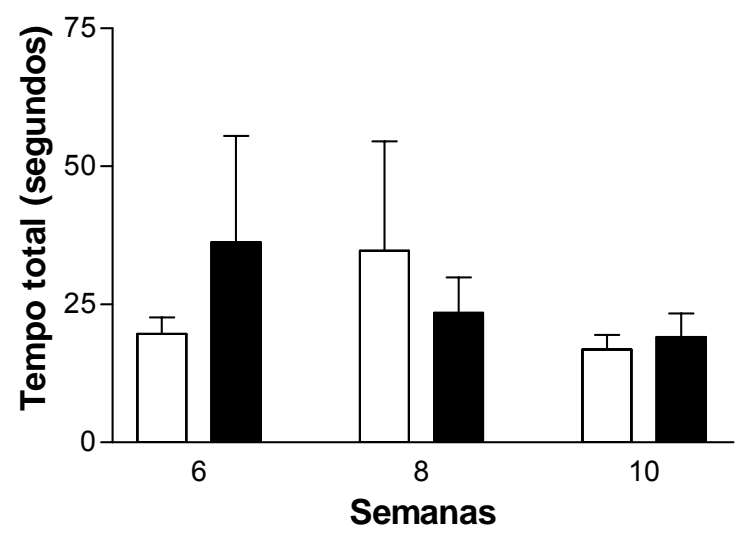

${ }^{*} P<0,10$, diferem da primeira sessão. PDIFF, seguida de teste $F$

Figura 49 - Labirinto difícil realizado por cabritos cujas mães consumiram ração contendo 0 e $3 \%$ de sementes de Senna occidentalis durante a gestação. São apresentadas as médias e os respectivos erros padrão 


\subsection{EXPERIMENTO 4: ESTUDO DOS EFEITOS TÓXICOS PRODUZIDOS PELA $S$. occidentalis ADMINISTRADO A CABRAS DURANTE A LACTAÇÃO. AVALIAÇÃO DOS LACTENTES}

A tabela 38 mostra e a figura 50 ilustra o ganho de peso mensal e total da prole. A análise de variância revelou não haver diferença significante $(P>0,05)$ entre os valores dos diferentes grupos durante o período de 4 meses após o nascimento.

Quanto aos níveis séricos de glicose e das enzimas GGT e AST destes filhotes, a análise da variância utilizada revelou não haver diferença significante $(P>0,05)$ entre os grupos (Tabela 39 e Figura 51).

Quanto à atividade sérica da enzima aldolase destes filhotes, a análise da variância utilizada revelou haver diferenças significantes $(P<0,05)$, entre grupos. O teste "T" de Student revelou diminuição significante na atividade desta enzima, naqueles animais do grupo LAC durante o quarto mês, quando comparados com aqueles resultados obtidos dos animais do grupo controle $(F=3,05$ e $D F=3 / 27 ; P<0,05)$ (Tabela 39 e Figura 51).

A tabela 40 mostra e figura 52 ilustra a atividade das enzimas FA, CK e LDH, além do nível de triglicerídeos sangüíneos, quando submetidos à ANOVA, não foram observadas alterações significantes $(P>0,05)$. O mesmo foi observado para os níveis de proteína, albumina e creatinina (Tabela 41 e Figura 53).

A análise da variância utilizada revelou haver diferenças significantes $(P<0,05)$, no nível de uréia entre grupos. O teste "T" de Student revelou diminuição significante na atividade desta enzima, naqueles animais do grupo LAC durante o segundo mês, quando comparados com aqueles resultados obtidos dos animais do grupo controle $(F=9,83$ e $\mathrm{DF}=3 / 27 ; \mathrm{P}<0,05)$ (Tabela 41 e Figura 53).

Os níveis de colesterol não apresentarm diferenças signioficantes $(P>0,05)$ entre os grupos avaliados (Tabela 42 e Figura 54).

A avaliação da morfometria corporal, quando submetidas à ANOVA, revelou haver diferença significante $(P<0,05)$, no parâmetro $C C$, o subseqüente teste " $T$ " indicou diferença significante $(F=5,0 ; D F=4 / 36 ; P<0,05)$, no primeiro mês de idade, em relação aos animais pertencentes ao grupo LAC (Tabela 43 e Figura 55).

A ANOVA revelou haver diferença significante $(P>0,05)$, em relação ao parâmetro 
perímetro torácico (PT). O teste "T" indicou que os animais do grupo LAC tiveram maior perímetro torácico durante o primeiro mês de idade, no entanto foram menores do terceiro ao quarto mês de idade ( $F=5,91 ; D F=4 / 36 ; P<0,05)$ (Tabela 43 e Figura 55).

Quanto ao parâmetro DCab, a ANOVA revelou haver diferença significante $(P>0,05)$ entre os grupos avaliados. O teste "T" indicou que os animais do grupo LAC tiveram maior diâmetro de cabeça no primeiro mês de idade e menor no quarto mês de idade (F=6,72; $D F=4 / 36 ; P<0,05)$ (Tabela 45 e Figura 57).

Em relação a altura corporal, CTIB (Tabela 43 e Figura 55), CRad, CMT, CMC, CCab, (Tabela 44 e Figura 56), CIMT, CIMC (Tabela 45 e Figura 57), a análise estatística revelou não haver qualquer diferença significante $(P>0,05)$ nestes parâmetros morfométricos.

A análise histológica realizada nestes filhotes revelou haver lesões focais em musculatura esquelética, caracterizadas por necrose, edema intersticial, tumefação e afrouxamento de fibras além de invasão de células inflamatórias, mais evidentemente observado em diafragma (Figura 58 A). Lesões focais como necrose, vacuolizações, edema intersticial, tumefação e fragmentação de fibras em musculatura cardíaca (Figura 58 B). Extensa vacuolização de hepatócitos em torno da veia hepática terminal (Figura 58 C). No rim observaram-se discretas vacuolizações em endotélio de túbulos contornados e em glomérulos (Figura 58 D). 
Tabela 38 - Média do ganho de peso $(\mathrm{kg})$ mensal e total de cabritos cujas mães consumiram ração contendo 0 e $4 \%$ (LAC) de sementes de Senna occidentalis durante a lactação. São apresentadas as médias e os respectivos erros padrão através do método dos quadrados mínimos. ANOVA seguida de teste T de student

\begin{tabular}{ccc}
\hline \multirow{2}{*}{ Meses de coleta } & \multicolumn{2}{c}{ Grupos } \\
\cline { 2 - 3 } & Controle & LAC \\
\hline $0^{\mathrm{a}}$ & $4,06 \pm 1,29(7)^{\mathrm{b}}$ & $2,97 \pm 1,46(6)$ \\
1 & $8,71 \pm 1,29(7)$ & $7,41 \pm 1,46(6)$ \\
2 & $12,76 \pm 1,29(7)$ & $8,47 \pm 1,46(6)$ \\
3 & $17,17 \pm 1,29(7)$ & $14,89 \pm 1,46(6)$ \\
4 & $19,83 \pm 1,29(7)$ & $15,87 \pm 1,46(6)$ \\
Total & $14,68 \pm 2,06(7)$ & $13,47 \pm 1,04(6)$ \\
\hline
\end{tabular}

peso ao nascer

${ }^{\mathrm{b}}$ entre parênteses o número de animais avaliados.
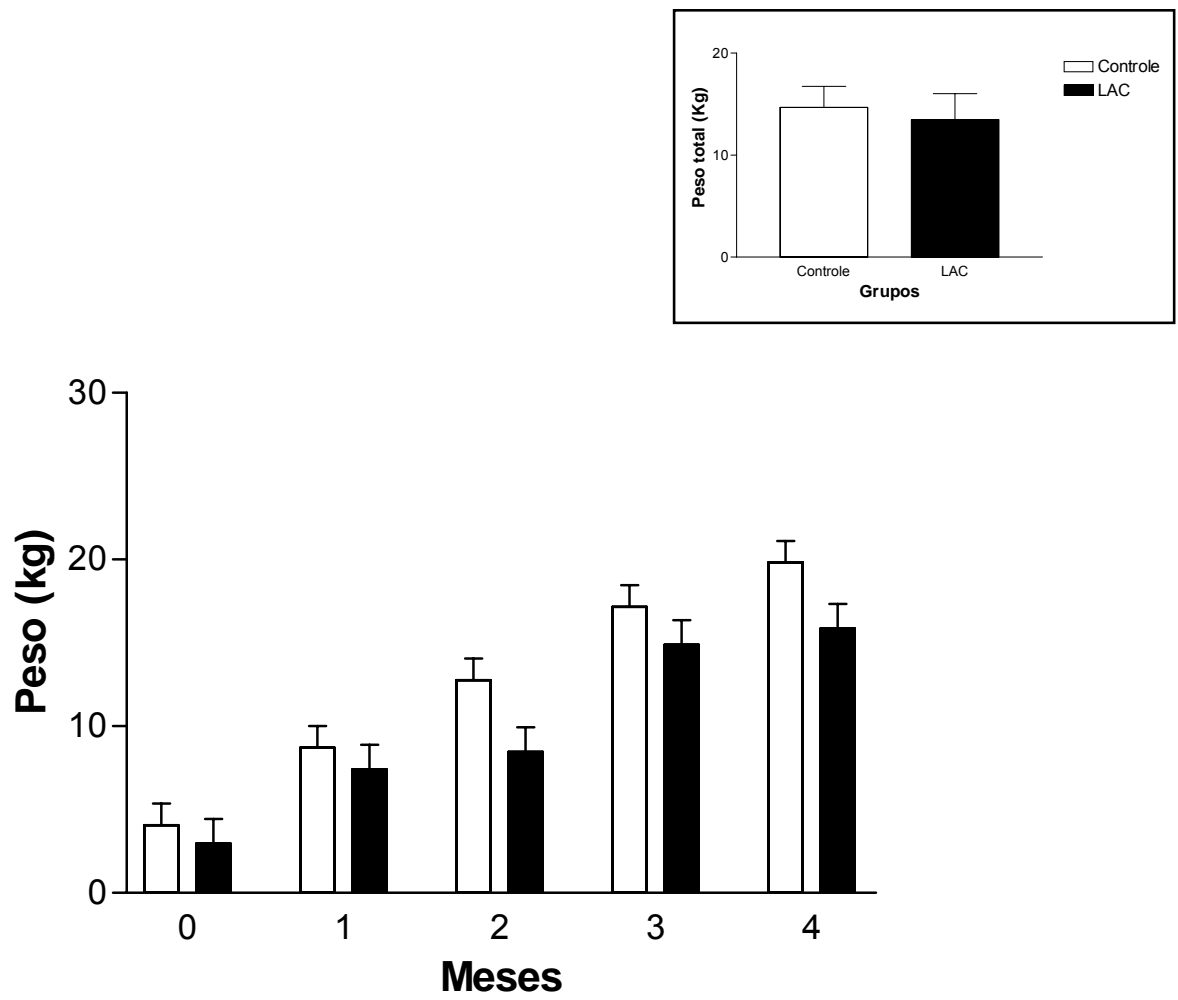

Figura 50 - Média do ganho de peso $(\mathrm{kg})$ mensal e total de cabritos cujas mães consumiram ração contendo 0 e $4 \%$ (LAC) de sementes de Senna occidentalis durante a lactação. São apresentadas as médias e os respectivos erros padrão através do método dos quadrados mínimos. ANOVA seguida de teste T de student 
Tabela 39 - Níveis séricos de glicose, aldolase, GGT e AST de cabritos cujas mães consumiram ração contendo 0 e $4 \%$ (LAC) de sementes de Senna occidentalis durante a lactação. São apresentadas as médias e os respectivos erros padrão através do método dos quadrados mínimos. ANOVA seguida de teste T de student

\begin{tabular}{|c|c|c|c|}
\hline \multirow{2}{*}{ Substâncias } & \multirow{2}{*}{ Datas de coleta ${ }^{a}$} & \multicolumn{2}{|c|}{ Grupos } \\
\hline & & Controle & LAC \\
\hline \multirow{4}{*}{$\begin{array}{l}\text { Glicose } \\
\text { (mg/dl) }\end{array}$} & 1 & $79,98 \pm 5,97(7)^{b}$ & $87,19 \pm 6,76(6)$ \\
\hline & 2 & $71,63 \pm 5,97(7)$ & $52,61 \pm 6,76(6)$ \\
\hline & 3 & $54,80 \pm 5,97(7)$ & $52,91 \pm 6,76(6)$ \\
\hline & 4 & $45,81 \pm 5,97(7)$ & $40,04 \pm 6,76(6)$ \\
\hline \multirow{4}{*}{$\begin{array}{l}\text { Aldolase } \\
\quad(\mathrm{U} / \mathrm{I})\end{array}$} & 1 & $14,37 \pm 1,37(7)$ & $13,66 \pm 1,60(4)$ \\
\hline & 2 & $14,62 \pm 1,37(7)$ & $16,26 \pm 1,60(4)$ \\
\hline & 3 & $10,69 \pm 1,37(7)$ & $13,50 \pm 1,60(4)$ \\
\hline & 4 & $15,82 \pm 1,37(7)$ & $10,91 \pm 1,60(4)$ * \\
\hline \multirow{4}{*}{$\begin{array}{l}\text { GGT } \\
(\mathrm{U} / \mathrm{I})\end{array}$} & 1 & $109,38 \pm 8,26(7)$ & $122,89 \pm 9,36(6)$ \\
\hline & 2 & $78,80 \pm 8,26(7)$ & $63,09 \pm 9,36(6)$ \\
\hline & 3 & $67,89 \pm 8,26(7)$ & $73,52 \pm 19,36(6)$ \\
\hline & 4 & $75,21 \pm 8,26(7)$ & $66,44 \pm 9,36(6)$ \\
\hline \multirow{4}{*}{$\begin{array}{l}\text { AST } \\
(\mathrm{U} / \mathrm{I})\end{array}$} & 1 & $53,60 \pm 6,17(7)$ & $47,04 \pm 7,00(6)$ \\
\hline & 2 & $64,27 \pm 6,17(7)$ & $65,68 \pm 7,00(6)$ \\
\hline & 3 & $47,74 \pm 6,17(7)$ & $65,08 \pm 7,00(6)$ \\
\hline & 4 & $57,46 \pm 6,17(7)$ & $60,97 \pm 7,00(6)$ \\
\hline
\end{tabular}



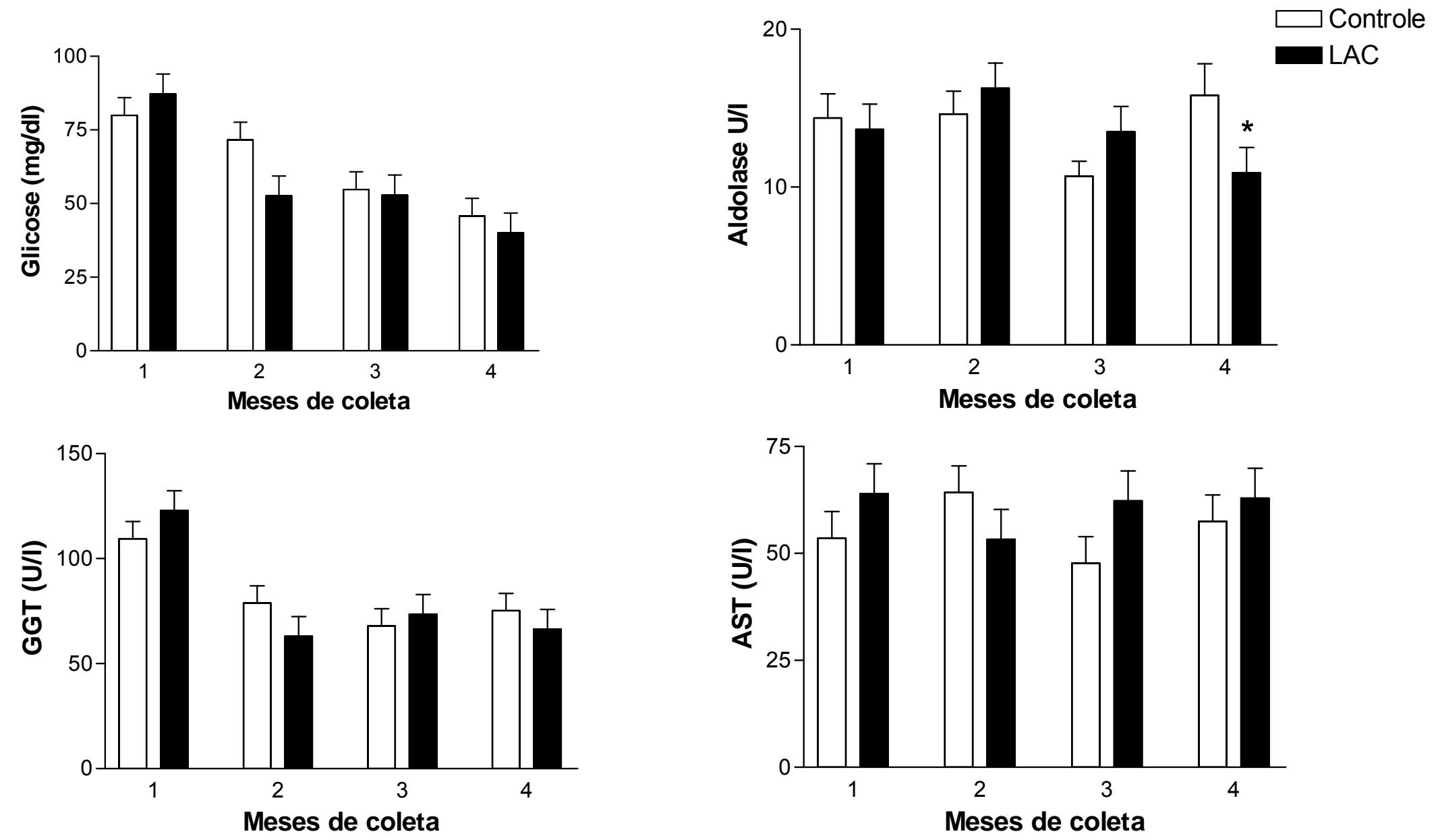

* Difere significantemente $(\mathrm{P}<0,05)$

Figura 51 - Níveis séricos de glicose (mg/dl), aldolase (u/l), GGT (u/l) e AST (u/l) de cabritos cujas mães consumiram ração contendo 0 e 4\% (LAC) de sementes de Senna occidentalis durante a lactação. São apresentadas as médias e os respectivos erros padrão através do método dos quadrados mínimos. ANOVA seguida de teste $T$ de student. 
Tabela 40 - Níveis séricos de FA (u/l), CK (u/l), LDH (u/l) e triglicerídeos (u/l) de cabritos cujas mães consumiram ração contendo 0 e $4 \%$ (LAC) de sementes de Senna occidentalis durante a lactação. São apresentadas as médias e os respectivos erros padrão através do método dos quadrados mínimos. ANOVA, seguida de teste "T" de Student

\begin{tabular}{|c|c|c|c|}
\hline \multirow{2}{*}{ Substâncias } & \multirow{2}{*}{$\begin{array}{l}\text { Datas de } \\
\text { coleta }^{a}\end{array}$} & \multicolumn{2}{|c|}{ Grupos } \\
\hline & & Controle & LAC \\
\hline \multirow{4}{*}{$\begin{array}{l}\text { FA } \\
(\mathrm{U} / \mathrm{l})\end{array}$} & 1 & $297,91 \pm 63,19(7)^{b}$ & $393,95 \pm 71,66(6)$ \\
\hline & 2 & $306,70 \pm 63,19(7)$ & $313,26 \pm 71,66(6)$ \\
\hline & 3 & $226,66 \pm 63,19(7)$ & $339,07 \pm 71,66(6)$ \\
\hline & 4 & $255,68 \pm 63,19(7)$ & $267,41 \pm 71,66(6)$ \\
\hline \multirow{4}{*}{$\begin{array}{l}\text { CK } \\
(\mathrm{U} / \mathrm{l})\end{array}$} & 1 & $42,63 \pm 15,69(7)$ & $24,25 \pm 16,80(6)$ \\
\hline & 2 & $89,54 \pm 14,80(7)$ & $73,00 \pm 16,80(6)$ \\
\hline & 3 & $88,25 \pm 14,80(7)$ & $128,38 \pm 16,80(6)$ \\
\hline & 4 & $113,58 \pm 14,80(7)$ & $138,75 \pm 16,80(6)$ \\
\hline \multirow{4}{*}{$\begin{array}{l}\mathrm{LDH} \\
(\mathrm{U} / \mathrm{I})\end{array}$} & 1 & $559,54 \pm 109,22(7)$ & $706,87 \pm 123,85(6)$ \\
\hline & 2 & $879,50 \pm 109,22(7)$ & $682,26 \pm 123,85(6)$ \\
\hline & 3 & $420,00 \pm 109,22(7)$ & $421,00 \pm 123,85(6)$ \\
\hline & 4 & $597,92 \pm 109,22(7)$ & $525,50 \pm 123,85(6)$ \\
\hline \multirow{4}{*}{$\begin{array}{l}\text { Triglicerídeos } \\
\qquad(\mathrm{mg} / \mathrm{dl})\end{array}$} & 1 & $71,18 \pm 14,77(7)$ & $102,63 \pm 16,75(6)$ \\
\hline & 2 & $56,82 \pm 14,77(7)$ & $46,35 \pm 16,75(6)$ \\
\hline & 3 & $46,63 \pm 14,77(7)$ & $56,82 \pm 16,75(6)$ \\
\hline & 4 & $48,62 \pm 14,77(7)$ & $57,40 \pm 16,75(6)$ \\
\hline
\end{tabular}

bono após o nascimento ate o quâto mês de vida. 

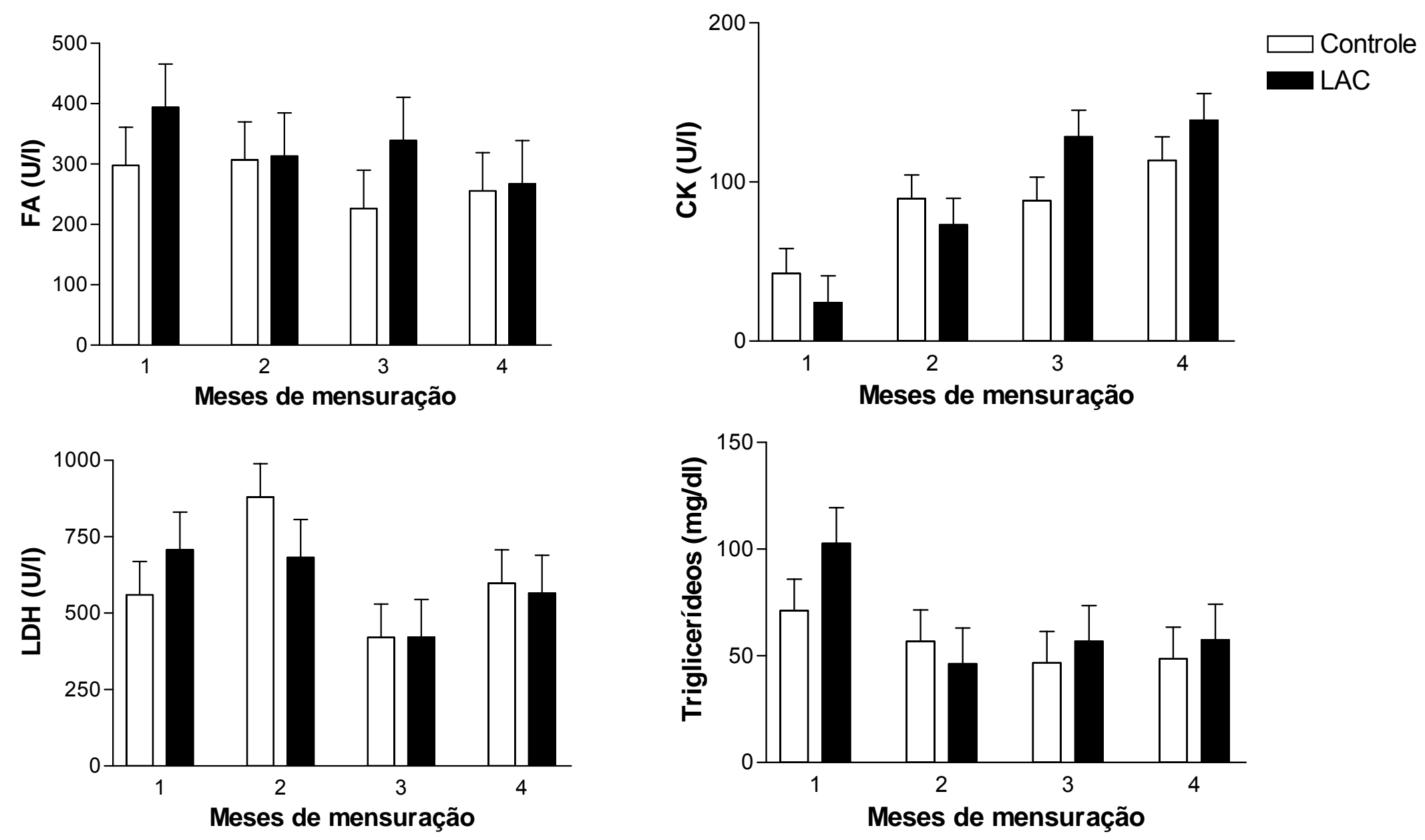

Figura 52 - Níveis séricos de FA (u/l), CK (u/l), LDH (u/l) e triglicerídeos (u/l) de cabritos cujas mães consumiram ração contendo 0 e 4\% (LAC) de sementes de Senna occidentalis durante a lactação. São apresentadas as médias e os respectivos erros padrão através do método dos quadrados mínimos. ANOVA, seguida de teste "T" de Student 
Tabela 41 - Níveis séricos de proteína total $(\mathrm{mg} / \mathrm{dl})$, albumina $(\mathrm{g} / \mathrm{L})$, uréia $(\mathrm{mg} / \mathrm{dl})$ e creatinina $(\mathrm{u} / \mathrm{l})$ de cabritos cujas mães consumiram ração contendo 0 e $4 \%$ (LAC) de sementes de Senna occidentalis durante a lactação. São apresentadas as médias e os respectivos erros padrão através do método dos quadrados mínimos. ANOVA, seguida de teste "T" de Student

\begin{tabular}{|c|c|c|c|}
\hline \multirow{2}{*}{ Substâncias } & \multirow{2}{*}{$\begin{array}{l}\text { Datas de } \\
\text { coleta }^{a}\end{array}$} & \multicolumn{2}{|c|}{ Grupos } \\
\hline & & Controle & LAC \\
\hline \multirow{4}{*}{$\begin{array}{l}\text { Proteína total } \\
\qquad(\mathrm{mg} / \mathrm{dl})\end{array}$} & 1 & $5,72 \pm 0,28(7)^{b}$ & $4,84 \pm 0,31(6)$ \\
\hline & 2 & $5,90 \pm 0,28(7)$ & $4,79 \pm 0,31(6)$ \\
\hline & 3 & $4,99 \pm 0,28(7)$ & $5,23 \pm 0,31(6)$ \\
\hline & 4 & $5,88 \pm 0,28(7)$ & $5,67 \pm 0,31(6)$ \\
\hline \multirow{4}{*}{$\begin{array}{l}\text { Albumina } \\
(\mathrm{g} / \mathrm{l})\end{array}$} & 1 & $3,00 \pm 0,17(7)$ & $2,86 \pm 0,19(6)$ \\
\hline & 2 & $3,83 \pm 0,17(7)$ & $3,21 \pm 0,19(6)$ \\
\hline & 3 & $3,42 \pm 0,17(7)$ & $3,47 \pm 0,19(6)$ \\
\hline & 4 & $3,64 \pm 0,17(7)$ & $3,38 \pm 0,19(6)$ \\
\hline \multirow{4}{*}{$\begin{array}{l}\text { Uréia } \\
(\mathrm{mg} / \mathrm{dl})\end{array}$} & 1 & $54,83 \pm 5,18(7)$ & $40,51 \pm 5,87(6)$ \\
\hline & 2 & $63,66 \pm 5,18(7)$ & $18,98 \pm 5,87(6)^{*}$ \\
\hline & 3 & $39,36 \pm 5,18(7)$ & $35,16 \pm 5,87(6)$ \\
\hline & 4 & $31,85 \pm 5,18(7)$ & $28,95 \pm 5,87(6)$ \\
\hline \multirow{4}{*}{$\begin{array}{c}\text { Creatinina } \\
(\mathrm{U} / \mathrm{I})\end{array}$} & 1 & $1,23 \pm 0,12(7)$ & $1,22 \pm 0,13(6)$ \\
\hline & 2 & $1,32 \pm 0,12(7)$ & $1,01 \pm 0,13(6)$ \\
\hline & 3 & $0,99 \pm 0,12(7)$ & $1,02 \pm 0,13(6)$ \\
\hline & 4 & $1,06 \pm 0,12(7)$ & $0,92 \pm 0,13(6)$ \\
\hline
\end{tabular}

Logo após o nascimento até o quarto mês de vida.

${ }^{b}$ Entre parênteses o número de animais avaliados.

* Difere significantemente do controle $(P<0,05)$. 

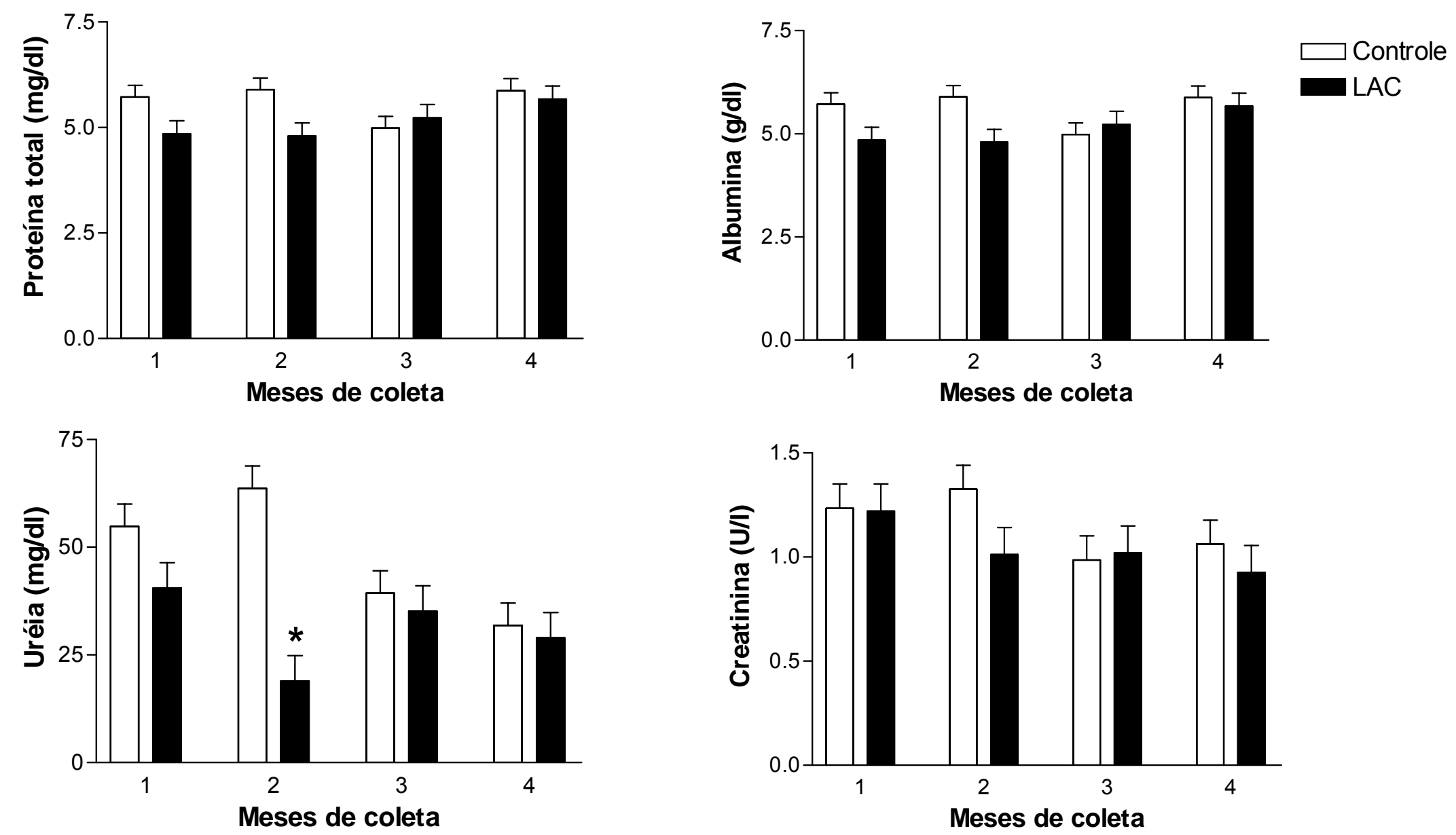

*Difere significantemente do grupo controle $(\mathrm{P}<0,05)$

Figura 53 - Níveis séricos de proteína total $(\mathrm{mg} / \mathrm{dl})$, albumina $(\mathrm{g} / \mathrm{L})$, uréia $(\mathrm{mg} / \mathrm{dl})$ e creatinina $(\mathrm{u} / \mathrm{l})$ de cabritos cujas mães consumiram ração contendo 0 e $4 \%$ (LAC) de sementes de Senna occidentalis durante a lactação. São apresentadas as médias e os respectivos erros padrão através do método dos quadrados mínimos. ANOVA, seguida de teste "T" de Student 
Tabela 42 - Níveis séricos de colesterol $(\mathrm{mg} / \mathrm{dl})$ de cabritos cujas mães consumiram ração contendo 0 e 4\% (LAC) de sementes de Senna occidentalis durante a lactação. São apresentadas as médias e os respectivos erros padrão através do método dos quadrados mínimos. ANOVA, seguida de teste "T" de Student

\begin{tabular}{cccc}
\hline \multirow{2}{*}{ Substâncias } & \multirow{2}{*}{ Datas de coleta $^{\mathbf{a}}$} & \multicolumn{2}{c}{ Grupos } \\
\cline { 2 - 4 } & 1 & $178,31 \pm 32,18(7)^{\mathbf{b}}$ & Controle \\
\hline & 2 & $291,24 \pm 32,18(7)$ & $277,57 \pm 36,49(6)$ \\
Colesterol & 3 & $198,26 \pm 32,18(7)$ & $207,79 \pm 36,49(6)$ \\
(mg/dl) & 4 & $216,67 \pm 32,18(7)$ & $176,46 \pm 36,49(6)$ \\
\hline
\end{tabular}

a logo após o nascimento até o quarto mês de vida.

b entre parênteses o número de animais estudados.

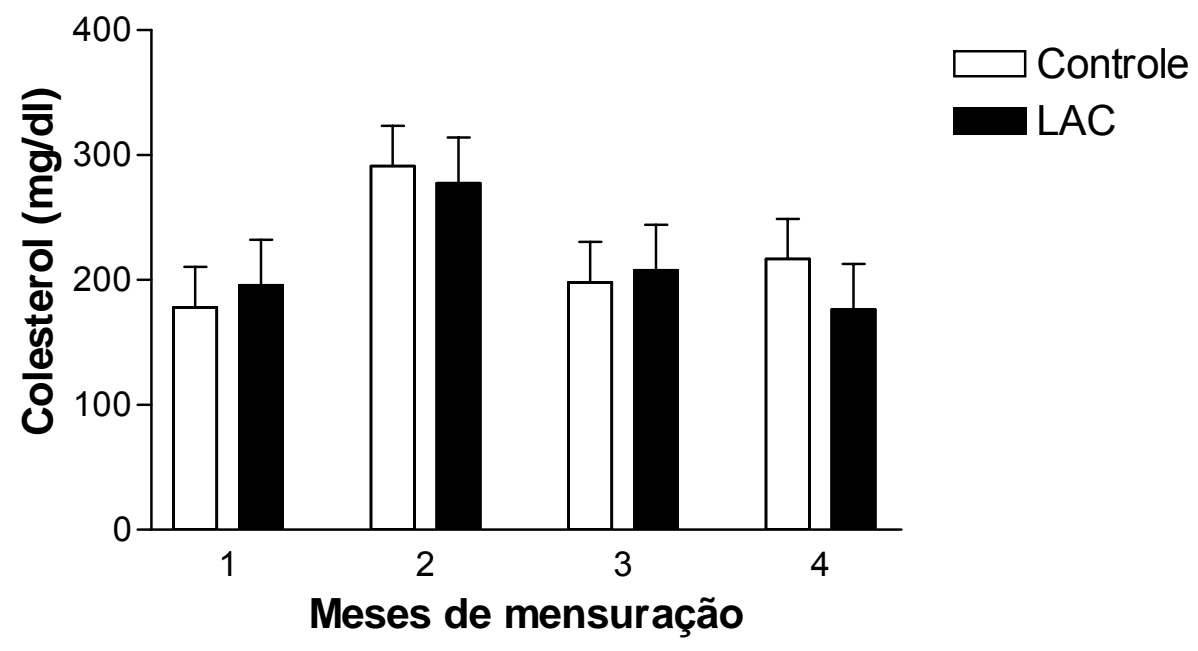

Figura 54 - Níveis séricos de colesterol $(\mathrm{mg} / \mathrm{dl})$ de cabritos cujas mães consumiram ração contendo 0 e 4\% (LAC) de sementes de Senna occidentalis durante a lactação. São apresentadas as médias e os respectivos erros padrão através do método dos quadrados mínimos. ANOVA, seguida de teste "T" de Student 
Tabela 43 - Altura corporal (AC), comprimento corporal (CC), perímetro torácico (PT) e comprimento da tíbia (CTib) de cabritos cujas mães consumiram ração contendo 0 e $4 \%$ (LAC) de sementes de Senna occidentalis durante a lactação. São apresentadas as médias e os respectivos erros padrão através do método dos quadrados mínimos. ANOVA seguida de teste $\mathrm{T}$ de Student

\begin{tabular}{|c|c|c|c|}
\hline \multirow{2}{*}{$\begin{array}{l}\text { Parâmetros } \\
\text { (cm) }\end{array}$} & \multirow{2}{*}{$\begin{array}{l}\text { Datas de } \\
\text { coleta }^{\mathrm{a}}\end{array}$} & \multicolumn{2}{|c|}{ Grupos } \\
\hline & & Controle & LAC \\
\hline \multirow{5}{*}{ Altura } & 0 & $35,04 \pm 1,39(7)^{\mathbf{b}}$ & $34,37 \pm 1,58(6)$ \\
\hline & 1 & $36,79 \pm 1,39(7)$ & $40,62 \pm 1,58(6)$ \\
\hline & 2 & $48,00 \pm 1,39(7)$ & $45,12 \pm 1,58(6)$ \\
\hline & 3 & $52,08 \pm 1,39(7)$ & $47,87 \pm 1,58(6)$ \\
\hline & 4 & $53,17 \pm 1,39(7)$ & $52,25 \pm 1,58(6)$ \\
\hline \multirow{5}{*}{$\mathrm{CC}$} & 0 & $32,02 \pm 1,36(7)$ & $32,12 \pm 1,54(6)$ \\
\hline & 1 & $41,12 \pm 1,36(7)$ & $39,37 \pm 1,54(6)$ * \\
\hline & 2 & $46,33 \pm 1,36(7)$ & $44,87 \pm 1,54(6)$ \\
\hline & 3 & $49,12 \pm 1,36(7)$ & $48,00 \pm 1,54(6)$ \\
\hline & 4 & $51,62 \pm 1,36(7)$ & $50,37 \pm 1,54(6)$ \\
\hline \multirow{5}{*}{ PT } & 0 & $36,42 \pm 2,03(7)$ & $35,56 \pm 2,30(6)$ \\
\hline & 1 & $47,70 \pm 2,03(7)$ & $15,31 \pm 2,30(6)$ * \\
\hline & 2 & $53,52 \pm 2,03(7)$ & $49,75 \pm 2,30(6)$ \\
\hline & 3 & $58,81 \pm 2,03(7)$ & $54,62 \pm 2,30(6)$ * \\
\hline & 4 & $61,08 \pm 2,03(7)$ & $52,25 \pm 2,30(6)$ * \\
\hline \multirow{5}{*}{ CTIB } & 0 & $12,37 \pm 0,72(7)$ & $12,87 \pm 0,81(6)$ \\
\hline & 1 & $12,87 \pm 0,72(7)$ & $15,00 \pm 0,81(6)$ \\
\hline & 2 & $16,56 \pm 0,72(7)$ & $15,44 \pm 0,81(6)$ \\
\hline & 3 & $17,35 \pm 0,72(7)$ & $17,62 \pm 0,81(6)$ \\
\hline & 4 & $19,04 \pm 0,72(7)$ & $18,06 \pm 0,81(6)$ \\
\hline
\end{tabular}

a logo após o nascimento até o quarto mês de vida.

${ }^{b}$ entre parênteses o número de animais avaliados.

* Difere significantemente do controle $(P<0,05)$. 

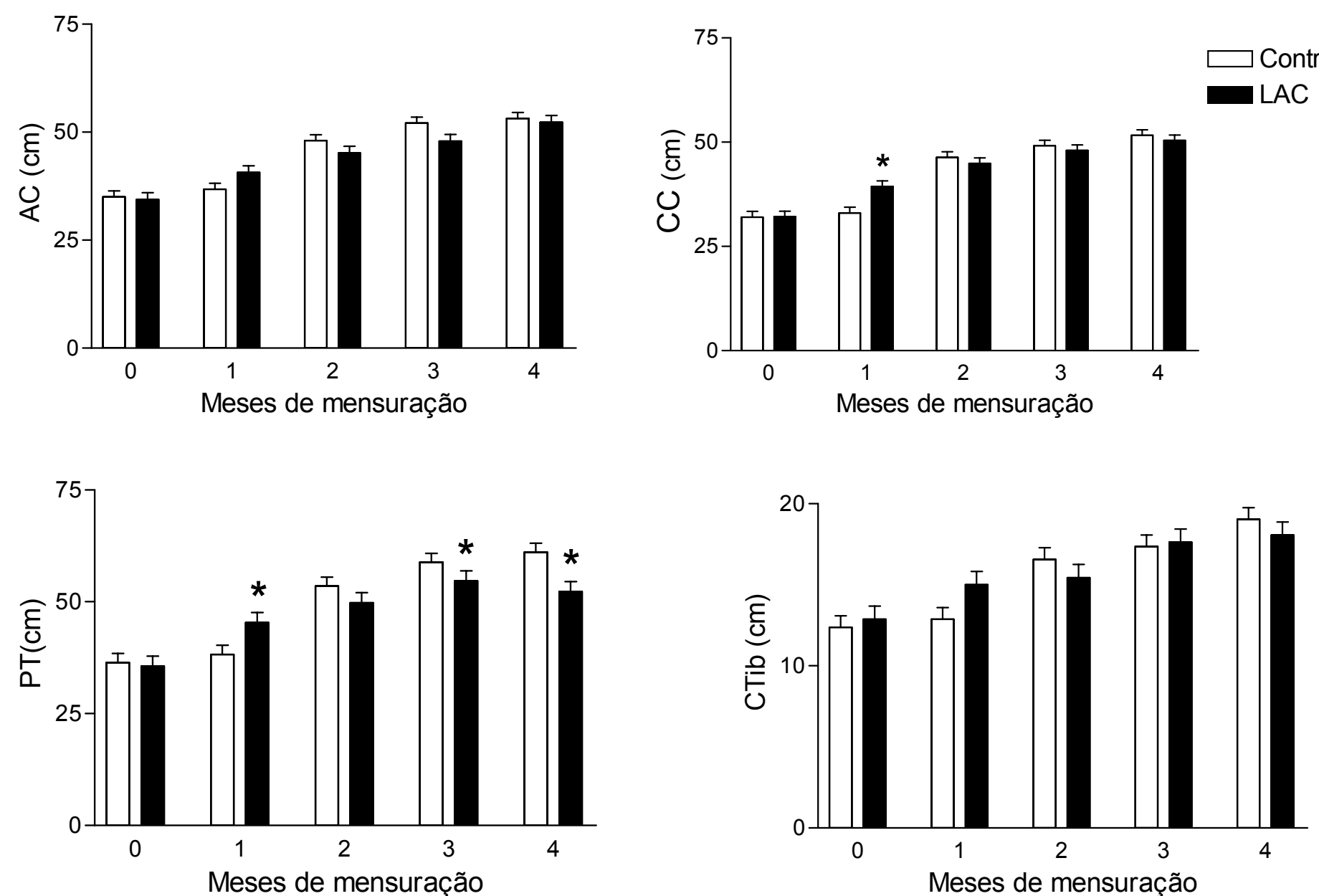

${ }^{*}$ Difere significantemente do grupo controle $(P<0,05)$

Figura 55 - Altura corporal (AC), comprimento corporal (CC), perímetro torácico (PT) e comprimento da tíbia (CTib) de cabritos cujas mães consumiram ração contendo 0 e $4 \%$ (LAC) de sementes de Senna occidentalis durante a lactação. São apresentadas as médias e os respectivos erros padrão através do método dos quadrados mínimos. ANOVA seguida de teste T de Student. 
Tabela 44 - Comprimento do rádio (CRad), comprimento do metatarso (CMT), comprimento do metacarpo (CMC) e comprimento da cabeça (CCab) de cabritos cujas mães consumiram ração contendo 0 e $4 \%$ (LAC) de sementes de Senna occidentalis durante a lactação. São apresentadas as médias e os respectivos erros padrão através do método dos quadrados mínimos. ANOVA seguida de teste T de Student

\begin{tabular}{|c|c|c|c|}
\hline \multirow{2}{*}{$\begin{array}{l}\text { Parâmetros } \\
\text { (cm) }\end{array}$} & \multirow{2}{*}{ Datas de coleta ${ }^{a}$} & \multicolumn{2}{|c|}{ Grupos } \\
\hline & & Controle & LAC \\
\hline & 0 & $11,31 \pm 0,50(7)^{b}$ & $11,43 \pm 0,57(6)$ \\
\hline & 1 & $13,29 \pm 0,50(7)$ & $12,81 \pm 0,57(6)$ \\
\hline \multirow[t]{5}{*}{ CRad } & 2 & $13,98 \pm 0,50(7)$ & $13,37 \pm 0,57(6)$ \\
\hline & 3 & $15,08 \pm 0,50(7)$ & $13,75 \pm 0,57(6)$ \\
\hline & 4 & $15,56 \pm 0,50(7)$ & $14,12 \pm 0,57(6)$ \\
\hline & 0 & $10,93 \pm 0,38(7)$ & $9,87 \pm 0,42(6)$ \\
\hline & 1 & $11,83 \pm 0,38(7)$ & $11,43 \pm 0,42(6)$ \\
\hline \multirow[t]{5}{*}{$\mathrm{CMT}$} & 2 & $12,37 \pm 0,38(7)$ & $11,50 \pm 0,42(6)$ \\
\hline & 3 & $12,85 \pm 0,38(7)$ & $12,37 \pm 0,42(6)$ \\
\hline & 4 & $13,19 \pm 0,38(7)$ & $12,94 \pm 0,42(6)$ \\
\hline & 0 & $8,71 \pm 0,40(7)$ & $8,75 \pm 0,45(6)$ \\
\hline & 1 & $10,06 \pm 0,40(7)$ & $9,81 \pm 0,45(6)$ \\
\hline \multirow[t]{5}{*}{ CMC } & 2 & $10,50 \pm 0,40(7)$ & $10,00 \pm 0,45(6)$ \\
\hline & 3 & $11,23 \pm 0,40(7)$ & $10,56 \pm 0,45(6)$ \\
\hline & 4 & $11,85 \pm 0,40(7)$ & $11,12 \pm 0,45(6)$ \\
\hline & 0 & $16,56 \pm 0,71(7)$ & $16,37 \pm 0,81(6)$ \\
\hline & 1 & $20,38 \pm 0,71(7)$ & $19,87 \pm 0,81(6)$ \\
\hline \multirow[t]{3}{*}{ CCab } & 2 & $23,08 \pm 0,71(7)$ & $22,25 \pm 0,81(6)$ \\
\hline & 3 & $24,98 \pm 0,71(7)$ & $24,87 \pm 0,81(6)$ \\
\hline & 4 & $25,27 \pm 0,71(7)$ & $25,25 \pm 0,81(6)$ \\
\hline
\end{tabular}

a logo após o nascimento até o quarto mês de vida.

b entre parênteses o número de animais avaliados. 

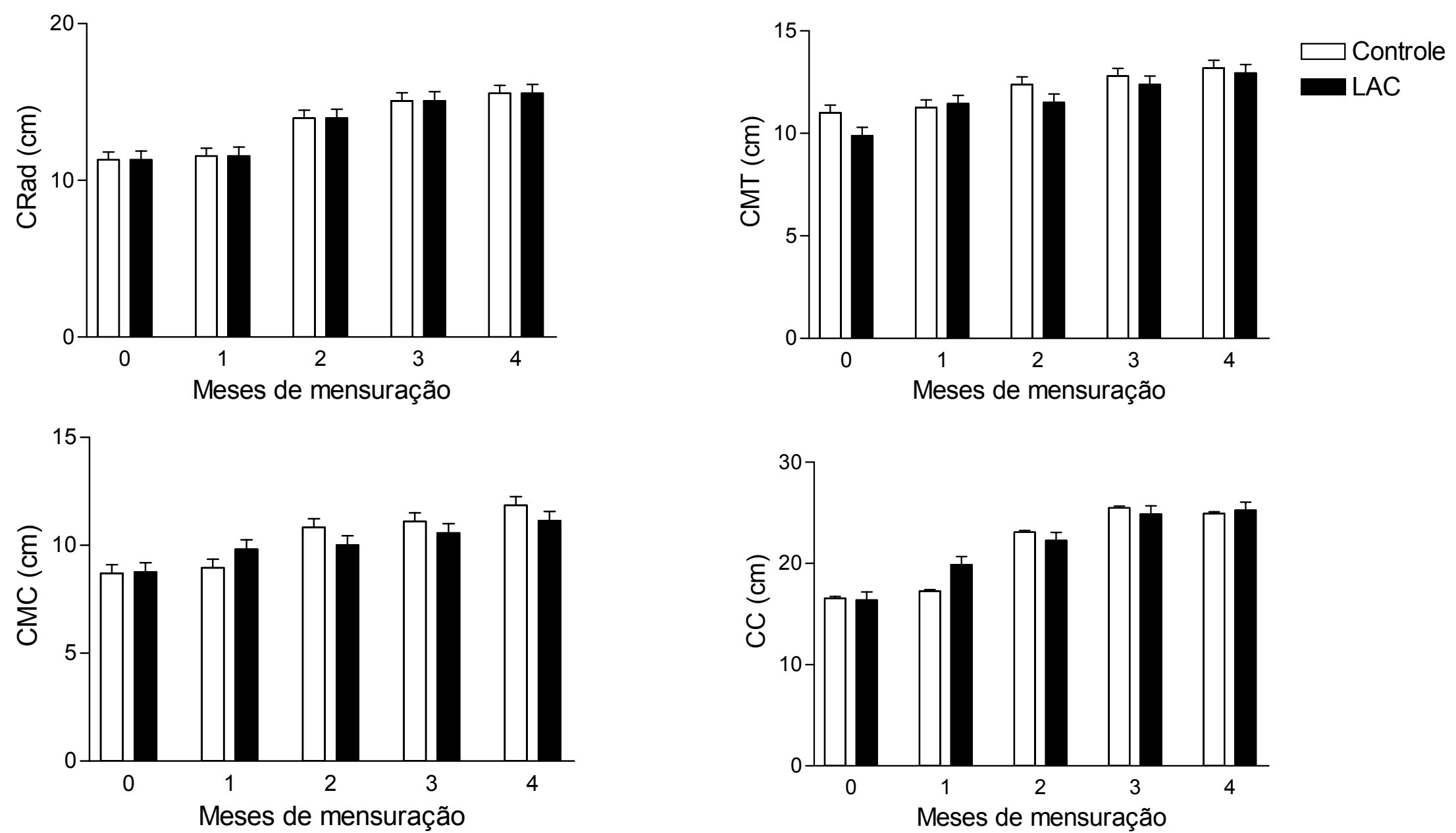

Figura 56 - Comprimento do rádio (CRad), comprimento do metatarso (CMT), comprimento do metacarpo (CMC) e comprimento da cabeça (CCab) de cabritos cujas mães consumiram ração contendo 0 e $4 \%$ (LAC) de sementes de Senna occidentalis durante a lactação. São apresentadas as médias e os respectivos erros padrão através do método dos quadrados mínimos. ANOVA seguida de teste T de Student 
Tabela 45 - Diâmetro da cabeça (DCab), circunferência do metatarso (CIMT) e circunferência do metacarpo (CIMC) de cabritos cujas mães consumiram ração contendo 0 e $4 \%$ (LAC) de sementes de sementes de Senna occidentalis durante a lactação. São apresentadas as médias e os respectivos erros padrão

\begin{tabular}{cccc}
\hline \multirow{2}{*}{$\begin{array}{c}\text { Parâmetros } \\
(\mathbf{c m})\end{array}$} & Datas de coleta $^{\mathrm{a}}$ & \multicolumn{2}{c}{ Grupos } \\
\cline { 3 - 4 } & 0 & $10,79 \pm 0,50(7)^{\mathrm{b}}$ & LAC \\
\hline \multirow{2}{*}{ DCab } & 1 & $11,42 \pm 0,50(7)$ & $13,19 \pm 0,57(6)$ \\
& 2 & $15,06 \pm 0,50(7)$ & $15,12 \pm 0,57(6)$ \\
& 3 & $16,50 \pm 0,50(7)$ & $15,75 \pm 0,57(6)$ \\
& 4 & $17,33 \pm 0,50(7)$ & $15,69 \pm 0,57(6)$ \\
& 0 & $7,25 \pm 0,37(7)$ & $6,81 \pm 0,42(6)$ \\
CIMT & 1 & $7,44 \pm 0,37(7)$ & $6,81 \pm 0,42(6)$ \\
& 2 & $7,46 \pm 0,37(7)$ & $7,25 \pm 0,42(6)$ \\
& 3 & $7,47 \pm 0,37(7)$ & $7,25 \pm 0,42(6)$ \\
& 4 & $7,77 \pm 0,37(7)$ & $7,50 \pm 0,42(6)$ \\
& & & \\
CIMC & 0 & $6,37 \pm 0,37(7)$ & $6,19 \pm 0,32(6)$ \\
& 1 & $6,69 \pm 0,37(7)$ & $6,62 \pm 0,32(6)$ \\
& 2 & $7,17 \pm 0,37(7)$ & $6,69 \pm 0,32(6)$ \\
& 3 & $7,62 \pm 0,37(7)$ & $7,06 \pm 0,32(6)$ \\
& 4 & $7,69 \pm 0,37(7)$ & $7,31 \pm 0,32(6)$ \\
& & &
\end{tabular}

a logo após o nascimento até o quarto mês de vida.

${ }^{\mathrm{b}}$ entre parênteses o número de animais avaliados.

* Difere significantemente do controle. ANOVA seguida de teste T de Student. 

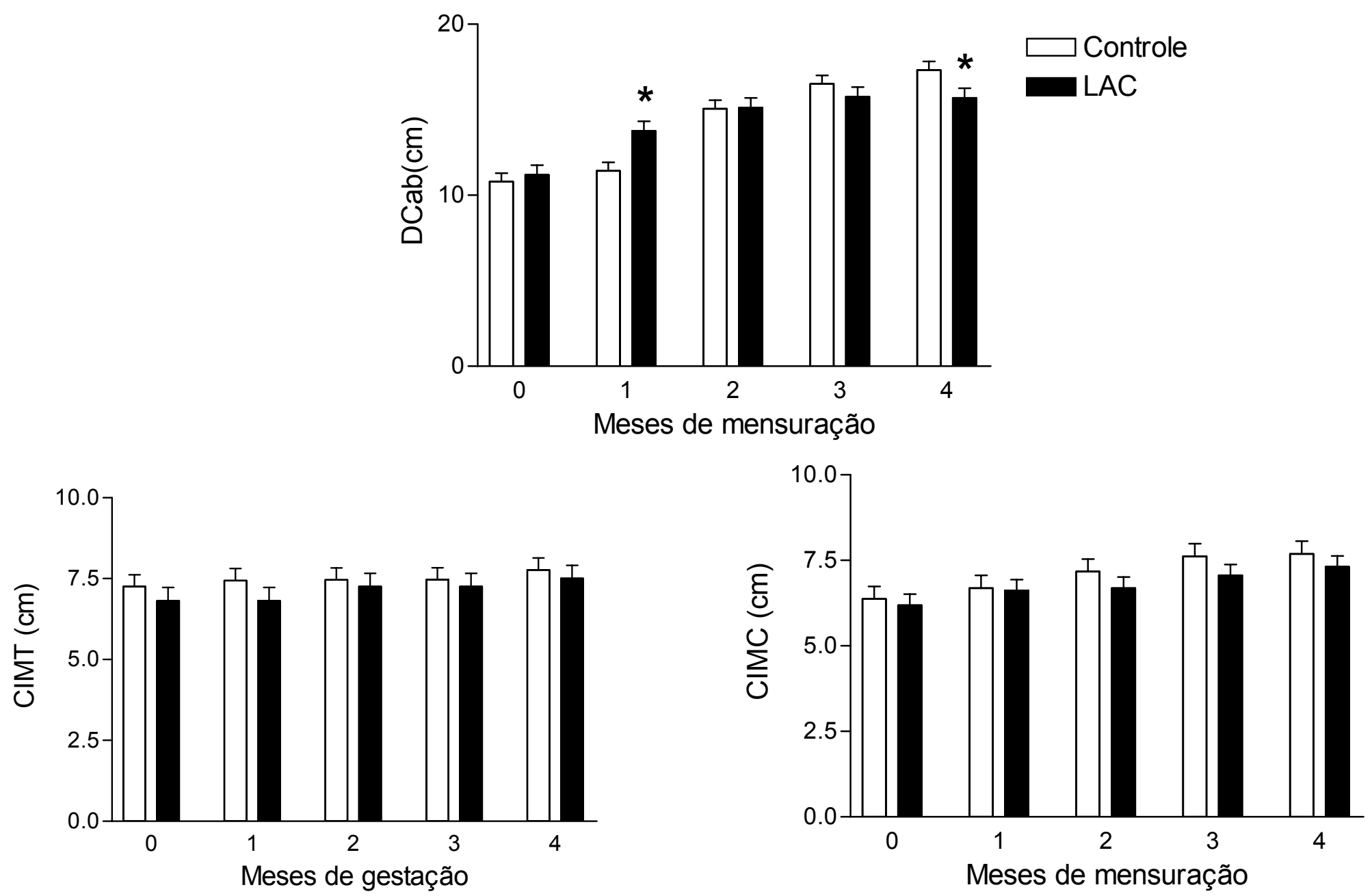

*Difere significantemente do grupo controle $(P<0,05)$

Figura 57 - Diâmetro da cabeça (DCab), circunferência do metatarso (CIMT) e circunferência do metacarpo (CIMC) de cabritos cujas mães consumiram ração contendo 0 e $4 \%$ (LAC) de sementes de sementes de Senna occidentalis durante a lactação. São apresentadas as médias e os respectivos erros padrão 

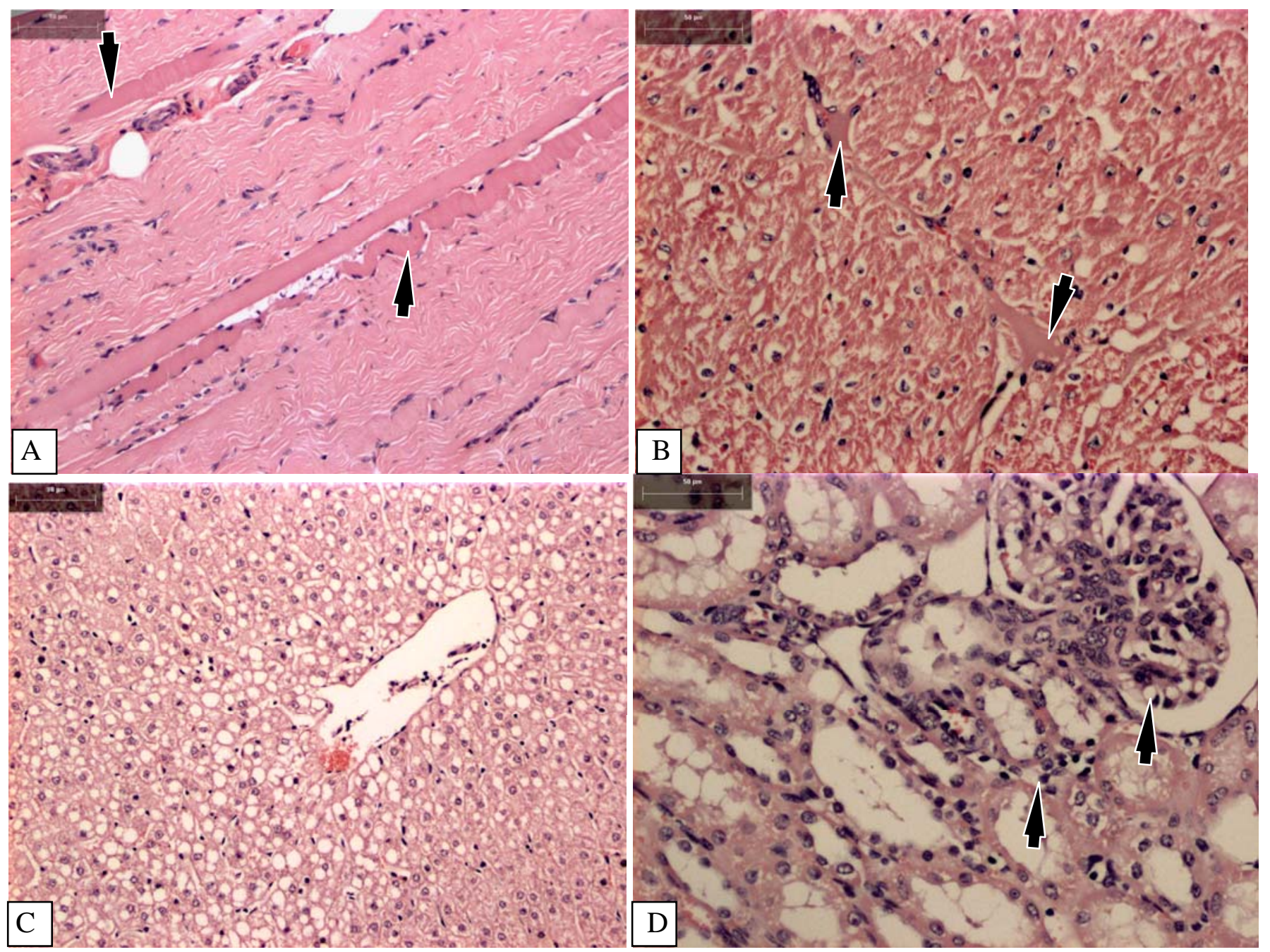

Figura 58 - Fotomicrografia de luz de cortes histológicos cabritos pertencentes ao grupo LAC. Músculo diafragmático (A), observa-se lesões caracterizadas por necrose tumefação e afrouxamento de fibras (setas). HE, A: 10X. Coração (B), observa-se necrose, vacuolizações (cabeça de seta), edema intersticial, tumefação (setas) e fragmentação de fibras. HE, A: 20X. Fígado (C), evidencia-se extensa vacuolização de hepatócitos em torno da veia hepática terminal. HE, A: 10X. Rim (D) observam-se discretas vacuolizações de túbulos contornados e em glomérulos (setas) HE, A: 20X 


\subsection{EXPERIMENTO 5: ESTUDO QUÍMICO DO LEITE DE CABRAS QUE CONSUMIRAM 4\% DE SEMENTES DE S. OCCIDENTALIS. PESQUISA DA PRESENÇA DE ANTRAQUINONAS}

As amostras de colostro (A1 e A2) e de leite de cabra do grupo LAC (A3) extraídos, conforme a descrito no Material e métodos, não apresentaram, em CCD, manchas evidentes que correspondessem à mancha do padrão $(P)$, para o sistema utilizado (Figura 59). Os $\mathrm{R}_{\mathrm{fs}}$ das manchas róseas observadas para $\mathrm{P}$, detectados com vapores de iodo e revelados com hidróxido de potássio $10 \%$ e com ácido nítrico $100 \%$ foram de: 0,42 e 0,52; 0,43 e 0,50; e 0,54, respectivamente.

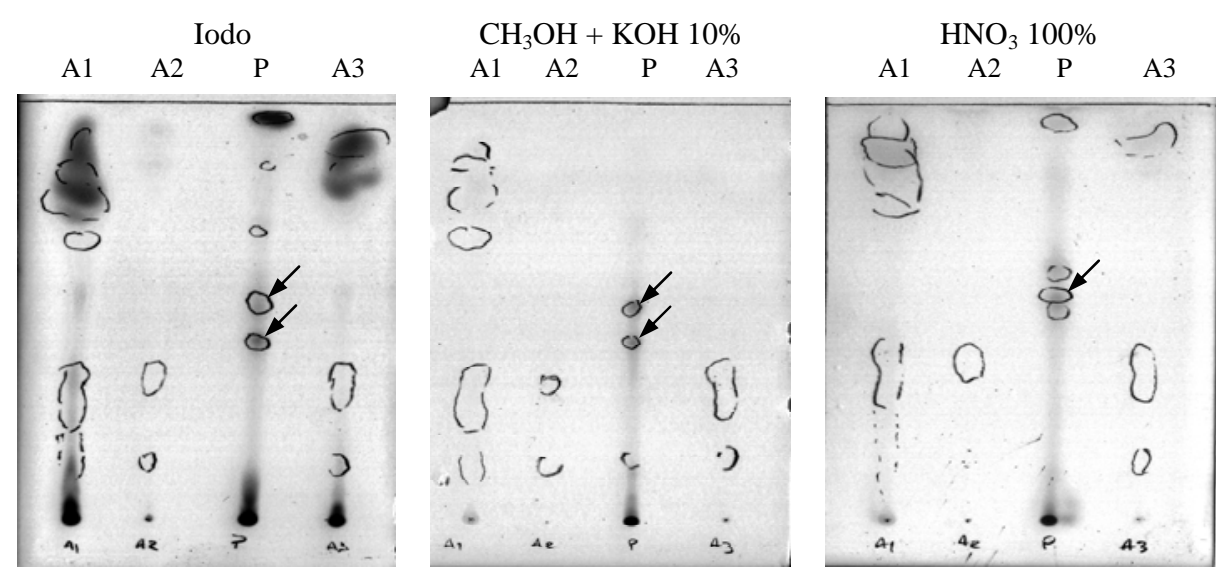

Figura 59 - Fotografias de cromatogramas revelados em câmara de iodo $10 \%$; solução $\mathrm{CH}_{3} \mathrm{OH}+\mathrm{KOH} 10 \%$ e, por último $\mathrm{HNO}_{3} 100 \%$, desenvolvidos em acetato de etila:metanol:água (77:13:10). São evidenciadas as manchas obtidas após 0 desenvolvimento. Manchas róseas, indicativas da presença de antraquinonas (setas)

Em CLAE, o cromatograma do resíduo obtido $A 3$, quando comparado com $P$, não apresentou semelhança nas condições empregadas. 


\section{DISCUSSÃO}

c 1767 J. DANIEL Tesouro do Rio Amazonas in RIH, III. (1841) 293: [A segunda doença muito usual na America são catarrhos,] Para os curar usam tambem muito de sudoriferos, já por fóra em suadouros, e já por dentro em xaropes, os quaes tem excellentes os Americanos, já na aguardente queimada, já no chá ordinario, café, e muitas outras hervas sodoriferas: e sobre todas a raiz de pajé merioba, qeu obra prodigiosa, amsi que o chá de violas, o chá de pimenta cozida, cebolas, e outras boticas, (CUNHA, 1999) 
A toxicologia do desenvolvimento, atualmente, não se limita apenas ao estudo das malformações anatômicas macroscópicas, mas abrange também outros tantos parâmetros, entre os quais o estudo da patogênese e das conseqüências da exposição aos agentes tóxicos ou condições que levam ao desenvolvimento anormal do animal, tais como retardo do crescimento e distúrbios bioquímicos (ROGERS; KAVLOCK, 2001). Assim, segundo Wilson (1977), a teratologia pode ser definida como "a ciência interessada em determinar as causas, os mecanismos e as manifestações dos erros no desenvolvimento, sejam eles estruturais ou funcionais e podem ser iniciados em qualquer período entre a fertilização e maturação".

Atualmente, embora existam muitas informações disponíveis sobre a origem das desordens do desenvolvimento, resultante da exposição perinatal, há ainda grande preocupação dos pesquisadores em relação à acurácia dos protocolos existentes, principalmente no que se refere à extrapolação de dados obtidos de uma espécie para outra. Neste contexto a literatura é farta de exemplos de substâncias que são capazes de produzir teratogênese em uma determinada espécie, mas que não produzem qualquer alteração no concepto de mães de uma outra espécie exposta a este mesmo agente tóxico. Neste sentido, segundo Schardein et al. (1983) a resposta de uma substância química para um particular modelo animal é quase tão variável quanto o número de substâncias testadas. Pode-se exemplificar tal situação pelo caso clássico ocorrido com a talidomida, que é teratogênica para o homem, mas não para ratos. Considerando-se principalmente as diferenças na fisiologia e na anatomia como um dos principais fatores na disparidade de efeitos teratogênicos, entre as distintas espécies animais, pode-se supor que a extrapolação de dados obtidos na avaliação de risco com animais monogástricos para aqueles poligástricos e vice-versa, poderá ser catastrófica.

Assim, o objetivo do presente estudo foi o de avaliar a toxicidade reprodutiva e do desenvolvimento da intoxicação causada pela S. occidentalis em caprinos, com o intuito de refinar o protocolo para avaliação de teratogenicidade para ruminantes, o qual vem sendo desenvolvido neste laboratório, sendo tema de duas teses de doutoramento aqui realizadas (SOTO-BLANCO, 2003; SCHUMAHER-HENRIQUE, 2005). Deste modo, nesta pesquisa procurou-se adicionar alguns protocolos para avaliação de desenvolvimento físico e neurocomportamental do neonato.

Embora existam pequenas variações nos protocolos de avaliação de risco de toxicologia pré-natal entre as agências de regulamentação, de maneira geral estas 
agências requerem para este estudo um grupo de animais controle e, no mínimo, outros três, nos quais os animais receberão as diferentes doses da substância química a ser avaliada. Em geral, a escolha destas doses é baseada nos seguintes critérios: uma que produza efeitos tóxicos, outra dose com a qual os animais não manifestem qualquer alteração de toxicidade e a outra, intermediária entre estas. Esta administração deverá ser feita, no mínimo, da implantação do óvulo ao final da organogênese (WHO, 1967; USEPA, 1991; OECD, 1996). Portanto, na presente pesquisa, foram utilizadas concentrações de sementes de $S$. occidentalis previamente escolhidas baseadas em estudos anteriores conduzidos em nosso laboratório em caprinos quando em fase de crescimento (BARBOSA-FERREIRA, 2003). Inicialmente, foram utilizadas concentrações de 1, 2 e 4\% de sementes da planta na ração das cabras (grupos So1, So2 e So4 respectivamente), já que os dados obtidos no Mestrado (BARBOSA-FERREIRA, 2003) revelaram que estas seriam aquelas três doses preconizadas nos protocolos de toxicologia da reprodução. Posteriormente, acrescentou-se mais um grupo de animais experimentais, aqueles tratados com ração acrescida de $3 \%$ de sementes de $S$. occidentalis, haja vista que as gestantes do grupo So4 apresentaram diversos efeitos tóxicos que impediram constituir o número de filhotes suficientes para análise do desenvolvimento pós-natal.

No presente estudo, em relação às avaliações bioquímicas, poucas foram as diferenças detectadas entre as cabras dos grupos controle e experimentais, embora as alterações histopatológicas em musculatura esquelética e cardíaca, além de fígado e rim tenham sido bastante consistentes. Assim, foram encontradas apenas diminuições dos níveis de albumina nas fêmeas do grupo So2 na $4^{\mathrm{a}}$ semana e na $17^{\text {a }}$ semana de gestação. A diminuição nos valores de albumina poderia sugerir lesão hepática (DUNCAN; PRASSE, 1982); no entanto, como outros parâmetros bioquímicos que auxiliam na avaliação da função hepática, a saber: AST, GGT, FA, glicose, lactato desidrogenase (LDH), proteína total (PT), bilirrubina total e colinesterase, não revelaram qualquer alteração durante o período gestacional e, ainda, considerando-se que esta alteração de albumina ocorreu de maneira esporádica, em apenas duas semanas do período gestacional, pode-se sugerir que a avaliação bioquímica não se prestou para monitorar a possível toxicidade produzida pela $S$. occidentalis às fêmeas durante a prenhez. Reforça esta suposição o fato de ter sido verificado também que os níveis de creatinina naquelas gestantes 
pertencentes aos grupos So2 e So4 na primeira coleta mostraram-se elevados em relação ao grupo controle, o que poderia permitir levantar-se a hipótese de ter havido alterações consistentes na função renal. No entanto, quando foram analisados os níveis desta substância em outras coletas subseqüentes verificou-se que esta alteração ocorreu de maneira diametralmente oposta aos dados obtidos naquela primeira avaliação.

Estes achados corroboram estudos prévios conduzidos em nosso laboratório nos quais, apesar de terem sido detectadas lesões renais, hepáticas e em musculatura esquelética em cabritos que consumiram diferentes concentrações de sementes de $S$. occidentalis prolongadamente, também não foram observadas alterações relevantes na bioquímica sérica (BARBOSA-FERREIRA, 2003). Ainda, deve-se considerar que em uma outra pesquisa, na qual se estudou a toxicidade aguda da $S$. occidentalis em bovinos, foi evidenciado que, embora houvesse severas lesões induzidas pela planta nestes animais, não houve nenhuma alteração consistente na análise da bioquímica sérica das diferentes substâncias mensuradas (BARROS et al., 1990). Reunindo-se todos os dados aqui obtidos com aqueles encontrados na literatura, pode-se inferir que o estudo da bioquímica sérica não é uma ferramenta de grande auxílio no diagnóstico da intoxicação natural ou experimental causada pela $S$. occidentalis, principalmente quando a exposição a esta planta ocorre de maneira prolongada.

O peso corporal é um parâmetro amplamente utilizado em avaliações toxicológicas para indicar efeitos de uma determinada substância no organismo animal (STEVENS; GALLO, 1989). No presente trabalho, observaram-se diferenças no ganho de peso total somente nas fêmeas gestantes do grupo So3, em relação ao grupo controle. Interessante observar que a análise estatística não revelou diminuição significante no peso daquelas fêmeas provenientes do grupo So4, embora os valores obtidos de cada um dos animais pertencentes a este grupo experimental mostravam-se sempre menores que aqueles de animais do grupo controle. Assim, uma hipótese para justificar este dado seria de que havia pequena quantidade de sujeitos experimentais no grupo So4 ao final do experimento, o que não permitiu a realização do estudo estatístico adequado. Desta maneira, pode-se sugerir que há relação entre a intoxicação da $S$. occidentalis e a diminuição do ganho de peso durante a gestação.

Estudos realizados, tanto com suínos (RODRIGUES et al., 1993) como em 
ratos (WEG, 2001; BARBOSA-FERREIRA, 2003; MARIANO-SOUZA, 2005), nos quais se administrou prolongadamente sementes de $S$. occidentalis na ração, mostraram diminuição de maneira dose-resposta no ganho de peso, à medida que estes animais adoeciam, os quais apresentaram, entre outras alterações clínicas, fraqueza muscular, ataxia dos membros posteriores, relutância em se mover, depressão e também anorexia. Portanto, pode-se inferir que a diminuição no peso dos animais, tanto em ratos como em suínos, estaria diretamente relacionada ao adoecimento dos animais expostos à planta. Entretanto, na presente pesquisa, nenhuma cabra apresentou sinais clínicos de intoxicação pela S. occidentalis, além disto, aqui neste estudo, embora não tenha sido aferido o consumo de alimentos das cabras dentro dos diferentes grupos estudados, foi possível verificar claramente, por meio de inspeção diária nos cochos, que não havia diferença no consumo entre os animais dos grupos controle e experimentais. Estes dados corroboram os achados anteriores em que caprinos machos, em fase de desenvolvimento, e que consumiram, prolongadamente, ração contaminada com $2 \%$ de sementes da planta, também não adoeceram, exceto apresentando uma leve diarréia em um curto período de tempo, mas que da mesma maneira que o aqui observado naquelas cabras gestantes, pertencentes ao grupo So3, tiveram queda no ganho de peso (BARBOSA-FERREIRA, 2003). Assim, embora não seja possível neste momento propor os mecanismos pelos quais os caprinos perdem peso quando da exposição prolongada à S. occidentalis, evidencia-se a característica insidiosa desta planta na intoxicação prolongada e com baixas doses, na qual embora não seja observado o sinal clínico de intoxicação, esta pode causar perdas no ganho de peso, refletindo diretamente na queda dos parâmetros zootécnicos do rebanho caprino.

As alterações macroscópicas descritas na intoxicação aguda com altas concentrações de $S$. occidentalis em caprinos são estrias esbranquiçadas em musculatura cardíaca e fígado com aspecto de noz-moscada (DOLLAHITE; HENSON, 1965; SULIMAN et al., 1982). No presente trabalho, estas mesmas alterações foram evidentes naquela cabra pertencente ao grupo So4. Entretanto, estas alterações diferiram daqueles achados macroscópicos, tanto em cabras que consumiram ração contendo $4 \%$ de sementes da planta durante o período de lactação (grupo LAC), como daqueles observados no estudo anterior, em caprinos em crescimento (BARBOSA-FERREIRA, 2003). Assim, em ambos estudos não foram observadas lesões à avaliação macroscópica. Considerando-se que os 
achados histopatológicos naquelas fêmeas expostas à planta durante a gestação revelaram alterações severas e difusas nestes mesmos locais (ou seja, musculatura cardíaca e esquelética, fígado e rim), enquanto que naquelas do grupo LAC as lesões, quando encontradas nestes tecidos, foram focais e brandas, poder-se-ia sugerir que o estado fisiológico do animal influencia na severidade da intoxicação pela S. occidentalis; assim, a gestação poderia promover uma maior sensibilidade aos efeitos tóxicos da planta. No entanto, futuros experimentos deverão ser realizados, com o objetivo de se comprovar esta hipótese.

Calore et al. (1998) estudando os efeitos tóxicos das sementes de $S$. occidentalis em frangos, descreveram lesões axonais ao nível de musculatura lisa intestinal. Uma outra pesquisa, conduzida neste laboratório, avaliando-se os efeitos quando da administração prolongada desta planta em ratos, evidenciou lesões em SNC (BARBOSA-FERREIRA et al., 2005). Na presente pesquisa verificou-se lesão no nervo ciático naquela cabra pertencente ao grupo So4. Assim, embora esta alteração, produzida pela $S$. occidentalis e pela primeira vez descrita na espécie caprina, não esteja completamente caracterizada, corrobora os achados anteriores nos quais evidenciam a propriedade neurotóxica da desta planta.

Relatos da literatura têm associado o consumo de Senna spp a casos de infertilidade em ratos e humanos (YADAV; JAIN, 1999; BADAMI et al., 2003; STUART, 2003); no entanto, muito pouco se conhece sobre os efeitos desta planta no concepto. Neste sentido, apenas um trabalho, desenvolvido por este grupo de pesquisa, evidenciou que diferentes concentrações de sementes de $S$. occidentalis administradas a coelhas gestantes produziram efeitos tóxicos tanto nas mães como nos seus fetos (TASAKA et al., 2004).

O período de implantação do embrião nas cabras inicia-se no $17^{\circ}$ dia e termina no $23^{\circ}$ dia pós coito (WANGO; WOODING; HEAP, 1990). Uma vez que um dos objetivos do presente trabalho foi averiguar possíveis efeitos teratogênicos sem que houvesse interferência na implantação embrionária, a administração da $S$. occidentalis foi iniciada após a confirmação da prenhez, que só foi possível, quando de avaliação ultra-sonográfica, a partir do $27^{\circ}$ dia pós-parto.

Aborto (ou perda fetal) é um dos primeiros efeitos observados na toxicidade pré-natal dos animais de produção (JAMES et al., 1994). De fato, os dados aqui obtidos revelaram morte fetal em duas cabras pertencentes ao grupo So4, evidenciadas pela ausência de imagens ultra-sonográficas na data da primeira 
mensuração, aos 35 dias de prenhez. Além deste dado, neste mesmo grupo também se observou morte ao nascimento de um filhote; nascimento de um filhote debilitado e morte de uma cabra no final da gestação. Portanto, posteriormente, como não seria possível ter um número de filhotes suficientes que permitisse analisar os efeitos da administração desta maior dose de S. occidentalis, foi necessário introduzir um outro grupo de cabras, tratadas com uma concentração menor que aqueles 4\%; assim sendo, optou-se por realizar um outro experimento, administrando-se $3 \%$ de sementes da planta às cabras gestantes.

Sabe-se que alguns agentes produtores de doenças infecciosas, tais como Mycoplasma sp, Brucella sp, Toxoplasma sp, e Leptospira sp, poderiam promover abortos (KIRKBRIDE, 1990; AIELLO; MAYS, 1997); no entanto, a pesquisa para estes agentes infecciosos responsáveis pelas principais causas de abortamentos em caprinos no Brasil, resultou negativa. Desta maneira, apesar de outras causas, infecciosas ou não, poderem ter sido aquelas responsáveis pelos abortamentos aqui verificados, é factível considerar a exposição à $S$. occidentalis como sendo a causadora deste efeito.

A intoxicação materna é reconhecida como fator causador de alterações no desenvolvimento e/ou morte fetal (KHERA, 1984). Portanto, pode-se sugerir que a morte fetal, aqui verificada, estaria relacionada à intoxicação materna. Por outro lado, considerando-se que a toxina diantrona ocasiona o desacoplamento da fosforilação oxidativa na mitocôndria (CALORE et al., 1997) e, sabendo-se que grande parte do oxigênio consumido na placenta é usado na fosforilação oxidativa (CARTER, 2000), pode-se sugerir que a morte do concepto seria devida a uma toxicidade placentária; assim, futuros estudos, avaliando o tecido placentário, deverão ser realizados para melhor verificar esta hipótese.

Outra possibilidade para justificar o aqui verificado seria de que o princípio ativo tóxico da planta poderia atravessar a placenta, causando toxicidade fetal. Reforça esta conjectura o fato de que se sabe que a diantrona é uma substância com baixo peso molecular, 450D (HARAGUCHI et al., 1996), o que permitiria a passagem livre desta antraquinona através das membranas placentárias, atingindo diretamente o concepto. De fato, em um estudo anterior, realizado neste laboratório, administrando-se sementes de $S$. occidentalis a coelhas gestantes, verificou-se que as proles destes animais mostraram, ao nível hepático, destruição de cristas mitocondriais (TASAKA et al., 2004), lesão esta tipicamente produzida pela diantrona 
e já bem descrita em outros estudos (CAVALIERI et al., 1997; CALORE et al., 1997; HARAGUCHI et al., 1998).

Segundo Schumaher-Henrique (2005), o qual estudou cabras intoxicadas por Ipomoea carnea durante a gestação, a avaliação ultra-sonográfica demonstra ser um método bastante útil, não invasivo, para o monitoramento fetal, uma vez que se pode observar o desenvolvimento do concepto em diferentes períodos durante boa parte da gestação. De fato, Panter et al. (1987) observaram alterações como acúmulo de líquidos na placenta, alteração no desenvolvimento cotiledonário, alterações no batimento cardíaco e morte fetal quando utilizaram esta técnica no estudo de ovelhas gestantes intoxicadas por Astragalus lentiginosus.

No presente estudo verificou-se que, em relação aos dados obtidos na avaliação ultra-sonográfica, o único parâmetro que apresentou diferença significante entre os animais dos grupos controle e experimentais, foi a diminuição da freqüência cardíaca naqueles fetos pertencentes ao grupo de mães tratadas com 1\% da planta. No entanto, este dado deve ser visto com cautela, já que esta alteração foi verificada justamente nos fetos daquelas fêmeas pertencentes ao grupo que recebeu a menor concentração da planta. Portanto, provavelmente este efeito não estaria relacionado à toxicidade promovida pela $S$. occidentalis.

Diversos pesquisadores discutem sobre a acurácia dos protocolos existentes para determinar os riscos potenciais da exposição a numerosas substâncias químicas durante o período de desenvolvimento perinatal. Segundo Claudio et al. (1999), a maior limitação destes protocolos de avaliação de toxicidade é que não há o exame dos filhotes, em nenhuma fase pós-natal, o que, na maioria das vezes, poderá levar a erros no julgamento sobre o efeito teratogênico da substância testada. De fato, são vários os dados encontrados na literatura os quais mostram que o efeito tóxico nos filhotes de gestantes expostas a um determinado agente irá se manifestar no filhote apenas um longo período após o nascimento, como é o caso do heptacloro, que pode causar aumento de morte pós-natal no filhote de mãe exposta durante a gestação somente depois do $6^{\circ}$ dia após o nascimento; esta substância pode também produzir catarata no filhote após o $21^{\circ}$ dia de vida (NAROTSKY; KAVLOCK, 1995). Assim, o objetivo do presente estudo foi refinar o protocolo de teratologia em ruminantes, dando ênfase à avaliação do desenvolvimento da prole, do período pós-parto até o desmame.

A ausência de malformações físicas como artrogripose, presença de fenda 
palatina, spina bífida entre outras, associadas aos dados da ultra-sonografia daqueles filhotes provenientes das cabras pertencentes aos diferentes grupos experimentais, revela que a $S$. occidentalis não causa alterações morfológicas visíveis como os descritos anteriormente, o que ratifica os estudos conduzidos por Tasaka et al. (2004), que estudaram a intoxicação perinatal pela planta em coelhas, e também relataram não ter observado malformações na prole, ao nascimento.

O peso ao nascimento é um dos mais importantes parâmetros em estudos teratológicos (WHO, 1967; USEPA, 1991). Na presente pesquisa não foi observada alteração no peso ao nascer nem no ganho de peso dos filhotes provenientes de todos os grupos experimentais, durante todo o período de lactação. Resultados semelhantes também ocorreram nos estudos perinatais realizados com coelhas (TASAKA et al., 2004); entretanto, segundo Stevens e Gallo (1989), a ausência de alteração neste parâmetro não significa que uma substância não produza efeitos teratogênicos.

A avaliação bioquímica das proles dos diferentes grupos, controle e experimentais, não apresentou alterações significantes, assim como o observado no caso das mães. Um fator que deve ser levado em conta é o constante crescimento corporal pós-natal que continuamente altera os parâmetros sorológicos (HOOD, 2006), caracterizando grandes flutuações nestes parâmetros. Portanto, além de a bioquímica sérica não se mostrar de grande valor na intoxicação pela S. occidentalis, como já apontado anteriormente, esta avaliação torna-se ainda mais difícil quando se considera o animal em crescimento, que devido a estas amplas variações, impede que sejam detectadas possíveis alterações mais sutis.

Mensurações corporais são de uso comum em pesquisas em que se pretende determinar parâmetros produtivos em animais domésticos, tais como avaliação de padrão de crescimento em bovinos de leite (ARRAYET et al., 2002), avaliação de conformação zootécnica em ovelhas (COSTA JR. et al., 2006), além de estudo do crescimento em caprinos (KHAN et al., 2006). No entanto, esta é a primeira vez que se propõe que estes parâmetros sejam usados para a avaliação de possíveis efeitos teratogênicos no período pós-natal.

No presente estudo, a análise dos dados provenientes da avaliação do desenvolvimento dos filhotes de cabras que consumiram a planta durante a gestação, mostrou poucas diferenças significantes na morfometria corporal quando comparado aos dados dos filhotes do grupo controle. É, portanto, possível inferir que 
a S. occidentalis de per se não influencie de maneira significante no desenvolvimento corporal. No entanto, embora esta pesquisa não tenha revelado alterações nos parâmetros propostos, já que provavelmente esta planta não seja um teratógeno potente, mostrou que estas mensurações são bastante úteis para se avaliar o desenvolvimento físico pós-natal após a exposição por diferentes toxicantes, já que permitem detectar alterações sutis durante o período de desenvolvimento.

A necropsia de filhotes de mães gestantes expostas à $S$. occidentalis não mostrou quaisquer alterações macroscópicas. Da mesma maneira, a análise histopatológica, também não evidenciou lesões teciduais em nenhum dos órgãos avaliados. No entanto, seria precoce afirmar neste momento que a exposição da gestante não comprometeria seu filhote. Neste sentido, seria plausível também supor que a ausência destes achados poderia estar relacionada à característica reversível das injúrias causadas pela $S$. occidentalis. De fato, sabe-se que a diantrona não possui caráter acumulativo no organismo (BARROS et al., 1990). Uma vez que o filhote foi retirado da exposição à planta durante todo o período de lactação, já que somente suas mães foram expostas à S. occidentalis na gestação, poder-se-ia propor que neste período, ou seja, estes quatro meses da fase de lactação, tivesse havido o restabelecimento das funções mitocondriais o que, conseqüentemente, possibilitaria a regeneração tecidual. No entanto, esta suposição deverá ser melhor averiguada em futuros estudos, coletando-se material para o estudo histopatológico em uma fase mais precoce do que a aqui estudada.

Um organismo em desenvolvimento passa por períodos críticos de maturação, sendo um deles o desenvolvimento perinatal do cérebro. Sabe-se que em mamíferos este período no desenvolvimento está associado a inúmeras alterações bioquímicas (ERIKSSON,1997); portanto, qualquer evento que possa conturbar tal processo, como a exposição a um agente tóxico neste período, poderá alterar significantemente o desenvolvimento pós-natal. Assim, também foi objetivo do presente trabalho avaliar os possíveis efeitos neurotóxicos naqueles filhotes de mães expostas à planta durante a gestação, propondo-se para tal, testes em caprinos, de avaliação neurocomportamental, particularmente aqueles ligados à memória e aprendizado.

Diferentes procedimentos podem ser adotados para avaliar a habilidade de aprendizado nos animais (MATZEL et al., 2003), neste sentido, avaliações de 
orientação espacial e aprendizado em eqüinos (MCLEAN, 2004), aprendizado em ovelhas (LEE; COLEGATE; FISHER, 2006) e em bovinos (BROUČEK; KIŠAC; UHRINČAŤ, 2003) têm sido relatados na literatura, utilizando-se diferentes arquiteturas em labirintos de avaliação comportamental. No entanto, não há relatos de trabalhos em que se estudam os efeitos tóxicos pós-natais em caprinos.

O presente estudo claramente evidenciou no teste do labirinto progressivo, que aqueles filhotes de mães tratadas com a planta gastaram maior tempo para chegar ao fim do trajeto, na primeira sessão. Desta maneira, é possível supor que estes filhotes apresentaram maior dificuldade em se situar no ambiente e em aprender como chegar ao objetivo, quando expostos ao problema pela primeira vez. Assim, embora o tempo gasto por estes animais nas outras sessões não tenha sido díspar daquele dos filhotes provenientes de fêmeas do grupo controle, pode-se verificar que a planta promoveu um déficit na capacidade de aprendizado, nas primeiras 48 horas após o nascimento.

Da mesma maneira, quando se avaliou o desempenho dos filhotes no labirinto em $T$, verificou-se que os filhotes do grupo experimental tiveram dificuldade em discernir imediatamente entre o chamado de suas mães e os balidos de outra cabra, dirigindo-se primeiramente às cabras "estranhas". Esta dificuldade dos filhotes de escolherem o caminho correto por meio dos sinais das mães, denota déficit de cognição.

Os testes realizados no labirinto de dificuldade média (Lashley Maze) não foram de grande valia devido à ampla variabilidade de fatores, entre estas está o interessante fato de que aqueles filhotes experimentais demonstraram claramente maior "ansiedade" dentro do labirinto, assim, estes animais apresentavam-se agitados, pulando para fora das áreas de teste, por cima das paredes, não terminando a prova.

A análise dos dados referentes ao labirinto com grau de dificuldade alto (Hebb-Williams Maze), mostrou que na $10^{\text {a }}$ semana de testes, os filhotes experimentais despendiam muito maior tempo na área 2, que aqueles cabritos provenientes de mães do grupo controle, evidenciando-se, desta maneira, que ainda nesta fase, estes animais apresentavam déficit de aprendizado.

Assim, o presente estudo mostrou que embora outras avaliações, utilizandose os protocolos convencionais (p.ex.: deteç̧ão de malformações físicas ou alterações do ganho de peso), ou não, como a morfometria corporal, não 
detectassem alterações nos filhotes de mães expostas à planta durante a gestação, o uso de protocolos de avaliação neurocomportamental permitiu verificar alterações funcionais nestes filhotes na fase de crescimento. Este achado revela que a intoxicação perinatal pela S. occidentalis poderá ter importante implicação na criação animal, já que se sabe que falhas no processo cognitivo como aprendizado espacial e memória, podem causar problemas de manejo nos animais de produção (MENDL; LAUGHLIN; HITCHCOCK, 1997). Neste sentido, se o animal tiver dificuldade de aprender como lidar com as alterações do ambiente de produção como novas instalações, inclusão em novos rebanhos, mudança de tratadores entre outras, haverá queda no desempenho e, conseqüentemente, perdas econômicas na exploração animal (WECHSLER; LEA, 2007).

Um aspecto que deve ser levado em conta quando ocorre a ingestão de plantas tóxicas por lactantes é que as toxinas podem ser transferidas para o leite (PANTER; JAMES 1990; RIET-CORREA; MEDEIROS, 2001). Assim, o lactente poderá expor-se indiretamente ao agente tóxico. Deve-se considerar ainda que além da saúde animal, há risco de intoxicação no ser humano (JAMES et al., 1994). Um exemplo deste tipo de intoxicação indireta é aquele que foi descrita, nos Estados Unidos, nos anos de 1841 e 1985, para a planta Eupatorium rugosum, a qual foi relacionada a uma doença conhecida como enfermidade do leite ("milksickness"); além desta, também foi relatada naquele país a intoxicação em vacas, seus filhotes e seres humanos consumidores do leite destas fêmeas doentes, que consumiram a planta Haplopappus heterophyllus (PANTER; JAMES 1990; JAMES et al., 1994). Em vista destes fatos, houve o interesse em investigar os possíveis efeitos tóxicos da $S$. occidentalis durante o período da lactação.

Com o objetivo de se verificar a possível transferência para o leite do princípio ativo da S. occidentalis (HARAGUCHI et al., 1996) foi feita a avaliação química de amostras de colostro e leite de cabras que consumiram a planta na gestação e na lactação, respectivamente. Entretanto, este estudo não permitiu evidenciar a presença de antraquinona nas amostras avaliadas, tanto através da técnica de cromatografia de camada delgada (CCD) como pela técnica de cromatografia líquida de alta eficiência (CLAE). Uma possível explicação para este fato poderia ser a presença em quantidades muito reduzidas das antraquinonas no leite, não tendo o método sensibilidade suficiente para conseguir detectar tais níveis. Uma outra possibilidade factível seria a ocorrência de biotransformação da antraquinona no 
organismo da lactante. Assim, embora uma busca na literatura tenha revelado não haver estudos relativos à biotransformação da diantrona, é possível supor que, não esta substância, mas sim o seu metabólito ativo seria o composto presente no leite da fêmea exposta à $S$. occidentalis, o que impossibilitaria a detecção pela técnica aqui empregada.

Uma outra maneira com a qual se procurou verificar a passagem do princípio ativo tóxico da planta através do leite foi a observação de possíveis efeitos tóxicos nos filhotes. Assim, embora não tenham sido detectadas alterações no ganho de peso, nem no estudo bioquímico, além de discreta alteração quando da avaliação na morfometria corporal naqueles filhotes provenientes do grupo LAC, verificou-se que, à análise histológica, estes filhotes apresentaram lesões focais teciduais, em fibras musculares esqueléticas, além de necrose, vacuolizações, edema intersticial, tumefação e fragmentação de fibras de músculo cardíaco; vacuolização de hepatócitos em torno da veia hepática terminal e discretas vacuolizações em endotélio dos túbulos contornados e em glomérulos. Como estas alterações aqui encontradas são características da intoxicação pela S. occidentalis (BARROS, 1990; MÉNDEZ; RIET-CORREA, 2000; BARBOSA-FERREIRA, 2003), é possível inferir que o princípio ativo tóxico da planta passe para o leite, promovendo intoxicação indireta no lactente.

Finalizando, o modelo aqui proposto poderá ter grande valia para estudar o potencial teratogênico, não só em relação a toxinas provenientes de plantas, mas também a um grande número de substâncias químicas, incluindo-se medicamentos aos quais os ruminantes são freqüentemente expostos. Este estudo permitiu também verificar que a $S$. occidentalis, embora não seja um potente teratógeno, quando consumida durante a gestação, pode causar efeitos tóxicos no feto, fato evidenciado durante $\mathrm{o}$ período pós-natal, pelo modelo de avaliação neurocomportamental, aqui proposto. 
Conclusões 177

\section{CONCLUSÕES}

1833 I. A. C. SILVA Corografia Paraense 13: São innumeraveis as medicinaes, notam-se a quina, herva santa, abútua, o fedegoso, ou páo magirioba, excellente febrifugo, barbatemão, cuja cásca he um famoso adstringente, artemisia, herva cidreira, que cresce espontaneamente, o mastruz, mentrasto, jalapa, ipecacuanha, [...] (CUNHA, 1999). 
- A ingestão prolongada e em baixas concentrações de sementes de $S$. occidentalis influencia diretamente na prenhez, podendo interromper a gestação;

- A ingestão prolongada e em baixas concentrações de sementes de $S$. occidentalis pode causar a morte de cabras gestantes, além de influenciar negativamente no neonato, podendo causar morte após o nascimento;

- A S. occidentalis, nas concentrações utilizadas, não produz malformações físicas na prole;

- As lesões histológicas causadas pela planta, em caprinos, parecem estar relacionadas ao estado fisiológico do animal;

- A bioquímica sangüínea tem pouco auxílio no diagnóstico na intoxicação pela S. occidentalis em caprinos;

- A planta causa lesões em sistema nervoso periférico;

- A S. occidentalis causa leões indiretas em lactentes que estejam consumindo o leite de mães expostas à planta durante o período de lactação, revelando sua transferência para o leite;

- O protocolo de morfometria corporal demonstrou ser bastante útil para o estudo do desenvolvimento pós-natal;

- O protocolo de avaliação neurocomportamental pode detectar alterações funcionais nos filhotes, na fase de crescimento, cujas mães foram expostas à planta durante a gestação, mesmo quando esta planta não seja um potente teratógeno;

- O modelo de avaliação do crescimento pós-natal, proposto no presente trabalho, demonstrou ser exeqüível e adequado para o estudo da teratogênese do desenvolvimento. 


\section{REFERÊNCIAS}

AIELLO, S. E.; MAYS, A. (ed.). Manual Merck de Veterinária. 7 ed. São Paulo: Roca, 1997, 2169p.

ARRAYET, j. I.; OBERBAUER, A. M.; FAMULA, T. R.; GARNETT, I.; OLTJEN, J. W.; IMHOOF, J.; KEHRLI Jr., M. E.; GRAHAM, T. W. Growth of holstein calves from birth to 90 days: The influence of dietary zinc and BLAD status. Journal of Animal Science, v.80, p.545-552, 2002.

BADAMI, S.; ANEESH, R.; SANKAR, S.; SATHISHKUMAR, M. N.; SURESH, B.; RAJAN, S. Antifertility activity of Derris brevis variety coriacea. Journal of Ethnopharmacology, v.84, n.1, p.99-104, 2003.

BARBOSA-FERREIRA, M. Estudo dos efeitos tóxicos produzidos pela administração prolongada de sementes de Senna occidentalis. Avaliação em ratos e caprinos. 2003.139f. Dissertação (Mestrado em Ciências) - Faculdade de Medicina Veterinária e Zootecnia, Universidade de São Paulo, São Paulo. 2003.

BARBOSA-FERREIRA, M.; DAGLI, M. L. Z.; MAIORKA, P. C.; GÓRNIAK, S. L. Subacute intoxication by Senna occidentalis seeds in rats. Food and Chemical Toxicology, v.43, n.4, p.497-503, 2005.

BARROS, C. S. L.; PILATI, C.; ANDUJAR, M. B.; GRAÇA, D. L.; IRIGOYEN, L. F.; LOPES, S. T.; SANTOS, C. F. Intoxicação por Cassia occidentalis (Leg. Caes.) em bovinos. Pesquisa Veterinária Brasileira, v.10, n.3-4, p.47-48, 1990.

BROCQ-ROUSSEAU, S.; BRUERE, P. Accidents mortels sur des chevals, dus a la grains de Cassia occidentalis L. Comptes Rendus Des Séances de la Societé de Biologie, v.92, p.555-557, 1925.

BROUČEK, J.; KIŠAC, P.; UHRINČAŤ, M. The effect of sire line on learning and locomotor behaviour of heifers. Czech Journal of Animal Science, v.48, n.9, p.387394, 2003.

CALORE, E. E. ; CAVALIERI, M. J.,; HARAGUCHI, M. ; GÓRNIAK, S. L. ; DAGLI, M. L. Z. ; RASPATINI, P. C. F. ; CALORE, N. M. P. Experimental mitochondrial myopathy induced by chronic intoxication by Senna occidentalis seeds. Journal of Neurological Sciences, v.146, n.1, p.1-6, 1997.

CALORE, E. E. ; CAVALIERI, M. J. ; HARAGUCHI, M. ; GÓRNIAK, S. L. ; DAGLI, M. L. Z. ; RASPATINI, P. C. F. ; CALORE, N. M. P. ; WEG, R. Toxic peripheral neuropathy of chicks fed Senna occidentalis seeds. Ecotoxicology environmental safety, v.39, n.1, p.27-30, 1998.

CARTER, A. M. Placental oxygen consumption. Part I: in vivo studies - a review. Placenta, v.21, n.14, p.31-37, 2000. Suplementum A. Trophoblast Research.

CAVALIERI, M. J.; CALORE, E. E.; HARAGUCHI, M.; GÓRNIAK, S. L.; DAGLI, M. L. Z.; RASPATINI, P. C. F.; CALORE, N. M. P; WEG, R. Mitocondrial myopathy in 
Senna occidentalis seed-feed chicken. Ecotoxicology and Environmental Safety, v.37, p.181-185, 1997.

CERQUEIRA, D. Reminiscências da campanha do Paraguai: 1865-1870. Ed. especial. Rio de Janeiro: Biblioteca do Exército, 1980, 341 p.

CHAVEZ MORENO, J.; STEINMANN CHAVEZ, C.; BICKHARDT, K. Fetal heart rate measurement and sonographic fetometry for determination of fetal age in sheep. Dtsch Tierarztl Wochenschr, v.103, n.11, p.478-480, 1996.

CLAUDIO, L.; BEARER, C.F.; WALLINGA, D. Assessment of the U.S. environmental protection agency methods for identification of hazards to developing organisms, part II: the developing toxicity testing guideline, American Journal of Industrial Medicine, v.35, p.554-563, 1999.

COLLINS, C. H.; BRAGA, G. L.; BONATO, P. S. Introdução a métodos cromatográficos. $7^{a}$ ed. São Paulo: Editora da UNICAMP, 1997, 279p.

COLVIN, B. M.; HARRISON, L. R.; SANGSTER, L. T.; GOSSER, H. S. Cassia occidentalis toxicosis in growing pigs. Journal of American Veterinary Medical Association, v.189, n.4, p.423-426, 1986.

COSTA JÚNIOR, G. da S.; CAMPELO, J. E. G.; AZEVÊDO, D. M. M. R.; FILHO, R. M.; CAVALCANTE, R. R.; LOPES, J. B.; OLIVEIRA, M. E. Caracterização morfométrica de ovinos da raça Santa Inês criados nas microrregiões de Teresina e Campo Maior, Piauí. Revista Brasileira de Zootecnia, v.35, n.6, p.2260-2267, 2006.

CRUZ, F. C. Fitogeografia da Amazônia. Belo Horizonte: Palpite editora Itda, 2000, p.230.

CUNHA, A. G. da. Dicionário Histórico das Palavras Portuguesas de Origem Tupi. Editora Melhoramentos/ UnB. 1999.

DASTON, G. P.; SEED, J. Skeletal malformations and variations in developmental toxicity studies: Interpretation issues for human risk assessment. Birth Defects Research Part B: Developmental and Reproductive Toxicology, v.80, n.6, p.421424, 2007.

DELATOUR, P.; PARISH, R. C.; GYURIK, R. J. Albendazole: a comparison of relay embryotoxicity of individual metabolites. Annales de Recherche Vetérinaire, v.12, n.2, p.159-67, 1981.

DUNCAN, J.R.; PRASSE, K.W. Patologia clínica veterinária. Rio de Janeiro: Guanabara Koogan, 1982. 217 p.

DOLLAHITE, J. W.; HENSON, J. B. Toxic plants as the etiologic agent of myopathies in animals. American Journal Veterinary Research, v.26, n.112, p.749-752, 1965.

ERIKSSON, P. Developmental toxicology: neurodevelopmental toxicity in mammals. UPPSALA UNIVERSITET, Environmental Toxicology, Norbyvägen 18A, 75236 
Uppsala. Last updated: 2007-08-16. Disponível em:

<http://www.fu.uu.se/etox/devtox 1.html>. Acesso em: 28 ago. 2007.

GONZALES de BULNES, A.; GARCIA, P. F.; MAYENCO, A. M.; SANCHES de LA MUELA, M. Ultrasonographic imaging of canine mammary tumours. Veterinary Records, v.143, n.25, p. 687-689, 1998.

GRAZIANO, M. J.; FLORY, W.; SEGER, C. L.; HEBERT, C. D. Effects of Cassia occidentalis extract in the domestic chicken (Gallus domesticus). American Journal Veterinary Research, v.44, n.7, p.1238-1244, 1983.

GREGG, N. M. Congenital cataract following German measles in the mother. Transactions of The Ophthalmological Society of Australia, v.3, p.35-46, 1941.

HARAGUCHI, M.; GÓRNIAK, S. L; DAGLI, M. L. Z.; RASPANTINI, P. C. F.; Determinação dos constituintes químicos das frações tóxicas de fedegoso, (Senna occidentalis (L.)). In: REUNIÃO ANUAL DA SOCIEDADE BRASILEIRA DE QUÍMICA, 19., 1996, Poços de Caldas. Anais... Poços de Caldas, 1996. p.96.

HARAGUCHI, M.; GÓRNIAK, S. L; CALORE, E. E.; CAVALIERE, M. J.; RASPANTINI, P. C. F.; CALORE, N. M.; DAGLI, M. L. Z. Muscle degeneration in chicks caused by Senna occidentalis seeds. Avian Pathology, v.27, p.346-351, 1998.

HENSON, J. B.; DOLLAHITE, J. W.; BRIDGES, C. H.; RAO, R. R. Myodegeneration in cattle grazing Cassia specie. Journal of American Veterinary Medical Association, v.147, n.2, p.142-145, 1965.

HENSON, J. B.; DOLLAHITE, J. W. Toxic myodegeneration in calves produced by experimental Cassia occidentalis intoxication. American Journal Vetetrinary Research, v.27, n.119, p.947-950, 1966.

HERBERT, C. D.; FLORY, W.; SEGER, C.; BLANCHARD, R. E. Preliminary isolation of a myodegenerative toxic principle from Cassia occidentalis. American Journal of Veterinary Research, v.44, n.7, p.1370-1374, 1983.

HOEHENE, F. C. Plantas e substâncias vegetais tóxicas e medicinais. São Paulo: Departamento de botânica do estado de São Paulo, 1939, p.355.

HOOD, R. D. Principles of Developmental Toxicology Revisited. In:

Developmental and Reproductive Toxicology. A Practical Approach. 2 nd ed. Boca Raton, FL, USA: Taylor \& Francis Group, 2006. p.3-14.

IRIGOYEN, L. F.; GRAÇA, D. L.; BARROS, C. S. L. Intoxicação experimental por Cassia occidentalis (Leg. Caes.) em eqüinos. Pesquisa Veterinária Brasileira, v.11, n.1/2, p.35-44, 1991.

JAMES, L. F. Solving poisonous plant problems by a team approach, p.1-6. In: Colegate S.M. \& Dorling P.R. (ed.), 1994 Plant Associated Toxins. CAB International, Wallingford. 
JAMES, L. F.; PANTER, K. E.; STEGELMEIER, B. L.; MOLYNEUX, R. J. Effect of natural toxins on reproduction. The Veterinary Clinics of North America Food Animal Practice, v.10, n.3, p.587-603, 1994.

JOLY, A. B. Botânica: Introdução à taxonomia vegetal. $4^{\mathrm{a}}$ ed. Editora Nacional, São Paulo, 1977, p.542.

KAHN, W. Veterinary reproductive ultrasonography. London: Mosbywife, 1994, p.256.

KHAN, H.; MUHAMMAD, F.; AHMAD, R.; NAWAZ, G.; RAHIMULLAH; ZUBAIR, M. Relationship of body weight with linear body measurements in goats. Journal of Agricultural and Biological Science, v.1, n.3, p. 51-54, 2006.

KHERA, K. S. Maternal toxicity - A possible factor in fetal malformations in mice. Teratology, v.29, n.3, p.411-416, 1984.

KIRKBRIDE, C. A. Laboratory diagnosis of livestock abortion. Third Edition, lowa state university press, 1990.

LEE, C.; COLEGATE, S.; FISHER, A. D. Development of a maze test and its application to assess spatial learning and memory in Merino sheep. Applied Animal Behaviour Science, v.96, p.43-51, 2006.

LEWIS, D. C.; SHIBAMOTO, T. Effects of Cassia obtusifolia (Sicklepod) extracts and anthraquinones on muscle mithocondrial function. Toxicon, v.27, n.5, p.519-529, 1989.

LORENZI, H. Plantas daninhas do Brasil: terrestres, aquáticas, parasitas, tóxicas e medicinais. $2^{a}$ ed. Nova Odessa: Plantarum, 1991. 273p.

MARIANO-SOUSA, D. P. Avaliação dos efeitos tóxicos da Senna occidentalis em ratos. Parâmetros: bioquímicos, hematológicos, anatomopatológicos e inflamatórios 2005. 110 f. Dissertação (Mestrado em Ciências) - Faculdade de Medicina Veterinária e Zootecnia, Universidade de São Paulo, São Paulo, 2005.

MARTINS, E.; MARTINS, V. M. V.; RIET-CORREA, F.; SONCINI, R. A.; PARABONI, S. V. Intoxicação por Cassia occidentalis (Leguminoseae) em suínos. Pesquisa Veterinária Brasileira, v.6, n.2, p.35-38, 1986.

MATZEL, L. D.; HAN, Y. R.; GROSSMAN, H.; KARNIK, M. S.; PATEL, D.; SCOTT, N.; SPENTCH, S. M.; GANDHI, C. C. Individual Differences in the Expression of a "General" Learning Ability in Mice. The Journal of Neuroscience, v.23, n.16, p.6423-6433, 2003.

MCLEAN, A. N. Short-term spatial memory in the domestic horse. Applied Animal Behaviour Science, v.85, p.93-105, 2004.

MÉNDEZ, M. del C., RIET-CORREA, F. Plantas tóxicas e toxicoses. Pelotas: Editora Universitária, 2000, 112p. 
MERCER, H. D.; NEAL, F. C.; HIMES, J. A.; EDDS, G. T. Cassia occidentalis toxicosis in cattle. Journal of American Veterinary Medical Association, v.151, n.6, p.735-741, 1967.

MOUSSU, R. Le intoxication par les grains de Cassia occidentalis L. est due a une toxoalbumine. Comptes Rendus des Séances de la Société de Biologie. v.92, p.862-863, 1925.

NAROTSKY, M. G. ; KAVLOCK, R. J. A multidisciplinary approach to toxicological screening. II. Developmental toxicity. Journal of Toxicological and Environmental Health, v.45, p.145-171, 1995.

OECD-ORGANIZATION FOR ECONOMIC CO-OPERATION AND DEVELOPMENT. Guielines for testing of chemical. OECD, n.415, p.1-7, 1996.

O'HARA, P. J.; PIERCE, K. R.; READ, W. K. Degenerative myopathy associated with ingestion of Cassia occidentalis and pathologic features of the experimentally induced disease. American Journal Veterinary Research, v.30, n.12, p.2173-2180, 1969.

O'HARA, P. J.; PIERCE, K. R. A toxic cardiomyopathy caused by Cassia occidentalis. I. Morphological studies in poisoned rabbits. Veterinary pathology, v.11, p.97-109, 1974a.

O'HARA, P. J.; PIERCE, K. R. A toxic cardiomyopathy caused by Cassia occidentalis. II. Biochemical studies in poisoned rabbits. Veterinary pathology, v.11, p.110-124, 1974b.

PANTER, K. E., BUNCH, T. D., JAMES, L. F., SISSON, D. V. Ultrasonographic imaging to monitor fetal and placental developments in ewes fed locoweed (Astragalus lentiginosus). American Journal Veterinary Research, v.48 p.686-690, 1987.

PANTER, K. E.; JAMES L .F. Natural plant toxicants in milk: a review. Journal of Animal Science, v.68, p.892-904, 1990.

PANTER, K. E. and KEELER, R. F. Induction of cleft palate in goats by Nicotina glauce during narrow gestational period and its relation to reduction in fetal development. Journal of natural toxins, v.1, p.25, 1992.

PANTER, K. E.; KEELER, R. F.; JAMES, L. F.; BUNCH, T. D. Impact of plant toxins on fetal and neonatal development: a review. Journal of Range Management, v.45, n.1, p.52-57, 1992.

PÉREZ-LANDEIRO, A.; ALLENDE-BANDRÉS, M. A.; AGUSTÍN FERNÁNDEZ, M. J.; PALOMO, P. P. Teratogénesis: clasificaciones. Farmacia Hospitalaria, v.26. n.3, p.171-177, 2002.

PIERCE, K. R.; O'HARA, P. J. Toxic myopathy in Texas cattle. The Southwestern Veterinarian, v.20, p.179-184, 1967. 
RIET-CORREA, F.; MEDEIROS, R. M. T. Intoxicações por plantas em ruminantes no Brasil e no Uruguai: importância econômica, controle e riscos para a saúde pública. Pesquisa Veterinária Brasileira, v.21, n.1, 2001.

RODRIGUES, U.; RIET-CORREA, F.; MORAES, N. Intoxicação experimental em suínos com baixas concentrações de Senna occidentalis (Leg. Caes.)na ração. Pesquisa Veterinária Brasileira, v.13, n.3/4, p.57-66, 1993.

ROGERS, R. J.; GIBSON, J.; REICHMANN, K. G. The toxicity of Cassia occidentalis for cattle. Australian Veterinary Journal, v.55, p.408-412, 1979.

ROGERS, J. M.; KAVLOCK, R. J. Developmental toxicity. In: Casarett \& Doull's Toxicology: The Basic Science of Poisons, 6th edition. Curtis D. Klaassen, editor. McGraw-Hill, Inc., New York, NY, 2001, p.351-386 (Chapter 10).

SAS - STATISTICAL ANALISYS SYSTEM. SAS user's guide: statistics. SAS Inst. Inc., Cary, NC; Version 9.1 for Windows, 2004.

SCHARDEIN, J. L. Teratogenic risk assessment. In: Kalter, H., ed. Issues and reviews in teratology, Plenum Press, New York; 1983. p.181-214.

SCHRICK, K. N.; SURFACE, R. A.; PRITCHARD, J. Y.; DAILEY R. A.; TOWNSEND, E. C.; INSKEEP, E. K. Ovarian structures during the estrous cycle and early pregnancy in ewes. Biology and Reprodution, v.49, n.5, p.1133-1140, 1993.

SCHUMAHER-HENRIQUE, B. Efeitos tóxicos da Ipomoea carnea em caprinos. II Estudo de teratogenicidade. 2005. Tese (Doutorado em Ciências) - Faculdade de Ciências Farmacêuticas, Universidade de São Paulo, São Paulo. 2005.

SIMPSON, C. F.; DAMRON, B. L.; HARMS, R. H. Toxic myopathy of chickens fed Cassia occidentalis seed. Avian Disease, v.15, p.284-290, 1971.

SOTO-BLANCO B. Toxicidade subaguda, prolongada, pré-natal e pós- natal do cianeto em caprinos. 2003. Tese (Doutorado em Ciências) - Faculdade de Medicina Veterinária e Zootecnia, Universidade de São Paulo. São Paulo. 2003.

STEVENS, K. R.; GALO, M. Practical considerations in the conduct chronic toxicity studies. In: HAYES, A. W. (ed.) Principles and methods of toxicology. New York: Raven Pres, 1989, p.237-250.

STUART, A. G. Herbs to avoid during pregnancy and lactation - Plantas a evitar durante embarazo y lactancia. University of Texas El Paso / University of Texas Austin Cooperative Pharmacy Program, 2003. Disponível em:

$<$ http://www.herbalsafety.utep.edu/populations/documents/Pregnancy\%20Plants.pdf $>$ Acesso em 30 de julho de 2007.

SULIMAN, H. B.; WASFI, I. A.; ADAM, S. E. I. The toxicity of Cassia occidentalis to goats. Veterinary and Human Toxicology, v.24, n.5, p.326-330, 1982.

TASAKA, A. C.; WEG, R.; CALORE, E. E.; SINHORINI, I. L.; DAGLI, M. L. Z.; HARAGUCHI, M.; GÓRNIAK, S. L. Toxicity of Senna occidentalis seed in rabbits. Veterinary Research Communications, v.24, p.573-582, 2000. 
TASAKA, A. C.; SINHORINI, I.L.; DAGLI, M. L. Z.; HARAGUCHI, M.; GÓRNIAK, S. L. Perinatal study of Senna occidentalis. Intoxication in rabbits. In: Acamovic, T., Stewart, C.S., Pennycott, T.W. (eds), Poisonous Plants and Related Toxins. CABI Publishing, Oxon, Wallingford, 2004, p.459-464.

TRALDI, A.S. Tópicos em Reprodução de Caprinos. São Paulo. Departamento de Reprodução da Faculdade de Medicina Veterinária Zootecnia da Universidade de São Paulo, 1994. p.84.

USEPA, 1991 USEPA, 1999. Guidelines for Developmental Toxicity Risk Assessment. Published on December 5, 1991, Federal Register v.56, n.234, p.63798-63826. Disponível em: <http://www.epa.gov/ncea/raf/pdfs/devtox.pdf.> Acesso em 30 de junho de 2007.

WANGO, E. O.; WOODING, F. B. P.; HEAP, R. B. The hole of trophoblast binuclease cells in implantation in the goat: a quantitative study. Placenta, v.11, p.381-394, 1990.

WEBSTER, W. S. Teratogen update: congenital rubella. Teratology, v.58, n.1, p.1323, 1998.

WECHSLER, B.; LEA, S. E. G. Adaptation by learning: Its significance for farm animal husbandry. Applied Animal Behaviour Science, v.108, p.197-214, 2007.

WEG, R. Indução de miopatia mitocondrial tóxica em ratos tratados com sementes de Senna occidentalis. Tese (doutorado) - Faculdade de Medicina Veterinária e Zootecnia, Universidade se São Paulo, Departamento de Patologia, São Paulo, 2001, p. 93.

WHO-WORLD HEALTH ORGANIZATION., 1967. Principles for the testing of drugs for Teratogenicity, World Health Organization Technical Report Series, Geneva, p. 364.

WILSON, J. G. Current status of teratology-General principles and mechanisms derived from animal studies. In Wilson JG, Fraser FC (eds): Handbook of Teratology, Vol. 1. New York, 1977: Plenum Press, p. 47-74.

YADAV, R.; JAIN, G. C. Antifertility effect of aqueous extract of seeds of Cassia fistula in female rats. Advances in Contraception, v.15, n.4, p.293-301, 1999. 